1916327

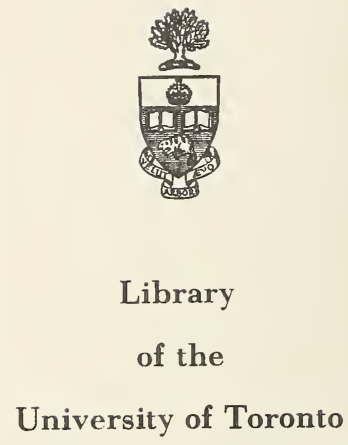


-

$-1$

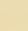


Digitized by the Internet Archive in 2017 with funding from University of Toronto 
SCRIPTURAL GEOLOGY.

VOL. II. 



\title{
SCRIPTURAL GEOLOGY;
}

\author{
OR, \\ GEOLOGICAL PHENOMENA,
}

CONSISTENT ONLY

WITH THE LITERAL INTERPRETATION

OF THE

Earred Brriptures,

UPON THE SUBJECTS OF THE CREATION AND DELUGE;

\section{IN ANSWER}

TO AN "ESSAY ON THE THEORY OF THE EARTH," BY M. CUVIER, PERPETUAL SECRETARY OF THE FRENCH INSTITUTE, \&C. \&C. AND TO DR. BUCKLAND'S TREORY OF THE CAVES, AS DELINEATED IN HIS " RELIQUIA DILUVIANE," \&c. \&c. \&c.

VOLUME II.

"Some drill and bore

"The solid earth, and from the strata there

" Bxtract a Register, by which we learn,

"That He who made it, and revealed its date

"To Moses, was mistaken in its age."-Cowper.

"By Faith we understand that the worlds were framed by the Word of God." Saint Paul.

"In six days the Lord made heaven and earth, the sea, and all that in them is." Moses,

"Lo, they have rejected the Word of the Lord; and what wisdom is in them "" Jeremiah the Prophet.

\section{PUBLISHED BY HATCHARD \& SON,} 187, PICCADILLY;

AND BY L. B. SEELEY AND SON, 169, FLEET STREET, LONDON, $182 \%$. 



\section{DEDICATION.}

'TO THE BISHOPS AND CLERGY, TO THE MEMBERS OF OUR UNIVERSITIES, AND OF O'THER SCIENTIFIC INSTITUTIONS;

AS THE DIVINELY APPOINTED,

OR LAWFULLY CONSTITUTED, PATRONS

AND GUARDIANS OF REVEALED TRUTH, AND OF LEGITIMATE PHILOSOPHY:

THE FOLLOWING TREATISE, ON " SCRIPTURAL GEOLOGY," IS HUMBLY SUBMITTED,

AND MOST RESPECTFULLY INSCRIBED, BY

THE AUTHOR. 


\section{LIST OF SUBSCRIBERS.}

Abbott, J. W. Esq. Coton

A cheson, Lady N.

Adam, J. Esq. Clifton.

Adams, Mr. I. Kettering.

Allport, Rev. J. Atherstone. 2 copies.

Arnold, I. A. Esq. Lutterworth.

Atkinson, Rev. T. M. A. Hartishead.

Bagge, Rev. W. Kings Newton.

Bailey, Rev. H. Dighlington.

Bailey, J. Esq. Atherstone.

Baines, H. Esq. Queen's College, Cambridge

Barfoot, Rev. C. Liddington.

Barker, Rev. T. Brampton.

Bartlett, Mrs. Buckingham.

Bartlett, Rev. J. Rector of Spratton.

Baxter, S. S. Esq. Atherstone.

Beachcroft, Rev. Mr. Blunham.

Bell, Mr. J. F. Leicester.

Bellin, B. Esq. Wolverhampton.

Bentinck, Lord W. Lower Grosvenor Street.

Bevan, S. Esq.

Bevan, Rev. G.

Bevan, Rev. G. J. Crickhowel.

Bishop, T. Esq. M. D. Thornby.

Blackburn, Rev. J. M. A. Altercliffe.

Brackenbury, Mrs. Raithby.

Blackiston, Sir M. Bart.

Blakler, Rev. I. Stockton.

Blundell, Esq. M. D. London, 2 copies.

Bosworth, Miss, Highgate House.

Bosworth, Rev. W. Stafford, 3 copies.

Brook, Sir Rich. Bart.

Bolland, Rev. W. M. A. Vicar of Swineshead.

Brown, J. B. Esq. L.L.D. London.

Brotherhood, Rev. W. Desborough.

Buckworth, Rev. J. M. A. Dewsbury.

Bugg, Mr. Horbling. 
Bugg, H. Esq. Spalding.

Bugg, I. Jun, Esq. ditto.

Burcham, Mr. Heckington.

Burdett, Rev. D. J. B. A. Gilmorton.

Burgess, Mrs. Lutterworth.

Buszard, M. Esq. Lutterworth.

Butlin, W. Esq. Rugby.

Butlin, Mr. T. Spratton.

Calthorpe, Lord. 4 copies.

Chawner, T. Esq. Atherstone.

Chambers, Rev. T. Willoughby, 4 copies.

Chapman, Mr. S. Lutterworth.

Child, S. H. Esq. Wolverhampton.

Churchill, J. C. Esq. Nottingham.

Clarke, T. Esq. Queen's Col. Cambridge.

Clarke, F. F. Esq. ditto.

Cobb, J. W. Esq. Margate.

Cobb, Rev. J. Spratton.

Coleman, J. S. Esq. Bitteswell.

Collyer, Rev. W. B. D.D. L.L.D. F.A.S。

Cooper, H. D. Esq. London.

Cooper, Rev. A. Occold.

Cooper, Edward, Esq. Wakefield.

Corbett, T. Esq. Atherstone.

Cornwallis, the Marchioness of,

Corrance, Rev. F. T'. Great Glenn, 4 copies.

Corrie, Rev. G. Cambridge. 4 copies.

Corrie, Rev. D. L.L.B. A rchdeacon, of Calcutta,

Corrie, Rev. Dr. Harringworth.

Corral, Mr. F. Lutterworth.

Coutts, Mrs. London.

Crabbe, Rev. G. Trowbridge.

Dawson, H. Esq. Wakefield.

Dawson, Rev. J. Wistenstow.

Day, Rev. Charles, Falkingham.

Deacon, J. Esq. Stamford Street, London.

Doyle, Rev. Stony Stanton.

Duddington, Rev. B. Raunds.

Dumelow, C. Esq. Bedford.

Edwards, Rev. E. Lynn.

Esdale, Mrs. Surfleet.

Evans, James, Esq. Nisbett's, London.

Fancourt, Rev. L. D.D. London.

Fancourt, Mrs. St. John, 52, Great Ormond Street, London. Fisher, Mr. Heckington.

Fitzgerald, Gerald, Esq. Bath. 4 copies.

Footman, T. Esq. Lutterworth. 


\section{LIST OF SUBSCRIBERS.}

Ford, Rev. Mr. Northampton.

Fox, R. W. Esq. Lutterworth.

Fox, H. Esq· St. John's College, Cambridge.

Franks, Rev. J. C. M.A. Huddersfield.

Francis, R. Esq. Churchover.

Freer, W. Esq. A therstone.

Fry, Rev. T. M.A. Emberton. 2 copies.

Fuller, Mr. J. H. Aston.

Galway, Right Hon. L. D.

Gambier, Lord, Iver Grove.

Gates, Mrs. Spalding.

Gilbee, Rev. William, M.A.

Gillman, W. Esq. London.

Gosford, the Countess of

Green, Rev. W. M.A. Iver. 3 copies.

Green, Mrs. Stockwell Common.

Grimshaw, Rev. T. S. Biddenham.

Gurney, J. J. Esq. Esham Hall. 2 copies.

Gwyther, Rev. Mr. Yardley.

Harding, W. Esq. Pimlico.

Hardwicke, the Earl of

Hardyman, Rev. W. Luffenham.

Harridge, D. T. Esq. Queen's College, Cambridge

Harrison, J. Esq. Broseley.

Hewitt, Rev. A. Nottingham.

Hoare, Rev. E. H. Bath.

Hoare, Rev. E. H. Leicester.

Hogg, Mr. W. Kettering.

Hogg, Rev. J. Kettering.

Holloway, Rev. Mr. Norwich.

Houghton, G. Esq. Lutterwortl.

Hounsfield, G. W. Esq. Wakefield.

Huntley, the Marchioness of 3 copies

Jackson, Rev. W. Hatton.

Jarman, Rev. T. Mark, Somerset.

Jenkinson, Rev. J. Kettering.

Inman,-Esq. Leicester.

Jones, Rev. T. Creaton. 2 copies.

Jones, H. Esq. Grendon.

Jones, Rev. T. Broseley.

Julian, J. P. Esq.

Kenny, Rev. R. from India.

Kett, Mrs. Brook House, Norfolk.

Kilvington, Rev. Edward, M.A. Ripon. 12 copies.

King, Rev. T. Buckingham.

King, Mr. J. Appleford.

Kinion, Rev. Thomas, B.A Harrowgate. 
Knight, Rev. George, M.A. Harwell.

Lamb, H. Esq. Kettering. 2 copies.

Langston, Rev. S. Sheffield.

Lawson, Mr. Aston, Bucks.

Ley, Robert, Esq. Ratcliff.

Levesley, Mr. Heckington.

Levesley, Mr. B. Heckington.

Lievre, Rev J. G. M.A. Clandon, Surrey.

Lockey, Rev. F. Blackford, Somerset.

Lockton, Rev. T. Church Brampton. 2 copies.

Lousley, Mr. Job, Blewbury.

Lye, Rev. E. B. Raunds. 2 copies.

A Friend, by ditto. 2 copies.

Lythell, M. E. Esq. Hartshill.

Maddock, Rev. H. J. M.A. Huddersfield.

Mandeville, Lord

Mandeville, Lady

Marriott, Rev. R. M.A. Cotesbatch.

Marriott, Miss, Newton.

Marsden, W. Esq. Thavies Inn.

Marsh, Rev W. M.A. Colchester. 2 copies.

Matthews, Rev. R. New Walk, Leicester.

Miller, Rev. R. M. A therstone.

Monckton, Rev. H. M.A. Seaton. 6 copies.

Monckton, Hon. John, Fineshade.

Monckton, Hon. Edward, London.

Montague, Lady Emily.

Montague, Lady Caroline

Morewood, J. Esq. Atherstone.

Mottershaw, J. Esq. Silkmore House, Stafford. 3 copies.

Neale, E. Esq. Atherstone.

Neal, Mr. Kettering.

Newbery, Rev. H. J. Lutterworth. 2 copies.

Noble, Miss, Frisby.

Nunn, Rev. T. Stockton.

Nurse, Mr. L. Ashby.

Obins, Rev.-M.A.

Ormond, The Marquis of

Pantin, Rev. T. P. B.A. Lutterworth.

Payne, Miss, Atherstone.

Phillips, Sir Thomas, Bart. Middle Hill.

Phillips, Lady, ditto.

Piccope, Rev. J. Manchester.

Plant, F. Esq. A therstone.

Plumptree, Miss, Spratton.

Powell, Rev. J. M.A. Bitteswell.

Powley, Mrs. Ripon. 12 copies. 
Power, E. Esq. Atherstone.

Powys, Hon. and Rev. L. Titchmarsh.

Pratt, Rev. Josiah, L.L.B. London.

Price, Rev. J. Crickhowel Monmouth.

Rabett, Rev. R. Lilieshall.

Raffles, Rev. T. L.L.D. Liverpool.

Ramsden, R. Esq. Spratton. 2 copies,

Ramsden, Rev. R. D,D. Grundisburgh.

Raworth, Mr. O. Leicester.

Read, Mr. Bath. 2 copies.

Redford, H. Esq. A therstone.

Rickett,-Esq.

Richmond, Rev. L. M.A. Turvey.

Roberson, Rev. H. Liversidge.

Rogers, Rev. T. M. A. Wakefield

Rogers, Rev. S. Flockton

Roughton, W. Esq. Kettering.

Russell, J. W. Esq. M.P. Biggin.

Russell, Mrs. Watts.

Sargeant, Rev. J. Lavington, Sussex.

Sattersthwaite, Miss, Atherstone.

Schomberg, Rev. J. D. A.B. Stoke Golding。

Schutry, Miss, Gillingham-hall, Suffolk.

Sharp, T. Esq. Deeping.

Sharp, R. Esq.

Sherer, S. W. Esq. Morcott.

Shirley, Rev. W. Melbourne.

Simeon, Rev. C. King's College, M.A. Cambridge.

Simons, J. Esq. Queen's College, ditto.

Simons, Mr. W. Ullesthorpe,

Simpson, S. Esq. Leicester.

Smith, Mr. R. C. Lutterworth.

Snook, Cap. Iver.

Spackman, R. Esq. Lutterworth.

Sparrow, Lady Olivia B. 6 copies.

Spence, Rev. J. M.A.

Stammers, R. Esq. St. John's College, Cambridge.

Stirling, Mrs. Glasgow.

Strachan, Mrs. Emberton, 6 copies.

Sutton, Mrs. Ditchington-lodge.

Unwin, Rev. Edward

Vale, Rev. W. H. M.A. Sheffield.

Vaughan, Rev. E. T. M.A. Leicester.

Vinrace, J. Esq. A therstone, 2 copies.

Voile, Mr. Frolesworth.

Vyse, R. Gent. Yardley.

Vyse, Thomas, Esq. Finsbury Square. 


\section{LIST OF SUBSCRIBERS.}

Wade, Rev. Thomas, Tottington, 2 copies.

Wallis, G. Esq. Kettering.

Warren, Rev. Mr. Oakham.

Watkins, Rev. H. G. M.A. London.

Watson, Rev. Mr. Northampton.

Wawn, Rev. J. D. Stanton, Derbyshire.

Westoby, Rev. A. Emberton.

Wheatley, T. Esq. Madely.

Willday, J. Esq. A therstone.

Williams, Rev. C. Barby, 2 copies.

Wilson, Rev. J. Laxton.

Wilson, Rev. R. C. M.A. Preston.

Wilson, Rev. J. Vicar of Dunnington.

Woods, G. A. Esq.

Young, Mrs. Dewsbury. 


\section{CONTENTS.}

\section{BOOK IV.}

CHAP. I. Geology without Analogy, or data for First For-

Page. mations.-Revelation the proper and only source of Knowledge respecting the Creation. .......... 1

Chap. II. Geology without Analogy for Secondary Formations. .... 24

Chap. III. The genuine provinces of Geology and of Revelation. .... 39

Chap. IV. Scriptural account of Diluvial Operations, and their Effects upon Geology................... 56

Chap. V. Geological Phenomena only to be accounted for on Scriptural Data. Physical Phenomena ......... 82

Chap. VI. Fosssil Phenomena .................... 109

\section{BOOK V.}

CHAP I Dr. Buckland's Diluvial Theory Page.

Transportation of Rocks \&c................ 134

Chap. II. Channels, Valleys, and Gorges ................. 164

Chap. III. Dr. Buckland's Theory of the Caves. Evidences of

the Cave Theory examined. ................ 187

Chap. IV. Evidences opposed to the Cave Theory............ 206

Chap. V. Scriptural evidence against it................. 229

Chap. VI. History of Extinct Animals. ............... 250

Chap. VII. Extinct and dispersed Animals................ 274

Chap. VIII. Miscellaneous Subjects. Dr. Buckland............. 303

Chap. IX. Bad effects of Modern Geology on the Bible........... 328

Conclusion $\ldots \ldots \ldots \ldots \ldots \ldots \ldots \ldots \ldots . \ldots . \ldots . \ldots 346$ 


\title{
PHILOSOPHY OF MODERN GEOLOGY.
}

\author{
BOOK III.
}

\section{CHAPTER I.}

GEOLOGY WITHOUT ANALOGY, OR DATA FOR FIRST FORMATIONS.-REVELATION THE PROPER AND ONLY SOURCE OF KNOWLEDGE RESPECTING THE CREATION.

I CONSIDER the following proposition a truth which cannot be denied; and I think a due consideration of its importance and bearing on the subjects essentially connected with Geology, would go very far to settle the grand point in dispute between Geologists and the Bible. It is this;

That experimental and deductive Philosophy, being only conversant with the actual operations of nature, affords no data for a Theory on 'first formations'; and that, therefore, the time and manner of Creation, or the real origin of the world, is the province of Revelation and not of Philosophy.

Every person conducts himself unwisely, who does not duly appreciate the boundaries of the sphere in which he engages to act. Geology has its province,

vor. II. 
and divine Revelation has its province. But if Geology undertakes to correct the Most High in the knowledge of the work of his own hands, it puts itself into the place of God, and makesitse If wiser than He.

It is clearly not the province of Geology to speculate on first formations. It has no data for any such thing. Analogy is manifestly all it has from which to determine, either what has been, or what shall be. It cannot supply itself with any corresponding case, and therefore can gain nothing by comparison.

Analogy supplies no evidence towards any conclusion about when or how things first began to be.

Philosophy supplies no data either from theory or fact; though we may derive from what Mr. Buckland calls, the "sister sciences," some theoretical principles by which to reason on this science.

OUR THEOR Y may assure us that there is a first origin of every created object. But we have in the Process and operations of nature no analogy of such first origin. Nor any CAUSE in that process, which can produce it.

IN FACT ; Geology, by M. Cuvier's own admissions, has no support from analogy respecting first formations. He confesses we have nothing now to compare with them, and therefore no analogy.

-None by which to say how the primitive mountains were formed. The sea has now lost all such power. And as we have already shewn, "secondary formations" can afford no analogy for first formations. -None for the revolutions. All the powers of nature cannot effect such changes.

-None for the origin of animals, much less the numerous fresh races of animals which his theory makes 
necessary.-To suppose fresh races of animals therefore, is a violation of analogy.

- None for the origin of the world. M. Cuvier seems to smile at Geologists for ascribing to the earth a " certain primitive state." And says that we have no data for the first origin of the world.

Respecting the origin of animals, I admit Mr. Buckland says something which might be construed to imply the contrary. He writes thus ;

"It is demonstrable from Geology, that there was a "period when no organic beings had existence: these " organic beings must therefore have had a beginning " subsequently to this period; and where is that begin" ning to be found, but in the will and fiat of an intel" ligent and all-wise Creator"? (Inaug. Lec. 21.)

That " organic beings" had their " beginning" from God, is a truth; but this truth Mr. Buckland did not derive from Geology but from divine Revelation.-That " it is demonstrable from Geology, that there was a period when no organic beings had existence," is an error; ; and for this our author is indebted to Geology.

Instead of endless answers to the above notion, I shall give one. It has no existence but on the supposition of M. Cuvier's theory being correct, which I hope we have seen, is demonstrably erroneous. Let the reader but cast out of his mind that system, and take another, and instantly the fallacy of Mr. B's argument will appear. Suppose the Bible to be literally correct when it says,- " In six days the Lord made heaven and earth, the sea and all that in them is ; -and we shall see that unless Geology can demonstrate the distinct periods in that one week's operations, it knows 
nothing whatever of the earth before it was occupied by " organic beings."-Again. On this principle it would demonstrate that the earth was uninhabited till the Deluge, whence fossils were derived; and that man did not exist till long after the flood. For all modern Geologists assert that man is not found in the diluvial deposits, nor till long afterwards.

The following propositions are fairly deducible from modern geology.

I. Geologists do not mean by "first" or "primitive formations," the FIRST ORIGINATION of the thing; They do not mean $\mathrm{CR}$ EATION.

When M. Cuvier, speaking of the "PRIMITIVE, or primordial mountains," says,

"Their crystallization, and even the nature of their strata, shew that they also have been formed in a fluid ;"

He certainly has no thought that this mountain is the fist origin of the materials of which it is composed: Because he speaks of the materials before they became a mountain. He says that the mountain was formed in a "fluid." Then this "fuid" and whatever it contained were before the mountain, and were the authors of it.-And when De Luc, as we before quoted, declares that

"The materials of which these strata were formed" proceeded from a confused assemblage of elements, of "which water was the basis; and (that) it is from this "first mixture, that all substances whatever which en"gage our observation or experience, formed them"selves ;"

He does not here mean any thing like Creation 
or the first origin of this mixture. He informs us that all things came from this "confused assemblage of elements ;" but he does not tell us where this "assemblage" itself came from: And when he calls it" this first mixture," he cannot mean that it was created thus, or that it primarily originated in this state of mixture. And he surely cannot mean that this was always such.

II. Their theory does Not reach first FORMATIONS.

Let Geologists mean what they may, when they speak of primitive formations, it is perfectly clear that nothing of the true nature of Creation, or the origin of matter, is found in any thing they say about these mixtures, compounds, or compositions. To speak of a " mountain" "formed in a fluid," and of a "first mix ture from which, the materials, of which the strata were formed," are derived, is saying nothing. If materials" were furnished by this assemblage, for the formation of the strata, and if the "fluid" formed the "mountain," I hope we are not to consider these as "first formations."

The " materials" themselves are a formation. The "fuid" itself is a compound, and it contains all the "materials" of the "mouniain." But Geologists can go no further; their ne plus ultra is here. But it is perfectly certain we have gained nothing by coming from the "mountain" to the "fluid," or from the "strata" to their assembled "materials." For here is the mountain, and here are the strata, only in a different form. And to suppose that any useful information is given by saying "all "things" "formed themselves" 
out of these "materials," or that a mountain was formed "in a fluid," is unworthy the operation of a sound mind.

To wish it to be implied that this fluid is the primitive state of things, and that our knowledge reaches no further, is folly. Or if, when bound to say something, it should be argued that this being the primary and " first assemblage" of "elements," it would be unreasonable to expect us to go further than the first, I can only reply, that this is explaining one thing of which we know little, by saying it came from another of which we know nothing: or, it is an effort to conceal our ignorance or our infidelity, under an unintelligible jargon; or to cover one piece of extravagance by a greater.

But let this "fuid", this "first mixture," be the primary and original fountain of all the "strata," whether mountains or plains, what then? We have arrived at no 'data for any Theory on first formations.'

This" FLUID MIXTURE" is ITSELF a FORMATION.

Indeed it is not only a formation, but is considered as the matrix, the mother, the fountain of all formations. Yea as containing in its womb the MATERI A LS of " all substances whatever, which engage our observation or experience."-This then is the first formation. What we enquire after, then, is still wanting. viz.

A THEORY ON FIRST FORMATIONS.

Our Geologists send us to this first formation, this " deposition in a fluid", very readily and very frequently. But then they say no more. They say nothing about where it came from, how it came there, 
or what was the origin of it. Then it is quite obvious that we have no Theory of its origin; -we have no first cause; - no Creation.

With respect to the 'mountain from this fluid,' and all the world from this 'first mixture,' there are two grand defects, relative to the object we seek.

1. The mountain itself has not been proved to come from a fuid.

No man ever saw the operation of a mountain's formation,-no mountain was ever known to be so formed,- - there is no testimony to any such fact,- and no analogous reasoning in its favour. Nay; so far otherwise, it has been demonstrated that "deposition in a fluid," in our Geologists' meaning of the phrase, is amongst the absurdest of all absurdities. And that all the analogy which we can produce, is directly in the face of it.

2. We have obtained no evidence either that there ever was such a fluid mixture, or where it came from.

A globe of earth eight thousand miles diameter suspended and deposited in a fluid! How many times eight thousand miles deep was the fluid? And where is it gone!

But from whence and from whom did it come? This is the point. Answer this, or we arrive at no Theory on first formations.

Did this "first mixture" come from dissolved strata? And the "Auid" from the debris washed down from the " mountains."!!

Now, however extraordinary it may be, reither $M$. Cuvier, De Luc, nor any other man, know any thing of this fluid, or any thing of a "confused assemblage 
of elements of which water was the basis," unless in those cases where "WATER has DISSOLVED and become incorporated with, elements," which PREVIousLy existed.

And if M. Cuvier were to analyze "water" containing the "elements" of a " primitive mountain," does any one in his right mind doubt, that he would instantly refer this impregnated water, (this "first mixture,") to a spring running through the mountain?

Thus we are where we were. We arrive no nearer to a first cause, or to a Theory on first formations.

III. No reasoning from EXPERIMENTS, or from the actual OPERATIONs of nature, can lead us to any conception, or enable us to estrablish any Theory, either as to the TIME or MANNER of first formations.

"The heavens declare the glory of God, and the " firmament sheweth his handy-work." And "they " are without excuse" who do not see "his eternal "power and Godhead" "from the creation of the "world," and clearly understand that an "invisible" " hand has produced " the things that are made."

Scepticism has, however, taken occasion from modern Geology to attempt to rob God of the honour of creating the world. I tremble to think that Christians and Divines are not more cautious how they trust themselves under the direction of such guides.

But though Revelation makes every Atheist guilty, it never blames him for not knowing, and never supposes him capable of knowing, either how "first formations" were made, or how long they were forming.

Indeed, every mode of reasoning upon any such thing, and every attempt to form a Theory which will 
account for it, are both vain and presumptuous. All such reasonings arise from vanity and lead to Atheism.

The truth of these declarations is manifest;-we have no data for such argumentation. If therefore we attempt to reason at all on that subject, we are sure to reason wrong. Because we cannot argue but from such data as we possess. But as these data are, for such a purpose, wrong data, it would shew a want of reason to expect them to lead us to a right conclusion. - For instance; our former example the mountain and its fuid:

From what data now does any man undertake to assert, relative to "primitive mountains," their " crys"tallization, and even the nature of their strata, shew " that they also have been formed in a fluid?"

To pretend to know by inspection how a thing originated, implies one of two things.

1. Either a second cause origination. And this indeed may be true; as all the course of nature both animal and vegetable, now proceed on this principle; but "first formations" did not thus originate. Second causes can no more produce "first formations" than a child can beget his father.-Or

2. It implies what leads to Atheism. It supposes an infinite series of causes and effects.

If we see an animal, we say it came from another animal, and a vegetable came from another vegetable, of the same species. But we do not say the "first vegetable came from another vegetable, and the first animal from a former animal. - Vegetables and animals are thus derived from one another in succession, and they pass away. But if they were stationary, like 
the ' everlasting hills,' we could not then say, that one animal came from another, and that the first came from a former one.

Besides. If any anulogy is to be derived from what we see and know, towards the formation of what we do not know, we should say the mountain came from another mountain, and not from a "fluid." And indeed, according to M. Cuvier, and I may add every one's understanding, every formation with whose origin we are acquainted, is of this description. It is the debris of some prior formation. It is not the production of a fluid. The sea indeed conveys the debris, but the materials are derived from other formations.

If our Geologists therefore will reason from ail we see and know to what is gone before, they must not and cannot stop at their "first mixture," for in truth there can be no first. Every stratum will come from a fluid mixture, and every fluid mixture from prior strata. So that in spite of all Mr. Buckland has said, in his Inaugural Lecture, to rescue modern Geologists from the imputation of holding an "infinite series" of formations, the imputation can never be separated from the inevitable consequences of their doctrine.

This Theory, and the reasoning of its authors upon it, imply that every thing we see is the effect of some ratural cause, and is also itself the effect of something else which is also natural. Thus the origin of matter is indirectly denied. For if we allow that matter did ever begin to exist, we have no data to assert in WHA T STATE it commenced its existence.

If a man therefore asserts that he knows from the strata of a primitive rock how that rock was originally 
formed, that man, if he knows what his assertion implies, means to say that that rock arose from a natural or material cause. For with any other cause or its mode of operation, he has no acquaintance. Then he certainly means that its cause or the mode of its operation is familiar to him. This implies an infinite series, and that there is no cause of formations but this.

Such an Author ought to know, however he may slight the information, that he is treading upon ground which leads, and not very indirectly, to a denial of the God that made him!

If we allow that "all the strata," and all the mountains were " deposited in a fluid"; in all this we have no "first formation." "Deposition in a fluid," is itself an operation of nature, a result of a material cause. Matter exists before this operation, because it is the action or operation of matter. But the operation of matter does not produce matter. Less still does it produce the first matter, for it cannot operate before it exists, and so be the cause of its own being.

We ask how matter itself was produced, or how it originated? But the operations of nature and the speculations of Geologists afford us no answer!

3. We have no data which will enable us to guess at the time, any more than the manner of "first formations."

As the operations of nature, (which is all from which we can judge,) are not concerned in the origin of nature, so those operations afford us no data for judging about the levgth or shortness of time taken up during their formation, or since that period.

When M. Cuvier says (even of secondary forma- 
tions) " the sea must have remained a long time," and that this was necessary" for formations so "solid"; and when he argues from these to "primitive rocks" and mountains-we are authorised to say, this is all imagination: He has no data, as to this matter. He sees that a mountain is a long time in being washed level, and the sea is a long time making a "hillock" on the beach. But these have nothing to do with this matter. These operations have no concern in first formations. Therefore he has no DATA, AND No A N A LOGY.

Nor has he any data from which to judge of the time which has elapsed since the primitive mountains were formed. For we have very largely shewn that the successive epochs from which alone he judges, have no existence whatever.

Then it is perfectly certain that he cannot even guess whether the mountain was a thousand years in forming, or a single second. We might just as well assert the one as the other, for he knows nothing of either.

Thus then, we see with perfect certainty, that the OPERATIONS of nature afford us no data for a Theory on first formations; and that it is not the province of philosophy, which is concerned only with the operations of nature, to speculate about the time or manner of the World's First EXISTENCE. For of this matter, the infant knows as much as the greatest philosopher.

IV. M. Cuvier's Theory finds no "first origin of the world" and implies that no knowledge of its origin can be obtained.

This author then must not be censured for even thinking to form a Theory of the "first origin" of 
the earth, when he gives us a "Theory of the earth," and tells us how " primitive formations" arose. And this again will convince us that Geologists do not mean the origin of matter, or the beginning of things when they speak of " first formations." Indeed they never find a beginning, and it is very doubtful whether their system admits of any.

M. Cuvier in discussing the subject of different situations of fossil remains, such as the Paris Basin, \&c. writes as follows.

"It appears to me, that a consecutive history of "such singular deposits would be infinitely more "valuable than so many contradictory conjectures " respecting the first origin of the world and other "planets, and respecting phenomena which have con"fessedly no resemblance whatever to those of the " present physical state of the world; such conjec" tures finding, in these hypothetical facts, neither " materials to build upon, nor any means of verification "whatever." (p. 182.)

1. The first remark we would make on this passage, relates to its confirmation of our previous reasoning relative to Geology's affording no data for a theory on first formations.

We see in this quotation, (however the reader and Christian authors may, from the pretensions and general bearings of this Theory, have supposed the contrary), that M. Cuvier explicitly and expressly declares, "the PRESENT PHYSICAL state of the world" bears "confessedly NO RESEMBLANCE WHATEVER to those" supposed operations which regard the "FIRST ORIGIN of the world and other planets." 
And he clearly assures us, that existing "facts" afford to a "Theory" on "the first origin of the world, neither materials to build upon, nor any means of verification whatever."

There is clearly something very mysterious and portentous in all this. It turns out now that "primitive mountains," although they have been there ever since this Globe was a globe, and have attended it through all its transformations, are not PRIMITIVE TH INGS. It appears too that this " first mixture," this primitive "fluid" out of which the "primitive rocks" were deposited, was not itself really PR I M ITIVE.

No. This "fluid" which deposited our "primitive mountains" was not the "first origin of the world." Had M. Cuvier considered it as such, and beheld any thing like evidence for it, he would have had the "first origin" of our "world" before him, when he viewed this "deposition in a fuid," and he could not therefore, have spoken of " contradictory conjectures."

2. This author further considers Geologists who speculate on the earth's first origin and attend little to its present history, as like French historians who only regard what passed before the time of Julius Cæsar. " Their imaginations, of course, must supply the place "of authentic documents; and accordingly each "composes his own romance according to his own "fancy."

Thus we learn that all pretensions to know any thing about the "first origin of the world and other planets" are only "so many contradictory conjectures," and that those who undertake to write a history 
of its "first origin" only imagine what they please, and write a "romance" out of their "own fancy."

Even Moses is not noted by our author, as at all exempted from this sweeping censure. Nor is there the least appearance of evidence, as I have ever found, in this extraordinary system, which either leads to a "first origin of the world" by its own discoveries, or recognises the origin of the world as described by the sacred historian. Indeed it is very clear that that history is not only not recognised, but wholly rejected by $M$. Cuvier. This idea is strongly implied in such passages as the following.

"But what is still more astonishing and not less cer" tain, there have not been always living creatures on the earth."

"During a long time, two events only, the Creation " and the Deluge, were admitted as comprehending " the changes which have occurred upon the globe; " and all the efforts of Geologists were directed to ac" count for the present actual state of the earth, by " arbitrarily ascribing to it a certain primitive state, "afterwards changed and modified by the Deluge." (p. 40.)

With respect to the first of these quotations we may observe, that if the Mosa Ic narrative be correct, there "were" " always" living creatures on the earth," even from the first week of its Creation. Dry land only appeared on the "third day," while fishes and animals were created on the "fifth" and "sixth."

On the second passage upon which we made a remark in the early stages of this treatise, we may observe, that the Mosa Ic narrative is very express in 
" ascribing to it (the earth) a certain PRIMITIVE STATE," and that this "primilive state" was "afterwards CHANGED and MODIFIED by the deluge."

What the author means by the word "arbitrarily" I cannot tell, unless he mean something like this; namely; that there are no "authentic documents," which give us any just account of the "firsi origin of the world," and that "geological phenomena" and existing "facts" bear " no resemblance whatever" to this "certain primitive state," and therefore we have no reason at all to suppose there was any such " primitive state ;" Hence, when Geologists ascribed to the earth, in conformity with the Mosaic record, a "certain primitive state," it was a mere arbitrary and unwarranted "conjecture."

Whether or not the use of the above term be as we have here supposed, it is perfectly clear and evident from what we have lately seen.

That M. Cuvier's theory finds no "first origin" of the world, and implies that no information respecting such origin can be attained!

Mr. Buckland's language I admit, may appear at first sight, to imply that GEoLOGY has actually found out the orIGIN of the primitive formations. He says, "It is surely gratifying to behold science, compelling " the primeval mountains of the globe to unfold the " hidden records of their origin." But as Geology has not furnished one atom of evidence from these " hidden records," and it is perfectly demonstrable that it never can furnish any, we are bound to ascribe such language to Geological boasting, and not to the discoveries of science. In his more sober moments, $\mathrm{Mr}$. 
Buckland refers to " the sister sciences," as affording " the most admirable proofs of design and intelli"gence, originally exerted at the Creation," but he never gives any rational prospect, that Geology can at all reach the case of first formations.-When therefore we find an amiable and ingenious mind so led away by the fascinations of Geological speculations, as to speak of this " science compelling the primeval mountains of " the globe, to unfold the hidden records of their origin ;" we seem at a loss whether more to smile at the vanity, or to lament the presumption which this anti-scriptural theory engenders.

Thus, then, we have perfect assurance, that Geology has no powers by which it can at all reach " first formations," strictly so called. There is no analogy whatever, as M. Cuvier admits, which affords the Geologist any " materials to build upon," or " any means of verification." Nor has he any data whatever on which he can construct a Theory which will meet the case.

It is equally certain, that every record, not deriving its materials from the Mosaic narrative of Creation, is either a fancy or a fable. Then, if the Mosaic history of Creation give us no accurate information respecting the "first origin of the world," it is perfectly certain we have no information of any such event.

But happily for us, (as we have largely proved) Geology can say nothing AGAINsT the literal interpretation of the scriptural narrative of the Creation, and of the flood. All its pretensions are vain. They fall short and do not, and cannot approach the case. When therefore, Mr. Buckland (as before noticed) 
speaks of "Geology" going "furthes" than thé Mosaic narrative; we hardly know how to understand him.

$\mathrm{V}$. The real origin of the roorld, is the province of revelation and not of philosophy.

We have seen that Geology (and in this every branch of philosophy unites) knows nothing but of second or created causes, and can only therefore describe their operation. But these do not R E A CH "first formations."

M. Cuvier seems every where to ascribe all to the operations of nature."

Mr. Buckland however, as we have seen, views those operations, as directed and controlled by an Allwise Providence.

But the genuine system appears to disapprove of searching for "Geological causes beyond the established limits of PHYSICAL and CHEMICAL science !" (Cuv. 45.)

It finds no "BEGINNING," no " FIRST ORIGIN" OF THE WORLD; and SEEMS TO ADMIT OF NONE. $(182,3:)$

It speaks of no Creation, and ascribes the ohanges of successive races of animals to no Creation. (126.)

REvELATION then is the proper source of infor-: mation upon this subject, and the oN LX source which has any information to give. Philosoply $y$ has no province liere, because it has no data, no instruction, no analogy: Its Divine Author alone, knows how he made the world ; and His wor D therefore in this matter, is our only guide.

I know we hear from all quarters, that the Bible was not given to teach us Geology. 
This, however, is both true and false.

True as it respects the legitimate province of Geology.

False as it respects its illegitimate character.

Of these, we shall perhaps say a few words in the next chapter. It is enough to say here, that the Bible is given to teach us expressly, among other things, the time and nuture of CREATION. It is the first instruction given us in the revealed will of God.-It is among the most important branches of information, because it points out to us the Author of our being, and the manner of our " beginning," or Creation:- and, because it is information which nothing else can communicate.

Philosophy admonishes us, that that which begins to be, must have a cause. Geology, however, does not say the world ever began. But the Almighty himself alone, can tell How and wheN. This then is what Philosophy shews us to be necessary, -it is what the Bible professes to teach, - and it is what therefore we should expect to find there.

And her I cannot suppress my feelings. When I peruse the writings of Philosophers, and the speculations of Geologists, and find them Theorizing without data, and discussing without real principles, and like rash and inexperienced travellers, fearlessly pursuing: their course in midnight darkness, without a lamp and without a guide; how does my heart beat with delight to quit their dangerous path, to follow the light which shines from heaver, and which alone can irradiate this, otherwise, impenetrable gloom.

"Through faith we understand that the worlds were " framed by the word of God, so that things which 
" are seen were not made of things which do appear." How appropriate! How important this language! Though we have referred to it before, we do it with pleasure now ; and probably shall again. The instant we desert this guide, on subjects of this description, we wander in endless mazes lost.

I admit that this Divine guide affords no satisfaction to those who distrust its fidelity, and dispute its pretensions. But those who profess to believe in its authority, and to " rejoice in his light" who gave it, ought to pay it the more respect and reverence; and in no sort to forsake this infallible director, to follow the guidance of Geologists, on first principles, who have neither "Theory" nor "fact" to direct their way. And especially to give the all-wise and all-bountiful Creator credit that what $H e$ has told us about the Creation and the Deluge, is information which is true, intelligible, important, and useful.

And even relative to such authors as M. Cuvier, I would not only say, with the learned reviewer of Mr. Buckland's work before noticed, that it is " unphilosophical" to neglect that history which professes, (as it regards diluvial and especially creative operations,) to give "a detailed narrative of the whole transaction ;" but I would remind such authors that it is rebellion against the Most High; - their conduct is not that of the poor heathen who had no such book as the Bible in their possession, and therefore groped without a guide; but it is voluntarily extinguishing the LIGHT which the Divine Being has graciously vouchsafed us, to "walk in darkness." 
And not only so, but this is done in defiance of example as well as of revelation. We have seen M. Cuvier admits that "during a long time, two events or epochs only, the Creation and the Deluge, were admitted."

Now if our modern Geologists, who have forsaken the path, for " a long time" trod, had revealed to us some new state of things, and opened before us matters which the revelation of God does not professedly teach, they might well have deserved our praise. But they have tried, (and in some quarters too far succeeded,) to blot out the light of the divine record, and have given us nothing in its place!

I would therefore kindly invite these wanderers, in the words of this neglected book to return.

"Thus saith the Lord, stand ye in the ways, and "see, and ask for the old paths, where is the good way, "and walk therein."

And let them not fear but the promise shall be fulfilled;

"And thine ear shall hear a word behind thee, "saying. This is the way, walk ye in it, when ye " turn to the right hand, and when ye turn to the "left ;" "and ye shall find rest unto your souls." (Isaiah xxx. 21. Jeremiah vi. 16.)

I should regret indeed to hear the reply to this which was returned by them to whom it was originally addressed :

"But they said, we will not walk therein." INFERENCES.

1. As this discussion has shewn that Geology does 
not at all arrive at "first formations," nor in any way whatever reach the genuine character of Creation, and finds no ancilogy by which, in the least possible degree, to inform or control our minds relative to it; it must follow that the Bible account of creation stands, in every respect; unaffected by Geology.

We have long ago delivered our view of the Creation, as Moses has recorder it. All which we need here repeat is, that THAT NARRATIVE not only stands UNW ARPED by any gloss which Geology can throw upon it, but with this additional corroboration; namely, that it is:

The GENUINE PROVINCE OF REVELATION,

And the province of revelation oNLY, to teach uS WHEN and HOW the world began.

Thus then the genuine literal interpretation of the Mosaic narrative is the true one. And the BIBLE RECOR $\mathrm{D}$ is the ONLY information which the world affords, respecting CREATION.

2. As the Scriptural account of CREATION, so the scriptural account of the DELUGE, stands untouched by the speculations of Geology. As the Bible narrative is plain and positive as to one Creation, and one Deluge, so we now perceive that that narrative in every point on which it at all professes to give instruction, is to be fully and implicitly embraced. Geology, as we have abundantly shewn, has Nот H I G which aught in the least possible degree, to bias our interpretation.

I hope it has, in the first volume, been perfectly proved

-That there is no evidence for successive eras. 
-No evidence for numerous revolutions.

-No new races of animals. And

-That the "fossil strata" are full against them.

- That the physical character of the strata, as well as all analogy, bear their full testimony in opposition to Geological deductions.

The conclusion then is clear and unshackled. There has been ONE CREATION ONLY, and ONLY one Universal Deluge. And that

"God created the heavens and the earth in six DAYS;" and that before THAT CREATION, the EARTH had NO EXISTENCE. 


\section{CHAPTER II.}

\section{GEOLOGY WITHOUT ANALOGY FOR SECONDARY}

FORMATIONS.

THE whole force of the modern Geological system, as we have frequently, more or less, seen, originates in the supposed unchangeableness of the form of animals. This point of natural philosophy must, beyond a question, be greatly Theoretical and assumed. For the practical acquaintance of any one man, with matters of this description, must of course be limited to a short period. And the recorded character of animals, is neither sufficiently accurate, nor sufficiently ancient, to ground a general Theory upon it.

The Theory however, as M. Cuvier holds it, makes his system an anomaly in the philosophy of nature. He contends that the form and habits of animals are stationary, and that they do not transgress certain known boundaries, in the varieties which result from the same species. From this he concludes that animals which vary so much as fossil animals do, from existing ones, are of different species or genera, which have become extinct. But it is natural to enquire why M. Cuvier makes this conclusion? How does he 
know that these animals, many of them at least, may not have changed their form as well as their diet, from vegetable to flesh.

Avalogy is the only source from which he draws his conclusion. Animials, he supposes, have a peculiar conformation of parts, from which they never materially depart, either by change of food, time, or place. I ask for evidence of this. M. Cuvier thinks it enough for us to infer the answer ; which is ; because we never know them to change, and we have no information to that effect, and have therefore no reason to believe they have changed.

Here then it is clear, that analogy is the only ground of evidence or argument. Well then let analogy be our guide. I ask then, upon what philosophy, what analogy, does M. Cuvier proceed in this other part of his system, viz: "DEPOSITION IN A FLUID," and subsequent violent REvOLUTIONS. I ask seriously, respecting this essential part of his Theory, this corner stone, this fundamental principle, from which every thing else is derived, and to the support of which, every thing else is made subservient; Has he any analogy?

I admit M. Cuvier conceives, that his evidence upon this subject is infallible. And that no possible objection can arise against it. He views "fossil remains" as positively demonstrative, and as giving us the "utmost certainty." He conceives, however, that he is authorised,

1. To give his own interpretation, to the mode of fossil deposits. And then

2. To transfer that mode to primitive formations. 
First. With respect to the mode in which fossils have been produced, he considers that it is " known with certainty," "that the strata, or at least those which contain their remains, have been quietly deposited in a fluid."” (55.)

" QUIETLY DEPOSITED IN A FLUID?"

This is explained to mean, "that the sea has re" mained there for a long time, and in a state of tran"quility ; which circumstance: was necessary for the "formation of deposits so extensive, so thick, and in "part so solid."

Secondly. He carries this view of quiet deposit to first formations, thus,

"It is only by means of analogy, that we have been " 6 enabled to extend to the primitive formations, the "same conclusions which are furnished directly for "the secondary formations, by the extraneous fossils." (55.)

What then are the "conclusions which are furnished directly" by the fossils?

". "The remains of the shells certainly indicate that "the sea has once, [once] existed in the places where "these collections have been formed." True. (58.) "s But

"It is from them, (quadrupeds,) therefore, that we " learn with perfect certainty, the important fact of the "srepeated irruptions of the sea upon the land." (59.) "Indeed!

Proofs of " repeated irruptions" we have abundantly seen, have perfectly failed. And now lask for the evidence, upon which it is with such certainty and confidence concluded, that the "s secondary strata" " have 
been quietly deposited in a fluid." - I deny the "fact.". And I think we have already proved, that a more extravagant fancy was never entertained by a man of sound mind.-But what I here ask for, is A N A LOG Y.

M. Cuvier may, if he please, carry his "analogy" from one formation to another. But he must first prove that that one has been "quietly deposited in a fluid." According to his own declarations and arguments repeatedly urged, there is no analogy of any such thing as deposition in a fluid being long and quietly formed. "Quiet deposition in a fuid" involves as we have constantly seen, two things.

Formations.

\section{Revolutions.}

I. Now it is very remarkable that M. Cuvier, after De Luc, \&c. most decidedly and intentionally informs us that (though there are some fresh-water formations) the "sea" has now no power to form any of the ancient secondary strata; and that all the existing powers of nature combined, could not "form a single stratum of any kind," or "produce the smallest hillock!!'” (39.)

II. With regard to revolutions which arise out of this deposition in a fluid, he says,

"Thus we shall seek in vain among the various "forces which still operate on the surface of our earth, "for causes competent to the productions of those "revolutions." (36, 37.)

Thus we learn from this author's own most fixed and determined opinion that there is no INSTANCE of DEPOSITION in a fluid, nor powers in nature to form such deposit. 
Thus also, we learn that there is no I NSTANCE of such REVOLUTION as he speaks of and no powers in nature to produce such revolutions.

How much less then shall we be able to quote analogy for the extirpation and reproduction of the successive races of animals, - fish, and birds, and quadrupeds.

But let us inquire into this matter. If $\mathrm{M}$. Cuvier make ANA LOGY, as he certainly does, the basis upon which he raises thewhole system of "formations," "revolutions" "epochs," and "catastrophes," A N A LoG Y 'must bear him through on these subjects, or his scheme falls, and that from defect in the philosophy and agreement of his first principles.

We have learnt from his own pen, that M. Cuvier has no analogy in nature to prove either his "formations" or "revolutions." He asserts, (however erroneously) that there are not now, and have not been for a great length of time, any powers in operation which could produce either:--we will take one, out of the many revolutions which this "Theor:" supposes as a specimen of the rest, and enquire into the extraordinary result of such a catastrophe; always remembering that ANALOGY forces the inquiry, and analogy must be ever kept in view. We will take for the sake of example, and as an instance respecting which we have a little information,

\section{THE MOSAIC CREATION.}

Suppose the modern Geological Theory to be true, and that the "present races" of animals are of "distinct species" from those which préceded them; and that, in short, both land and sea not only put on a 
new aspect at our creation but were entirely;ireplenished with NEW INHABITANTs. This much must at least be admitted, by all believers in REVELATION, to be intended by the Scripture representation of Creation. However numerous, agreeably to Geology, we suppose the animals in earth and sea, to have been, before that period, it is clear there were no inhabitants either in sea or land, when as Moses writes,

" The earth was without form and void ; and dark" ness was upon the face of the deep. And the spirit " of God moved upon the face of the waters."

It is certain, I say, that when this took place, and when, as in the subsequent history we learn that the waters retired into the earth, or were confined to the sea -that the "dry land" appeared-that the earth and the sea were caused to produce and bring forth "fishes," "birds," and animals-when these things were dcne, I repeat, there were no fishes in the sea, and no animals on the land. If we deny this we may as well reject the Bible at once. If we admit it, this is all I want. But if it be cienied, this Theory is also denied; for the Theory itself certainly supposes this, and it is perfectly useless upon any other supposition.

"Amidst these changes in the general fluid, it must " have been almost impossible for the same kind of "animals to continue to live:-nor did they do so in " in fact. Their species, and even their genera change "with the strata." And again, in the same page;

"In animal nature, therefore, there has been a suc" cession of changes corresponding to those which " have taken place in the chemical nature of the fluid; " and when the sea last receded from our continent 
"its inhabitants were not very different from those "which it still continues to support." (13.)

Here we learn that the earth had numerous " inhabitants" during this long "succession of changes" in which the "species and genera" "gradually disappear," till, in the last change, they are "not very different" from the present." The last change, even our Geologists allow, was Noah's flood. The preceding one, then, must be, as we before shewed, тн $\mathbf{E}$ Mosaic CREATION.

Now, as all the animals, both according to the Mosaic account, and the Theory of Geology; (for I do not here stop to account for its inconsistences in supposing our present races to have been living in some other part of the Globe, for this as we before shewed, is as destructive to itself as it is to the Bible,) as all animals must have been NEW at our Creation, and as there were many upon the earth, according to this system, pre-

" "Gradually disappear." Mr. Jameson in his notes on Cuvier's Theory, draws the following conclusions from the premises of Geologists. "From the " preceding details it appears, that the most simple animals are those first " met with in a mineralized state; that they are succeeded by others more " perfect, and which are contained in newer formations; and the most per" fect, as quadrupeds occur only in the newest formations." (p. 356.)

This notwithstanding the undeviating nature of animals is certainly very like the Atheistic process of Demaillet and his followers: who "suppose that " every thing was originally fluid; that this universal fluid gave existence to "s animals, which were at first of the simplest kind; - that, in process of time " and by acquiring different habits, the races of these animals became com" plicated, and assumed that diversity of nature and character in which they " now exist." (Theory 43.)

From all this it would rather appear that continental Geologists view animals as arising out of the earth in the course of nature, rather than as Mr. Buckland, a Scriptural Divine, puts it, "in the will and FIA T of an intelligent and allwise Creator ?"-But if so, how monstrous! Animals spring up in the course 
vious to that event, what will follow from these considerations?

We have No ANALOGY for any part of this process. There is

1. A REVOLUTION WHYCH DESTROYS ALL THE A NIMALS.

2. SEA, AND LANDSWARMING WITH NEW LIFE.

Here then we have a "Revolution" for the "production" of which all the existing " forces" of nature are confessedly incompetent. Then we must be compelled to believe that God wrought a miracle and one of a most extraordinary character, for the purpose of destroying the work of his own hands. Yes a miracle, and that most extraordinary. For no such event even as Noah's flood, though Mr. Buckland supposes it was intended "only to destroy," could have effected so dreadful a desolation.

If we allow that flood therefore to have been miraculous with respect to its cause and operations, its effects upon animal life were those which are general and natural. We must indeed suppose that so dread an event must have destroyed vast numbers of fishes, but their races were in no sort generally extinguished by it, and only those animals, as a whole, which were in the "dry land, died." - In order to destroy all the;

of nature, but natire goes quite out of her way for their destruction!Mr. Jameson also writes;

"It would appear that animals and vegetables were not called into existence " until the period when the transition rocks began to be formed. Hence it is " that petrifactions have not been met with in any rock older than those of " the transition class." (338.)

How extraordinary a reason this, why we do not find "petrifactions" in strata older than the "transition" formations : reason enlightened by revela. tion will see the impossibility of its being otherwise. $\rightarrow$ But of this hereafter. 
fishes (which, according to Geology, must have been, the case,) by a revolutionary catastrophe, the very nature of their element must have been changed.

No mechanical revolution, however violent, could be imagined to produce such an effect; much less could it effect this throughout the whole sea. When this destruction of all the fishes took place, the "waters" instead of being "waters" indeed, must have become allied to some Asphaltus Lake,-not pure sea water, but "waters" impregnated, from one end of the globe to the other, with sulphur or bitumen. But in such case a new Creation, or regeneration of waters, would have become necessary, to restore them to vital purity. And all this extinction of animal life must be supposed, though the globe, as yet, was free from offending creatures.

Behold now how this extraordinary Theory rushes into the very evil it seeks to avoid. M. Cuvier thus introduces the identical thing which he says never takes place in nature; viz. a deviation from its ordinary and usual operations. For these animals, these fishes, could not be destroyed without a miracle;they could not be re-produced but by the same cause, a miracle;-The different changes in the water, required, each a miracle; - and every change of which he speaks, required $a$ deviation from the ordinary course of nature almost infinitely greater than any suppossed deviation in the "varieties" among animal nature!!

Thus to avoid trifling changes in animal natures, (for trifling changes would remove great part of his difficulty, existing animals may remove to another part, and a few cxtinguished by or since the flood, would 
remove the 'whole,) he will risk such consequences as the above; and resort to frequent, literal, and unheard of miracles in both the physical and animal character of the globe! All this he will hazard, without any analogy, and precedent, or even the least historic testimony!-The whole of these extraordinary miracles and miraculous catastrophes have now long since ceased. All sorts of known fishes suitable to that situation now live in the same element, the salt sea; and it implies a miracle to suppose they ever did otherwise.

It does not signify whether we view these changes as caused by the hand of God ; viz. as strictly miraculous and direct interpositions of the most High ; or whether they be called extraordinary changes or operations of nature. For a thousandth part of all these deviations from the ordinary course of nature, would have produced all the changes in animals, which $\mathbf{M}$. Cuvier assumes could never happen. Mr. Buckland, however, and all of his opinion in this matter, must it is presumed, believe that the interposition of the Almighty did all this.

It is cvident that Mr. Buckland considers those "ancient revolutions that have overturned the globe" as directed by "the moulding finger of its Creator" "with a view to the welfare of the present inhabitants " of the earth."

Indeed, that very respectable author discusses this point seriously. He very properly asserts as before noticed that " laws impressed on matter is an expres"sion, which can only denote the continued exertion 
" of the will of the lawgiver, the prime agent, the first " mover." And he illustrates this position

"By the subserviency of the present structure of the " earth's surface to final causes, for that structure (he "says) is evidently the result of many and violent " convulsions subsequent to its original formation. "When therefore we perceive that secondary causes "producing these convulsions have operated at suc" cessive periods, not blindly and at random, but with "a direction to beneficial ends, we see at once the "proofs of an overruling intelligence continuing to " superintend, direct, modify, and control the opera" tions of the agents, which he originally ordained." (Inaug. Lect. 16,18.)

But we have seen that positive and direct miraculous interference was necessary in the catastrophes and reproductions which we have been reviewing. And it must be regarded that in every revolution, when the preceding races of fishes are supposed to be destroyed, we are obliged not only to assume, without any analogy, a deviation from the natural course of events in order to produce that revolution, but that revolution itself must be as great a deviation from the usual course of revolutions, as common revolutions are from natural operations. For, as we have observed, an ordinary revolution would no more extirpate all the fishes than (the last revolution) Noah's flood did. Thus we arrive at $a$ climax of absurdities.

1. M. Cuvier discovers, or fancies he discovers, "fossil shells" \&c. in some strata which deviate essentially in character, from those found in other strata.- 
As they do not come from one common stock, then, whence are they derived?

2. To avoid the necessity of so great a deviation from the course of nature, he resorts to deviations from the course of nature a thousand fold more distant and extraordinary.—For

3. He resorts, without precedent or analogy, and indeed directly in the face of both, to revolutions in the earth and to changes in the sea:- these revolutions and these clianges, themselves gratuitous and without any assigned cause, are to be the forerunners of new generations of animals, springing up also without assigned cause. But these changes in the earth, in the sea, and in animal natures are a thousand-fold further from nature and more difficult to be accounted for, than any variations discernable among animals.M. Cuvier's "Theory" will not allow the earth, or climate, or time, materially to change existing animals, but it will admit the earth, or climate, or some thing, or nothing, to produce NEW RACES of animals as oft as they are wanted.

4. Though we do know of changes in animal natures, and of a very extraordinary revolution in the earth at Noah's deluge, yet we know of no deviations from nature, such as this Theory makes necessary, nor any thing which in the least resembles them.

Noah's flood, the only universal catastrophe of which history gives us any account, has not the least analogy to the revolutions of which M. Cuvier speaks.

-It could not and did not extirpate the fishes, which all his revolutions required. 
- It did not generate new races of animals, which was the result of every one of M. Cuvier's catastrophes.

It did not, according to this author, produce the east knob of a rock of the same nature with those ormed by his supposed revolutions.

And, what is most singular, he contends that the sea has not had for ages, even before the Deluge, the power to deposit any thing whatever, in any degree like the hard and ancient strata.

There we may observe, that in the only revolution which the Scriptures record, the Almighty carefully preserved the land animals, and the sea did not, as we know of, destroy any genera of fishes; he must then resort to miraculous catastrophes and new creations in every one of M. Cuvier's revolutions.

The author's notion that modern animals might, during his ancient revolutions, be in some other part of the globe, is absolutely destructive of the whole Theory. For, if all the different races of animals were contemporanous at the revolutions, one Deluge is as good as many, and would as certainly deposit their remains in the strata as ten thousand.

Our conclusions then are these;

1. We are forbid by M. Cuvier's own principles, very good and wise when properly applied, to receive his "Theory", because it is the greatest deviation from the course of nature which can be supposed. It would be a miracle even among miracles.

2. Because we have no testimony and no evidence whatever in its favour.

3. Because it is the most extravagant thing which the imagination could invent. Revolutions in the earth ! - changes in the basins and fluids of the sea!- 
"Thousands of ages" passing over!-Animals destroyed, and animals created! - Whole races ingulphed that others nearly like them might succeed !! \&c. \&c.

4. It is the most unphilosophical thing conceivable. The CAUSE compared with the EFFECT, or the means compared with the end, are beyond all measure preposterous and unnatural. We smile when we read that the "Mountain was in labour and brought forth a mouse." But here all nature labours. The whole earth trembles; - its surface is rent to atoms;-mountains are torn up by the roots; - the whole face of nature sinks in a gulph; - and the waters rise into a mountain;-The land disappears-the sea becomes dry land:- and this is several times repeated.-And for what?-For an answerable and adequate effect? No!-Only to change the form or appearance of shell to fishes,-the lowest animals in the scale of being !!!

- That philosophy, which fixed our globe in the centre, and whirled the sun and heavens round it, for the earth's sake, was not a quarter so absurd, and void of utility and common sense.

ON THE WHOLE, then, two things are plain. The first is, that M. Cuvier's Theory, respecting the formation and habits of animals undergoing no material change from time or place, is gratuitous and improved. And if allowed, it could only prove that animals became extinct at or since the Deluge.

The second is, that this author's "Theory" involves a violation of the order of nature almost infinitely greater than any change in the animal creation, which he seeks to avoid by adopting it. 
N.B. I have, for the sake of doing away every possible objection, supposed that animals may have become extinct at the Deluge. I am not, however, yet satisfied upon the evidence before me, that it actually was so;-the Bible, I feel convinced, bears in a different direction. And we have seen too much of the unproved statements of Geological Theorists, to pay much respect to their bare assertions. 


\section{CHAP'TER III.}

THE GENUINE PROVINCES OF GEOLOGY, AND OF REVELATION.

HAVING, as I would humbly trust, very satisfactorily cleared the way for whatever the Word of God may suggest to us relative to the preceding subjects, we must now beg the reader's attention to it. But, lest he should feel disappointment in the sequel, it will be well to observe at the beginning, what is, and what is not, to be expected from Scripture. We before-mentioned

The legitımate, and

The illegitimate provinces of GEOLOGY and of the BI BLE.

THE BIBLE is certainly not given to teach us Geology, as a Science. But it is given to teach us what nothing else can teach us, - the time and manner of the world's Creation. It is, moreover, given to inform us that the world has since been destroyed, and why it was destroyed. These "two events or epochs" are, when received in the light of Revelation of IMMENSE IMPORTANCE. The one, displays the Being and natural perfections of the 
Deity, or as the Psalmist and St. Paul have recorded it ;- " The glory of God," and " His eternal power and Godhead."-The other exhibits him in his moral character, as the just and righteous Governor of the world.

GEOLOGY, in its modern character, does not only fall short of both these grand objects, but in its obvious consequences, thwarts, if not destroys them both. For, as we have seen, it would merge our Creation among the geologieal revolutions, even among the least of them, and thus annihilate its CHARACTER. And as to the time and manner of the Creation, it would make the "Word of God" to speak what is unintelligible or erroneous. With respect to the other, its obvious tendency is to diminish, if not subvert the MORA L causes which operated at the DELUGE. For it bewilders and leads away the mind of the beholder from the awful import of that catastrophe, by presenting to him indefinite numbers of such events. And it blunts the edge of his moral feeling by familiarizing him with the misery and destruction of the earth's inhabitants, so many times repeated, without any connexion of offence, with the suffering beings.

It is the province, then, of Geology, and not of the Bible, to afford us "any curious information as to the structure of the earth." But it is not the province of Geology, as Mr. Sumner seems to think it is, to "speculate on the formation of the globe." The Bible does not " interfere with philosophical inquiry," or repress the researches of mankind." But it does forbid us to interfere with "the literal interpretations of terms in Scripture," when such interference would 
change the character of the thing revealed, and fritter down the Creation of the Bible into "тн т т Creation which Moses records, and of which Adam and Eve were the first inhabitants ;" and so make " the Mosaic account of Creation" a mere epoch in the progress of Geology from the "primitive formations" to the present times.

Mr. Buckland wishes to advance the science of Geology in the estimation of believers in the Scriptures, and in a Divine Providence, by stating, as we before hinted, the "striking marks of design and benevolence in the structure of the earth," (as de Luc writes,), and the "overruling intelligence continuing to superintend, direct, modify, and control the operations of the agents" which were employed in "producing these convulsions" and "ancient revolutions that have overturned the globe."

The learned author instances in what are called "faults" or interruptions to the continuity of horizontal beds of coal by which inundations of the mines are prevented, and the working of the coal measures facilitated; and in the case of springs, \&c. Mr. Buckland also states, the wise design exhibited in the "inclined" state of the "strata; by which arrangement numerous " mineral productions are made to emerge on the " surface of the earth which must have been buried " for ever beneath it, had their position been strictly " horizontal."-(Lect. 11, 12.)

- Surely this argument, of itself, ought to be esteemed sufficient to destroy the theory which Mr. Buckland in the same pages defends; viz. that these "strata" were formed " under water," and subject to the 
"laws of gravitation," and must therefore have been formed "horizontal", had no "disturbing powers interposed."---As the author adopts M. Cuvier's "theory of the earth," with respect to "deposition in a fluid," and "horizontal formation," I presume he must mean by "disturbing forces," what M. Cuvier means when he states that the strata must necessarily have been deposited horizontal, and, of course, elevated by violence afterwards. If Mr. Buckland means that "forces" disturbed the horizontal formation while the strata were being deposited, he forsakes M. Cuvier's theory of formation without giving us another. And it is like saying that the strata would have been deposited horizontally, if they had not been deposited otherwise.

But I would state in reference to the general position which Mr. Buckland has here advanced relative to "final causes" that, though I must highly approve the principle, I very much doubt the propriety of its application to modern Geology. When a writer advocates a "system," " in the Geological arrangement" which he considers "prospectively subsidiary to the wants and comforts of the future inhabitants of the globe," as "wise and benevolent," he pledges his system upon the character of the Author of that system; and thus leads us to a test of its truth, arising from the known perfections of Him who "framed," and who continues to "superintend" it.

But here we shall beg leave to demur. Few persons, I should think, who are not shackled by the prejudices of a certain school, would ever think of denominating the modern "system" of "Geology" either " wise" or "benevolent." 
Mr. Buckland gives another illustration of his subject from the suitableness of the earth's materials, to support vegetables.

"Here is an instance (he says) of relation be"tween the vegetable and mineral kingdoms, and of " the adaptation of one to the other, which always im"plies design in the surest manner : for had not the "surface of the earth been thus (that is by its "de"composition") prepared for their reception, where " would have been the use of all that admirable system "of organization bestowed upon vegetables?"' (Lect. 17)

The Professor may be fairly considered as having here, in an indirect way, committed modern Geology, upon the assumption of the roisdom and benevolence of its character.-That the earth is very wisely and benevolently constituted for the comfort and utility of its inhabitants, is certainly true. But how do these appear on the face of our modern Geological Theories? I should wish for nothing more decisive of the error of this Geology than its failure to exhibit wisdom and benevolence, when contrasted with the Scriptural system upon the same subjects.

We have no information of the true character and perfections of the Divine Being, but what the Scriptures give us. The "world by wisdom knew not God." Let us then just glance at this branch of our subject, in the light of divine Revelation; and contrast Geology with the representations of the Bible relative to the divine attributes.

The Bible in contrast with Geology RELATIVE TO THE DIVINE PHRECTIONS.

GEology informs us that the "primitive rocks" 
were first deposited horizontally, where violently torn up and projected into turrets and pinnacles, undergoing numerous convulsions and catastrophes, while they were alone, and before the existence of any living being.-Where is the wisdom of this !!

Thence arose "transition" and "secondary rocks," in combination with a few "shell fish" imbedded in their substance. Those rocks, deposited horizontally, were subsequently thrown up and "overturned in a thousand ways," and most of the animal existences buried in their ruins. We can discover no wisdom here.

After these, arose up in succession, "flætz or flat rocks" and "newer flætz rocks," to the amount of twelve or fifteen. These sustained, first reptiles, then birds, some lower-rank quadrupeds, then higher class quadrupeds; most or all of which in their turn, sunk and perished. Was this wise and kind!!

Next to these spring up (from what source we are not told) elephants, rhinoceros's, bears, hyænas, tigers, and with them, some extinct races of elks, buffalos, horses, oxen, and deer. These according to the Theory should be found in the lower strata of alluvial formations. All these were overthrown, perished, and become extınct before the existence of man.

I will not ask where is the wisdom, but where is the "benevolence", not to say justice of all this? Not a creature capable of offending its Creator! Nevertheless we find "whole genera" and whole nations of animals perishing in succession; and this numerous times repeated, as if their "Author (as Mr. Faber from the Hindoos has told us) were in sport, forming and destroying worlds again and again"!! 
ThE BIBLE, on the other hand, informs us of a destructive catastrophe, and gives a wise and holy reason for it.

"And God saw that the wickedness of man was " great in the earth.- And the Lord said, I will de"stroy man whom 1 have created from the face of the " earth; both man, and beast, and the creeping thing, " and the fowls of the air: for it repenteth me that I " have made them."

Behold here the moral perfections of the Deity, (which are lost if not destroyed in the detail of geological revolutions,) shining forth. We see here, a wise and just reason for all this. But in Geology, the whole mass of destruction and misery is gratuitous, uncalled for, and useless!! But again,

GEOLOGY makes provision for animals and animate nature, in a most circuitous operose, tedious, and extraordinary manner. It supposes the "Primitive rocks" for thousands of ages, existed under various revolutions and destructions, which shattered them into millions of fragments. From these shattered morsels (I believe this is the meaning of Geologists, for if not, fresh creations must have supplied what succeeded, but of this we never hear,) arose another sort of formation, which Mr. Buckland speaks of as

"Composed of derivative or secondary strata, in " which the compound" nature of their ingredients

b " Compound nature." Mr. Buckland speaks of the secondary strata as derived from the "exuvice" of the primary. But when they obtained their " compound nature" he has not informed us. But it is evident that any strata derived from fotmer strata, can only possess the ingredients of those former, though perhaps in a difierent state of combination. But thus we find the primitive rocks differing from each other. The gneiss which is a 
"qualifies them to be of the greatest utility to man" kind by their subserviency to the purposes of luxuri" ant vegetation."

How many "thousands of ages" this process would require for "luxuriant vegetation",-where the vegetables came from,-and who originally planted them, Geology gives no information. And how these secondary slate, and limestone rocks, issuing as we are to understand, from the bottom of the sea, on every successive revolution, became pulverized, sown, and luxuriant, we are left to guess. How many millions of animals perished on these naked rocks before vegetables sprung up, we know nothing. But this we do know, that no man living can see either wisdom or benevolence in such a process.

The Bible, however, informs us, that when man and beast were created, the whole surface of our globe WaS A FRUITFUL FIELD; - that "SOIL" Of a FERT1LE and PRODUCTIVE nature was FORMED by the Almighty fiat at ONCE; - and that m: found himself and his animated associates surrounded by and furnished with every created good, in their full grown perfection.-No one, surely no Christian at least, can contrast the divine and dignified simplicity of the BIBLE narrative on this subject, with the unnatural, unphilosophical, and ungracious process which GEOLOGY draws out before our eyes, without being ashamed to embrace a system so uncongenial with every dictate of the understanding, and so revolting to every feeling of the heart.

slaty structure, is compounded of quartz, mica, and feltspar, which are precisely the same ingredients with those which compose the granite which is a crystalline formation, though in different proportions. 
"In the BEGINring God created the heaven and the earth."

"And God said, Let there be light, and there was light."

"Let there be a firmament." "Let the dry land appear."

"And God said, Let the earth bring forth grassAND IT was so."

Here we behold at once, a "luxuriant vegetation", indeed. Here the "Eternal power and Godhead" shew their divine and creative character.-And the exuberant bounty and rich "benevolence" of the Deity immediately break forth in loving kindness to the creatures which his hand had formed, and beheld, thus, "very good."

"And-God said, Behold I have given you every "herb bearing seed, which is upon the face of all the " earth, and every TREE in the which is the fruit of a " tree yielding seed; to you it shall be For MEAT."

Thus we see that, when compared with the Scriptures, the modern Geological Theory makes every thing unwise, unkind, and perhaps, unjust. It finds no original Creation:-And it cannot prove a first Creation, from " wise design." For " primitive rocks remaining thousands of years alone is unwise, because useless. And, dashing these to pieces, in order to mend them and make fresh ones, designates either a want of wisdom in the primitive " design," or a failure in the attempt, and a want of experience and power to execute a wise one. But whoever predicates either of these on the Most High, "charges God foolishly."

I am aware it may be suggested that there are many 
dispensations of the "Most High which we cannot fathom, though we feel disposed to acquiesce in them, because they are ordained of God who cannot err. To this I freely' assent. But what then? The objection cannot here apply. Geology cannot take refuge in the above suggestion, unless it can plead Revelation, or some other evidence distinct from the perfection of its own nature.-Let it be remembered that we commenced the comparison which we have instituted between the Bible and Geology, expressly on the alleged ground,- that the latter exhibits undeniable evidence of the Deity. That the location and adaptation of the strata to the use of man are wise and good, is fully admitted. But these are facts. That the time and manner of these formations, however, which the modern Geological Theory professes to develope, shew "wise foresight and benevolent intention," and exhibit " proofs of the most exalted attributes of the Creator, is, I believe, what few will have boldness enough to assert. Yet, if Geolgists would recommend their science (which involves their "theory" of formations), they must not only shew that there is wisdom and goodness manifested in the formation of the strata, but in their Theory of that formation.

In a philosophical view, Geology exhibits itself to no better purpose than it does in a Theological and moral one. It has ever been held as a consequence of the wisdom and superabundant goodness of the Deity, discoverable in our globe, and from similar congruities apparent in the heavenly bodies, that they, like our own globe, are peopled with rational inhabitants. But if Geology, as it pretends, have 
proved that our globe was for indefinite ages without a "living being" upon it, the heavenly bodies may be so too ; and that not for ages, but as long as they continue in the heavens.

Geology, therefore, when contrasted with the system of the Bible, is weak, or rather profane; when weighed in the balance of philosophy is lighter than vanity itself. Once more ;

THE BIBLE is given to correct such sentiments as the following. Mr. Sumner, as before quoted, speaking of the "Mosaic history," writes thus ;

"According to that history, we are bound to admit " that only one general destruction or revolution of " the globe has taken place since the period of that "Creation which Moses records, and of which Adam " and Eve were the first inhabitants. The certainty " of one event of that kind would appear from the " discovery of Geologers, even if it were not declared " by the sacred historian. But we are not called upon "to deny the possible existence of previous worlds, "from the wreck of sohich our globe wo's organized, "and the ruins of which are now furnishing matter "for our curiosity." -(Inaug. Lect. 26, 27.)

There are three clauses in this passage, each of which I think lies open to very serious objection.

1. The first clause, when it speaks of "that Creation which Moses records, and of which Adam and Eve were the first inhabitants," implies that there may have been other Creations which he does not record. To this I would observe as follows.

Moses describes and records one Creation, and one Creation only. And this one Creation only, applies 
to the earth, to animals, and to the human race. Moses records no other Creation with respect to any of these. It will follow then, if Geologists have proved that there were "previous worlds," which "we are not called upon to deny," and animals prior to those which Moses records, there may have been "human beings" prior to "Adam and Eve." For, if this earth was not the first earth, and those animals were not the first animals, we have no authority to say that "Adam and Eve" were the first man and first woman.

Thus Saint Paul's declaration respecting " the first man Adam," \&c., would be interpreted to mean, like Mr. Sumner's "Adam and Eve," the first inhabitants of " " Тн A T Creation which Moses records;" "but we are not called upon to deny the possible existence" of other "Adams" and other "Eves" in those "previous worlds" which Geology reveals. Thus Geology would make the Bible mean just what its advocates please; and thus, moreover, the assurance of Mr. Buckland as before noticed, respecting the Bible, that is, that the declaration of Scripture is positive and decisive, as for instance, in asserting the:" low antiquity of the human race;" would fall to the ground. (Lect. p. 23.)

2. The second clause also states that "one general destruction of the globe" "would appear from the discoveries of Geologers without the aid of Scripture.

This implies that Geology, in this matter, knows all that the Bible reveals and a great deal more. This accords with Mr. Buckland's implication, that "Geology goes further" than the "Mosaic account" of creation goes. This is surely making very light of the Scriptural narrative! 
But in answer to the above insinuation, I would remark that if we are obliged to give Geologists credit for their pretended "discoveries," it is not "one destructive" "event" only which they have found out but great numbers.

It would also follow from these " numerous catastrophes" that Mr. Buckland's celebrated treatise respecting "diluvial operations," is gratuitous and inapplicable. For what he calls " diluvial" would, according to this "Theory of the earth," be found, in very numerous cases, to belong to prior revolutions. For not only M. Cuvier, but Mr. Webster, and Congluare and Phillips hold that "alluvial strata," (all which, except some modern formations, Mr. Buckland makes to be "diluvial,") include two or three such catastrophes, at least.-But neither Mr. Buckland nor any one else can at all point out to what portion of these " alluvial formations," Noah's flood belongs.

3. The third clause says "we are not called upon to deny the possible existence of previous worlds."

It is not the "possible" but real "existence of previous worlds," that we are concerned with. Mr. Buckland also says of "Moses" "he does not deny the prior existence of another system of things." Surely he does deny it, as much as a person describing the first " order of things," can, by that act, deny the existence of a former oné.

But why (may we not ask Mr. Sumner,) are we "bound to admit, according to that history that only one general destruction of the globe has taken place since the period of that Creation which Moses records"? Does Moses call upon us, "to deny" other "revolutions" and "destructions" any more than other "pre- 
vious worlds"? No. He records that one, and certainly implies by the circumstances of his description that there was no ither. But so he does of Creation. If there had been former Creations, the one Moses described was not the "beginning"; yea, was not even a "Creation" of the "earth" in any true sense of Creation, whatever!

Thus we perceive, if we once leave this infallible guide, we are instantly lost.

THE BIBLE is given to teach us that there has been one Creation, and one Deluge, attaching to our globe, and no more.

This is the very point to which, and upon which, the whole discussion turns, and for the maintaining of which, we are now most fully warranted. All I need here add to the prodigious mass of unanswerable evidence previously laid before the reader, is the following, (if it stood alone,) most conclusive position, If we were to admit, as Geologists require us to admit, other Creations, belonging to our globe, besides the Mosaic Creation, and other Deluges besides Noah's Deluge, it would merge both our Creation and our Deluge among the Geological revolutions, and thus makeTHE CREATION and THE DELUGE essentially the SAMETHING.

We have seen that our "Creation," according to M. Cuvier's "Theory of the earth," would be one among the many "revolutions" which have affected our globe; and Noah's flood, he expressly contends, was another, namely, the last of those revolutions.

Mr. Buckland and Mr. Sumner, as before quoted, expressly imply, the same thing.

The former says, "Moses confines the detail of his 
" history (of Creation) to the preparation of this globe "for the reception of the human race."

This "preparation," we have lately been taught according to M. Cuvier, Webster, Jameson, Conybeare and Phillips, \&c. \&c. could only embrace a part of the alluvial strata; - and was therefore only a very slight revolution.

Mr. Sumner, certainly merges our "Creation" among the Geological "Revolutrons," when he says,- " тHAT CREATION which Moses records." And he expressly ranks our Deluge among those revolutions; for he says, "that only one general destruction or revolution of the globe has taken place since the period of that Creation which Moses records."

Thus then, the Creation and the Deluge are both revolutions. And indeed, in the language of Geologists, if indeed they ever use such language, a Creation and a revolution mean the same thing. In every one of the numerous revolutions of which M. Cuvier \&c. speak, the very same process with respect to both the earth and the animals, which took place at our Creation and our. Deluge, must then have taken place.

Certainly therefore, according to these Geologists, it will follow that the Creation and the Deluge are essentially the same thing.

As it respects the EART, they are much the same.

For, as we have been considering the matter, the "alluvial soils" include two or three revolutions. And these alluvial strata being the upper strata which the earth contains, the revolutions affecting those strata are the last revolutions which have taken place. But our Déluge and Creation were also the two last revo- 
lutions. Then our Creation and our Deluge are both confined in their operations to the alluvial strata;the Deluge on the surface and the Creation on'one stratum lower.

The reader will probably recollect that in the former part of this treatise, we considered our Creation, in the scale of Geological progress, to have been occupied about the "Paris formation," and not as here, about the "alluvialstrata." This is true. And the reason for it was there given: Which was this; - that allowing Geology all it could possibly claim upon any part of its Theory, it would make next to nothing of our Creation. But according to these Geologists above quoted, our Creation is reduced even lower still, and becomes diminished into nothing but a flood or wash of the prior formations. For the inconsistency of Geology with itself, I am not accountable.

With respect to the ANIMALS, moreover; it is true that the Bible considers animals to have been produced at the Creation, and preserved at the Deluge. But Geology will not admit even of this difference. For it is absolutely demonstrable that at every revolution, not excluding even our Creation or Deluge, A N I M A LS must either have been preserved or newly created. To avoid the destructive consequences of new Creations M. Cuvier, as we have mentioned before, resorts to the equally destructive consideration, that animals, at each revolution, "came from some other part of the globe"'!!

I need not weaken the force of the impression which the above statement must make on the mind of every Biblical reader, by stopping to argue the matter and to 
prove to him the absurdity of making the Creation and the Deluge essentially one and the same thing. I may assure myself that his reverence for " the word of truth," which professes to be, and is or it is nothing, a plain declaration of the mind of God to man, will make him shrink back with disgust and trembling, from admissions so abhorrent from its meaning, and so destructive of its character!-But when in addition to this, he reflects upon what is gone before, and calls to mind that the Geological "Theory" which boasts such great things and involves such consequences, is itself not only void of evidence but involved in war against truth, and fact, and evidence, and argument, he will need no further inducement to give this Geological Theory his utter disavowal, and the Bible his implicit confidence.

According to THE BIBLE then, and to all analogy" and fact (the conclusion is inevitable, "we are bound to admit, that only one general destruction or revolution of the globe has taken place since the period of that Creation which Moses records"; and that "that Creation" is the oNLY CREATION and that revolution the ONLY REVOLUTION which haveever attached to this globe since Creation existed. 


\section{CHAPTER IV.}

SCRIPTURAL ACCOUNT OF DILUVIAL OPERATIONS, AND THEIR EFFECTS UPON GEOLOGY.

The Geological Theory being quite laid aside as abortive, and without all claim, leaves us entirely free to follow a better guide. It must not, however, be expected, that any high degree of satisfaction is likely to be afforded by the Scriptures to those who wish for a curious detail of circumstances respecting the situation of the earth, or how it came into that situation. The Bible is given for infinitely weightier purposes than to teach us useless sciences, or to gratify a vain " curiosity." Geology, I regret to say; has hitherto but ill supported its claim to rank among the sciences; it having scarcely ever, as it should seem, afforded any valuable suggestions on any one individual subject. And so long as it is cultivated only or chiefly to supply " matter to our curiosity," we cannot expect any profitable result from such labours.

When, moreover, Geology, which, doubtless, both might and ought to be brought in aid of "Divine Revelation," is made, however undesignedly, to un- 
dermine its credit and contradict its decisions, we ought to fear the consequences of such illegitimate occupations.

We have shewn in the last chapter that there has been one Creation and one Deluge accruing to this globe, according to the Seriptural verity; and that Geology has no evidence (but the contrary,) on which it can contradict the plain and obvious meaning of the Bible.

This, of course, will now become a matter for our consideration. Because, as we now, on Scriptural authority, refer every thing of magnitude which the secondary strata of the earth exhibit, to that "one event," it will naturally be expected that something further should be said relative to so important an affair.

We have already explicitly declined indulging all "curiosity" on this point. And we shall as explicitly disavow all pretensions to a system of operations and. causes, as well as classification and arrangement in the stratification.

We must consider, however, the character of the diluvial operations, as they may be reasonably collected from the hints given us in Scripture.

From these operations I trust we shall be able to derive troq, important results. The one

-That, such operations are perfectly inconsistent with modern Geological Theories respecting the stratification. The other,

That such operations will alone account, and that: they only will account, for the existence of geological phenomena.

The reader will, of course, let his own good sense 
forbid the expectation of any thing like detail or minuteness in our deduction from Scriptural records. Had any such thing been possible, it would long ago have been found out, and it would have precluded any difference of opinion on Geological subjects. But such particularity does not belong to the Bible. Nor would men in that case have been left to the decision of faith and to general principles in their deference for revealed determinations.

\section{DILUVIAL OPERATIONS.}

The reader will recollect that in our review of the Scriptural account of the Deluge, we learned that the waters which destroyed the inhabitants of the earth were partly derived from the "rain" and partly from the "fountains of the great deep." These "fountains" were shewn to mean not the sea, but passages from waters under ground, whether under sea or land: and the supply from both sources amounted, on an average, to about 700 feet per day; and that their retirement or decline amounted to about 100 feet per day, or about one seventh part the amount of their egress.

This issuing of the waters - their prodigious amount -and their prevalence and effect, as stated in the Bible, are duta from which we may collect certain ideas of vast importance in this discussion. And so long as we keep close to these dala, and do not give way to curious theorizing, we shall at least stand on safe ground, however dissatisfied the vain or the over. speculative may'remain. 
I. THE OPERATION OF THE OUTBREAKING WATERS.

THE RAINs, - -heavy, and teeming in cataracts, -as the "windows of heaven," (the terms made use of in Scripture,) imply; would descend in torrents and precipitous floods down the hills. These would naturally sweep away almost every thing which was of a moveable character, and hurry it into the low grounds; or, they would rush downward till they were stopped in their course by waters bursting out of the hills, or by waters meeting them from the valleys below.

THE BREAKING UP of the "fountains of the great deep" mean, as we have shewn, the issuing of the waters from the bowels of the earth. The French philosophers used to laugh at the notion of the earth's being deluged by 40 days' rain. But they overlooked the Scriptural account of these underground "fountains." Indefinite supplies would be hence derived; and as at the Creation, the waters, before they were commanded to retire, "stood above the mountains," so now at the universal Deluge, on the same Almighty fiat, they issued forth to cover them again.

It would seem probable from what Mr. Sumner and Mr. Buckland say, as found in the 237 page, of the "Reliquiæ Diluvianæ," that they both contemplate the Flood as arising greatly or wholly (though they cannot, in the view of Scripture, mean this,) from the "waters" of " the ocean pouring in over the land when its level was destroyed.",

That the waters of the sea were poured over the land, is very certain ; but their "level" was not apparently "destroyed," otherwise than by the "fountains under the earth" bursting up under the sea, and 
forcing its waters over their own boundaries.-In considering the Scriptural account of the Deluge, we saw demonstrative evidence why the "sea could not be the thing, or the only thing intended by the "fountains of the great deep," and why its waters could not supply the quantity required to cover the highest mountains; (it requiring nearly 90 seas to cause the Deluge:) and that it would be unscriptural, unphilosophical, and unreasonable to suppose they did:

This turn of the subject relative to the souree of the diluvial waters, as we shall probably hereafter consider, will change the entive character of the "diluvial operations" from that which the above-mentioned authors consider to have taken place.

Without pretending to great accuracy where our data does not supply us with abundant information, suppose we admit, which is probably much under the matter, that these underground fountains only supplied one-half of the waters of the Deluge; they would then discharge, upon an average, for 40 days, 350 feet of depth per day. What a prodigious emission of water !

These waters, by whatever power they were raised, would spout up in fountains all over the earth. For we know of no place where the waters are not. The quantity of water thus raised may be somewhat guessed at. But the force which caused them to rush forth from their subterranean caverns, we cannot calculate. This, however, seems very certain, both from the historic narrative, and the nature of the case, that the force which caused their elevation, did actually tear and break up the solid strata by which they were previously covered. 
By such an immense issue of waters, it is certain innumerable rents and openings would be caused in the earth. Their number, their depth, and their magnitude, we cannot tell. But this is evident, "all the fountains of the great deep" being "broken up, must imply that the underground waters, whether near the surface of the earth, or far off, were made to pour forth their abundant streams; and the rents or fractures may be supposed to vary according to the depth or compactness of the strata through which they had to pass. And we have no reason to suppose but that every part of the earth and sea united in this universal out-pouring of the mighty waters.

I do not think that Mr. Buckland has said too much relative to the Diluvial action on the earth, in the following passage, though we differ essentially as to the mode of that action. Speaking of the "Agency" of the Deluge, he says, "the ravages of which have not, perhaps, left a single portion of the ante-diluvial surface of the whole earth, which is not excavated and remodelled, so as to have lost all traces of the exact features it bore antecedently to the operations of the Deluge." (Rel. Diluv. note p. 43.)

As we now consider ourselves warranted in saying that one Deluge, namely, Noah's Flood, will alone account for all the stratified phenomena, we must of necessity admit that the "fountains" under the sea were opened, as well as the fountains under land. For we have clear proof, as will probably be hereafter shewn, that the sea and land did not, properly speaking, "change places."

From these irruptive fountains and descending cata- 
racts of water we may, without fancy or theoretical pretensions, contemplate a scene most awful and tremendous. The waters would instantly, and from all quarters, descend to the low grounds. For we have no reason to suppose that gravity was "suspended. These, meeting with waters boiling up from beneath the earth, would disturb each other, and form commotions. The diluvium, of whatever it might consist, whether of fragments of rocks, of soil and vegetables from the hills, and the loose or solid earth which the bursting forth of the waters would urge from beneath, would mingle and form unknown compounds. Stones and detritus, and whatever else might come in the way, would be dashed about, and rolled backwards and forwards in proportion to the impetuosity of the commotions occasioned by the issuing and falling waters.

The amount of the wreck, or the extent to which the hilly contents would be mixed with those in the valleys, or from beneath, cannot be calculated. Nor can we say to what distances either laterally, longitudinally, or perpendicularly, any current formed by the issuing waters, under particular circumstances, might advance. Nor can we conjecture how great a quantity of rocks, stones, mud, detritus, small pebbles, or shells, such a mass of spouting waters, rushing with irresistible impetuosity, might force upon contiguous eminences, or deposit in the neighbouring hollows.

We may further contemplate this operation in the progress it made towards completing the work of Almighty vengeance. The divine narrative says, 
"The waters increased and bare up the Ark, and it was "lift up above the earth.-And the waters prevailed " exceedingly upon the earth; and all the high hills, that "were under the whole heaven, were covered. Fif" teen cubits upwards did the waters prevail and the " mountains were covered. And all flesh died that " moved upon the earth, both of fowl, and of cattle, " and of beast, and of every creeping thing that creep"eth upon the earth, and every man." " All that "was in the dry land, died."

The out-breaking waters would, in their first breaking forth from beneath the earth's surface, be attended with inconceivably destructive violence. As however the superincumbent floods increased they would naturally possess less power to force the ingredients mingled with them to a great height or to diffuse them in lateral directions: because they would be opposed by a perpetually increasing obstruction; the waters, being a denser medium than the atmosphere, and its resistance continually increasing with its height. And this process would go on, the waters increasing in depth and the local issues diminishing in their disturbing influence, till the Deluge was completed, and the further progress of the waters stayed.

The rains and the fountains also of the great deep were then restrained, and the diluvial action of descending and ascending waters was no more.

II. THE RETURNING WATERS.

The Bible informs us, not only whence the waters issued, but whither they retired, and how long they were in declining. We have shewn that they retired little more than one hundred feet of perpendicular 
depth in a day, while they rose seven hundred. After the waters had arrived at their destined height, and had executed fully the divine displeasure against sin, we are told by the sacred penman that,

"God made a wind to pass over the earth, and the "waters were assuaged; the fountains also of the " deep, and the windows of heaven were stopped, and " the rain from heaven was restrained; and the waters " returned from off the earth continually."

Hence we derive information that the waters ascended, by evaporation through this drying " wind," into the atmosphere where they were before ; and that the other portions "returned" also into their under ground receptacles from which they issued.

Now it seems obvious that we must judge of the violence and commotion of the returning waters from the nature of the case. Having performed their punitive office it might be rationally conjectured that their incontrolable impetuosity would abate. But this is hypothesis. However as the waters retired only one seventh part so fast as they rose, their violence ought not to be considered as very great. Nor ought we to assume that mighty "currents" were formed, or immense commotions produced, in the retiring waters. Nothing but what is natural in such a case, ought to be supposed.

Now the evaporation, as such, would cause no disturbance in the waters : the drying "wind," which was probably very strong, might. Yet as this wind was, as its purpose required, not partial but general over the whole surface of the waters, it would not cause partial effects or currents. 
As the openings under ground, to which the waters "returned," were beneath the waters, their motion begin and go on at the bottom; and the disturbance caused to the waters, as a body, and to the earth, would be in proportion to the magnitude, and to their distance from each other, of the openings into which they retired. But as the Bible speaks of "all the fountains of the great deep" being broken up," we may assure ourselves that the ruptures were numerous.

Although we are assured that the breaches were nunnerous, we have no data for saying how many or how great they were. In situations where they were numerous and comparatively small, the mere subsidence of the water, one hundred feet per day, would not be perceptible from above. If a fishpond, ten feet in depth, were drawn off in two hours through numerous holes, at its bottom, the subsidence, or motion of the surface, would be nearly, or wholly, insensible to the eye of a beholder. In would be only an inch in a minute. Yet this is more than one-seventh part quicker than the subsidence of the waters of the Deluge.

In other situations where, possibly, the chasms might be more like volcanic craters or yawning gulphs, than wells of the numerous shafts of coal pits; the distance above ground which the waters. would have to pass to these chasms, might be considerable. And to be sure, the headlong course of waters, four or five miles deep into such gulphs, (perhaps, as the lake of Geneva,) cannot be conceived. Their rush from all the neighbourhood, into the mouths of these chasms, 
would be in proportion to the magnitude or paucity of those chasms.

Into large chasms, it is easy to see, and almost necessary to conclude, that vast quantities of whatever was within reach, would be hurried down. Only it is also probable that these vast openings would soon become in a measure obstructed by their own spoils.

From these outbreaking and retiring waters, issuing for forty days, and seven times as long in returning, under all the circumstances of the universal Deluge, we may, or rather must, contemplate a desolation in the earth, never before or since occurring. In the angles of large mountains, a sea of issuing waters would rage, with impetuous destruction, through a large portion of the "forty days." 'Trees, and even forests, would probably be little obstruction to such a mass of waters, and moving with such rapidity. Indeed, if they were not checked by the waters spouting out from beneath the earth, or modified in their destructive fury by that supernatural power which gave them birth, it does not appear how any thing but hard rocks, or rather mountains, could retain their places on the earth, or be prevented from becoming an universal chaos.

And, indeed, even mountains, (which, as Dr. Buckland justly observes, contain large portions of our "springs," or "fountains" of water,) would most probably undergo very violent lacerations and dismemberment from the irruptive fury of the outbreaking waters. These mountain chasms being laid open by the Deluge, would be either again filled up in a measure by their own debris, or remain frightful and 
impassible gulphs, as we find numbers about the Alps, $\& x$., are to this present day.

The sensible reader will easily perceive that the above observations are not offered as a Theory, in any wise, or as any thing like a full explanation of what we know so little. What we have said is, however, what would, upon natural principles, for substance, occur on the issuing of waters from the bowels of the earth. Now, we know from the Word of God himself, that an issue of waters did take place, and we know also, from the same infallible source, how long those waters were in rising and in returning. And from creditable historic testimony we learn the height to which they must have risen in order to cover the highest mountains; by which we have calculated the rate per diem at which they rose and retired.

But we are ignorant of the means, because we are not informed, by which this issue was effected; only we know that its author was God. "And, behold I, " even I, do bring a flood of waters upon the earth, " to destroy all flesh wherein is the breath of life, from " under heaven." The effect of this catastrophe, we have seen, must have been tremendous, even to the earth; for the 40 days' rain would necessarily overwhelm the upper portions of the furnished earth, and the " breaking up of the fountains of the great deep," would disrupt the strata through which they issued.

\section{OBSERVATIONS.}

It may, perhaps, be well to make a reflection or two in this place, by way of exhibiting before the reader the genuine state of the earth as it seems to have been before and after the Deluge. 
1. The state of the earth before and after the Deluge.

We have pretty clearly seen, I think, from the Bible, that the "earth" was "created" in all its substantial parts, with rocks, hills, mountains, and valleys, as it is now. (Ps. civ. 6-8.)

-That the "waters" covered the "mountains" at the Creation, but retired at God's command into the places "founded for them," and thus "let the dry land appear." (Gen. i. 9.)

- That the Almighty, after this division into land and water, planted the earth with trees in a rich and luxuriant soil, and there he caused the earth to bring forth in perfect maturity on the third day.

- That on the fifth and six days God caused the sea and land to "bring forth" fishes and animals; but that the Most High paid particular regard to the formation of man. (i. 26, 27.)

- That the earth remained materially the same as it was created till its surface was torn and rent to pieces by the "Fountains of the great deep" being " all broken up" at the general Deluge, when God destroyed the earth with its inhabitants. (vi. 13.)

-That this destruction of the "earth" was a destroying of it only as a habilation, and was not a dissolution of its more substantial framework; because the large "Hills and Mountains" "under the whole heaven," were found such, and left such, (generally,) by the Flood, however greatly they might be rent or shattered by its operation.

It is natural to conclude that the surface of the earth at the Deluge must have contained the bones of antediluvial animals. These would generally, of course, 
be overturned, when the surface of the earth was disrupted by the diluvial waters, and mingled in different ways, with the drowned animal remains. Probably, however, nothing can give Geologists any clew by which to separate them. And if it could, it would only confirm the scriptural account, and not modern geological theories.

If I am asked, how the Deluge operated in producing the effer:ts ascribed so it-or how the materials which it disturbed came to be as we now find them, I can only answer that I do not know: For He who alone knows, has not told us. Geologists, too, are equally ignorant of these matters, on their own hypothesis. But the following observation ought to silence our unsatisfied curiosity.

2. The Deluge was of a miraculous character.

The bringing of the animals into the Ark, wild and tame, was quite beyond nature. The wild and ferocious animals came to Noah for preservation, though his own species derided his admonitions.

The ejection of the subterranean waters, and the breaking up of the rocks which contained or covered them, were also manifestly a reversal of every usual operation of nature ; unless, indeed, volcanoes may be considered as an usual operation of nature.

The preservation af the Ark, and the directing of that moveable floating body to rest upon the high mountains, and not in the valleys, where it would have been so much longer afoat.

The food for animals and man must either have been preserved in the Ark, in sufficient quantity, till fresh vegetables grew; or a new class of vegetables must 
have been produced beyond the usual way. For though seeds, \&c. may be supposed to have lodged on the surface of the mud, \&c. preserved from destruction in order to produce a fresh stock, it must have been some time first, and great inconveniences would have followed.

The declaration; "Behold I, even I, do bring a flood of waters upon the earth ;" and this ; "God remembered Noah and every living thing," seem to, imply a peculiar and immediate interposition of the Almighty, both in destroying the previous roicked race, and in preserving the present one, in "righteous Noah and his family."

3. The reader must remember that we do not, in asserting miraculous interposition, flee like many philosophers when they can go no further, to "occult qualities," for the purpose of concealing what we do not understand. For, though Geologists cannot consistently with their own principles, as before shewn, admit of "Geological causes beyond the established laws of chemical and physical science," yet miraculous interposition necessarily belongs to our subject. Indeed it is an essential part of the scriptural system upon this point. We have abundantly proved that the "Theories" of our Authors, can do nothing. They are over and short, they are inconsistent and self-destructive, in every direction.

But let it be remembered, the scriptures do not assert miracles any further than they are manifestly necessary. The cause of the Flood, and the objects to which it was directed, were doubtless peculiar to that event. But the grand laws of nature do not ap- 
pear to have been, in other points, superseded. The laws of gravity-the usual effects of " mighty waters," projected, falling, or rushing in various directions,as well as their usual tendency to destroy animal life, were all unquestionably, in full force.

And further, the waters of the sea, though violently forced over the land, and made again to retire into their former receptacles, were clearly not altered materially in their nature. They were salt before, and are salt now. They supported all sorts of fishes before, and they do the same still.

4. Whether, however, whole genera of fishes and animals were exterminated by this awful event, we are not told. The Bible narrative would certainly induce us to believe, they were not destroyed by the Flood. Whether they be actually "extinct" now, must depend upon two circumstances, the limits of which, (however he may guess at them,) are certainly not known to man. These circumstances are, - a knoweledge of all the animals now living on the globe; and also, that existing races did not proceed from the ancient fossil ones. The Scriptures seem very strong, both as to the fact, that all animals, (not fishes,) were preserved in the Ark; and that the Almighty's design, as to the fiture, was to keep them alive.

(1.) It is so often repeated, respecting the animals preserved, that "every beast," and " all the cattle," and every creeping thing wherein is the breath of life," that we must not make any exceptions to the universality of the animals which "went into the Ark." (Gen. chap. vi. 19,20 . vii. $8,9,15,16$.)

(2.) It is also very expressly said, "to keep them 
alive" " to keep seed alive upon the face of the earth"; - and Noah is expressly charged after the flood, to " bring forth every creeping thing that creepeth upon " the earth ; that they may breed abundantly in the " earth, and be fruitful, and multiply upon the earth ;" and it is added ; and "every beast, every creeping "thing, and every fowl-went forth out of the Ark." (vi 20. vii 3. viii 17, 19.)

In reflecting upon the universal and positive and repeated language of the word of God, in connexion with the great and numerous errors committed by Geologists, when their dogmas have confronted that word, I feel increasing reverence and dependance upon the literal meaning of the Scriptures, and decreasing confidence in the opinions of Geologists, and in their capacity for judging respecting " extinct animals."

\section{CONSEQUENCES OF DILUVIAL OPERATIONS}

ON THE THEORY OF GEOLOGISTS.

The statement which the Bible seems plainly to give relative to the out-breaking of the waters of the Deluge will afford, I conceive, a very powerful argument, if more arguments upon that subject can be necessary, against the modern "Theory of the earth." That Theory, whether Wernerian or Huttonian; whether water or fire be esteemed as the basis of the physical operations of the globe, considers all the transition, all the flætz, and part of the alluvial strata, as having Ibeen deposited long before our Deluge. The diluvial operations which we have been now contemplating will enable us to examine this matter, with some prospect of success. 
There are Two poIsts in this subject, arising from the state of the strata. The strata, generally, and especially the limestone strata, wherein the greatest number of the shelly fossils upon which M. Cuvier relies so much, are contained, have troo singular properties belonging to them. (In this, as in almost all other matters of fact relative to the state and character of the strata, I follow the description, given by Geologists themselves.) The one point is, that the fossil limestone rocks are at the spring-head and source of the very largest issues of water in Europe. The отнеR is, that they are exceedingly cavernous, and have a prodigious number of large fissures and cavities in their substance. Every part however, of the rocky strata, is attended by numerous fissures.

Now the argument, derived from the fact that "all the fountains of the great deep were broken up" at the Deluge, applies to this case. Those waters bursting up as we have seen they must have done, in every situation, and tearing up the solid strata in which they lay, or through which they passed, afford, in two ways, a conclusive argument against modern Geology.

I. The Disturbance CAUSEd to the Strata.

We have been informed by M. Cuvier, that the inclined strata, previous to the formation of the horizontal strata which lie above them, "had been broken lifted up, and overturned in a thousand ways :" and every succeeding stratum, of whatever kind, whether of fresh or salt-water formation, must, upon their principles, as we have often proved, have undergone a revolution of some violent nature, in order to the very formation of a succession. But the alluvial forma- 
tions are always supposed to be posterior to all the rest in point of time, and to be totally of another character.

Now it is clear from Scriptural data, that all these strata, had they been situated at the Deluge, as they are now situated, would have been rent and disrupted by the issuing waters of the Deluge. For those very waters, lodge in and under them in every situation; and indeed, ought to be considered as the great channels of the "fountains of the great deep." Had those fossil strata been as now, they would have been "broken up." For the diluvial waters must have come quite through them. So that the Scriptural relation would apply directly to these very rocks and their watery contents when it says, "all the fountains of the great deep were broken up." These rocks would have been "broken up," and the apertures made by the issuing waters would have been as visibly displayed, as the strata through which they passed.

It is perfectly clear that these waters did not pass by the apertures now called,

"Fissures."

There are "fissures" every where in the solid strata, which the miners say, "vary from half an inch to several fathoms" in width. But it is perfectly demonstrable that the waters of the Deluge neither made these fissures, nor found them ready made for their emission through them.

1. The issuing waters did not cause the fissures by their ejection. For the cracks and breaches which are every where found in the strata are not in the least of the same nature with the fractures caused by the force 
of waters. - They are generally very long and narrow: they traverse the strata, it is asserted, for miles: and, in some places, they are only like a perfect crack in the strata. But the violent rushing of water never makes cracks of such length and so extremely narrow. Besides; if the out-breaking waters had forced out these fissures they would have torn away the materials that filled them up, and have left the inner surface in some sort of roundness. But in very many instances, their figure positively forbids this. For the different sides of the fissures have most unquestionably been in conjunction, as they correspond in their projections and hollows, like the upper and lower ranges of teeth in the jaws of a shark.

2. Nor could they possibly have found these fissures previously open, and so pass through them. For then they would have torn out holes and masses, and would have smoothed and rounded the edges of the fissures, and modelled them to their own character. But nothing of this sort has taken place. Besides; had the diluvial waters issued through the open fissures, those fissures must then have been open to the surface of the earth. In which case they would, except in elevated or concealed places, have been inevitably filled up with diluvial detritus.

Again. As the waters "returned" into these, "fissures," spoils of the Deluge, animal and vegetable, of all kinds, would undoubtedly have been carried into them. Mud, and animals, and shells, and vegetables would as certainly have followed the track of these issuing and retiring waters, as wreck of all sorts, follows the course of a land flood! 
3. As it is a positive demonstration, therefore, upon natural principles, that the diluvial waters did not either issue from or return by, the fissures which are now found in the strata; so it is equally certain that the fissures themselves were not in the strata at the Deluge. For had they been there, the consequences we have been considering would certainly have followed. They would have been "broken up" into thousands of shapes, and filled up with detritus, and all kinds of diluvium, by the rushing or returning waters. For when the soil, which our Geologists call alluvial or diluvial, is removed, these fissures are open and must then have been open, very numerously, to the earth's surface.

I wish particularly to keep clear of hypothesis and Theory, respecting even part of the earth's formation. But what would be the obvious and natural result of turbulent waters like those of the Noahic Deluge, we may, though we ought to do it with modesty, form some rational conclusions. I admit therefore that there are difficulties respecting the fissures both in the primitive and secondary formations, which it does not belong to my province to discuss. But it does I assure myself, bear a demonstrative character, (without denying that there might be various individual exceptions,) that had there been fissures in the strata at the Deluge, such as now exist in our limestone rocks, those fissures would, generally speaking, have been indubitably choaked up by the rushing of the diluvial waters over them-by the sediment which those waters deposited-and by the wreck which they would every where make, amongst the animal and vegetable occu- 
pants of the earth.-I esteem it therefore a clear case

That the Fissures very generally, but especially those of the secondary strata which are open to the alluvium ncar the surface, are demonstrably PosT DILUVI A L.

The following consequence, I consider equally unavoidable. Namely this ;

It is certain from the Mosaic account, that " all the fountains of the great deep were "broken up,"-it is equally certain that those breaches (as we have been proving,) would have been extremely visible in every part of the secondary strata,-but as there are no such fractures or breaches in the regular strata, as this hypothesis supposes, it is perfectly clear that the regular strata, such as "fossil rocks" \&c. were not in EXIsTENCE, AT THE DELUGE.

II. The Diluvial Deposition.

1. It is quite obvious that the violent torrents of water bursting up from beneath the earth and teaming from the opened windows of heaven, must have caused a prodigiously greater DEPOSITION upon the earth, than is consistent with the Theory of modern stratification. The wash of "superficial loam, gravel, and sand," which Dr. Buckland speaks of as diluvial, and to which he appears to confine the diluvial detritus, cannot possibly constitute all the effects of that catastrophe.

The Theory, however, of Modern Geologists, (and Dr. Buckland especially is in union with M. Cuvier in this,) considers the waters of the "last Deluge" to have operated only, or chiefly, upon the surface of the earth. And Dr. Buckland never, to my recollection, 
contemplates the waters as being partly supplied from beneath the earth. With respect, however, to the superficial loam, gravel, and sand of which, we shall hereafter see, Dr. Buckland says so much, I must observe a few things.

(1.) The Geological "Theory" of M. Cuvier, and Mr. Webster, as well as of Messrs. Conybeare and Phillips, considers the "alluvial strata," of loam, said, gravel, and pebbles, as constituting two or even three catastrophes, floods, or separate deposits. Then according to this scheme, a third only or at most one half" of the pebbles, and sand which Dr. Buckland calls " diluvial," were the effects of Noah's flood.

(2.) As the earth was inhabited before the Flood as well as since, and as loam, sand, and gravel in their different combinations, constitute that soil which is essential to the growth of productive vegetation, it is obvious that loam and sand were requisite from the creation, and were certainly the soil in which trees, and grass, and herbs grew from the "beginning." These, then would necessarily be found by the Flood. What then our Deluge could have to do in forming these things, it is impossible to say.

Dr. Buckland of course would say, the Flood has driven that into heaps which was found before that catastrophe, and greatly added to the quantity by its own detritus. Be it so. This would in no sort answer the Scriptural account of the breaking up of the "fountains of the great deep," and of the mighty mass of debris which must have resulted from that catastrophe. From this Scriptural data, and from deductions necessarily arising out of them, we may conclude 
with great certainty, that there must have been very deep deposits of every thing torn up from beneath, and of every thing hurried down from the hills and eminences above.

We have before observed the high probability that, in the early stages of the Deluge, the waters must have covered the low grounds at the rate of a thousand feet in a day; more than five hundred of which, probably came from the "fountains of the great deep." Now, if these waters were ejected with immense velocity, their mighty vehemence must have proportionably "broken up" the strata through which they passed. If they were not expelled with so great velocity, the very emission of five hundred feet of water in so short a time, must have required a proportionably larger space, or numerous spaces, through which it might issue.

It would seem almost inevitable that such an immense body of water rushing forth for "forty days" together would break up, overthrow, and dash to pieces the greatest part of the superincumbent strata. And the mountain-cataracts caused by the gushing waters and the opened "windows of heaven" would demolish, in proportion, the upper regions of the earth ; So that the diluvial roreck must, without a miracle prevented it, be extremely great. The loose earth, rocks, soil, vegetables, and detritus must have been hurried into situations unknown; and animals of all sorts $b u$ ricd in a mass, or scattered into distant parts, in a way, and to a depth, not easily calculated. Furlongs depth of deposit in all the flat and low countries would seem little, from the ruins of such a catastrophe. 
Conclusions pretty nearly as fatal to the Theory of Geologists, would arise from Professor Buckland's statement, respecting the amount of what he calls " diluvial loam" in the caves, hereafter to be considered. In some cases, he finds them filled with mud; and in one, at the height of six hundred feet above the valley, his statement makes the "diluvial waters" to be, at least, half mud. But, if those waters were half mud, on a hill six hundred feet above the adjoining valley, what a mass of mud must they have sustained!!! many hundred feet in depth unquestionably. I admit, that I consider Dr. Buckland's views respecting these caves, to be quite erroneous; but it is fair to draw an argument against a Theorist, from his own statements.

Deductions something like the above seem inevitably to arise from the due contemplation of the Scriptural data-from the height of the mountains-from the time in which the waters issued-and from the consequent height to which they arose. And much the same may be derived from Dr. Buckland's cave system.

I shall not weaken the force of the preceding representation by any additional arguments. But I shall close this statement by recapitulating the general principles. I would observe that we have strictly proved from obvious Scriptural data,

1. That the diluvial waters issuing from "the fountains of the great deep," (probably at the rate of three hundred and fifty feet per day,) when they were "broken up," must necessarily pass through the same strata.

2. That the Scriptural language, which says; "all the fountains of the great deep were broken up," 
implies in the very words, that all the passages to the waters under ground were opened, and the rocks "broken up;" and, of course, that the strata covering those waters were rent to pieces, and torn from their beds.

3. That the same conclusion will naturally follow, from the contemplation of the prodigious amount of water forced through the superincumbent strata in so short a time.

5. That the strata, thus disrupted, were situated where the secondary strata are now situated. And, that, of course, had the secondary strata been at the Deluge, where they now are, they must have been rent and torn to pieces.

5. That the present "fissures" which the secondary strata now exhibit, were not the passages through which the diluvial waters issued;-that they would have been burst into large chasms by the ejected fluid, and filled with diluvial debris by the retiring waters.

6. That as these "strata" are not disrupted in the way, in which the diluvial waters would have disrupted them ; and as the "fissures" are not so rent, or so filled up, as they would have been by the above catastrophe, it follows,

7. That neither the Fissures nor the SECONDARY STRATA DID AT ALL EXIST AT THE time of the Deluge. 


\section{CHAPTER V.}

GEOLOGICAL PHENOMENA ONLY TO BE ACCOUNTED FOR ON SCRIPTURAL DATA.

\section{PHYSICAL PHENOMENA.}

THE preceding discussion has shewn us, in some important particulars, that the Geological Theory is perfectiy at variance with the obvious deductions made from the Scriptural statement of the Deluge; viz. that a large portion of the diluvial waters were derived from under the earth; the consequence of which must be that all the strata must have been exceedingly broken up, and immense masses of debris covered the earth.

This debris I consider to have been the pabulum for all secondary strata in which the ancient fossils were imbedded.

No one will be unwise enough to expect that all the phenomena with which the earth abounds can be explained from the brief narration of the Bible. Much less must the reader expect me to make such an arrogant attempt. It will be quite enough if the leading features of the Geological phenomena can be seen to correspond with the foregoing statement. It is perfectly certain they do not in any sense agree with the modern "Theory of the earth." 
I do not mean to establish any Theory of my own. If we can discover a correspondence between the Bible account of the Deluge and the actual state of the earth, such as not all the wise men under heaven could frame by their Theories without it, that will be quite enough. It is perfectly certain that so far as the Divine Being has told us, whether directly or indirectly, respecting this matter, so far that relation will agree with the actual state of the earth. It may be little indeed which is told us, but that little may be important. From it we may learn - what directon to take,-from it we may gather, when we materially err.

We shall begin our examination with the primitive formations.

\section{Primitive rocks.}

Geologists no sooner enter upon the investigation of the objects of pursuit than they are puzzled and confounded. M. Cuvier as before remarked, stands in astonishment when he learns that the "primilive mountains" "contain no vestige at all of living creatures." And after shewing how the fossil strata are situated, he says ; "but what is still more astonishing "and not less certain, there have not been always liv" ing creatures on the earth." (17.)

And Professor Jameson also in language before referred to, says; "Petrifactions have not hitherto " been discovered in any of the primitive rocks ; indeed " it would appear that animals and vegetables were " not called into existence until the period when the " transition rocks began to be formed." (338.)

What these two most eminent Professors (and it is the language of all Geologists) do not at all know 
how to comprehend from their Geological system, with which indeed it is quite inconsistent, any person who duly contemplates the subject under the guidance of the Word of God, will easily be able to explain. What is perfectly unaccountable by Geological theories is the very principle of the oracles of the Most High.

Let any intelligent person dismiss from his thoughts all Geological speculations, or of worlds existing before our world, and take the Bible narrative just as it is, what will be his conclusion about this astonishing phenomenon-The primitive rocks without a "vestige at all of living creatures?" He will immediately learn there, that the Creation and the Deluge form two grand epochs of the Bible. The Creation, of which the primitive rocks are a part, was effected in six day.s. He will learn also that at the Deluge the surjace of the earth was rent and broken to pieces, the debris of which forms the secondary ${ }^{~}$ strata and is the depository of the "fossil remains." But he will further find, that the " high hills and mountains," which might indeed have large fragments rent from them, and which fragments might partly become secondary strata, were still left standing in their "primitive" state, undemolished by the Deluge.

Here then is the true explanation of this mystery. If the Bible account be correct, whatever continued in its primitive state till the Deluge, and remained unaffected by it, cannot possibly contain organic remains. Because those remains were either caused by the Deluge, and therefore could be deposited no where

" I use the word "secondary" for every thing not "primitive," except post-diluvial formations, of recent occurrence. 
but in that mass-which was broken up into mud and debris by its operations: or else, they were remains which in the course of nature were buried or deposited, as now, before the flood on, or near the surface of the ground. Physical, vegetable and animal transitions are constantly taking place, and doubtless were so then. But those deposits, being generally superficial, cannot be expected to have been frequently so situated before the Deluge, as to become hard, rocky, and permanent: though some of them possibly might become so, and may so remain at this time, if they escaped being torn up, though the imperfect state of Geology may not enable us to distinguish them from diluvial remains.

But the "primitive mountains" are proved both from the Bible and from matter of fact, not to have been overthrown and subverted by that catastrophe, and could not therefore have "organic remains" incorporated into their substance, which substance was so established before animal natures had a being. Instead then of its being considered as a wonderful and inexplicable event, that "primitive strata" contain no "organic remains," it is a truth very plainly implied in the word of God, and a fact necessary to the correctness of its statements.

\section{SEA AND LAND.}

From this subject we learn that the sea aud land, as such, have not changed places.

These primitive rocks both in the old and new world, form the grand framework of every country, and could not have been a part of the sea, before the Deluge. It is clear from what we have seen from the 
Scriptures and from the fact of their containing no " organic remains," that they have not been materially changed since their Creation. It is not unlikely, from their stationary character, (being greatly unaffected by time or catastrophes,) that they are figuratively denominated, by the sacred writers, "the everlasting hills."

There are however various other intimations in the Bible which satisfy us fully that sea and land have not as such, " changed places.

-The "olive leaf plucked off", implies that it was a relic of the ancient vegetable world, and not surely as some have supposed,-a "fresh Creation,"

-The "rivers of Eden;" though by no means very distinctly marked, and probably much changed in their bed, by the Deluge, were, the Scripture informs us, very certainly in existence, when Moses wrote the second chapter of Genesis. I know of no authority upon which we are warranted, with Granville Penn, Esq. to suppose the verses relating to that subject, an interpolation.

- The RETURN of the diluvial waters is, in all fairness of construction positive proof. It is said, "and the waters returned from off the earth continually." Now if we are inhabiting what was then the sea, but which is now the land, this could not be true. For "earth" here cannot mean theglobe of the earth, but the habitable earth which was drowned; upon the change of the sea and land, this could not apply in any way. - If we suppose " earth" here to mean the dry land before the flood; the waters could not, on the above hypothesis, be said to return "from off" it, for that earth being now become sea, the waters remain permanently upon it:- 
Nor can it apply to the present land, which, as here supposed, was the former sea. For, to "return from off" the earth, in order to remove the flood, implies that they came upon the earth, to cause the flood, which, as it respects what was sea before is not true.

But on the hypothesis, that the sea and land changed places at the Deluge, I do not see how we could have any thing of the character of "primitive mountains," at all. For if we suppose our large mountains now to have been mountains when in the sea; no reason can be given why they should not have contained fishes and shells, as well as other sea formations.-But the impracticability of this hypothesis of modern Geology, as well as its unscriptural and unphilosophical character, compel us to disavow it. If moreover " coral rocks" apply, they are decisive.

Modern Geologists are therefore in great error on this point; I do not know that even Dr. Buckland is to be excepted. For though he does not appear to have been of the opinion of those who hold that the sea changed its place at the Deluge, he embraces very firmly M. Cuvier's “ Theory” generally, which makes the change of the sea and land, at some former epochs, an essential article of belief.

"After all, (writes M. Cuvier,) philosophers are " only agreed on one point, which is, that the sea " has changed its place; and this could never have" "been known, but for the existence of extraneous "fossils." (56:)

We shall not here take up more time in exhibiting the amazing absurdity of this extraordinary "Theory." What we are here considering is, the want of accord- 
ance of this "Theory," with what we have lately established from Scripture, namely, one Creation, and one Deluge; which points involve the stationary character of the "Primitive mountains" and the general permanency of sea and land, which this modern "Theory" contravenes.

I only say, the general permanency of sea and land. For, I think, itappears pretty evident that partial changes have taken place.-I dare not say it was so, but it might seem somewhat probable that many of the limestone rocks, were either formed in the sea, or were ejected greatly by the sea and urged to a greater or less distance from it, by the violence of the diluvial waters.

III. ThE GENERAL PHYSICAL CHARACTER OF THE SECONDARY STRATA.

It is difficult to contemplate the general conformity in common with the variableness of the appearance of the earth, or peruse any writings on Geology describing the diversity of its form and materials, without being greatly struck with the surprising coincidence, which is every where manifest, between the Scriptural character of the Deluge and the physical nature of the earth's surface.

The irruptive character which the Bible ascribes to the diluvial waters, and the obvious consequences of their disruptive operations, most accurately accord with the form of the land, and with the situation of the materials of which the earth, near its surface is composed.

1. The arrangement.

(1.) The arrangement of the surface of the globe is sufficiently similar in its different parts, to prove 
that it was formed by one general system of operations: There is, in the principal secondary rocks, as is well known in the coal and mining districts, a not very uncommon general order of superposition; and by this the workmen are guided in their expectation of finding iminerals. There is, also, a prevailing angle of inclination to the horizon, in these fossil and mineral strata.

(2.) But there is a sufficient diversily to demonstrate that the strata were not deposited in a fluid, in an horizontal position upon each other, like the coatings of an onion. And to speak of " earthquakes," or "violent convulsions" operating from beneath, after the strata were hardened into rocks, as elevating the horizontal rocks into inclined ones, is highly unreasonable. For though it be true that they exhibit every possible angle from a plain to 90 degrees, the dip is far too uniform to be ascribed to such fortuitous and irregular operations.

The general conformity in the midst of almost infinite variety, in the form and elevation of hills, and in the form, the size, and direction of valleys ; is very remarkable: some are large, others small; some long, others oval or round; some again, are almost flat at top, while others are towering like a dome or a pyramid. There are hills upon other hills, and hills in the bottom of the valleys.

What Mr. Jameson says of the chalk, may be said of many other extensive formations. Their irregularity is exactly what the Bible would lead us to expect: but it is absolutely inconsistent with, and, as we have before proved, impossible on the system of Geology. 
"The chalk," (he says,) "forms the bottom of the "basin or gulph, in which are deposited the different "formations that occur around Paris. Its surface "must have presented numerous inequalities before " the present strata were deposited over it, because, "we observe, promontories and islands of chalk " rising through the newer formations." (405.)

It would be a great satisfaction if our Geologists: would point out how these inequalities can have occurred consistently with their Theory of "horizontal deposition." We have fully shewn in the first Volume, under the consideration of Basins, that the thing is perfectly absurd and impossible.

\section{The Materials.}

With respect to rocks and hills of all sorts and in all situations, we perceive that one hill consists of one sort of stone, another close by of another sort ; and many times the same hill will exhibit nearly all the varieties, while we may travel a hundred miles and not find its fellow. It is very remarkable that the last Quarterly Review, (pub. Sept. 1826), though it advocates the system of modem Geology, and asserts that there is, in the strata, a " regular order of superposition;" and "that this order is never inverted ;" nevertheless, admits a most extraordinary diversity. There are, it says, in the southwestern coast district, two great series of rocks, "the "greywache, transition limestone, old red sandstone, "mountain limestone, and coal measures." "Those " of the second series"-are "the newest red sand"stone, lias, and oolite." Of these two series of rocks, the former highly inclined and the latter nearly horizontal, it informs us, that " in consequence of the 
" total want of conformity between these, and the " occasional absence of some of the overlying forma"tions, any member of one series may in this district "be in contact with any member of the other." $(507,533$.

Here, we perceive, that both the arrangement and the muterials of what are called "the regular rocky strata,", are circumstanced in a way which is utterly inconsistent with the geological Theory, as we have before particularly shewn. But over all those we shall find as great a non-conformity in the upper strata, and in their external appearance. In one spot gravel prevails; in another, clay ; in a third, loam ; in a fourth, sand ; in others, a mixture of them all ; and they are of all forms and all sizes.

Now though it is very likely that many of these variations in the external character of the earth's surface, took something of their bearing and character from the previous form of the antediluvian earth, we cannot but recognize the Scriptural character of the Deluge in these diversified forms and varieties. Every part of what we recognize or read in the description of travellers and in works of Geologists, appears perfectly correspondent with the violent and universal, though doubtless, irregular nature of the diluvial operations; which operations, being regulated by the same system, would have much similarity; but as having different materials to work upon, and being in different states of operation, would be likely to produce great variations. But,

ON THE OTHER HAND: If we take the nature of the diluvial operations from the 'Theory of our Geolo- 
gists, from Dr. Buckland for instance, who has given the subject very particular attention, what do we find? We behold with dismay the impracticable character of those operations. Nature is violated in every shape, and our understandings are stunned, bewildered, and confounded. Every operation of physical powers, and every knowneffect of moving waters, are precisely inverted. He wholly overlooks the Scriptural character of the irruptive waters and their necessary effects in breaking up the rocks and strata generaly, and confines their operations to excavations and transpositions upon the surface. Thus, he exactly inverts the true character of that great event. Its irresistibly outbreaking violence, would surely tend to cast up innumerable and diversified mounds and hills; and form chasms and hollows of all descriptions. But a violent rushing water passing rapidly on the surface, would certainly tend to wash the whole globe level. But these anomalies will receive a separate consideration, hereafter.

With respect, however, to these events as connected with the system which the Scriptures reveal, we have not only an explanation which we might think possible; but, supposing the debris and ejectment of the Deluge to be as before described, and as it must very greatly have been, sof $t$ and loose, these are two grand arguments hence arising, by which the existing form of the earth's surface may be greatly demonsstrated.

1. The infinite number and variety of the "fountains of the great deep" which were broken up at the Deluge, the tearing up of the strata, dissolving or 
dashing them to pieces; - these being mingled with or aided by the debris, hurried down from the mountains, and from out of the sea, would exactly account for the prodigious number and variety of strata, and of hills and rising grounds; but especially those isolated, abrupt, and sugar loaf hills, which no other supposition can account for.

2. It is probable that the greater part of the strata above where the waters were lodged, and out of which they broke forth, would be entirely torn, and the mighty action of these issuing waters would have a natural tendency to form mounds of indefinite shape and number, near to their openings; but at a greater distance from these, their tendency would be according to natural principles, to form levels or flat surfaces. Because the heaviest materials would, in most cases, be deposited on the brinks of the fountains, while the lighter sand or mud would be carried further off.

The form, too, of hills thus ejected, would be natuturally round at the top, as we find that issues of this description, whether large or small, almost always are. Besides, the contending waters becoming confluent, would modify them very greatly at their external surfaces.

The retiring waters, moreover, would have every advantage in the form of the surface of the earth thus deposited, and in the general softness and mobility of of its component parts, to effect such changes and denudations, as we find more or less in almost every situation. In recently formed strata, and muddy debris, the retiring waters would be able, according as 
the form of the earth and of the ejectment directed them, to make considerable modifications in the comparatively soft surface of the soil. And this is what both Scriptural data and rational reflection would lead us to expect.

Hence it would seem a natural conclusion, that

The peculiar character (not necessarily the existence) of the SECONDARY hills and mountains were greatly, perhaps, entirely, CAUSED and FORMED by the OUTBREAKING waters, and MODIFIED, rounded and subdued by the RETIRING waters.

Thus we see that the Scriptural nature of the Deluge, and its probable operations, correspund very exactly with the general aspect of the earth's surface. Any thing of minuteness, or great particularity, is quite beside our subject; and, probably, beyond our reach. But a few striking matters may be mentioned.

IV. LAKES, Gorges, barriers, and basins.

We have seen that the form of the secondary hills and valleys would be affected by the waters of the Deluge. This circumstance will account for several things with which Geologists are quite puzzled.

\section{Basins.}

They speak much of "Basins," as we have repeatedly experienced. There is the "Paris Basin," the "Isle of Wight Basin," the "London Basin," \&c. These, we are informed, are so called, because the chalk, or other stratum, which may be considered as the bottom, rim, or shell of the inclosed strata is hollow in the middle, and high at the edges, somewhat like a Basin.

That imagination has a great deal to do with this, 
it is easy to believe. But as the edges of these (so called) Basins often terminate in lofty hills, or in the neighbourhood of lofty hills, the rim of these Basins may be somewhat elevated on the skirts of those mountains, or, possibly, they might form hills out of their own materials.

Now, though we have in the first volume satisfactorily shewn (as I trust will be admitted) that, upon the principles of "modern Geology," Basins cannot possibly be found, the judicious reader in calling to mind the nature of the diluvial operations, will immemediately perceive the coincidence of the Scriptural suggestions with the character of these Basins. We have there, I think, proved that nothing of the nature of regular Basins does in fact exist : only flat-downs, hollows, and levels, skirted by partial ranges of hills formed of the same materials (chalk, for instance) as the lower and most extensive stratum in the Basins.But whether the Basins be really Basins, or only flat and hollow surfaces, skirted by projecting ridges, their formation is not only consistent with the Scriptural account of the Deluge, but a very natural result of diluvial operations.

Without claiming, and we certainly have no direct authority from Scripture to claim, or to deny, a volcanic action for the operations of the Deluge, so long as those operations were of a projectile nature, every feature belonging, either in Theory or fact, to Geological Basins, is precisely of the nature of diluvial action. Strata cast upon the skirts of existing eminences, or materials ejected, to form elevated rims or edges out of their own bowels, would most naturally 
form every part and portion of these celebrated Basins. And the changes in the strata, which we find so often and so similarly taking place, to the utter destruction of the modern Theory, as well as the alterations or risings of the chalk above the strata, which Geology requires that it uniformly be beneath, is exactly what the Scriptural nature of projected materials, and the variable effects produced by their operation, would lead us to expect.

2. Lakes.

Now, it is further obvious, that barriers causing mountain lakes would be naturally lodged in vallies sloping between the hills. It is pretty certain that we cannot know any thing about lakes, gorges, \&c., which existed before the Deluge, as all these would almost inevitably be destroyed by the outbreaking waters. But, as large hills and mountains, meeting in angles at top, would probably be only fractured and modified, barriers would, in many cases, be thrown across the vallies, whence lakes would ensue; and across narrow passes between the hills. Hence would arise lakes and reservoirs of all kinds. Or some of these might become lakes by their own operation, if the debris closed up the bottom of the basin without filling the basin with earthy matter.

Now, these barriers being some strong and some weak, would burst or break sooner or later according to circumstances. Many of these hollows, bowls, or basins might have strength enough in their debris to support themselves after the external waters had subsided, till the bottom of the lake suffered the water to filter through, or till it evaporated. Some might burst soon, because the weight of the water within would 
become too great for the banks, in consequence of the external waters subsiding; and some may remain to this day. Others might become quite dry from the bottom being porous. But, when once dry, the bottom might become impervious to water. These empty basins being again filled by returning rains or springs descending from the heights above, might endure indefinite periods. But the descending waters forcing over the lowest edge, or becoming too weighty for the weakest parts to support, might wear down or burst the sides of the basin under circumstances of time and manner which we cannot calculate.

This is doubtless in character with what we know of barriers and gorges. And it will account for the burst ing of lakes and the cutting out of gorges, which are, even to the present period, events not unknown in the world. For, upon the supposition that these basins and barriers were formed by the Deluge, it is very natural for rocks as they contract, divide, or become porous, to be subject to the ravages of time, and liable to be blown up by the pressure of water, or worn down by its perpetual recurrence.

But the opinion of Dr. Buckland and others, seems very unnatural. Their hypothesis implies that these rocks were deposited in a fluid, namely, the sea, and were become hard and compact, thousands of years before the flood, and were so hard and immoveable as to bear without fracture, the immense shock of that tremendous catastrophe, and yet now, so comparatively soon after that event, to give way under circumstances almost infinitely less likely to distrupt them. ${ }^{d}$ For,

a This argument is of course confined to those rocks whose gorges have 
whatever the retiring waters might do, it is certain that the irruptive and falling waters of the Deluge would assault, like a battery, every lake and every barrier which stood in their way.

V. Faults, dips, and inclinations.

Some of these things, in their causes at least, lie more under the surface, and out of view. But the preceding considerations will afford data for some very probable opinions relative to them. It seems pretty certain, if waters break out from under the earth in numerous openings, and in a very violent manner, that the earth will be broken very unevenly. Some places may be very deep, others shallow, some level, others ragged, pointed, and uneven. And, probably, caverns and underground vaultings may be made by the issuing waters; or, possibly, numerous and immense gulphs vacated by the issuing waters, while the roofs and arches of these caverns were not wholly thrown off, but only shattered and weakened.

All these concurring, and numberless other circumstances consistent with them, of which we know nothing, will enable us, at least, to see how perfectly natural, under the Scriptural data, is the expectation of that falling out which we learn from experience, has actually taken place. If it be allowed that places of this sort were covered over, or partially filled by different materials, trees, vegetables, and debris, it is perfectly

been modernly cut out. Dr. Buckland, as will be further noticed afterwards, views the retrograde waters of the Deluge as scooping out narrow channels very deep through solid rocks. But, towards such an effect we shall shew, and indeed it is manifest from what has gone before, that the declining of the Delige had no particular tendency towards any such effect. 
easy to suppose that all sorts of failures, fractures, dips, and ingulphments, would ensue. Some of these might possibly occur early, and others late, doubtless in ways and manners quite unknown to us; and whether under circumstances which might leave the surface of the earth uneven, we probably cannot at all tell.

I trust the reader will not consider these thoughts as any thing more than bare suggestions. It is a subject upon which I should tremble to theorize or trifle. The whole of this catastrophe was the work of the Most High, and who clare undertake to say he fully comprehends it? So true is the record of his Word; " No man can find out the work that God maketh "from the beginning to the end. He doeth great things " past finding out, and wonders without number."

It becomes us truly to speak with great humility and diffidence on matters "which are too high" for us. Yet, though the detail of those wonderful operations may be quite incomprehensible by man, the scriptural data certainly afford a reasonable supposition as far as a mere outline of operations may be indulged upon this subject.

Whether, however, our thoughts are right or wrong, it is certain the strata of the earth are fractured and broken, as we have supposed they might be broken by the aforesaid caverns and subsidences. Dr. Buckland, and other persons who write about mines, state that "breaches" and "dips" and "faults" are found in the strata, to a very great extent. In some of these places it is said, that the strata have parted asunder, and that one part is now found four or five hundred feet above that with which it was formerly united. 
Dr. Buckland has indeed observed the essential benefit of these "faults" or breaches, (as we before noticed,) and that without them many extensive mines could not be wrought; the clayey materials in the fractures now prevent the waters from inundating the mines, and so enable the workmen to proceed.

The "faults" however, are by no means aiways beneficial. They are in certain situations, "an end"less source of difficulty and expence to the coal "owner, throwing the seams out of their levels, and " filling the mines with water and fire damp." (Phillips' Geology, 112.)

In the mines of Northumberland, there is a fissure, " called the Main or Great Dike, or 90 fathom dike. "The latter name has been given to it, because the " (coal) beds on the northern side are 90 fathoms lower " than those on the southern side of it.-In Montagu "Colliery, it is 22 yards wide, and is filled with hard "and soft sandslone."-(ib.)

The "inclined" strata may be supposed to have had their origin partly from the above process. But many of these, I believe, lie upon the skirts of large mountains; or on considerable elevations. In that situation, some of these may be viewed in the light of the exterior rims of the basins before spoken of, though they may not, in the Theory of Geologists, be classed in the same order of formations.

But if it be true that the diluvial waters did actually throw up, both from the earth and sea, immense masses of debris, mud, and whatever else; if it be true that those waters would have both tendency and power, to urge up hills, or over hollows, whatever 
came in their way; - if we could be allowed to suppose a sufficient quantity of tenacious mud successively cast upon the sides of hills, or on successive portions of itself, hills of strata, of greater or less extent would thus be formed in an inclined position. For many of the inclined strata consist of materials which will actually set under water. But the successive waves of mud, or these stiffened so as not to become fluid, and thereby horizontal, is all that for this purpose would be required. And a supposition of different consistences, or of successive masses being forced over or short, would at once account for the different inclinations which these rocks discover.

Mr. Jameson does not indeed give any data for conjecturing how the inclined strata were formed, but he has the boldness and integrity in the face of the modern geological Theory which he generally embraces, to avow his opinion that the inclined strata have not generally been subverted since their formation, but that they were formed in an inclined position. His thoughts on this point are worth recording.

"M. Cuvier adopts the opinion of de Luc, that all " the older strata of which the crust of the earth is " composed, were originally in a horizontal situation, " and have been raised into their highly inclined posi" tion, by subsidences which have taken place over " the whole surface of the earth."

"It cannot be doubted, that subsidences to a con-

e Mr. Jameson, in speaking of the chalk in some of its varieties, says, " Like " all other argillaceous limestone, it possesses, in a considerable degree, the " property of setting under water when calcined and made into mortar." -p. 430. 
"siderable extent, have taken place; yet we are not "of opinion that these have been so general as main"tained by those Geologists. We are rather inclined " to believe, that the present inclined position of the "strata is in general their original one;-an opinion " which is countenanced by the known mode of con" nexion of strata, the phenomena of veins, particu"larly contemporaneous veins, the crystalline nature " of every species of older rock, and the great regu"larity in the direction of the strata throughout the " globe." (297.)

What we have just said about the inclined strata being formed upon the sides of the primitive mountains, and of their consistency being such as would prevent their subsiding into fat and horizontal tops during their formation, will explain another difficulty in the strata which Geologists cannot comprehend.M. Cuvier, writes thus;

"There are actually considerable portions of the "primitive strata uncovered, although placed in lower "situations than many of the secondary strata; and "we cannot conceive how it should have so happened, " unless the primitive strata, in those places, had forced "themseives into view, after the formation of those "which are secondary."

What M. Cuvier considers, as well he may upon the principles of horizontal formation, consider an inexplicable matter, becomes, on Scriptural grounds, only a natural phenomenon. It was not of the character of diluvial operations under which the secondary strata were chielly formed, to produce very extensive horizontal formations, and especially not such as are 
found in the neighbourhood of large mountains. The exposed or "uncover ed" state, therefore, of the "primitive strata" which M. Cuvier views as so inexplicable, would necessarily, in some cases, take place. Because the ejected materials which form the inclinerl as well as other strata were often thrown up unevenly. Any of those uneven formations placed contiguous to "primitive strata" would leave those strata, of course, " uncovered," and that in proportion to the elevation and abruptness of the secondary formation which rested on the flanks of the primitive.

Moreover; possibly it might not be necessary that the inclined strata should be considered as cast up in any such peculiarly tenacious consistency as we have above supposed, for a prodigious deal of the fcetz or flat formations, as they are very erroneously called, are also more or less inclincd; and indeed so is much even of the sand and gravel. A vast portion of the ejected materials may easily be supposed to have become depressed or elevated at different angles from the nature of the inclinations on which they were cast, or even from the manner in which they were forced, or fell, upon each other.

Vl. Horizontal Strata.

Though I consider the geological distinction between inclined and horizontal strata as a mere fancy, or at most as marking only the different positions of the secondary strata and not different epochs of formation, we may possibly conclude from what is gone before, something relative to this matter.

It is easy to conceive that the ejectments from the earth, and the primary dislodgments from the channels 
and bottom of the sea might, generally speaking, form the more solid and inclined strata. But that the subsequent deposits from the diluvial waters, and the higher or finer and more soluble mud, suspended for a time in their bosom, or wasted off from early ejectments, might naturally be expected to form strata of a more level and hortzontal character. Deep chasms might be filled with this,-_large flat plains covered with it,- and the hills and inclined strata greatly modified by its lodging upon their flanks or tops. Such precisely is the location of the existing strata.

Indeed it is a matter of physical necessity that the light matter which floated longest in the waters would be the last in being deposited, and be more horizontal in its character.-This will explain M. Cuvier's statement;

"The latter (the horizontal strata) are placed upon " the declivities of the former. (The inclined strata.) "When we dig through the horizontal strata in the "neighbourhood of the inclined strata, the inclined "strata are invariably found below. Nay, sometimes, "when the inclined strata are not too much elevated their "summit is surmounted by horizontal strata." (p. 10.)

No system will explain this, or agree with it, but the Bible system.

VII. Diluvial Islands and Trap Rocks.

We saw before in speaking of the Guadaloupe Skeleton, that part of some of those West Indian Islands is of "volcanic," and part of "stratified" materials. Now we have seen in contemplating the Scriptural system throughout, how extremely likely it is, that Islands would be formed during the operation of the Deluge. If any thing of a volcanic nature, as is not 
unlikely, operated along with the diluvial waters, though under different systems of operation, we see how an Island or a hill might be formed partly of volcanic matter and partly of diluvial. Yea, and we are not authorised to say, that these two sources of agency did not sometimes even unite. In such case, probably, productions might result, and combinations both in form and materials, which we cannot easily comprehend. Thus, TrAP Rocks, to Geologists, the most puzzling of all phenomena, might be formed in all their peculiarities.

VIII. Fissures and Fractures of the Strata.

On the "geological theory". which supposes the strata to have been formed by quiet and slow deposition in a fluid which became compact and hard as they were deposited, it is not possible to conceive how they should become so fissured, fractured, and broken as we now find them. M. Cuvier supposes this to have been caused by "violent convulsions" subsequent to their formation. And Dr. Buckland confesses that the "cause of these cavities has never been satisfactorily ascertained." (Dil. Rel. p. 5.)

It may be true that a satisfactory account cannot be given by man. But if we abide by our previously established guide respecting the formation of the secondary strata, we shall at once perceive not only the probability of fractures, but their correspondence with every thing we know which bears a similar character. All things with which we are acquainted, whether natural or artificial, which are deposited in a mass from water, or which are greatly mixed up with water, contract, divide, and Jracture as they become dry and hardened. 
If the strata had been deposited as "Geology" requires, by quiet, gradual, and uniform deposition, which became compact and hard, as it was formed, each successive particle would thus assume its own permanent situation to the exclusion of all extraneous matter, and especially of water, as the particles would be too minutc and too slow in fixing, to retain any fluid or any glutinous cement which was not necessary to the composition of the stratum. Such a compact and solid mass might possibly fare when exposed. But for strata formed as the Bible records instruct us, it would really be a miracle if they did not split into fractures and fissures. For such numerous fountains ejecting materials, and such masses of matter deposited in so short a space as " 40 days," and the whole mass of water removed in less than a year, would leave the strata in a situation necessarily exposed to fracture as it became indurated.

1. In limestone rocks especially, which would appear to have had from the first, a peculiar viscidity about them, it is easy to imagine how successive waves of their fluid mass rushing over each other, perhaps meeting one another, or coming in contact with heterogeneous matter, might in various ways become confuent or stagnant, or even re-fuent. Such materials and such operations would lead us to expect fissures, ruptures, and chasms, of every character and of all dimensions.

2. The time that this would take and the manner in which it would be effected, would perhaps vary according to circumstances, and be fully known only to Him who executed it. But every analogy leads us to expect a vastly extensive variation in the time of 
settling, drying, or contracting. And as it is not yet 5,000 years since the Deluge occurred, we cio not feel surprised that even now fissures should actually be made.

3. The number and magnitude of these ruptures are so ordered by a merciful Providence, as to be generally suitable to the earth as a habitation for beings living upon its fruits; if they were exceedingly large and very common, the inhabitants of the globe would be swallowed up by them, and the earth would be rendered nearly useless to them. But now the Almighty has made these fractures subservient to the convenience and supply of the occupants of the globe.

I am neither competent nor inclined to inquire resperting the "primitive strata," whether their nature leads to the disruptions found in them, or whether those disruptions were caused by the violence of the out-breaking waters of the Deluge, or by any other means. Perhaps I may be entirely mistaken as to all which I have presumed here to advance respecting these fissures; which I have done not without great reluctance and much fear. I only wish to hint to the reader that such fissures as those with which we see the earth in almost all its strata to be intersected, as it were, by a rude kind of network, are, from their correspondence with every thing we know, likely to have resulted from the Scriptural intimations respecting the operations and depositions of the Deluge.

If I shall not be thought arrogant, (of arrogance I am greatly afraid,) I might mention what has occurred to me, and very probably to the reader, in reflecting upon this matter, without at all daring to intimate that it is so in fact. It is this ; 
We have seen reason to believe that all the secondary strata have been formed by the Deluge. These strata are every where fractured; and, of course, have opened into fissures since their formation:- some, (according to Dr. Buckland, and naturalists, I think, generally) have been modernly formed. Some of these probably take place by subsidence of the strata, and others by contraction and induration of the rocks themselves, - the opposite sides of whose fissures, now perhaps some fathoms distant, have as is evident from their correspondent surfaces, been in contact. The query then is, for I only put it as a query, may not the separation and parting of these hard rocks be the cause of EARTHQUAKES?

I dare not say more on this sulject. I almost tremble to write this.- "Such knowledge is too wonderful for me, I cannot attain unto it."

Numerous other correspondences might be traced between the Scriptural data and the aclual state of geological phenomena for which Geology according to this modern system cannot account, and which phenomena indeed according to this Theory, violate in their causation every operation of physics and every rational exercise of the human understanding.

I think, therefore, we may with perfect assurance say, so far as the physical part of geological phenomena have been compared with the Scriplural data ;" TH A T THE PHENOMENA OF THE STRATA AS GIVEN BY Geologists themselves, are Inconsistent WITH EVERY THEORY AND WITH EVERY SUPPOSition, but that of the Scriptures, LiteRALLY AND PLAINLY UNDERSTOOD." 


\section{CHAPTER VI.}

GEOLOGICAL PHENOMENA ONLY TO BE ACCOUNTED FOR ON SCRIPTURAL DATA.

\section{FOSSIL PHENOMENA.}

HAVING in the last chapter exhibited a few instances of correspondence between the physical state of the earth and the scriptural statement relative to diluvial operations, and shewn a variety of coincidence of matters which agree with no Geological Theory not built upon the revealed Will of the Most High, we shall in this chapter endeavour to do the same respecting some "fossil phenomena."

It ought not, however, to be expected that coincidences between the "fossil strata" and the Scriptural suggestions can be many, because it would be unfair to suppose that such minute particulars could have any regard paid them in Scripture. Nevertheless, we may without much trouble point out a few important circumstances perfectly accordant with the Bible, but agreeing in no respect with the modern system of Geology.

VEGETABLES FOSSILLIZED IN ALL SORTS OF STR A T A. 
Even in the "transition rocks" which, according to our Geologists are the most ancient of the secondary formations, we find "vegetable pretrifactions." As low as in the "greyreucke," Mr. Jameson says;

"The vegetable petrifactions are alledged to be " fruits, stems, and leaves of palm-like vegetables and "parts of reeds." (339.)

In the next stratum to the transition, (the "old red sand stone,") are found " trunks or branches of trees" of a tropical aspect. Also in the "coal formation" are found "ferns, reeds, palms, and leaves." Again, in the next limestone — and what might seem extraordinary, "the shell limestone" itself embraces vegetable petrifactions.

"The vegetable petrifactions that occur in this (shell limestone) formation are of stems and leaves of unknown vegetables." (346.)

I need not of course mention vegetables as occurring in the higher flatz and alluvial formations. Every one knows they abound in those strata.

Now I would here remark that the Bible account of the Deluge would instantly lead us to expect vegetables every where. Because they would be stripped off, beaten down, and overthrown, even from the first; and wherever they were entangled, there they would of course remain. Being also light, they would be easily transported according to circumstances, to any distance.

But these facts are perfectly inconsistent with and destructive of modern Geology. It would be little short of insanity to speak of plants, leaves, trees, ferns, 
and reeds every where in solid ${ }^{\circ}$ rocks formed at the bottom of the sea and among the transition rocks which were thousands of ages before vegetables existed.

We need not puzzle ourselves or the reader by inquiring into the different species of vegetables. In the scheme of Geology there ought to be none.

\section{Land AND SEA PETRIFACTIONS Mixed.}

From what was observed long ago about the petrifactions abounding in different formations, we perceive according to Geology the strange mixture and rapid successions of "fresh" and "salt water" formations.

In the Paris basin we discover ten formations above the chalk. Five of these are denominated " marine," -three "fresh-zwater" and three not determined! In the centre of these deposits is the gypsum or Paris formation consisting of "three layers;" the upper and lower, fresh water ; the middle, "murine" !!

Now we are told that these distinctions depend on " their containing salt or fresh water petrifactions." It is further stated, that, "the marine formations are conjectured to have been deposited from the waters of

8 I am aware that some modern writers wish to have it believed that snch basins as our " coal measures," for instance, were a kind of estuary or bay nearly enclosed by the land, in which leaves, reeds, trees, and vegetables, must be supposed to be floated down. This opinion, perfectly inconsistent in many ways with itself and with modern Geology; would not in the least account for vegetables in all the rocks, especially the regular marine strata which the Theory holds to have been quietly deposited in the sea, with which the land is now supposed to have changed places. Such an opinion would render these basins mere local deposits, accessible to both sea and land contributions, - to fishes and to quadrupeds and to animals of all descriptions: than which, nothing can more directly subvert the Geological Theory. 
the ocean, but the fresh-water rocks from the waters of lakes." $(426,427$.

This confused mixture of sea and land productions is of itself a perfect demonstration of the erroneousness of the Geological "Theory." In the Paris stone quarries alone there would be needed ten or twelve revolutions to effect the compound which this Theory makes necessary, and which revolutions, we have seen are not only gratuitous but impossible.

But here we have mixtures which are positively destructive of the "Theory" and impossible in existence, but upon principles which absolutely-destroy the "Theory." For not only are there salt-water depositions, and fresh-water depositions, (which nevertheless cannot be,) but there are actually salt and fresh water shells in the SA M formation.

M. Cuvier, as we long ago noticed, says

"IN THE MIDST OF THE MOST ANCIENT SECONDARY (MARINE) STRATA, (WE Discover) OTHER STRATA THAT ARE CROWDED WITH ANIMAL AND VEGETABLE PRODUCTIONS, WHICH BELONG TO LAND AND FRESH-WATER; AND AMONGST THE MORE RECENT STRATA, THAT IS THE STRATA WHICH ARE NEAREST THE SURFACE, THERE ARE SOME OF THEM IN WHICH LAND ANIMALS ARE BURIED UNDER HEAPSOF MARINE PRODUCTIONS." (p. 14.)

That the above mixture of sea and land productions is perfectly destructive of the "Theory" is demonstrable. For land productions do not exist in the sea and the marine ones on the land. They could not be deposited together.-But further Mr. Jameson in his 
notes, has given us even more specific information of the extraordinary character of this Theory and its accountableness. In the Paris Basin, as we have often seen, there are about a dozen strata above the chalk. In this series there are several very unaccountable, and, to this Theory, perfectly impracticable mixtures.

The THIRD FORMATION is the coarse MARINE limestone" This formation consists of four systems of strata. "Upwards of a thousand species of shells and other MARIN bodies of all sizes have been found in this formation." This very formation, however, contains “FRESH WATER” productions. Mr. Jameson says, the

"Second system of strata" is "very rich in shells. "It also contains a few impressions of leaves and "stems of vegetables and single fresh water shells." -Again,

"The third system of strata," though " less abun" dant" than the former, "sometimes contains beds " of sandstone, or masses of hornstone filled with "MARINE shells. LAND shells and fresh water "shells have also been observed in this sandstone." (p. 406-9.) The same remarks might be made on the strata of gypsum.

Nothing can be more out of character, more unchemical, and more unphilosophical, as well as more inconsistent with a "long and quiet continuance of the waters of the sea" which M. Cuvier tells us this very "limestoue strata" experienced, than such unaccountable confusions and mixtures of sea and land productions. 
But on the Scriptural principles these admixtures are a natural and necessary consequence of the diluvial operations. It were impossible that sea and land should not intermix their waters and their contents more or less almost everywhere, which we find they have done. And where the sea in its narrow necks intruded into the land, and the land into the sea, it is certain that such irruptions as we have been contemplating, would mix salt and fresh water in the same basin or gulph. But still the salt and fresh water debris might each, in some considerable degree, retain their distinctive characters.

Whether intermixtures of this sort may be from among contiguous locations only, or from distant situations also, I cannot tell; but, probably, in some cases, from bock. Many other fossils appear to come chiefly from the tropical regions.

In all these matters I give our Geologists credit for being correct when they profess to ascertain what are salt and what fresh water shells. Though in this, as well as other matters, they may be too confident.

And as to " fresh and salt water formations," as these Geologists hold them, there never was a fancy conceived more demonstrably absurd. This, I trust, we have most abundantly proved in the last chapter of the first volume, in which Headon Hill, \&c., were considered. It ought, however, to be known that there is much dispute among naturalists respecting the distinctive marks of salt and fresh water shells and fishes.

But fresh water sHELLS are not the only things found intermixed with sea productions. Land ANIM A LS are actually lodged in the midst of rocks which 
Geulogy says were deposited at the bottom of the sea. I do not here allude to amphibious animals such as toads and crocodiles, which are often found in slate and limestone. But birds and animals which live wholly upon land are imbedded in these rocks.

Various birds in the "limestone."

Guinea pig and mouse, in "slaty limestone."(Theory p. 363, 392.)

The bat in "limestone."

The opossum in "calcareous oolite slate."

Rabbit and mouse in "limestone." - (Sup. Ency. Brit. p. 71, 79.)

Among which we must not forget the Guadaloupe skeleton of a human being, which, I trust, we have rescued from the arbitrary and unnatural notion of a tufas formation.

If I should be reproved here for confounding fresh water with marine formations, in some of the above deposits of birds and land animals, I can only say, the authors referred to have not called them fresh water formations, much less have they proved them to be so. The distinction itself, as used by them, is perfectly absurd. I need not repeat that the Scriptural statement will alone account for such phenomena as these.

Though I do not quote reptiles, there is a singular animal, the monitor, which M. Cuvier's system forces him to rank among sea animals, though, as. appears from no other reason, but because it had a "strong tail," and was found among sea animals in the "soft limestone" at Maestricht. This extraordinary animal causes Mr. Jameson to make the following reflection upon it.

"We have here an instance of an animal far sur- 
" passing in its size any of the animals of those genera " to which it approaches the nearest in its general " character; at the same time, that, from its accom" panying organic remains, we find reason to believe it " an inhabitant of the ocean, whilst none of the " existing lizard tribe are known to live in salt water. " However remarkable these circumstances are, still " they are no more wonderful than those we contem" plate in many of the numerous discoveries in the " history of the ancient world. We have already seen " a tapir of the size of an elephant; the megalonix, " an animal of the sloth tribe as large as a rhinoceros; " and here we have a monitor possessing the mag" nitude of a crocodile."-(396.) The length of the "skeleton "was 24 feet. The head is a sixth part of " the whole length of the animal; a proportion ap" proaching very near that of the crocodile, but differ" ing much from that of the monitor, the head of "which animal forms hardly a 12th part of the "whole length."

Who but M. Cuvier would not class this animal with crocodiles?

But Dr. Buckland has, under the concurrence and authority of M. Cuvier, lately introduced to the Geological world an animal recently discovered, which cuts up all modern Theories, even upon their own ground. 'The Quarterly Review for Sept., 1826, has informed us that Professor Buckland has made particular mention of "the first example of a mammiferous quadruped occurring in an ancient secondary rock." 'These remains consist of "two portions of the jaw of the Didelphis or Opossum." It was discovered in "the calcareous slate of Stonesfield in Oxfordshire, 
which lies in the upper part of the lowest division of the oolitic rock." (529.)

Although the reviewer calls this the "first example" of the kind specified, I believe we have given instances before this ; and even an instance of the "human skeleton" in the limestone rock at Guadaloupe. But this "Opossum" is fatal to the "Theory" on the ground of Geologists themselves. It will not be forgotten that M. Cuvier (and every one else) rests the basis of the whole fabric upon the assumption of the following fuct ; that,

"Neither-during the formation of the chalk strata, "nor even for a long period afterwards, do we find " any fossil remains of mammiferous land-quadru"peds." (107.)

1. Here note; that, not till "long" after the "CHALK" was formed, are "ANY fossil remains of MAMMYFEROUS LAND-QUADRUPEDS" found; not even the "EXTINCT GENERA."

2. But HERE is discovered a "MAMMIFEROUS LAND-QUADRUPED in "OOLITE LIMESTONE."

3. And the "oolite limestone" is placed by the united consent of Geologists, (M. Cuvier, Professor Buckland, Professor Jameson, \&c.) Two formations BENEATH the CHALK. (Theory 34.5.)

4. Hence then we see the error of this "modern Theory." It must fall with the foundation on which it rests. It is literally and totally built upon the assumed ABSENCE of these animals in all the ancient formations.

Notwithstanding no demonstration can be clearer than that the "modern Theory" of Geology is posi- 
tively and absolutely stripped of all evidence and literally contradicted in its essential principle, by the above case; and notwithstanding the said Quarterly Reviewer observes, "this fact is completely at variance with all preceding observations ;" he still retains the " modern Theory" of horizontal deposition, "subsequent convulsions," and periods of great duration" elapsing during their formation, \&c. \&c. as "points no longer contested!!”

Surely the retaining of a THEORY as TRUE, when the PRINCIPLES upon which alone it is built are, by matter of fact, proved to be FALSE, and indirectly admitted to be so, is as great an anomaly in the rational world, as the remains of this Opossum are in the natural. I think nothing can well prove the folly and error of modern Geology more pointedly than such anomalies-namely; that, whether Geology have a foundation or no foundation, it still retains its credit among its professed friends. I suppose the reason is, it needs no foundation - it is a castle in the air !

When instances like the Guadaloupe skeleton, and the Stonesfield Opossum become, as they unquestionably will, sufficiently numerous, Geologists will be ashamed to maintain any longer their extraordinary credulity. It remains, therefore, with the Divine Providence to bring such cases to light. It will do this in due time.-I may here confess that, though I have spent between three and four years in endeavouring to exhibit the extreme futility and error of this modern Geology, I never ceased to possess the fullest conviction that God would one day, dash this infidel system to pieces with his own hand. 


\section{Shells in every place, and Fishes in} COMPARATIVELY FEW.

M. Cuvier intimates that it has never been satisfactorily accounted for, "why shells should be found almost every where while fishes are confined to a few places. (182.)

This may be a matter which we have no business to inquire into. But may we not perceive on Scriptural, not Geological grounds, some reason for this.

Had the strata been deposited in the sea, as Geology supposes, fishes must necessarily have died as well as shell fish, and been found among them. But if as, the Bible tells us, the sea only broke up at the Deluge and poured forth its contents upon the land, and after a few months withdrew those waters back again, the subject is quite plain. The heaps of shells which the out-breaking waters forced upon the land, must needs very numerously stick in the muddy debris and remain there; and so likewise would many fishes. But great bodies of those fishes would be likely either to remain in the sea, or to return with the waters when they returned into it again, as the Deluge subsided.

I do not with some persons suppose, that the immense masses of shells were generated during the Deluge, but some of them certainly might. And this again would partly account for the observations of Geologists, that some shells are only in FRAGMENTs, while others among them are just like fish deposited in their place.

If the bottom of the sea, moreover, were torn up in large masses, shells might be transported to considerable distances in such masses without much injury; 
while others being less shielded would be crushed to atoms.

But if shell rocks were quietly deposited in the sea, inclosing in their hardened formations the shells which lay easy and according to their natural habits, among them, no person living can assign a reason why such variations, should occur. While on the Scriptural data the whole is a genuine process of such violent and irregular operations.

Possibly this may give us some reason why "lacerte" are more common than fishes, and found in the neighbourhood of shelly strata. Crocodiles, \&c. are partly of the nature of land animals, and were doomed to the same destruction with them. While fishes were not. They are generally found too in the mouths of large rivers or in the borders of the seas. When, therefore, large masses of sea debris came rushing into their haunts, they would have little power to escape, and would therefure perish. But of these matters, I dare advance but little.

Ancient and Modern Animals mixed.

We know it is the very essence of the anti-biblical Theory, (for so I may now most certainly denominate it,) that the petrifactions are peculiar to their own strata, and designate those strata. This however, we have most abundantly shewn is not the fact. The demonstrable consequence is, that fancy, Theory, love of the marvellous, and a vain desire to be "wise above what is written," or some other motive, and not the evidence of facts, have prompted the extraordinary pretensions of the present day.

M. Cuvier makes, as we have several times noticed, 
one of the boldest declarations which any man responsible for the truth of what he declares, ever made, when he tells us that such "changes" have successively taken place in the " CHEMICAL nature of the fluid;" viz., in the WATER of the sea, that the "same kind" of animals could not "continue to live" in it. There is one thing however, which has caused me more surprise than this, which is, that this bold declaration should be received to the extent it is received, in a philosophic and christian country like our own, unaccompanied as this declaration is by fact or evidence; nay, in the face of both.

"Amidst the changes of the general fluid, (writes "this extraordinary man), it must have been almost " impossible for the same kind of animals to continue "to live:-nor did they do so in fact. Their species "and even their genera, change with the strata; and "although the same species occasionally occur at small "distances, it is generally the case that the shells of " the ancient strata have forms peculiar to themselves; "that they gradually disappear, till they are not to be "seen at all in the recent strata."

Now I shall quote a paragraph or two from Messrs. Conybeare and Phillips, referred to in the Scientific Journal, as the best answer to such assertions. The situation of the gravel above the clay designates its geognostical character. The "London clay" accords with the "Paris limestone,"-is all " newer flætz"and is the fourth from the surface out of eleven formations, containing shells and organic remains.

"On the east coast of Suffolk, low cliffs resting " upon the London clay, are found to consist of sand 
" and gravel, including peculiar fossils. The greater " number resemble the recent shells of the neighbour"ing seas ; there are however a few extinct varieties, " and among them, the murex contrarius, or reversed "whelk; though what is very curious, the fossil shell " with the whirl in the ordinary direction, is also found "here. There are also a few fossil bones belonging " to unknown animals." (No. 27.p. 146.)

There are fossils "differing, though sometimes very "slightly, from recent genera; yet extinct genera, so "common in the older formations, are rare; we "believe however, that cornua ammonis, and belem"nites have been found." (14.4.) Once more,

"In the Isle of Sheppey there have been found in "these clay strata no less than seven hundred varieties " of fruit and ligneous seed vessels, very few agreeing "with any known varieties at present in existence; "some seem to be cocoa nuts of various species." (ib.)

I need only, by way of illustration, remark two things. First; we see, in this last clause, that hundreds of varieties of petrifactions, which are now unknown, (and therefore according to their "Theory" extinct), are all found in these comparatively recent strata - the "London clay." Secondly ; we see how Geologists view the system of ancient and modern formations. These authors call the mountain limestone, the "older formations," and clay and gravel newer formations, with as much ease and satisfaction as if the point was absolutely proved and could not be contradicted.

The error, however, and absurdity of the whole system we have sufficiently proved. What we are 
here to observe is, the inconsistency of the abovestated facts with the Geologica L system, and their exact correspondence with the BIBLE narrative.

Geology cannot account for the facts above recited without destruction to its own Theory. Nor, indeed, can it account for them or any other facts, at all. But what I mean is, they are at variance with the first principles of their Theory. No extinct animal or vegetable can be found in recent strata, without piercing the Theory to the heart.

But the principles we deduce from the Bible accord minutely with these phenomena. From what we before advanced on this point, we should be led to expect, that if the Flood did break up and displace the bottom of the sea, as well as the surface of the earth, the shells would be more specifically associated where their numbers are more in mass, and where the fossil strata are designated as shelly. It would be natural, moreover, to expect that such violence, as we have contemplated in the diluvial waters, would also scatter numerous shells from among their own species all over the earth, and more or less in almost every stratum.

Now, this is exactly the state in which we find them. The main body is still numerous and dense, but stragglers are every where found scattered abroad. This precisely accords with all we know of the effects of turbulent and resistless waters.

But we must not suffer ourselves to be beguiled in the reverse direction, or suppose that the above fact will not hold as it respects recent amongst the ancient species. For this would be a mistake. We have 
learnt from Mr. Jameson himself, that shells, even in the transition limestone, "certainly approach in their external character," to the "present living ones."

Besides, we have found the "fossil roe of Orleans" among the palceotheria. And the "Jossil deer of Somme," the "fossil roe of Somme"; - the fossil red deer" and also "the fallow deer" have, though modern, been found among the "sand" and in "peat bogs," where "extinct species," as the "elk" are "often deposited." And, lastly, the modern discovery of the "human skeleton" at Guadaloupe, and Dr. Buckland's opossum, far BENEATH them all; are perfect demonstration.

Extinct animals in alluvial formations.

This subject might have merged in the preceding one, but I wished to say a few words about the larger animals in a separate shape.

Though the subject of "extinct animals" will probably come again under consideration when we discuss the subject of Dr. Buckland's Theory respecting the Caves, \&c ; sea and land productions in the alluvial soil are almost everywhere so confounded and intermixed, that it would be a waste of time to specify particular instances.

It would seem very surprising, if this Geological Theory were allowed to be just, that we should find animals the most unlike any that we are acquainted with, in the most recent formations When I say most recent formations, I assume that what are called " alluvial soils" are allowed to be the latest.

It is clear, however, that the alluvial soil includes two circumstances, both with respect to time and manner, of vast importance: that is, 1 . The first con- 
sists of the diluvial operations, or the more loose and moveable productions of the Deluge: the 2d. of what has since the Deluge taken place, and is now daily taking place on the earth.

Nor will it be easy to distinguish these in all situations, from each other. Bones every day are buried, or thrown out of the way; animals are drowned in pits, or smothered in bogs ; these, at some distance of time, become dry; the bones are dug up, or some way brought again to light. And no clear line of distinction has been drawn, or can be drawn by man.

Great indistinctness; therefore, as we before shewed, remains among our Geologists respecting the "alluvial soil." In the notes on M. Cuvier's Theory, it is described both as produced by " marinc inundation," and as being a "deposit from fresh water."-(p. 387, 425.) Mr. Webster considers it to consist of three or four epochs; M. Cuvier, of three, perhaps; Messrs. Conybeare and Phillips, the same; Mr. Jameson receives it much in the same light, but considers the alluvial soil as being "still but imperfectly known."-p. 444.) Dr. Buckland seems to ascribe all the ancient superficial alluvial soil, to the Deluge. The Edinburgh Encyclopædia, under the article, Fossil Remains, (p. 752-3) savs; " that man has never yet been found in the alluvial soil, is certain." But this same author instantly writes that "the celebrated (human) skeletons " of Guadaloupe we have already shewn (said) to be " imbedded in a very recent calcareous alluvial rock."

Such is the extraordinary mode in which these authors write. Man is and is not found in the "alluvial soil." 
When I say therefore the latest formations are those of the alluvial soils, I do not mean to countenance the notion of formations and catastrophes prior to the Deluge, but use the language of Geologists in their own meaning.

In the "alluvial soil" are found the palæotheria mastodon, elephant, rhinoceros, stag, megalonix, megathenium, and horse, all held to be species distinct from existing animals. (Cuvier, 268, 373, 37\%, 380, 388.)

M. Cuvier and Dr. Buckland consider many of those which are now tropical animals, but not derived from the modern ones, to have lived and died in the northern regions, on the spots where their bones are found. Of this I shall not say more at present, whether true or false, than merely ask Dr. Buckland how he can expect a Deluge, such as he describes the Noahic Deluge to be, which in its fury tore up solid rocks many hundred feet deep and many miles wide, and which brought stones many tons weight from Scotland or Norway to England, should suffer the drowned bodies of these beasts, (which would probably long float on the waters), to remain quietly in the spot where it had found them living!!

Of the elephant and rhinoceros, found in the sea in the north, we have already said enough in opposition to this Theory. The Deluge must have destroyed those animals. Then their species were not extinct at the Deluge. This at once, as we have already shewn, is destructive to the Theory. For if these animals (though called extinct) were present at the Deluge, others called extinct might be so too.

There are two animals here respecting which I would 
make a remark. The megatherium and the mastodon.

The mastodon, of which there are said to be five fossil species, Mr. Jameson informs us, " may be considered as forming a distinct and hitherto unknown genus."

These "five species" have all been found in " the " alluvial soil which covers the bottoms of vallies, or " is spread upon the surface of the plains."-(385.)

And the megatherium, a species of the "same genus" with the megalonix, is an extinct genus, and was found in the "alluvial soil" in South America. (371.)

The extraordinary circumstance that these genera should be found in the alluvial soil, when, according to the Theory of Geology, as " extinct genera," they ought to have been found in the "regular rocky strata," cannot consist with any pretensions to system, or correctness in Geology.

But upon Scriptural grounds, though it might be that some large animals would be buried deep in the earth, it was to be expected as a general position, that huge animals, whose bodies would swim, and whose carcases would probably, in many cases, travel a long way, should be found in the superficial parts of the diluvial deposits. And such is exactly the state of the case. Most of the bones of large animals both in Europe and America, have been dug up in the superficial soils.

LAstry, What we have been considering will precisely account for the amazing depth in the earth in which some fossil remains have been discovered. If the earth were, as we have seen it doubtless would be, torn up at vastly different depths, it would be 
likely that some of these deep gulphs would swallow up both vegetable and animal spoils, and bury them in unknown situations under the diluvial debris. Some fossil remains have been discovered at two or three thousand feet depth in the earth.

Dr. Buckland and other writers speak of prodigious masses of bones in certain situations, especially in the north of Germany, heaped together and accumulated in an extraordinary manner. And they offer various, not very probable, conjectures respecting the cause of such phenomena. Now, I am very far from advancing any thing positively upon this subject. But what we have seen from Scriptural data, will, at least, afford a very possible, if not probable cause of such events. If some of the "foundations of the great deep," all of which were "broken up" at the Deluge, remained open till the return of the diluvial waters, and admitted large portions of that retiring element, it is very possible that, while numerous floating bodies of animals were spread over large tracts of land, not a few might come within the reach of the whirlpool caused by these funnel-shaped gullies. In such case, whole animals, bones, and pieces of bones might be heaped and locked together, in a way which few other known causes could produce.

Thus we perceive that the diluvial action as the Scriptures enable us to view it, is precisely accordant with every important circumstance of Geological phenomena; while to the modern Theory of Geology every such circumstance is impracticable, inconsistent; and unaccountable.

The judicious reader will perceive that though 
has fallen in our way, because the most plausible, and popular, to notice chiefly the Wernerian or Aqueous system revived by M. Cuvier and his associates, yet all we have advanced applies with equal effect against every scheme, whether Aqueous or igneous, whose constituent parts consist of numerousepochs and successive secondary formations.

I need not, after all the very important coincidences which we have pointed out (and many more might have been produced) between the Scriptural Theory and matter of Fact, make any apology to the reader for having explained so little to his satisfaction, the "wonderful works of God" exhibited in the ravages of the Deluge. What we have seen is, I trust, perfectly sufficient to "justify the ways of God to man."

We did not set out with a view to gratify the nice curiosity of mankind. All we wished or pretended, was to exhibit such a state of things to the reader as would enable him satisfactorily to judge whether the Word of God or modern Geology is more to be regarded, relative to the nature and operations of the Creation and the Deluge.

It is no objection to what we have advanced to find that numberless matters remain untouched and unexplained. This was not our office. Others may go farther if they feel themselves warranted to do so, from their more minute and extensive acquaintance with the state of the secondary strata, and with the Diluvial operations. 
The Bible, we have already admitted, was not given to satisfy our curiosity, but to inform our understanding and rectify our principles, on points which nothing else can reach. However disdainfully lofty and proud minds may look down upon the man who pretends that Divine record ought to guide or controul our "philosophical inquiries" or our "geolological speculations," it is a truth which no man can contravene, that there is an "ultimate boundary in every science; and that beyond that boundary Revelation must teach us, and not pliilosoplyy."

I do not expect curious minds to feel that sufficient which we have laid before them; nor querulous persons to rest without their objections and their complaints. Probably some will boast, notwithstanding the gross absurdity of such pretensions, of the "demonstrations" of Geology-of facts and "phenomena" which " cannot be departed from," \&c. \&c.and may heap together difficulties which the Bible was not intended to remove, and set before us mysterious circumstances which its suggestions do not enable us to explain or comprehend. To such I can only answer in a very few observations. And I would remark,

1. In the first place, that when we look at the Scrip-. ture suggestions in contrast with the speculations of Geologists, we feel no difficulty in our minds, even independent of their Divine authority, w:нгсн то PREFER. The former have simplicity and consistency, and all analogy, and reason, in their favour; the latter, have complexity and incongruity, and a want of all analogy and accordance with reason itself.

2. The Bible gives us such information on this 
subject as, judging from every analogy, we had reason to expect.

- It suggests the way in which we ought to walk, by a general direction, without minutely pointing out every particular.

-It gives us such information as will, if duly attended to, check and controul us when we materially err.

3. The nature of the information is suitable to the subjects required.

Of Creation, Geology knows nothing; and yet the subject of Creation is, to moral and responsible beings, infinitely important. On this subject, therefore, the Bible is sufficiently particular, express, and minute.

Respecting the Dicuvial operations, its dictates are more general and less numerous. The cause of that catastrophe, being moral, is expressly recorded. But the manner of the flood, is only pointed out to us as being universal,- - as coming out of the clouds and out of the earth, and returning thither again. The noture, however, of the diluvial operations, implied in the above information, is exactly of the CHARACTER which the effects ascribed to it, required. That is to say, the effect of the out-breaking and falling waters, considered with respect to the time of their egress and retirement, were of the nature of those operations which, so far as analogy assists us, always produce such effects as the phenomena of the earth exhibit.

But the operations, catastrophes, and results which modern Geology pretends to unfold, are monstrous and unnatural. 'They afford us no moral reason for 
their occurrence;-they unfold no cause, no agency, natural or supernatural, for the effects assumed;-and nothing whatever with which we are acquainted possesses the NATURE of the operation which their catastrophes and resuscitations require. Every thing we know, or of which we can conceive, operates in exactly a reverse direction.-Here then is the conTRAST. The Scriptural system (if system it may be allowed to be called) is rational in its pretensions, and Natural in its operations. The Geological Theory on the other hand is gratuitous and unreason. able in its assumptions, and impracticable and UN NATURAL in its effects. In consequence of this it is driven to assume occult and mysterious causes, and unknown, yea, (never known,) operations and powers, which thousands of years ago have ceased!!!

4. The difficulties under which the Scripture here leaves us are such as we ought to expect. If we are compelled to say with the Egyptian Magi, "This is the finger of God," we almost imply, in the very adtaission, something which we may not be able fully to comprehend. This is analagous to the mysteries of the Divine Record. They are beyond our reason indeed, but not against it. And so we ought in reason to expect, that the rending of the surface of the earth to pieces, and putting it together again, in apparently a far more advantageous form for the utility and convenience of its inhabitants than it before possessed, must bear too great an analogy to its first formation for us to comprehend.

The sum of the whole then is this. The Scriptural account of the Deluge bears perfect. analogy with 
Chap. VI.] ALONE CONSISTENT WITH FOSSIL PHENOMENA. 133 every operation of nature, as far as its unique character will permit analogy to bear; and all we see of its effects approves itself to our understanding. But the characteristics of Geology are such as no man can understand; and if a messenger from heaven should pretend to assure us of its truth, we could never comprehend his meaning, nor derive one atom of information from his instruction.

I have only to add on this subject two reflections.

1. If then there were no Bible narrative against it, this Geological "Theory" could not stand.

2. If only we have humility enough to take the Word of God for our guide, and make a consistent and rational application of its instruction, we need not, as Dr. Buckland seems to think desirable, even on the Geological subject before us, wish that

"Some happier genius" should arise "to shed new light upon our inquiries." -(Lect. p. 23.) 


\section{CHAPTER I.}

\section{DR. BUCKLAND'S DILUVIAL THEORY.}

DENUDATIONS, TRANSPORTATION OF ROCKS, \&c.

HAVING discussed and pretty much settled two material and essential points, viz. the pretensions of the modern Theory of the Geologists, and the claims of the Bible to our particular and implicit confidence, we are prepared to meet the Theory of Professor Buckland upon the subject of diluvial operations. This Theory indeed, is involved in the modern and general Theory which, we have considered, and must needs fall with it. But as Dr. Buckland professes to bring forward some new and independent evidenceas he is thought by some, to advocate no peculiar system-as he, in some minor points, differs from $\mathbf{M}$. Cuvier in opinion-and as his "Reliquiæ Diluvianæ" is supposed by many to be demonstrative of the subjects which he undertakes to discuss; I believe our work would be considered imperfect, if we did not pay a more particular regard to this celebrated author's Theory. 
There seem to be three branches of testimony which Dr. Buckland adduces in proof of the Noahic Deluge, besides, perhaps, various minor points which we need not consider. These appear to be,

1. Denudatrons, including the removal of fragments of rocks, and the excavating of valleys.

2. The Caves, containing loam, pebbles, and bones.

3. The Fossil Bones in the superficial loam and gravel.

Our author discusses the subject of Denudations after his Theory of the Caves; but as we have been recently inquiring into the nature of the Diluvial operations, I think it best to invert that order, and consider the denudations first.-I cannot inform the reader, beforehand, how far we agree or disagree with Professor Buckland, in the several subjects before us. They are all not only pretty consistent with, but almost wholly built upon. M. Cuvier's "Theory of the earth." So far as they are so, I view them as decidedly erroneous. But whether or not Dr. Buckland be allowed to contend for M. Cuvier's Theory, he certainly contends for an Anti-scriptural one, if, as we have endeavoured to prove, the Scriptures, in these matters, are to be literally understood. And I am of opinion that our author cannot bring any specific proof of the Scriptural Deluge, without, at the same time, overthrowing the modern geological Theory which he embraces.

There are Two kinds of DENUDATIONS detailed in Dr. Buckland's Relics of the Deluge; both, as their name imports, respect the removal of portions of the former strata by the diluvial waters. The one is 
136 DR. BUCKLAND'S THEORY OF DENUDATIONS. [Book V.

known by the WRECK which the waters have deposited, as the spoils of former strata; the other by the valleys or CHANNELS which are made in the strata which remain. The former respects the destruction of portions of the rocks which preceded the Deluge in the deposit of what Dr. Buckland calls "diluvial gravel, sand, loam, and pebbles." The latter consists in channels and hollows cut out in the antediluvian rocks by the violent rushing of the diluvial waters.

The former of these, viz. the wreck, must form the subject of the present chapter.

I. Gravel, SAND, LOAM, AND PEBbles.

That these materials which now make up great part of the surface of our earth, are not, as such, of DILUviAL ORIGIN, we have before observed. They were necessary from the creation of the world to the productive character of vegetation; and, above all, as a firm footing for all kinds of trees. The globe itself, in short, would seem to be useless without them, as a habitation for beings which live on the fruits of the earth.

It cannot, however, be doubted, but that great changes have taken place in the loam and gravel which furnished the antediluvial surface with a vegetable pabulum. Indeed, we find, as was to be expected, vast quantities of these materials in almost every part of the secondary strata, all of which the Scriptural data enable us to ascribe to the Universal Deluge. But that same wise appointment which, at the first, made these materials necessary, has taken care to preserve to the post diluvian world an abundant supply of them. 
But all analogy lies against them. Their situation in the earth speaks for itself.

1. If they had been washed from mountains by the waters of the Deluge, it is clear that we should have seen at once the source from which they were derived. We should have found these ingredients intimately and pretty generally, united and blended together by the violence of the diluvial waters, as we do the debris of a land flood. If the waters had washed down, broken into innumerable fragments, and ground to powder portions of all the rocks which fell in their way, it is perfectly clear, that in the doing of this, these several rocks and their fragments must have been dashed one against another, and mixed in the most intimate manner possible.

Instead of this, however, we find, in many places, clean sand alone; in others clay only ; in others sharp gravel and pebbles. These, moreover, are often stratified and alternated in all manner of ways, but not always mixed and united. Witness the sand hills, clay hills, and gravel beds, in almost every division of the kingdom, and in great part of the world; and especially the large districts of each with which every agriculturalist is acquainted. While, on the other hand, we behold, in some places, that clay, sand, and pebbles, are intimately combined. These separations and combinations shew clearly, that they are not formed or produced by violent and mechanical operation and by that only. The diluvial operations, however, as suggested to us by the Scriptures, precisely account for this. They were antediluvial in part, altered, and probably added to by the Deluge, while, more than probably, 
138 DR. BUCKLAND'S THEORY OF DENUDATIONS. [Book V.

numerous pebbles are of post diluvial formation. Thus the whole is natural and reasonable.

I admit that narrow currents and steep declivities do, in flood time, partially separate and divide pebbles and the smaller detritus or mud from each other, and deposit them in different situations in their line of march. But these cases bear no analogy to the present ones. Pebbles washed from a mountain, or down a rapid stream, are lodged alone at the nearest easy declivity upon which they can rest; while the waters carry the lighter sand further down, and the still lighter mud, to a proportionably greater distance than the sand, all which is natural and easily accounted for. But not so in the sand, clay, and pebbles of which we are now treating. The heaviest parts of the rocks, as pebbles, boulders, and large blocks, are often farther from their supposed matrix than the loam. The " loam" usually varies with the " adjacent districts," but the fragments of rocks often come many hundreds of miles, even from Scotland or from Norway. (Rel. Dil. p. 191.)

2. The matrix, or primitive and other rocks and formations, from which the materials for these loam, sand, and pebbles are derived, would be distinct and visible. Dr. Buckland, from Mr. Conybeare says, " From Houghton on the Hill, near Leicester, to "Braunston, near Daventry, proceeding by Market " Harborough and Lutterworth, the traveller passes " over a continuous bed of gravel for about 40 miles. " Near Hinckley, great depositions of gravel, probably " connected with this mass are found, and afford " pebbles, containing specimens of most of the organic 
" remains of the secondary strata in England." "It "would not be difficult, on the west of Market "Harborough, to form almost a complete Geological "series of English rocks from among the rounded "fragments which often occur in boulders of very "considerable size."- $(196,197$.

I shall make two remarks on this.

First, It is founded in one of those errors so common in Geological speculations. This district is by no means a continued bed of gravel. For the far greater part of the soil from Harborough to Lutterworth is a fine rich loam, often approaching to a strong clay. And this is, in no small degree, the case from Lutterworth towards Daventry. We do, indeed, in great part, travel on a gravel road, but this is no proof that the country is therefore a continued bed of gravel. Nay, so far otherwise, that our Geologists will find, on proper investigation, that the spots where gravel is to be obtained, are comparatively few; - a close of some acres, (perhaps even 10 or 20) here and there, with possibly one, two, or even five miles of intervening loam or clay.

This same road is now from Lutterworth towards Hinckley, formed of hard stone, fetched 6 or 8 miles off, from Stony Stanton. The same argumentation as our Geologists have used to prove this district a continued bed of gravel, might now prove large portions of the said district to be a continued mass of rock. If Geologists, as in the above instance, decide the nature of the strata very greatly from the character of the roads upon which they travel, it is easy to see into how great errors they will certainly be led. 
'140 DR. BUCKLAND'S THEORY OF DENUDATIONS. [Book V.

Secondly. These beds of gravel are not derived from the detritus of rocks at different and distant parts of the kingdom. If they were, we should not have the gravel in one place, separate and nearly pure; the loam and clay in another, much the same. If these had come for some hundred of miles by the Deluge, they must have been mixed and tumbled together for scores of miles. How, then, came they now to be distant and separate? Such separations, are without analogy.

3. The clay, of itself, is perfectly destructive of the diluvial hypothesis. It has no matrix to which it can be traced. With respect to the pebbles, and consequently the gravel, we find rocks consisting of nearly the same materials; they must therefore, according to Geology, be derived from those rocks. But the clay has no rocks from which it can be supposed to be derived. Dr. Buckland himself, makes this acknowledgment, while at the same time he speaks of its being "of immense extent on the continent" and "is the cause of great fertility." (191.) Surely it is and in England too. But where does it come from? whence did the diluvial waters wash it up ? why is it not found spread over every part, nearly alike? and why are we not ableto trace it to its origin?-It is in vain for Geologists to pretend to a knowledge of the origin of gravel and sand, while that of clay or loam, perhaps more abundant than them both, is confessedly unknown!

4. But even gravel and sand cannot be traced to their origin.

Dr. Buckland speaks of gravel in steep declivities and low districts being now made by floods, and of superficial loam and gravel nearly all over the world, 
caused by the Deluge : but he has forgotten to observe that there was superficial loam and gravel on the earth independent of and prior to both.

If, however, the existing gravel were derived from the rocky mountains, we should certainly find its source, by tracing it backwards from every gravel pit we see. In finding a bed of gravel we should be able to follow its track all the way to its original mountains. And at the foot of the mountains from which it came, we should infallibly discover vast heaps of angular fragments of great dimensions, detached from the rocks. In their course these fragments would become less angular, more numerous, and smaller in magnitude: And this would go on, increasing in extent of their distribution, but diminishing in their bulk and thickness.

The gravel and pebbles would be always of greatest depth in the valleys, and this in proportion to their contiguity to their origin. For in the valleys the force of currents universally ceases. And if there were no currents there would be no detritus, and no rolled stones. At a great distance, moreover, from their original mountains, there would be neither heavy stones nor clay. And universally, (ceteris paribus), the stratum, of debris, of gravel, or loam, would grow thinner as well as smaller, as it advanced, till at length it would end in almost no visible effect whatever.

These are universal truths in the operations of nature, and from these she is never known to depart. If she does, it is then a case of miracles, in which the laws of nature are suspended or counteracted. But Geology would destroy itself by pleading such a de- 
142 DR. BUCKLAND'S THEORY OF DENUDATIONS, [Book V. parture from natural operations. If therefore the gravel and pebbles were drifted from their parent rocks at the flood, we should infallibly trace the current wherever it went, leaving behind it a broader but thinner stratum, all the way it advanced, supposing the ground made it practicable for it to spread.

If moreover, this rushing diluvial destroyer passed: over hills and valleys, we should constantly find it tearing down the summits of the hills and filling up the valleys ; and levelling, in short; or tending to level, all before it. Those who dispute these as general and established principles of natural operations, contradict the universal sense of mankind, deny the course of nature, and destroy every rational ground of argument and discussion : they open a door to fancy, and ruin all expectation of settling doubts or difficulties by: fair argumentation; or by an appeal to cases of analogy, which, indeed, is the only ground we have of coming to any just conclusion.-But the situation of loam, of gravel, of sand, and of pebbles, is upon the geological system, utterly inconsistent with every natural principle, and every analogical consideration.

Instead of finding the original matrix, as we certainly should, by the deposition of the wreck and the increasing devastation, we can seldom trace even a vestige of loam or gravel to or from any primitive mountain whatever. The instance of Leicestershire and Northamptonshire, which we adduced before, two counties in the centre of the kingdom, is one positive proot of this fact. These, Geologists tell us, that the gravel in those places contains pebbles from almost every rock in the kingdom. But how do they arrive at this 
conclusion? Not by being able to trace the rereck to its origin, but by the most uncertain assumption ; namely, their being of the same materials. But is a pebble of granite or quartz any evidence that it was washed out of a granite or quartz rock, especially if it comes from Cumberland or Cornwall. As well might we say that the sand hills in Bedfordshire and the clay-hills of many other countries were washed out of primitive rocks. For the gravel lies, very generally, in beds as distinct and separate from every trace of wreck as the sand and clay.

But for a philosopher gravely to tell us that these sand-hills, clay-hills, gravel-beds, being all diluvial, have their origin in the general debacle caused by the Deluge upon the previously formed strata, and that they were washed off the rocks, broken and ground into pebbles, into sand, and into clay, and then deposited as we now find them, he would surely make himself ridiculous. For common sense assures us that these sand, clay, and gravel were never mixed together, and then separated by the diluvial waters before their deposition where they are. For these waters, in order to cause the devastations contemplated, are supposed to have been prodigiously more rapid and violent than a mountain torrent, moving, as some have done, nearly 20 miles in an hour. And in order to grind the rocks to powder, they must have carried them over vast districts of country, and mixed them with every other moveable object which could be met witl.

And yet so distinct and separated are these diluvial deposits, in some situations, that in the short street 
144 DR. BUCKLAND'S THEORY OF DENUDATIONS. [Book V. where I am writing, one end affords pure clay near the surface; the middle of the street has sand and gravel, in various proportions, both mixed and stratified; at the upper end there is a bed of gravelly sand many feet in depth, and beneath it a deep bed of pure clay; about a hundred yards from this, is a bed of pure gravel, many feet deep ; and only a few closes further there are about two acres of pure red sand: these are all within a few feet of the surface. - Numerous instances might be produced where the sand, clay, and gravel are beautifully deposited one above the other, and yet as unmixed as if they were alone. These are not the known effects of turbulent waters bringing a mass of materials from all distances, unless they were brought in succession; nor will the diluvial operations of Geologists at all consist with the situation of these materials.

It is then perfectly miraculous that sand-hills, clayhills, and gravel-hills should be deposited as they are, in two respects. First. A miracle only could separate a hill of sand or clay from the general mass and deposit it by itself alone. Secondly. It would require another miracle to do this, and yet leave not a trace behind it, of the place whence it was derived. Yet it is perfectly certain that no man living can arrive at the gravel-beds, or clay-hills from any original whatever, by the traces left from their matrix to their present depositories.

II, Blocks of Granite, \&c. on lofty emiNENCES.

Not only do we often find large stratified and distinct beds of sand, clay, and gravel, which could not 
be on the system of our Geologists; but we also find, as is expressly stated by Dr. Buckland, gravel and clay, and even very large boulders upon lofty uplands, and at the very summit of high hills : great stones, of of many tons weight are now found in prodigious numbers, even upon mountains. It would take a treatise of itself to discuss this subject in all its branches. Dr. Buckland has adopted an extraordinary system relative to pebbles and blocks of stone. A system, moreover, so inconsistent with itself that it is made accountable for phenomena the most contradictory.

In some situations the diluvial waters are supposed to carry large pebbles and blocks of stone tons weight, up to the top of the highest hills which the country affords, and there to have deposited them even upon soft and moveable strata, as sand or clay.-In others it is held to have swept away all the strata of stone, leaving behind it only some "enormous blocks," as "wrecks of strata" previously existing.

1. "Pebbles" are "heaped together on the tops of "the insulated, steep, and nearly conical hill of "Wytham, and of the elevated ridge of Bagley wood " near Oxford," and "on the highest crest of the "Oolite ridge of Witchwood forest, and the chalky "summits near Henley." These pebbles form "large " beds" near Birmingham; and from this "enormous " deposit" they have been dispersed by the waters of a Deluge down the valley to Oxford, and thence to London. (249.) Some of these pebbles it seems come from a great distance. "The nearest possible. "point-is the neighbourhood of Spilsby in Lincoln- 
" shire, whence the diluvial current flowing from the " north-east would find an unobstructed passage " across the plains of Leicestershire to the Bay of "Shipton and Moreton in the Marsh." (250.)

Thus, some of these pebbles, have been drifted by the diluvial waters (probably) nearly 150 miles, and over very extensive valleys, and lodged upon some of the highest summits in the neighbourhood!-This statement cannot possibly consist with diluvial action, on two grounds.

First. There is no trace of rereck into Lincolnshire, whence part of these pebbles are said to be derived. From Birmingham towards London, Dr. Buckland professes to trace the line of march. But from Lincolnshire over the whole vale of the counties of Leicester and Nottingham, there does not appear to be one vestige of the "red chalk pebbles" in question. This is utterly impossible from all we know of moving waters. The Vale between Belvoir Castle, Nottingham, and Newark, 20 miles a part, would certainly have been greatly filled; and the train would have grown thinner all the way; as they are supposed to be at the Kensington gravel pits, derived from Warwickshire.

Secondly. It is perfectly unreasonable to suppose that these pebbles should be drifted over valleys where they would naturally lodge, and be left upon high hills from which it would be natural for them rather to fall.

2. In the counties of Wilts and Bucks the "enormous blocks of sandstone" above mentioned, are found in vast quantities like " sheep grazing in a flock;" (and thence called "grey wethers ;") the larger of which seem to have furnished the huge pillars of Stonehenge. 
They are found scattered in great abundance over the chalk valley at Ashdown Park. "Their present "position (says Dr. Buckland) can only be referred to " the same diluvial action which removed the softer "portions of the sandy strata of which the blocks " originally formed a part." (Note p. 248.)

I know of no reason why the strata of which these masses "originally formed a part," should be supposed to have been "washed away," but this ; it seems there is no rock nearer than Egypt which is of the same nature with these stones. Now it is entirely supposition and Theory which cause Professor Buckland to say that the rest of the strata are swept away. There is not the least evidence produced for any such thing. Nor does it appear possible in fact. Mr. Catcott, represents the "grey wethers" on the downs, -as consisting in weight, from a few pounds, to 60 or 70 tons; - -as having " no stone" like them in all England ; - that they are " much the same as Egyptian granite; - that they lie upon " the tops of the highest eminences in the downs ;"- that " these hills are manifestly the highest land in the south part of England;" and that they are scattered for "more than 40 miles in circuit." - It is not easy to conceive any thing more absurd than the principle which holds that the stone strata, for a circumference of 4.0 miles, should have been washed away by the Deluge, leaving only these scattered remnants behind, some of which are only a few pounds weight!! Why does not Dr. Buckland say, these stones were brought from Egypt! Would there be any thing incredible in this, to those who can believe that so many other large blocks were brought 
148 DR. BUCKLAND'S THEORY OF DENUDATIONS. [Book V. from Norway? - Only we must assert that Theorists whose systems involve such extraordinary transportations, must not be allowed, on the other hand, to assume that the same waters left the animals quietly were they found them, in the plains of Yorkshire and Germany!!

The salvo for this extraordinary and unnatural supposition; namely; that the strata washed away consisted of "softer materials," is worse still, if possible. It scems to admit the absurdity of contending that an uniform stratum could have been thus washed away, while these stones were leit behind. But it introduces a principle equally destructive to the Geological 'Theory; namely ; that of a formation contiguous, and apparently of synchronous and homogeneous character, not as one but two formations; yea and formations perfectly out of the compass of their system to produce. Geology supposes all these rocky strata were deposited in a fluid, from the waters resting quietly upon them. It is quite absurd, then, to assume that the waters of the same sea or basin of the sea, should deposit these huge stones, some of which are 80 tons weight, and some other small stones, only a few pounds, which are, of hard and impenetrable materials, while it deposited all around and in conjunction with them, in every direction, strata of "softer materials"!!

An anomaly equally gross is found in the "London clay" formation. This blue or blackish clay abounds with, what are called, "Septaria;" viz. nodules of "clayey limestone," like patches of grey-coloured wood let into the surface of a black table. Besides which, it contains sand, carbonate of lime, iron pyrites, 
phosphate of iron, and Epsom salt in abundance: and at Bognor this clay formation terminates in a number of dark grey limestone rocks, "including many organic remains belonging to the blue clay."-(Cuv. p. 232-3.) Yet this is all one marine formation!-Query, why then might not ALL the strata be one formation? No reason has yet been given, and 1 am unable to invent any thing like a satisfactory one.

Besides, where did the basin depositing the "grey wethers" above-mentioned find its limits? If stone of the same quality be found in Egypt and not nearer, Geology must refer them to the same formation. But, can a greater outrage to nature be supposed than this notion would introduce? Strata from England to Egypt washed away, and the only remains in Europe are found to be a company of insulated "blocks of stone" on the chalk downs!! We may assume any thing at this rate, however unnatural and monstrous. -If we say these are not one, but troo formations, we only make the matter worse by its complexity:

Further, Dr. Buckland writes thus; "The eastern " coast of England, from the mouth of the Tweed to " that of the Thames is covered irregularly with beds " of superficial loam, or clay and gravel of enormous " thickness, not only in the lowland districts, but also "on the summit of lofty inils." "Their most common " character is that of a tough bluish clay, through "which are dispersed pebbles of various kinds. The "pebbles are of two classes; 1. Composed of the " wreck of the adjacent inland districts of England; " 2. Large blocks and pebbles of many varieties of pri". mitive and transition rocks which do not occur in 
"England and which can only be accounted for by sup" posing them to have been drifted from the nearest " continental strata of Norway, by a force of water " analogous to and contemporaneous with that which " drifted the blocks of Finland granite over the plains " of Russia and the north of Germany."-(193.)

Our author speaks also of pebbles and "large " blocks of granite" and "of greenstone" in the vales of Durham and of Yorkshire; and tells us that "the " nearest point from which these blocks and pebbles " could possibly have been derived, is the lake district " of Cumberland, from which they are now separated "by the lofty ridge and escarpment of Cross Fell and "Stainmoor Forest."

Now, Mr. Phillips, in his plate of the strata, states Cross Fell to be, on that side, an abrupt mountain 2901 feet high. How many 1000 feet high the large blocks of granite have had to mount in passing through the sea, we are left to conjecture. But I am not aware that the depth of the sea between us and Norway, and especially between Russia and "Labrador" is known. In Russia, a block of granite, not less than 1,500 tons weight, was found in a bog in a forest, and is now the pedestal for the Equestrian statue of Peter the Great, in St. Petersburgh. Among many others, Dr. Buckland states, that masses of granite from "Mount Blanc" not less than 10,000 cubit feet have been drifted to the "Jura Mountains across the space which is now the Lake and Valley of Geneva," to an "elevation of 2000 feet above the Lake."-(212.)

Dr. Buckland, quoting from Dr. Bigsby and Sir 
Alexander Croke, further states that in America, "blocks of various primitive rocks" are "strewed" in " beaches and woods" between " Lake Erie--and Lake "Huron;" "and that similar blocks appear on the " north coast of Lake Erie, which itself is for the most "part composed of a series of clay-cliffs and sand"hills." And "that the summits of some of the " highest hills in Nova Scotia, being composed of " slate, are strewed over with large blocks of granite." -All these effects are ascribed to the violent rushing waters of the Deluge - " to the great debacle of a flood advancing from the north." (215-17.)

The result of all these facts is the same. Our author attributes them all to the violent rushing movements of the Deluge, both in Europe and America; and that this violeut movement was frum the "north." He writes thus ;

"It appears then we have evidence, that a current " from the north has drifted to their present place, along " the whole east coast of England, that portion of "pebbles there occuring, which cannot have been " derived from this country; a certain number of them " may possibly have come from the coast of Scotland, " but the greater part have apparently been drifted from "the other side of the German ocean. It appears " also that there are proofs of a similar current having "passed the central and south-eastern parts of "England." The same is also said respecting " its western side." (199, 100.)

I believe we have now before us the issue of Professor Buckland's evidence for " diluvial operations," so far as it respects the removal and dislodging from 
their primitive localities, of the masses of rocky strata, and the drifting of those to their present situations, in the shape of rocks, pebbles, loam, or sand.-As to the formation and drifting to where we now find them, of the loam, and sand, and gravel, we have perhaps already said enough. But we cannot pass over without further remark, the very extraordinary movements of masses of rocks and pebbles.

There are several points recorded in the preceding quotations, which will afford strong evidence against Dr. Buckland's Theory-that the "diluvial waters" have washed these blocks from their original places to their present ones. - I might here observe, that our author, and all to whom he makes particular reference, describe the operations of the "diluvial waters," only upon the surface of earth. They speak of its " rushing" in an immense "mass" "from the north ;" but never contemplate the origin of the "diluvial waters" or inquire at all from whence they came; whether from the clouds or out of the earth ; or whether they were created for the express purpose. They seem rather to consider the sea to have been thrown out of its level!

I. The first thing I would notice, connected with the rocks and their removals, respects the MAGNITUDE of the fragments which our Geologists assume to have been transported by the " diluvial waters."

These blocks are of all sizes, from small fragments, to a mass of 1000 , or even nearly 2000 , tons weight. These, in their original state, were a part of the mountain from which they have been dislodged:- for instance, the blocks on Jura said to come from Mount 
Blanc. Mount Blanc, however, is the highest mountain in Europe. The rushing waters, then, we perceive, had power, at the height of this mountain, to tear these portions of rock away from it, and hurry them to the distance of 50 or 60 miles. The force of the waters upon the top of these heights, I wish the reader particularly to mark. It is quite obvious to the meanest capacity, that the rushing waters which tore down and carried away masses of rock a 1000 tons weight, would certainly sweep away every thing of a more light and moveable nature. - This we must advert to again, by and by.

2. The Direction of the assumed movements.

It must not be forgotten that the direction of these rushing waters, is said to be "from the north;" and in America, "also from the north." This direction, however, is not discovered from tracing the fragments of the WRECK to that particular destination, but is deduced from the discovery that rocks of the same kind roith these fragments are found in that situation. This rule, however, does not hold. For the "blocks of Finland granite," "drifted over the plains of Russia," anc which are perhaps as large as any of these said blocks, must have been drifted nearly east : from Norway to England, south west: from Scotland to England, south: from Cumberland to Yorkshire, south east: from Spilsby to Birmingham, south reest: from Birmingham to Oxford, south east again: and from Oxford to London, greatly east : but from Mount Blanc to Jura, it is north bearing rest.

I do not search out minor cases, the above are more than enough to prove the fallacy of the principle upon 
154 DR. BUCKLAND'S THEORY OF DENUDATIONS, [Book V.

which Geologists have established this Theory. These pebbles and rocks, we perceive, are found to have moved, not only from the north, but in all directions. And, what of itself is perfect demonstration of the incorrectness of the Theory, is, the direction of these rushing waters from Finland into Russia and the north of Germany, is precisely against the direction from Blanc to Jura!!!-Had this Theory been true, we should have had blocks from Mount Blanc and from Finland, encountering one another on the plains of Russia and Germany, and mountains of wreck from each would have been left behind, to testify the conflict.

3. We must further notice the situation and the MATERIALS upon which these pebbles and granite blocks rest.

They are found, more or less, by the description of Geologists, in all parts of England; they are found in Scotland, in Germany, and in America. But what is remarkable, they are lodged upon and in large and deep beds of loam and clay, in England, and in America, on the summits of which are for the districts most part composed of "clay-cliff's and sand-hills."Again ; the action of this extraordinary moving water has been manifested, in tearing up a whole bed of strata from the downs in the south, and in depositing in Leicestershire, the centre of the Island, pebbles derived from nearly every rock in the kingdom.

That the whole of this operation is totally subversive of the hypothesis, I should deem manifest at first sight. What we observed respecting M. Cuvier's Theory generally, we may remark respecting this hypothesis of Dr. Buckland, in particular; it is with- 
out precedent, it is utterly void of all ANALOGY ;water was never known to act in this way. Many of these blocks and pebbles are now lying upon higher ground, than that which they have passed over, by several 1,000 feet: or, in other words, they have been drifted over hills some 1000 feet in height. This is evident in the instance of Jura, 2000 feet above the lake of Geneva; in Cross Fell, 2901 feet high; and in Erie, the very summits of which abound with these deposits. Besides; every thing drifted from Norway and Finland, has come through the Gulph of Finland, the Baltic, or the German Ocean!!

Now we know that it is the nature of the sea to wash up sand and cast it on the flat shores; to undermine high cliffs and wash out the softer parts, for the like purpose; and it is of the nature of heavy storms and mountain cataracts, to hurry down loose materials and fragments of rocks from above. These results of natural operations, M. Cuvier has well described in the tenth section of his Theory; but there is no such operations of nature, as those we here contemplate. There are two anomalies.

1. The hright of these situations. No water is ever known to drift stones up hill. It will drift them down hill; and throw them on eminences on the sides of its current, by the rapidity of its motion. And when it has a strong downward tendency, it will carry pebbles over a considerable eminence which comes in its way. Yea, a pebble or stone set in motion from an elevation would, by its own gravity, acquire impetus enough to carry it over, or upon a smaller eminence which lay in its direction below. 
All these movements, however, are perfectly known, and their distance or elevation may be readily calculated, as the whole is subject to known laws. The universal tendency of all natural operations of water is to hurry every moveable thing down hill and into valleys, and there to leave them.

On this ground it is easy to believe, as Dr. Buckland states, that "blocks of granite were lifted " to an elevated point on the side of a mountain by " the bursting of a small lake in the Val de Bagnes, " in Switzerland." (236.) - " Lifted to an elevated point." Yes ; but how? The water and the blocks were rushing headlong down a mountain side, and their velocity was extremely great. This impetus, alone, would force the blocks upon "an elevated point." But in the cases before us, any velocity thus acquired, has either never been had, or lias long ago ceased. These instances, therefore, are exactly the reverse of stones being carried over hills a mile high, and over plains many scores of miles wide!!

When a mass of rock has been hurried down a steep precipice, it will proceed on a valley at the bottom, or up a hill at its base, to a distance proportioned to the impetus and velocity acquired. But when these cease, the stone will universally rest. And if water do this, the effect is much the same Water itself never proceeds with a perpendicular front. And the wedge-like form in which it advances up hill. always recoils and curls again upon the succeeding waves, as it meets with strongly rising ground in its progress. In these situations, heavy bodies never fail to resist the force of the waters urging in the rear. 
In short, the first advancing waters, and lowest waves of a mass of waters urging up hill, become, as to their effect at least, stationary and quiescent. And it is the succeeding waves rolling over the advanced ones, which makes the progress of waters up hill. So that we know of no heavy body, much less stones many tons weight, that is ever carried by moving waters, far up hill.

If it be said that the diluvial waters moving in such an immense mass cannot be subjected to the usual laws of moving waters, and that mountains 2000 or 3000 feet high could be next to no obstacle to its advancement: I would answer that many objections lie against such a supposition.

Dr. Buckland himself supposes that high hills are a real difficulty in the way of his Theory. He says of the pebbles found near Durham; "If the difficulty of " transporting them over this barrier (Cross Fell and "Stainmoor Forest before noticed,) be thought too " great, the only remaining solution will be, that they " have come from Norway."-(194.) Nay, he even supposes, that pebbles on " the nearly conical hill "Wytham," and those on the "elevated ridge of Bagley Wood," \&c., as well as the blocks on Jura, were probably deposited there before the " excavation of the present valleys" and of the Lake of Geneva. Indeed, the only reason given by Dr. Buckland, why pebbles'are not found in the " animal cave" in Germany is, the "inclined plain" which they must have ascended in order to enter the cave.- $(253,141$.)

2. If we assume that these deep seas and these very lofty hills were so little an impediment to the diluvial 
158 DR. BUCKLAND'S THEORY OF DENUDATIONS. [Book V.

waters, that their force could easily overcome it, so as to urge these immense blocks of stone to their top, there will be two fatal difficulties incurred by the assumption.

First, Such an irresistible mass of waters moving with the rapidity of a mountain torrent 20 miles an hour, would never have suffered these masses of stone and rounded pebbles, which it had force enough to carry up these hills, to rest and abide upon "those summits" on the "highest crest" of a hill, and on " the tops of the insulated, steep, and nearly conical hill of: Wytham." It would require far less force to throw these "pebbles" down from this "nearly conical lill," than to carry them up to its "top." The waters would therefore infallibly have washed them into the valleys below.

Secondly, These hills, we learn, are themselves, some of them at least, greatly formed of clay and sand. Waters, therefore, moving with the force and rapidity which have been contemplated, would, according to every known effect of moving waters, have swept the sand and clay hills utterly away, instead of leaving them quietly standing, and the rolled pebbles upon their summits.

Nothing can resist the certain destruction of this Theory under considerations of phenomena like the present. It cannot be said that the "diluvial waters" did not act violently when passing over the high parts of the earth. For Mount Blanc is the highest summit in Europe, and from this mountain some of the largest masses of rock are stated to have been rent. From the hills about Birmingham also, masses of 
gravel 'and pebbles, as we have seen, are, by this hypothesis, supposed to be carried away for Oxford. And a circumference of 40 miles of stony strata are actually supposed to have been " washed away" from the high downs of Wilts, \&c. only leaving insulated blocks of "grey wethers" behind. So that nothing can easily be conceived more unnatural, inconsistent, and self-destructive, than is this scheme of modern Geology.

If Dr. Buckland should insist that " nothing but a rush of waters" can account for the contemplated phenomeni, and therefore we are bound to ascribe them to its operations; I would answer, that we are bound by the lares of nature and common sense in all our Theories and ascriptions. If we assume that the " diluvial waters" would have power to carry stone and pebbles to the top of high hills, but would not have power to roll them over on the other side, we assume what implies not only that the force of gravity was suspended, but IXVERTED, and that blocks of granite are more easily got to the tops of hills than thrown down again. Certainly the Creation of a rock was not miraculous, if such phenomena be not ! And, moreover, diluvial waters washing away granite mountains and stony downs, but leaving clay and sand hills safely standing!!

Any further consideration of this unnatural hypothesis I shall wave for the present, as being pretty much unnecessary, and as being involved in the discussion of the second part of these denudations.

INFERENCES.

1. Though the Geological hypothesis respecting "diluvial operations" will not account for these 
160 DR. BUCKLAND'S THEORY OF DENUDATIONS. [Book $\mathrm{V}$. phenomena, but is positively subverted by them; the Scriptural view which we have previously taken of the operations of the Deluge corresponds minutely with the phenomena ; and as far, perhaps, as they can be made intelligible to us, greatly explains them.

The operations naturally required to cast up hills of clay or sand, and to cause their scparate, or mixed, or stratified character, are found in the Scriptural suggestions respecting the diluvial operations. The " granite blocks," moreover, found on "secondlary formations," as well as the secondary formations themselves, are not only consistent with the Scriptural character of the Deluge, but it appears to be of the real nature of the "dilurial operations" to produce them. The Bible tells us that all the fountains of the great deep were "broken up." If then rocks of the above description lay in the way, they would be broken up. And with respect to either the weight of the fragments, or the distanee to which they were first projected or subsequently rolled; or whether they were forced out of granite rocks lying beneath where they are now found, as we have no data to calculate, so we have no ground for denying any result required. It was of the NATURE of the diluvial operations to produce them all.

2. We have seen in the foregoing consideration of pebbles and blocks of granite, \&c. that they are found not only (as is common) mixed up with loam and clay, but upon the top of "clay hills" and "sandhills :" that is ; we find "primitive" blocks upon diluvial formations. For, as we have seen, Dr. Buckland esteems loam and sand, diluvial. It will be remembered that superposition, as a general maxim, is 
considered by Geologists as proving the posteriority of formation. And formations of limestone, \&c., being found generally beneath diluvial formations, and sometimes (as Jura for instance, beneath primitive masses, are considered as forming eras of chronology respecting these formations.

The circumstance of primitive rocks (for Von Buch and Dr. Macculloch mention several) upon diluvial soil is decisive against the Theory of M. Cuvier and of Dr. Buckland. Here we have a primitive, not upon a secondary, but more, upon a diluvial formation. How is this? Dr. Buckland's hypothesis, we have seen, will not account for it. The Bible, we have seen, will. But account for it how we may, it will destroy the force of their objections, taken from the character and situation of the strata, against the DeLUGE being the cause of all but the primitive formations.

For whether these granite blocks were cast on these clay and sand hills by the projectile force of the diluvial waters, or formed where they are since that catastrophe, it is a case in point, and the analogy is applicable and decisive; similar blocks may have been placed in the same manner upon Mount Jura, or in a Russian forest. And it will no more prove Mount Jura to be antidiluvial, than Mount Erie. For, if "granite blocks" are found upon one diluvial stratum, they may be upon another. If "granite blocks," therefore, upon " clay and sand hills" do not diminish the evidence respecting the diluvial origin of those hills, the circumstance of there being " granite blocks" in other situations, will not diminish the evidence of 
162 DR. BUCKLAND'S THEORY OF DENUDATIONS. [Book V.

those situations being diluvial. It is perfectly in confirmation of the point respecting limestone, or chalk, or marble hills, being strewed with blocks of granite. And those hills are no more proved to be antediluvial, from the circumstance of those blocks being found upon them, than "sand" and "clay hills" are proved to be antediluvial by such blocks being found upon them.

3. I have not thought it necessary to dwell on the improbability of pebbles being rounded to any great extent in waters such as Dr. Buckland states the diluvial waters to have been. Yet they must needs have carried about with them, in every situation, a mass of loam, sand, mud, \&c., which would have presented much attrition among the fragments of rocks. Dr. Buckland speaks of a cave being half full of mud at the height of 600 feet above the adjoining valley. This mud he considers to have been deposited in this cave by the diluvial waters. What a mass of mud then, must the valley itself have sustained. Such a mass would rather form a soft bed to shield the pebbles from the action of the water upon them, and from their action upon each other, than a convenient situation for grinding them to roundness and to powder!!

Nor can I enter into a discussion of the philosophy respecting the FORMATION of "pebbles." But, that "pebbles" are a natural formation, per se, I think, admits of little doubt. That water rounds fragments of rocks into pebbles, is also certain, and to this every day's experience, both in the sea and in every runlet, bears testimony. Yet, that all pebbles are formed 
by attrition, is, I think, plainly and positively contrary to fact, proved by observation. It is observed under the word "Pebbles," in the Encyclopædia Britannica, that not less than 34 species of pebbles have been discovered, " usually formed by incrustation round a central nucleus," and that, when accurately examined, they will be found to possess "veins or coats, which surround the nucleus like the annular circles of a tree."

Mr. Webster, as quoted by Professor Jameson, in his notes on M. Cuvier's Theory, speaks of the Hertfordshire pudding stone as consisting of pebbles originally formed of concentric coats, or layers of different colours," like the embedded masses of flint in chalk, of agate in trap, and of feltspar in porphyry.- $(449,4$.

I should suppose that few persons, not biassed by Theory, can doubt of a similar formation of pebbles in gravel.-But who would undertake to "find out the Almighty," or his works, "to perfection!!" 
CHAPTER II.

\section{DENUDATIONS.}

CHANNELS, VALLEYS, AND GORGES.

IT has, I hope, appeared already, that Dr. Buckland's Theory of denudations, has arisen greatly from a mistaken view of "diluvial operations." He seems to regard the waters of the Deluge, as operating only superficially; or upon the surface of the ground. But the Scriptural history informs us that they (in part) certainly issued out of the earth, and returned to the earth again. We have before shewn that these issuing waters would have destroyed the fossil strata, had those strata been in existence at the flood. We have also hinted at the various formations which would be the probable result of that catastrophe. We must now endeavour to shew that the diluvial waters did not make the denudations of which Dr. Buckland speaks, out of rocks and formations existing prior to the Deluge.

It is not easy to collect Dr. Buckland's opinion respecting the primitive state of the globe, or how 
far he considers it to have sustained the form which it now possesses. Nor is this to be expected; for he adopts the essence of M. Cuvier's "Theory of the earth," from which no man can even guess at its original form. He does indeed speak of "the original form in which the strata were deposited in mountain districts."- "Deposited:" not created. Among these "mountain districts" he supposes that valleys have been caused-partly by their "original form," - partly by subsequent convulsions, - and lastly by the Deluge. But with respect to the formation of valleys of a minor character, Dr. Buckland writes thus :

"There are valleys of many miles in breadth, and " many 100 feet in depth, which owe their origin " exclusively to the excavating power of a flood of " waters.

"Our present rivers excavate but little, as they flow " through valleys already formed by an overwhelming " ocean.-Yet we know by the effect of a mountain " torrent in cutting ravines and drifting gravel ; from " the blocks of granite which were lifted to an elevated " point on the side of a mountain by the bursting of a " small lake in the valley of Bagnes in Switzerland; " and from the excavation of the Zuyder Zee, by the "bursting of a dyke in Holland; that the force of "waters in rapid motion is competent both to trans" port such masses of gravel and granite blocks as we " have been tracing all over the world, and to exca"vate valleys which though many miles in breadth, and " many hundred, and in some cases perhaps, some " thousand feet in depth, still bear a proportion to " the bulk and power of the agent that produced " them." (236.) 
Dr. Buckland further argues in Mr. Sumner's words, respecting "waters like the ocean pouring "over the land when its level was destroyed;" and tells us that "An agent thus gigantic appears to have " operated universally on the surface of our planet, at " the period of the Deluge; the spaces then laid bare "by the sweeping away of the solid materials that had "before filled them, are called valleys of denudations." He speaks also of the "stupendous magnitude of those " forces by which whole strata were swept away, and " valleys laid open, and gorges excavated in the more " solid portions of the substance of the earth, as bear" ing the same proportion to the overwhelming ocean " by which they were produced, that modern ravines " on the sides of mountains bear to the torrents which "since the retreat of the Deluge have created and "continue to enlarge them." He adds ;

"When a gorge or valley takes its beginning and " continues its whole extent within the area of strata " that are horizontal, or nearly so, and which bear " no mark of having been moved from their original "place by elevation, depression, or disturbance of " any kind: and when it is also enclosed by hills " that afford an exact correspondence of opposite "parts, its origin must be referred to the removal of " the substances that once filled it: and as it is quite " impossible that this removal could have been pro" duced in any conceivable number of years by the " ravines that now flow through them,- - the only ad" missible explanation that suggests itself is, that they "were excavated by the denuding force of a transient "Deluge.” (237-8.) 
This Theory of denudations, the reader will perceive, is built upon the Theory of M. Cuvier; viz. " horizontal formation," and "deposition in a fluid." But as these are evidently and demonstrably fallacious, the Theory of denudations founded upon them, may be considered as having no ground to stand upon. There are two systems of operations embraced in the above passages; the formations of valleys, and that of rivers. These do not necessarily appear to have any connexion. And Dr. Buckland seems in part to attribute their origin to different causes.-Now we have seen enough from Scriptural data to learn; That

1. With respect to the larger mountains and valleys, the earth was orginally formed thus by the wise and Almighty hand of its Creator. And

2. From what we have further seen respecting the diluvial operations, from the same data we have reason to conclude that all real minor denudations are postdiluvian.

From this latter position Dr. Buckland dissents; and, indeed, from the former also, agreeably to what we have seen respecting Geology generally. We have now, however, to shew by further argument, that these denudations are not "diluvial," in Dr. Buckland's sense of the term "diluvial." We shall see more fully the real character of this system in its minor descriptions. The valleys in which many of the "caves" are situated which Dr. Buckland describes, afford some specimens. Those "valleys" (he writes) "are Larrow, and not deep, rarely exceeding 300 feet." - (125.) But the gorge of Bauman's Cave is described thus; 
"This gorge (the breadth of this gorge varies from " 100 to 300 feet, its depth is about 150 ; the rocks " on both sides are nearly precipitous,) is simply a " valley of denudation, produced (like hundreds more " which I could mention in compact limestone coun" tries,) by the force of diluvial waters." (p. 181 note.) These valleys are represented as looking like " open gutters on the surface of a meadow." (126.)

What I wish now to prove is, that the Universal Deluge did not produce these narrow and deep valleys, cuts, or gorges. I select as a specimen, (for more than a specimen would be unnecessary,) these narrow valleys, as more within the comprehension of the plainest reader. But, if we succeed in proving that these were not formed upon the principle of our author's Theory, the discerning reader will easily perceive that the larger valleys are not so produced. Dr. Buckland considers the retiring waters of the Deluge to have torn up and removed the strata of these previously level plains, and formed them into valleys and gorges.

I. This is contrary to the Scriptural suggestions respecting the diluvial operations, and especially of the retiring waters.

Independent of the demonstrable evidence which we have already adduced in proof that these rocks were not in existence, in their present character, before the Deluge, I would observe, that when we considered the Scriptural account of that catastrophe, we learned that the waters issued at the rate of 700 feet a day, and retired 100 feet. Dr. Buckland seems to estimate the force of these waters more from their amount, than 
from their real character for cutting out channels in the strata. Indeed, he seems to consider the waters of the Deluge as rushing from the $s c a$, when its "level was destroyed ;" and that this mass of water was made to pass with inconceivable velocity and violence, round the globe. (237.)

It is quite certain from Scripture, and from the character of an universal Deluge, that such was not the nature of Noah's flood. It issued out of the ground, and fell from the windows of heaven; and the amount, we have seen would be equal to 28 or 30 Seas. But Dr. Buckland seems to mistake the nature of the operations of the diluvial waters, altogether, and their tendency to cut out narrow channels or to tear up solid strata. The French philosophers, from their numerous experiments, appear to have discovered that the tendency of waters to cut the bed of their course, when out of register, is in proportion to the INCLINATION of their SURFACE, and not according to the depth of the water, though the depth of the water, when set in motion, has its proportionate efficacy.

Now it does not appear from Scriptural information, that the SURFACE of the RETIRING waters of the Deluge had any thing like the amazing inclination which such effect supposes. We have seen that the decline of the diluvial waters, was only 100 feet per day, in perpendicular depth. From the high mountains therefore whose sides are nearly upright, the surface of the waters would move almost imperceptibly down them, at a rate per day exceeding 100 feet as much as their oblique sides were longer than 
their perpendicular. On inclinations whose slope was ten times their height, the retiring surface would move but 1,000 feet per day. This is not near a quarter of a mile, and scarcely a 200 part the rapidity of our common rivers, which move two and some two and a half miles an hour; and it is but about a 2,000 part the velocity of the mountain torrent occasioned by the Deluge of Dranse.

Besides, the surface of the retiring waters would be, on every inclined plain, a mere wedge ; the thinness of whose edge could effect nothing at a place not faster than a snail would crawl.-It will probably be supposed that the retiring waters would have a tendency to tear up the ground in proportion to their depth; and that as the out-breaking waters were considered as terrible beyond expression, so would be the returning waters.

To this $I$ answer, that the cases are almost infinitely different. The issuing waters were projectile, and violent of course, but not so the retiring waters. In the first place, they returned only about one-seventeenth part as fast as they arose. And in the second place, they returned into the earth, and did not retire by an endlong course upon its surface.-Besides; the waters being universal, and of course balancing themselves by their own uniform pressure, would be in equilibrio. And it does not appear that any thing could destroy their equilibrium but in proportion as it tended to incline their surface.

I admit that the waters, as a body, returned rapidly from off the earth, and must, therefore, have had, somewhere, a ready course. But it is quite evident 
that if they had sunk into the ground uniformly, all over the earth, their descent would have been perpendicular only; and, as no lateral movement would be effected, so no disturbance could be produced in the strata. Now it is evident from Scriptural data that, in a great degree, this was literally the fact. In proportion as the strata were broken up and dislodged by the issuing waters, so would be the ready admission to the retiring waters. And in proportion to the paucity and largeness of the apertures made by the out-breaking waters, would be the length of course, and the rapidity of the returning waters.

But as the orifices into which these waters returned , were in the earth, and these very numerous, the tendency of the waters to remove the soil would be confined chiefly to the neighbourhood of the gulphs, and would be in some proportion to the magnitude of those gulphs. But as the waters would rush in all directions towards a large central opening, they would have little tendency to cut through rocky strata in longitudinal channels. For if the ground were level before they retired over it, the universal flow and equilibrium of the water would not cut out channels in it; and if the surface was found in the state of hollows and valleys, the retiring waters did not make it so.

The direction or motion of waters when rushing headlong into pits bencath the waters, is that of a circular or whirling motion about the mouth of the pit, forming funnel shaped holes or craters; and this motion would gradually but speedily give way, as it receded from the openings, to that of radii of a cirele directed from the circumference to the centre. But 
these motions, however rapid, would have no tendency to cut out channels and tear up longitudinal valleys; much less would they do this in solid compact strata and hard rocks. So that the tendency of such waters to cut, and especially to cut long channels, would only be in the neighbourhood of these holes, and that only, probably, when they were nearly drained off.

II. Torrents and currents in an universal Deluge are gratuitous.

1. With respect to torRents. Dr. Buckland supposes that the violence of a mountain torrent is a trifling thing compared with the rushing violence of the diluvial waters. (236-8.) - I admit the truth of this as regards the out-breaking waters, but deny it totally as applied to the retiring waters. On the Deluge of Dranse, the torrent rushed about 20 miles in an hour. But, from what we have before seen from Scriptural data, had the waters of the Deluge rushed with such rapidity, the high hills would have been clear in a quarter of an hour: nay, indeed, the whole globe, had the waters retired perpendicularly. And if the waters had come from the seas, all Europe would have been dry in Two DAYs, and Asia in a week!!

The retiring waters, moreover, we have shewn, had few or perhaps, no very extensive horizontal movements. None, however, in the neighbourhood of hills and mountains where their denuding efficacy is most of all seen. For from these hills especially the waters must have issued. And probably these out-brealing waters have been the cause of the vast devastations which many of those elevated districts have suffered. But, except about the mouths of certain "fountains of 
the great deep," whose contracted orifices would produce a rapid motion in the returning waters immediately about the mouths themselves, the general surface of the declining waters would denude nothing, for it did not move with one twentieth part of the rapidity of an ebbing tide.-This however I admit is only calculated upon the rate of the declining of the diluvial waters generally, without at all denying that the tides might then as well as now, accelerate or retard their motions.

It is perfectly demonstrable, therefore, from the time which the Deluge took up in removing from off the earth, that its motion as a retiring ftood was, on the surface of the waters, EXCEEDINGLY slow. On Scriptural grounds, we conclude that, probably, they did not move so much as a quarter of a mile in a day. And on any ground, had the waters come from the north and returned thither again, they might have flowed from the Indian Ocean to the north seas in less time than the flood was declining, at the rate of a river flowing Two MrLES an hour!

I am aware that Dr. Buckland seems to speak as if the denuding waters, in some places, rushed violently forward and then returned back again.

(1.) This is gratuitous. Nothing in the Bible gives us any authority to say this. Nor would either the tides, or the diurnal motion of the earth, or the retiring of the waters, warrant such an assumption.

(2.) Such violent rushing and revulsions are contrary to the character of the denudations ascribed to the diluvial waters. Violent rushes of such a mass of water, some miles deep, would produce effects exactly 
the reverse of narrow channels; they would tear up large masses, and gulphs, if they did tear, not narrow channels and gorges.

(3.) Such violent rushings to and fro of the deep masses of water concerned in the Deluge, would in another respect, be precisely the reverse of denudations; they would infallibly have washed the earth nearly level. If they had power to tear up rocks on the Downs, and throw down large portions of granite mountains, a repetition of such movements, (for they must have been exceedingly numerous) would certainly have thrown down into the valleys, every thing of a moveable nature.

2. CuRRENTs are unwarrantable in an universal Deluge.

It is obvious that nothing would cut out narrow valleys and gorges 100 feet wide, but a current passing over that part and that part alone. And yet before the retiring flood had cut out these channels in the rocks, they are supposed, by Dr. Buckland, to have been often nearly level with the rest of the surface!

1. It is pretty certain the Deluge had no such currents.

A current is a confined stream, and a continual stream. But the retiring Deluge differed essentially in both these respects. It was not continuous in its supply. Indeed it had no supply in the shape of a torrent, or raging current. What produces a very rapid current is the prodigious inclination of the surface.. And the headlong down-hill course of a quantity of water, produces a torrent. But where would be these currents or torrents if the waters, as 
was the case in the universal Deluge, rose up from the valleys till they reached above the tops of the highest hills? There could be no room for the top waters to move downwards any faster than the low waters subsided. As the low waters passed into the ground, the upper waters would follow. But not at all in the character of a torrent or rapid current, because an equilibrium would be kept up by the Deluge being universal. And as the waters would return into the mountains as well as other places, there would be no supply continuing to urge on from above: for the " rains ceased" and the fountains were restrained; therefore, there could not possibly be any thing in the nature of a cataract, or rapid narrow current attending the retiring waters of the Deluge.

(2.) No current in an universal Deluge could possibly cut out narrow valleys and gorges in " limestone "strata composed of uniform and moderately yielding " materials. (256.)

When Dr. Buckland says, "in such cases as we " have been describing. the simple force of water act" ing in mass on the surface of gently inclined and "regular strata of chalk and oolite is sufficient for " the effects produced"; (258) he must mean to argue that the force of water is "sufficient for these effects" when "acting in mass" upon NATURAL PRINCIPLES ; or as they are accustomed to act. This however, is by no means just. Indeed we have something like mathematical demonstration opposed to it. Let it be here particularly regarded how, many of these valleys of denudation, are situated. Our Author describes these valleys, in the Cave districts of Germany, in the following manner. 
"Though at a high elevation, this district cannot be " said to be mountainous ; its valleys are simply valleys " of denudation, excavated by the diluvial waters on " the surface of an elevated calcareous plain.-When " viewed on a correct map, or looked at from the sum" mit of a distant hill, these valleys appear but as open "gutters on the surface of a meadow." (126)

That these "gutters" were not excavated by the waters of the Universal Deluge, acting upon the natural principles of moving waters, is certain: For they have no such operation, and no tendency towards it. An universal Deluge, is not the case of rivers. An universal Deluge has an universal, and, therefore, an equable pressure. The laws of hydrostatics are quite applicable in the case. From those laws we know that the waters of an universal Deluge will not excavate or cut out narrow channels. Much less would they do this upon an " uniform" limestone plain."

The TENDENCY of these universal waters to $c u t$ the bed of its progress in this channel or gutter, more than the bed adjoining this gutter, can only be in proportion to the depth of the water in this gutter above the depth of the water close by the side of the gutter. But the Flood being universal, and miles deep, it would be insanity to assume that the surface of the diluvial waters was higher over these gutters than over the borders of them. And the ground was not previously so uneven as to cause this difference in these deep waters, for in that case, the Deluge did not make it uneven, and Dr. Buckland says, the ground was previously a "plain." 
(3.) If it be assumed that there was doubtless something of a channel already made in the earth to direct the course of the waters; I would reply; then those waters did not make the channel, which is the very point in dispute. If, moreover, the diluvial waters had been violently directed down gutters of this description previously excavated, it would infallibly have destroyed their character. The pressure of those waters upon the edges or rims of these gutters, being equal to their pressure upon any other part of equal depth, would have caused them (if they cut at all) to tear down those sharp and almost square edges, which, from their being sharp and projecting would be more exposed and more inclined to give way. Indieed so far would universal waters be from excavating, (like a channel made by a joiner's grooving plain in the middle of a board,) narrow valleys with almost perpendicular cliffs, which Dr. Buckland says, are like gutters cut in a meadow, it is perfectly demonstrable, upon natural principles, that they would do no such thing, but exactly the reverse.

(4.) If it be supposed that these channels were not cut by the diluvial waters when they were deep and general, but after they were reduced within the range of the hills, and so became more confined: I would answer, that this evasion has all the inconveniences of the former supposition against it, in addition to some other difficulties. - If the waters were so reduced as to become confined within high barriers, they would only cease to be universal at top. The lows would still be universally covered, and therefore we are further still if possible from obtaining a deep and rapid current.-But 
again. The waters, being reduced within the hills, would be reduced in the rear likewise. So that a rapid rush between the parallel hills would, in a few minutes, drain the whole valley; for it has no continued supply. Besides its weight and capacity for cutting would be proportionably decreasing.-And at all events, in that case, these waters would cut from hill to hill across the whole large valley or plain ; unless the valley was very hollow or channelled before-hand. But these gutters we see are not thus confined, but are upon the "plain." Nay indeed, where valleys are low and level between two hills, it even then sometimes happens that "gutters" or minor valleys of denudation are cut out for a river flowing in the midst of the greater valley.

Dr. Buckland, as will be seen by the foregoing quotations, in order I suppose to render the notion of "diluvial denudations" more feasible, speaks of these waters, when "acting in mass," as being sufficient to produce these effects on "regular strata of chall and oolite," which he considers as "moderately yielding. materials ;" but he writes very doubtingly as to the efforts of the diluvial waters on the "transition and primitive rocks."

But it ought to be remembered that one of the strongest instances of diluvial denudation which Dr. Buckland has produced, is in the Gorge of Baumans Höhle, in the valley of the Bode, in Germany. This gorge is a deep, but narrow channel in the rock. In the narrowest part it is but 100 feet in "breadth," while its "depth" is about 150. But though this gorge is in some parts, actually deeper than it is broad by about one half, it is nevertheless excavated in a 
"bed of transition limestone" rock, according to Dr. Buckland's own representation. Yet he adds, in a note, "this gorge is simply a valley of denudation, produced (like hundreds which I could mention in compact limestone countries) by the force of diluvial waters." (118.) To such insuperable difficulties is this Theory reduced, in every quarter.

No waters (it may be confidently concluded) which were universally diffused over the earth, could possibly, on natural principles, cut out these channels, and excavate these gorges in compact and transition limestone, not wider than Regent street, in London, and three times as high.- The Deluge confined by walls to these channels, and kept in violent motion for a sufficient length of time, might doubtless have answered this purpose, but nothing short of this, on natural grounds, could possibly do so.

III. Dr. Buckland's denudation Theory is contrary to the form and direction of the denudations themselves.

I need not say much against the notion that blocks were carried by the diluvial waters from Blanc to Jura, and then that the valley and Lake of Geneva were subsequently excavated. The absolute contrariety of such assumptions, with every known operation of nature, has I presume, been sufficiently proved already. There are $t$ wo things, however, peculiarly worthy of notice here, in connexion with the hypothesis, that the great rush of diluvial waters come from the north! We before observed that the blocks to mount Jura must have been carried by a current moving from the south. Now, however, we must take notice that as 
those blocks must have crossed the direction of the Lake of Geneva, the waters which tore up that lake must have moved at right angles to the former waters; viz; east and west.

2. The next thing is this. Jura is about 2000 feet high above the Lake of Geneva; and the Lake is nearly 1000 feet in depth; Jura therefore is about 3000 feet above the bottom of the Lake. But Mount Blanc is 15000 feet above the level of the sea, and not very far less, I should suppose, above the bottom of the Lake of Geneva. A line drawn, then, from Jura to the summit of Mount Blanc, (say 60 miles,) would rise considerably in an oblique direction. As this lake may be called the centre, the line would be about 6000 feet above it.

If now these granite blocks were drifted from Blanc to Jura after the Lake was cut, they would have to go through the Lake, and to rise near 3000 feet to Jura. -If, before the Lake was formed, they would still have to rise 2000 feet.-If we suppose the whole valley filled up before the stones were drifted, and that they moved all the way down hill; then the waters, in order to make the valley and Lake afterwards, would have to tear up the rocks 6 or 7000 feet in depth! which seems more unlikely than the former. Especially, as large portions of these rocks were probably granite. So that in any way we choose to escape the absurdity of blocks of granite, many 100 tons weight, being drifted up an immense hill, we run into the other absurdity of making the diluvial waters tear up solid rocks hundreds, or thousands of feet in depth and, perhaps, many miles in width. This how- 
ever, extraordinary as it is, our author expressly advocates. (236.)

But Dr. Buckland's rivers are a perfect demonstration, against his Theory.

Our author has given us a map of four rivers in Germany ; in conjunction with which are many of his celebrated caves: the Aufsees, the Weissent, the Esbach, and the Buttlach. The two first of these run nearly parallel a few miles, and then join each other at right angles. The two last named rivers, both coming from another side of the map, also form a conjunction with each other, nearly at right angles. The two first rivers after their junction with each other, run about 2 miles, partly in the direction of the Aufsees and then join the two last rivers, about a quarter of a mile below their union with each other. These four rivers, now in union, turn short about and flow for the distance of 5 miles nearly parallel with the first river, the Aufsees, but in a different direction; when they suddenly turn off at a right angle, being not so much as two miles distant from it.

These rivers, all run in valleys which Dr. Buckland calls valleys of denudation. Indeed they are the very same which he described as looking from a distant hill, like "gutters in a meadow." So that we have here in the district of Muggendorf Four RIVERS which, in the distance of Two MILES, run in FOUR different DIRECTIONS; and when united take a course differ ent from them all; making FIVE different or opposite courses in the space of about two miles.-Besides, each of these rivers has numerous short windings or meanderings in its course, as is common with rivers formed on a plain. 
The whole of this space for miles distant from the junction of these rivers, is "limestone table land." And before the valleys were cut in it, it must have been, pretty much as Dr. Buckland describes it, a "calcareous plain."--In reference then to what we before said about the impossibility of currents in an universal Deluge, we here find the incongruity multiplied many fold. There are not only currents, but currents in FIVE directions, and some of them in direct opposition to each other; and all on nearly a level area of a few miles!

In the first place, the zigzag motions of these denudations is out of all question for an universal Deluge. In the second, there is nothing to induce the least current whatever in a deep and universal flood. In the third place, these five different currents within a space not greater, probably, than the depth of the waters which caused them, would render it little short of insanity to maintain that these were caused by the universal Deluge.--I feel almost ashamed to be obliged to expose absurdities so many and so gross, belonging to a Theory espoused by a divine and a professor so patronised and so popular.

IV. The origin of valleys and gorges.

It does not necessarily attach to my design to enter at all into this subject. All that I pretend to understand about matters of this high character, has been already stated in the 5th chapter, entitled "Geological Phenomena only to be accounted for on Scriptural data." But I did not there presume to offer any thing like a Theoretical or Geological explanation. It is perfectly clear, however, that modern Geology, having deserted the Scriptural in- 
struction upon this subject generally, has been suffered to run into the wildest speculations, and to advance ideas, relative to this and every other branch of its Theory, the most extravagant and unphilosophical.

But why should we seek to be "wise above what is written?" Why should we be presumptuous enough to expect to account for works so little subject to experiment, and almost entirely without analogy, by "Theories" which are themselves the result of " the merest guesses, and the offspring of an unbridled imagination? Some parts of these " denudations" naturally merge in the "origin of rivers ;" a subject of as great difficulty as any connected with Geology, except, perhaps, the formations of the strata themselves. Dr. Buckland observes, that

"When a gorge or valley" is exclusively within the range of the strata which are nearly "horizontal," that valley is owing to the " removal " of " the strata; but that this removal cannot possibly " have been caused by the rivers which now flow " through them, because the rivers themselves owe " their existence to the prior existence of the valleys "through which they flow." To get away from this difficulty, he rushes into one much greater; that is, that the valleys were excavated by the Deluge.--(238.)

Here I would make a few remarks respecting what is pretty evident, and what is less so.

1. We have long ago proved that these rocky strata generally, and these fossil limestone formations, in particular, were not in EXISTENCE till they were formed by the DILUVIAL OPERATIONS.

2. From Scriptural data, we also proved, I hope 
satisfactorily, that our Globe-was CREATED, and formed at first, with H ILS and VALLEYs.

3. From the Rivers of Paradise, and from the existence of hills and valleys, we may, doubtless, conclude, there were SPRINGS and RIVERS commonly before the Flood; nay, even from the Creation.These points are clear.

4. As there were valleys and rivers before the Flood, we should disencumber ourselves very greatly were we to lay aside our "diluvial" speculations, and carry our views to the valleys and rivers of that preceding period. It does not, I think, appear that, constituted as men and animals are, they could long exist, or comfortably exist, were the Earth on which they dwell, deprived of hills, valleys, and rivers. If this, however, be a truth, we need not speculate long about their origin:-God MADE THEM. "He "sendeth the springs into the valleys which run " among the hills."- "The king's heart is in the hand " of the Lord, as the rivers of water; he turneth it " whithersoever he will." - (Ps. civ. 10.-Prov.xxi. 1.)

The following points are less decisive.

1. How many of our existing rivers and valleys were rivers and valleys before the Flood, we cannot judge. That many of the larger valleys, however, were such before the Flood, there need be no doubt.

2. How much these have been varied, or the waters stopped; or how far they have been new modelled, we have no authority to say. But the whole surface of the globe has certainly been greatly torn and newly modified by the Deluge.

3. Might not, then, many of the large dry valleys 
(which Dr. Buckland mentions,) have been antediluvian valleys, perhaps, containing rivers, whose source the Deluge has turned into another, or lower channel?

4. Might not the springs after the Deluge break out afresh at the heads of the valleys, and be conducted by the "finger of an Omnipotent" and "Benevolent" Disposer of all events, through all those situations which His Infinite $W$ isdom saw best, when, after making the earth desolate, he was again "providing for the daily wants of its rational inhabitants ?" (In. Lect. p. 12.)

5. Might not the recent deposition of the strata facilitate this "denudation" after the diluvial waters had just departed from them, and render even small streams sufficient for the effect ?

6. Do not Dr. Buckland's arguments for the diluvial denudations of these valleys as a course for the rivers, lose their force, from the consideration that valleys and rivers were common before the Deluge, as well as after it?

7. If, when we duly reflect upon all the known operations of moving waters, and have reason to conclude respecting their insufficiency to effect existing denudations, had we not better acknowledge our ignorance, than wantonly rush upon causes so manifestly inadequate and irrational ?

8. It seems pretty evident that much which Dr. Buckland, from the bias of his Geological Theory, would call denudations, is not so in fact. A more correct Theory would lead him to see that the notion of "horizontal formation," which has led him into many of his notions on the subject of denudations, is 
perfectly visionary : and that, in all probability, every substantial part of the globe we live in was thus framed at the beginning. That these channels in the plain surface of this limestone table land have been greatly cut away, there can be little room for doubt. And that they are postdILUVIAL, is also certain. But whether they were excavated very soon after the Deluge, and were a long time under the action of denuding waters, I dare not positively assert.

Objection.-Several of the Caves in which Dr. Buckland supposes animals to have dwelt, open into some of the almost perpendicular faces of these gorges which, therefore, are not now accessible to animals ; it will, therefore, be supposed, that the animals must have occupied these caves before these denudations took place; which could not, on that account, take place immediately after the Deluge, and while the strata were very recent.

To this I answer, the gorges might be excavated by the returning waters instantly after the Deluge. But it might be many centuries before the caves even existed, or were tenanted, at least. But as the disintegration of the face of the rock would, as in most other cases, be gradual, the animals might have room to enter. And, perhaps, they deserted these dens only when they became inaccessible. 


\section{DR. BUCKLAND'S THEORY OF THE CAVES.}

EVIDENCES OF THE CAVE THEORY EXAMINED.

INSTEAD of going through the whole circle of the Caves, and giving a separate argument from every one of them against the antediluvian Theory which Dr. Buckland attempts to prove respecting them, I think it will be both a shorter, and not less satisfactory plan, to draw out a few of the principal objections which occur from the subject in general. If we examine the evidence upon which Dr. Buckland grounds his Theory respecting these Caves, we shall find that it will not bear him out in the assertion that the Caves are antediluvial, while we shall derive, and still from the author's own statements, abundant proofs that the Caves are certainly not of an era prior to the Deluge.

The reader must particularly understand that if Dr. Buckland's Theory of the Caves be just, it will prove the material points of $M$. Cuvier's "Theory of the Earth" to be correct. For, if these Caves occupied their place in these limestone rocks before the Deluge, it is evident that there must have been one or more 
revolutions before the Flood. For, it is certain, that some revolution or other was concerned in the formation of the rocks in which these Caves are situated. These stones and rocks themselves, contain in their very substance, "remains" of fishes, shells, and vegetables, \&c., which Geologists consider to be, and which probably are, of an era prior to that which furnished the fossil remains which are found (not in the rocks only,) but in the interior of the Caves.

Our author undertakes to prove that the animals, whose remains are found in the Caves of England and Germany, actually lived in the neighbourhood of these Caves before the Deluge, and that the Flood destroyed them, or found them already deposited upon, or near the spot,- that some of them, as at Kirkdale, in Yorkshire especially, were dragged in by beasts of prey which inhabited the Caves prior to the Deluge,-and that others were swept by the diluvial waters into the recesses which they now respectively occupy.

The evidence upon which Dr. Buckland engages to prove the antediluvial character of these Caves, is derived from their contents. These, he assures us, could not be introduced, as they are now found, from any other source than the universal Deluge. Since which time, in many of the Caves, "they have been sealed up" from all further disturbance. The accuracy of all this we shall now proceed to investigate.

The chief, or only evidence, which Dr. Buckland adduces in proof of the antediluvial nature of the Caves, is the following.

I. "A bed of loam, or diluvial mud."-(p. 108-10.)

2. Rolled diluvial pebbles." - $(108,146$ note and passim. 
3. "Stalagmite," but never attenuating with the mud.-(121.)

4. The bones of extinct animals.- $(41,44$.

We shall not find much difficulty in proving that loam, pebbles, stalagmite, and bones, are very precarious testimonies upon which to found a Theory which would, in its consequences, very seriously affect the Word of God. We shall not, however, in examining the evidence of loam and pebbles, \&c., derive any part of our argument from Revelation, but entirely from the physical nature of the case. After we have taken away the force of Dr. Buckland's evidence for his Theory, it will be fair to make the Scriptural statement of the Deluge bear as evidence against it.

I. Diluvial loam in the Caves.

Dr. Buckland takes for granted that the "mud" in these Caves was generally carried in by a flood of water, though some of the Caves are moist, and others dry and dusty. And, because their mouths are all too high above the rivers to be flooded by them, he conceives they were flooded at the general Deluge; though he has taken no pains to explain to us how the thing could be. These deep Caves, originally like wells in the earth 50 or 100 feet deep, would certainly have been left by the Flood full of water, partly sea water, perhaps. Dr. Buckland has given us no opinion how it went away-whether by evaporation, percolation, or absorption,-how long he supposes it may have been gone,-why the Caves are not now full,-or how the mud has been kept soft for 4.000 years,-or how this is consistent with the dry loose earth so often talked of. I have laboured in vain in search of a plain and 
intelligible definition or description of what Dr. Buckland, almost every where, in his statement of these Caves, calls "diluvial mud," or " diluvial loam." In explaining the "word diluvium" our author says "I "apply it to those extensive and general deposits of " superficial loam and gravel, which appear to have been "produced by the last great convulsion [the Deluge] " that has affected our planet;" (2.) This description, howevcr, is too vague as a definition by which to ascertain the character of what is diluvial from what is not diluvial. Dr. Buckland, still, considers himself warranted to call that diluvial loam which is lodged in the Caves ; and says, "we find in every cave nearly the same proportion of diluvial loam and pebbles." (143.) And in another place he says "they enabled me to identify " the same bed of diluvial mud which I had already "seen at Bauman's Hohle, and Scharzfeld, and "Theux, and in the Caves of England." (123.)

Without at present saying any thing further about the identity of this loam or mud, we may remind the reader, that agreeably to this Theory, it was "produced" by the "last great convulsion which has affected our planet;" viz. the Deluge. Respecting this matter, I shall make some remarks.

1. It supposes what is not true; that is, that loam and gravel, were not in being before the Deluge, but were formed by it.

Dr. Buckland, to my great astonishment, adopts (as we before saw,) the notion that loam, which consists of different proportions of sand and clay, was produced by the mechanical action of the diluvial waters ; though he himself confesses, that there is no obvious M ATRIX 
from which it can have been derived. Sand and clay, however, as we before remarked, were as certainly existent before the flood, as after it, in the character loam. Before that event, both man and beast subsisted greatly on vegetables. But vegetables could not grow, and there could be no matrix for them to take root in, had there not been, from the beginning, clay, sand or gravel; or, in other words, loam. Vegetable mould, is only sand, or loam, in different proportions, levigated and mixed up with animal substances, and decayed vegetables, or manure. Unquestionably these things were graciously provided at the "beginning," by our benevolent Parent, as an abiding and necessary nidus for vegetables and fruits, and trees of all sorts.-To adduce therefore, as evidence of the action of the Deluge, what was obviously as necessary before the Deluge, is neither philosophical nor just.

2. Diluvial loam could not be produced and carried into the Caves by the waters of the Deluge.

Dr. Buckland supposes that this is "diluvial loam" which he finds in the Caves. But this is certainly incorrect. What the Deluge met with, already formed, upon the surface of the earth, cannot be called "diluvial;" or spoken of as a thing "produced" by the Deluge. It is certain, however, that vegetables, of all sorts, and therefore, vegetable mould, was common before the Deluge, in the neighbourhood of all those places where cattle and beasts inhabited. It is also certain that the moveable earth, whatever it was, which was close at hand by each cave, would be the earth which the rising waters would immediately introduce into every Cave accessible tothe diluvial waters. 
If the Deluge burst forth at an average in the first commencement, every Cave, having its mouth open to the surface, (as, according to Dr. Buckland's statement they most of them had,) would se filled with water in a few minutes. For as we before showed, the level ground would be flooded 6 feet deep in a quarter of an hour. There would therefore, be no space of time sufficient for the diluvial waters to produce loam which was not upon the spot before hand.If, moreover, we could suppose even a slow and gradual advance of the diluvial waters, the effect as to the mud in these Caves, would be precisely the same. A slow and gradual, water would as certainly run into and fill these well-mouthed Caves, as a hasty and powerful water. But a slowly advancing. Deluge would have no power to tear up strata aud form wreck; it would have neither depth nor violence till long after these Caves were filled with water. It is certain, therefore, that their charge of mud and debris would be only such as lay both loose and convenient.

But a deposition of mud from waters so charged, could in no sort, be called " diluvial" mud. And if it could be so called, it is perfectly clear that the deposition made by such waters could not be called $i d e n t i c a l$, or recognised as "diluvial mud" in England and Germany, any more than the respective soils in the neighbourhood of those Caves, could be called identical.-Beside the nature and quality of such earth would be the same, in the Caves, had it been conveyed into them by heavy rains from without ; or in whatever other way it might have been introduced.

II. Dinuvial Pebiegs in the Caves. 
Dr. Buckland makes a great point of these "pebbles," and considers that they are very strong evidence in favour of his Theory. He uniformly speaks of "the diluvial action that introduced the mud and pebbles." (143.) He believes that there is nearly an "irresistible argument arising from the almost universal presence of the pebbles themselves," which "renders it impossible to refer the earthy matter in "question to any other origin, than one violent move" ment of water over the land without." (145.) He esteems it matter which scarcely admits of dispute that the "pebbles" were rounded by the "attrition" of diluvial waters-that "the loam itself and pebbles are clearly of diluvial origin" - that " other writers "had, many of them overlooked the 'fact of the occur"rence of pebbles in the earthly sediment ;" from which circumstance he supposes they were led into the common error "of considering the diluvial loam as animal earth" - that in the case of Zahnlock, "the introduction of the mud and pebbles may be referred, as usual, to diluvial agency." $(58,60,143,146$.

Dr. Buckland gives his scheme in form respecting the diluvial character of mud and pebbles in these caves. He writes;

"All these circumstances are corroborative of the " hypothesis I am endeavouring to establish. First, "That the agent, by which the mud and pebbles were " introduced, was the same diluvial waters, which " extirpated the animals that had antecedently inha" bited the Cave, (called Baumans Hohle.) Secondly, "That this diluvial detritus was not introduced at " different intervals by the action of rivers, or land 
" floorls, but was by one single operation superadded " to the bones already existing in the dens. Thirdly, "That the period of its introduction is that from "which we must begin to date the superficial crust " of stalagmite, by which these diluvian and antedi" luvian records have been sealed up, and maintained " in such high preservation to the present hour." (121) What we are now particularly concerned to notice, in the arrangement of this ingenious Theory, is the circumstance of the PEBbLES - their being formed or rounded by the diluvial attrition, and then introduced by the "rush" of diluvial waters into the Caves. And, no doubt, it will occur to the reader, that the reasoning we have lately adopted respecting the "diluvial LOA.M," may be applied with even greater force, if possible, to the case of "diluvial pebbles." That the pebbles found in these Caves were not formed by the attrition and introduced into the Caves by the action of the Deluge, is, I think, as strictly demonstrable as any reasonable person could desire it to be. The circumstances of the Caves, the situation of the pebbles, and the universal laws by which moving waters are regulated, forbid the supposition.

These Caves, generally, are long, and many of them spacious caverns in the rocks, entering horizontally, or pretty much so, into the body of the hills in which they are respectively situated. Some of these, after you enter into the caves by a long narrow chimneyshaped entrance, have a large and sometimes lofty kind of hall 50 or 60 feet long, which leads, at the further end, to various cells or different suits of apartments, in which are found, pebbles, mud, and bones 
mixed together. I need but select one or two instances of Caves, in which pebbles are thus situated, to prove the impossibility of their diluvial introduction.

BAUman's HoHLE; (for instance); we enter by an " aperture into a low flat Cavern, 15 feet broad, and " 5 feet high,- -within, it descends rapidly to the broad " and lofty chamber. The form of this chamber is " irregularly oblong, varying from 30 to 50 feet in " diameter, and from 10 to 20 in height." At the extremity of this second long chamber, which we see, is 50 feet long, "we descend by a passage" to a hollow "vault, the lower half of which contains "several feet of mud or sand mixed with bones, and " extremely large pebbles of transition limestone" in a "state of perfect roundness" Beyond this third vault, which according to Dr. Buckland's plate, may be 20 or 30 feet long, "the rock rises suddenly about 20 feet." This rock, our author supposes, stopped the further progress of the bones and pebbles, in which situation he considers that "a rapid movement of the large pebbles introduced" by "the same diluvial waters" have crushed "to pieces the large and strong bones." "These "pebbles," which are "large" and in " unusual quantity," must be 60 or, indeed, 80 feet from their entrance, and in much larger number toward the further end, than near the mouth. (118-121.)

Cave of Gailenreuth (very much like the above,) has a large chamber "varying from 10 to 30 feet" in diameter, through which, over a rising part of the rock apparently above 5 feet high, the stones, mud, and bones are supposed by Dr. Buckland, to have passed into two further vaults, in which they 
are found prodigiously numerous, and in very extraordinary situations. To this we must again recur. Dr. Burk and adds, The diluvial "waters rushing, as " they would not fail to do, into these caverus, would " introduce pebbles and mud, and would also drili "downwards to their lowest recesses the bones that "lay perhaps more equally distributed than they are " at present."

Without adducing more instances of diluvial pebbles introduced by the same waters into the Caves, I would say that a little consideration of the subject, will convince us that the entire Theory, which supposes them to be so made and so introduced by the Deluge, is a perfect dream.

1. These pebbles could not possibly be formed and carried into the Caves at the FIRST InTRoduction of the diluvial waters.

We see that there are "pebbles unusually largeperfectly rounded"-and in much greater quantity at the distance of 60 or 80 feet from the entrance, than in the large and hollowed caverns through which they passed: and that these pebbles passed into the Caves hy long chimney-shaped, narrow, and jagged entrances, or by "fissures" opening near the mouth of the Caves, to the surface. - The whole of this is incredible and impossible. For

(1.) The diluvial waters, according to the Scriptural statements which we have before considered, would fill every one of these easily-accessible Caves, in a few minutes, if their mouths would admit the water so fast. And the Caves would be filled, as we before saw, with water which fell in their immediate neighbourhood. 
So that there would be no time nor opportunity for waters to come from a distance with "diluvial pebbles." Yet not only was there a want of ime, but the waters in order to tear up and wash into pebbles the hard, " ancient," and therefore " impracticable" "transition" rocks in the neighbourhood, must have acquired great depth and reeight: but before this could possibly be, the Caves would long be filled with diluvial water.

(2.) The situation of these pebbles in the Caves is such, as no waters, entering in by the chimney funnels or fissures, could place them in. If water rushing into the Caves found "large pebbles" near their mouths, and drove them in with it, it would leave them in greatest number at the bottom of the funnels, and not carry them to the further end of the Caves. The water having rushed down the passage and hurried the pebbles with it into the first large horizontal or hollow-bottomed vault, would instantly diminish its violent endlong progress, and diffuse itself over the whole breadth of the vault. In consequence of which the pebbles would lodge, and the water would make its way into the interior and distant Caverns alone; or most certainly with a force and rapidity diminished in proportion to the size of the vaults, the depth of their hollow floors, the length of its progress, and the impediments in the way. But most of the pebbles are found in largest numbers at the greatest distance from the entrance, and behind even strong impediments!!

There can be no pretence of evading this conclusion, from the presumption that the pebbles were carried into the Caves by a violent rush of deep waters; for these Caves are, many of them, reell-mouthed Caves, 
open to the surface of the ground. They would therefore admit into them the very first diluvial water which rose in their immediate neighbourhood, and would of consequence be filled, not by a deep and violently rushing current of water, but by the water instantly flooding about their mouths. Under these circumstances, the waters thus running into the Caves would necessarily become diffused and weak in their motion on the horizontal expanded floor of the Caves which they first entered; they would therefore of necessity, leave the greatest portion of the heavy materials with which they were loaded, in the large Caves through which they passed: on natural principle, they could not, (as we find to be the case,) carry the heaviest bodies into the furthest recesses, and most inaccessible, difficult, and impracticable parts of the Caves: yet these distant recesses are often nearly or wholly choaked up with these bones and pebbles.

(3.) I allow it may be argued from the Scriptural data that the out-breaking waters would be likely to tear up the rocks which lay above those waters, and that the waters would possibly tend to round and make pebbles of the fragments, which they might hurry into the Caves. There are many answers to this argument. 1. It is the ground of the Bible and not of Geology, and ooth cannot stand together. 2. On Scriptural data I should deny that pebbles were formed in any such way as the hypothesis supposes. 3. There would be no time equal to such a long continued operation as the "perfect roundness," which many of these pebbles exhibit, would require. And were the pebbles found already rounded, they would not be diluvial. 
(4.) The above hypothesis would admit the probable conjecture, that the "mud and pebbles" were partly introduced by heavy rains, - by the entrance of wild beasts, - and by various other incidents; all of which are destructive to the very existence of Dr. Buckland's Theory, that the contents of the Caves, especially the "mud and pebbles," are of diluvial introduction.

2. As the pebbles could not be introduced into these Caves, in the FIRST instance; so they could not, at any SUBSEQUENT stages of the diluvial opcrations.

(1.) This process we need not dwell upon; because Dr. Buckland uniformly supposes that the "rushing" of the water carried the pebbles into the Caves; and his Theory has no force upon any other ground. It is quite clear, however, that after the Caves once became filled, which they would be in the first instance of the diluvial floodings, the water in the Caves would become quicscent, and no more water could be admitted. But if the water could gain no subsequent admisssion, it certainly could not subsequently carry any pebbles into the Caves.

(2.) If, moreover, the pebbles were subsequently drifted over the mouth of the Caves, they could not gain admission further than the force of gravity would urge them. But this could reach no further than the first Cave; or, rather the bottom of the throat of the funnel leading into it. For having reached a horizontal floor, they would certainly have no tendency to move further. For the water within being now quiescent, it could not carry the pebbles further into the Caves; 
much less could it introduce them into the furthest recesses. So that it is perfectly demonstrable that the diluvial waters could not, and did not, round these pebbles and introduce them into their present positions, either at the FIRST INSTANCE, or in the SUBSEQUENT STAGES of the diluvial operations.

(3.) Should any assert that we have no right to conclude from the Scriptures that the Flood arose so rapidly, and should choose to say that it probably advanced in a more gradual and slow manner; I need only say in answer, that no Deluge advancing slowly and step by step could enable its waters to tear up rocks and form pebbles before its waters became deep and its movement rapid. But I may remark, that the more slow the more fatal to the Cave Theory. For as the diluvial rain and water fell in every part of the earth, the Caves would instantly be filled, from their own local and immediately contiguous waters; and this before the flood could possibly become deep, or its waters become rapid in endlong destructive currents.-There is certainly no way of conceiving how these Caves could possibly be filled by a sudden and violent " rush of waters," consistently with the Scriptural or philosophical character of an UNIVERSAL Deluge; because the very nature of such a Deluge implies that every place (though perhaps not equally) would, in the first instanee, be flooded by the rains falling directly upon it, and not by waters coming like a high tide from a distance. This, I repeat, is essential to the nature of a flood, produced as the Deluge was, (in part at least,) by an universal rain; whatever different opinions we may choose to form respecting the 
nature or number of the "fountains of the great deep." The inevitable conclusion therefore is ;

1. That these pebbles were not rounded and carried into the Caves by the FI I T entrance of diluvial waters.

2. And that they as certainly were not carried in by the diluvial waters at any SUBSEQUENT stages of the Deluge,

3. Therefore they cerlainly were not taken into the Caves A T AL by the diluvial waters.

III. Stalagmite Not alternating With MUD IN THE CAVES.

"Stalagmite" consists of " water impregnated with " particles of the calcareous carbonate, of which the "limestone is composed." (9.) Water dripping through the roof and falling to the bottom of the Caves, carries with it this carbonaceous matter, which, when it becomes extensively spread over the floor, forms a beautiful, glossy, smooth covering. This stalagmite becomes available to Dr. Buckland's Theory of the Caves only by a peculiar circumstance; viz. its connexion with the mud in the Caves. As limestone rocks, generally, have this property, we might expect to find stalagmite in the Caves, at least, occasionally, under every variation of form and circumstance. And so, perhaps, we do find it. But as Dr. Buckland considers that the MUD was introduced into the Caves by the Deluge, and, of course, all at one time, the mud must sustain a character and situation in the Caves consistent with this hypothesis. For instance, the mud must be one single covering, and no more. The stalagmite, therefore, upon the floor of the Caves must either be below the mud, and then it will prove that it was formed before the Deluge, as 
the mud is supposed to be introduced by the Deluge, or it must be above the mud, thereby shewing that it is post-diluvial. But it must not alternate with the mud; viz. the mud must not occur both below the stalagmite and above it. For, in that case, it would occur twice, and prove that it was not introduced at once only, and therefore was not diluvial. Dr. Buckland, therefore, of course, contends that they "never alternate," and that therefore there is no evidence that the mud has entered the Caves at twice.

As this peculiar situation of the stalagmite as connected with mud in the Caves, is the only point from which evidence can now be derived favourable to Dr. Buckland's Theory, it might be thought desirable to examine it minutely. I have, indeed, much before me upon this, as well as very many other points, which I shall not insert. A few remarks here may be sufficiently satisfactory.

1. If the truth of the non-alternating of the stalagmite and the mud could be proved, its evidence of the Theory would be merely negative, and therefore very unsatisfactory in its conclusion. But

2. The stalagmite is so very irregular in its occurrence, and in its manner of appearing, that no certain conclusion can be drawn from it. Dr. Buckland describes the stalagmite as sometimes occurring above the mud-sometimes below it-sometimes both above and below-as "often transfused bodily through the substance of the diluvial sediment" - and at other times as not occurring at all, though there be a perpetual dropping of wet through the roof. Surely no certain conclusion can be derived from premises so uncertain, partial, and arbitrary. 
3. Dr. Buckland's examination of the stalagmite is far too imperfect to afford satisfaction. In describing the stalagmite in the German Caves, he says, "from the thickness of the diluvium, there were so "very few points in which it was possible to make "any observations upon the subject, that at present "we are without any evidence" respecting a "lower crust of stalagmite-beneath the mud." (144.) But surely, if we are "without any evidence" whether there may not be "stalagmite beneath the mud," we are quite as uncertain whether there be not mud again beneath the stalagmite. For if we have not ascertained that there is no stalagmite under the mud, still less have we ascertained that there is not mud beneath the stalagmite.

4. The fact seems, however, to be even ascertained against the Theory, and that mud is actually deposited beneuth, as well as above the stalagmite, in the very Cave which of all others, is Dr. Buckland's confidence.

That something of this sort did occur in the Cave of Kirkdale, if Dr. Buckland's representation of the bones in the Cave be correct, is certain; and this before, or during its occupation by the animals. For he very particularly informs us that

"A partial polish and wearing away to a considerable depth of one side only" of the bones had taken place,- " many straight fragments of the larger bones "have one entire side, or the fractured edges " of one side, rubbed down and worn completely "smooth, while the opposite side and ends of the "same bone are sharp and untouched, in the same " manner as the upper portion of pitching stones in " the street become rounded and polished, while their 
"lower parts retain the exact form and angles which " they possessed when first laid down. This can " only be explained by referring the partial destruction "of the solid bone to friction" from the animals. Dr. Buckland speaks also of the jaw bones being worn in the same manner; which he explains by supposing that pressure, when the curved side lay upwards, "would cause its two extremities to sink " into any soft substance that lay beneath, and give " it a steady and fixed position." (31.)

(1.) Here I would observe that if these animals occupied this Cave before the Deluge, this "soft $s u b$ stance" must have been introduced before the Deluge. And that whatever it might be which introduced this "soft substance," might have introduced the whole quantity of mud.

(2.) It is evident that this "soft substance" was in considerable quantity and possessed very considerable tenacity. For it not only held fast the bones which stuck with their ends in it, but also the fragments of large bones which lay their length in it. It preserved even these from turning about or getting out of their place, as securely as if they had been "pitching stones in the street." And, as "many" fragments of bones were thus held fast in this mud, it is certain it was considerably extensive.

(3.) As Dr. Buckland has not told us what this "soft substance" was which kept these bones in this "steady and fixed position" - as he has not ascertained that it differed from the general body of mud in the Cave-as he has not explained how this mass of tenacious mud obtained its introduction-as he has not informed us how this body of mud could be beneath 
the stalagmite, and another above it (which he says there was,) consistently with the non-alternation of mud with the stalagmite, we must conclude that the evidence is both positive and strong against his Theory. Indeed, this FACT alone is positively destructive of his hypothesis; viz. that there is but one period, and that the Deluge, at which this mud could be introduced into the Caves; for we see that there was certainly a mass of tenaceous mud of very considerable extent in the Cave of Kirkdale during the period in which it was occupied by the animals. But, if it be correct that these animals (as Dr. Buckland contends,) occupied this Cave before the Deluge, this mud was in the Cave before the Deluge, and could not therefore be introduced by it. Therefore, Dr. Buckland's Theory is positively thwarted, instead of being established, by the mud and stalagmite in the Caves.

We have now, I trust, very satisfactorily proved that the mud, the pebbles, and the stalagmite, afford nn evidence in favour of Dr. Buckland's Cave Theory; that the mud and pebbles in the Caves were demonstrably not of diluviul origin; that the sialagmite does in fact prove that the mud was not all introduced into the Caves at one time; so that the WHOLE EVIDENCE upon which Dr. Buckland relies, in proof of the antediluvian character of these Caves, is entirely taken away. The subject of the "remains of ExTINCT ANIMALS" in the Caves, we must leave for future consideration. But it is obvious, there are so many ways in which the case of extinct animals may deceive the 'Theorist, that I can hardly suppose the sensible reader will deem the occurrence of such bones in these Caves as of much importance. 


\section{CHAPTER IV.}

\section{DR. BUCKLAND'S THEORY OF 'THE CAVES.}

EVIDENCE OPPOSED TO THE THEORY.

THE objections to the antediluvian Theory of the Caves are exceedingly numerous and diversified. I find it a very difficult matter to select and compress them within any thing like reasonable bounds. And many persons will doubtless think that, as we have shewn that Dr. Buckland has established no evidence for the correctness of his Theory, there is little need of proving it to be erroneous, by producing positive evidence against it. The pertinacity, however, with which erroneous systems of science are held, speaks a different language. And especially of a science, if it must be dignified with that appellation, whose very existence, as is confessed by some of our Geologists themselves, depends not upon its utility arising from a developement of the actual situation of the strata, but from the pleasure which the "Theory affords the mind by presenting to it "food for its curiosity," and vast and numerous catastrophes aud revolutions to excite its admiration! 
We shall therefore select a few topics of remark respecting these Caves and their contents, which I think will demonstrably prove that the contents of the Caves are not of diluvial origin; and moreover, that the rocks in which the Caves are situated, were not in exisience, as rocks, before the Deluge.

I. The irregularity of the contents of the Caves, both as to quantity and QuaLITY.

It is manifest from Dr. Buckland's character of the Universal Deluge, and from his assumed identity of the diluvial mud, \&c. in the Caves, and also from the general analogy which he claims between the German and English Caves, and especially from his statement that "whilst we find in every Cave nearly " the same proportion of diluvial loam and pebbles, " the occurrence of bones is limited to a small num"ber ;" (143); it is manifest, I repeat, from these circumstances, that there cannot be any great variation or irregularity in the contents of these Caves, without proving that they are not of diluvial origin. The variations however, which Dr. Buckland himself has described, are great beyond imagination.

\section{In Quantity.}

Dr. Buckland, in his consideration of the "evidence of diluvial action afforded by these caverns," tells us, that he discovered in the analogy subsisting between the Caves in Germany and the Caves in " England, a " harmony of circumstances exceeding what (he adds) " my fullest expectations would have anticipated; all " tending to establish the important conclusion of " their having once, and once only, been submitted to 
" the action of a Deluge, and that this event happened " since the period in which they were inhabited by " wild beasts. In every Cave 1 examined, I found a " similar deposit of mud or sand." (108.) And (as we have just seen) "we find in every Cave nearly " the same proportion of diluvial loam and pebbles."

With what surprise then, not to say, confusion, will the reader learn, that our author, in proceeding with his description and correspondence of the Caves, actually states, that "there is usually a bed of loam or " diluvial mud-and varying in thickness from a few " inches to 20 or 30 feet." (110.)

This "diluvial loam" then varies in quantity from " a ferw inches"-3 or 4, perhaps, " to 20 or 30 feet ;" that is, the "proportion" is greater in one Cave than another, nearly 100 times!! Again, in the very same rock, (Oreston,) some Caves or cavities seem to have little, or even no mud. "In almost all the cavities " there occurs a deposit of diluvial detritus, consist" ing of mud or sand." - "Almost all ;" not certainly in all therefore. Others "are more or less filled with mud." But we learn that one at least in this same rock, "was filled with solid clay. $(67,69,78$.) At Chudleigh too, the note in one of the same pages, informs us that in some fissures "the quantity of mud was small," while, in others, it "formed the principal substance.”( 69.)

Surely no person of consideration will allow that variations such as the above can possibly consist either with Dr. Buckland's professions respecting "nearly the same proportion" of "diluvial mud" in the Caves, or with the character of an universal Deluge. These 
"caverns" are described as being connected with the surface or top of the "solid limestone" rock by vertical or oblique "fissures-disposed in it (the rock) after the manner of chimney flues in a wall." (68.) - It is not possible that an universal Deluge, sweeping over a country where there were habitations in the rock, whose chimneys were level with and open to the surface of the same rock, should deposit in one room a "small" portion of mud, in another hard by, a " deep bed of mud," and in a third, connected with the same premises, leave a mass of clay which should fill it top full!! We should utterly destroy both Dr. Buckland's character of the evidence upon which he builds his Theory of the Caves, and that of a general Deluge, by the admission of such disproportionate operation in the very same rock and in Caves which our author considers "so identical as to their contents, that there appears to be no difference as to the time or manner in which they were filled." (69.)

In Quality.

1. The striking and absurd character of the contents of the Caves as it respects their quality, is more extraordinary than their variation in quantity. In one Cave, as we have seen, there is a mass of "solid clay;" in others, "loose earth;" some, have argillaceous loam ;" others, "calcareous loam ;" while some, have clay only; others, have sand, earth, and clay; some have these three ingredients all mixed in a diluvial loam; others have sand, earth, and clay stratified: -It is soft and hard, wet and dry.

Again. This loam, mud, sand, or clay, is sometimes alone; at others, it is mixed with "rounded 
pebbles ;" sometimes with "angular fragments of limestone," and at others with the same, "rounded by attrition ;" in some Caves, the same diluvial waters, deposit in the mouth of those flues, pebbles of quartz, or of granite; in others, they leave none, but in their place, cast in angular pieces of "slate," "bralls of ironstone," "manganese," "oclere," and concentric balls if ochere," \&c.

2. Now let any person of plain understanding ask himself here, whether "sand, earlh, and clay" actually separated and "strATIFIED" in the same Cave, do not prove, if any thing is to be proved from the evidence of analogy, that this sand, earth, and clay, were introduced into this Cave at different periods, or by different means? Let it be noted that "sand, earth, and clay," when mixed together, form precisely the "loam" of which our author says so much. These sand, earth, and clay could not be brought into these Caves separatezy. This is evident. First; From the reasons before stated respecting the "loam and pebbles" in the Caves. Secondly; From the consideration that the diluvial water could not possess itself of them separately; and because it would destroy the identity of the "diluvial loum" if it could.-.-It could not be separated and "stratified" by the diluvial waters after their arrival in the Caves. First; Because this "loam" has, in itself, no tendency to separate and stratify. Secondly; Because, the "diluvial waters," when in the Cave, would become "quiescent," and are constantly supposed by Dr. Buckland to have been in a "quiescent state," when they deposited this "diluvial loam ;" therefore they could 
posssibly deposit sand, and then earth, and then clay in different places, or in different elevations!!

3. But what are we to say of the ochre and manganese? "Ochre," "manganese," "and balls of ironstone”" of " diluvial origin !" Where did the diluvial waters obtain them? The sand, gravel, and pebbles Dr. Buckland ascribes to the rending power of the Deluge upon the rocks, and their attrition against each other, and against the rolling waters. But out of what rock did those waters wash the "ochre" and the "manganese?" Did the Deluge bring them from Scotland or from Norway, along with the granite pebbles, which it brought from thence?-Where is the matrix to which this ochre can be traced? And how shall we account for its coming? When tumbled along with the torn-up-rocks and stone, diluvial mud and gravel, how did those turbulent waters separate this "ochre" from this diluvial mass, and place it in these Caves, fit for the market as a pigment of traffic! Certainly no person, not deluded by Theory, and who wishes to retain a character for a sound mind, will give credit to an opinion so truly ridiculous.

But if this "ochre" and "manganese," \&c., \&c., are "clearly of diluvial origin," how is Dr. Buckland to find out the identity of the "diluvial deposits?" He could not more readily expose his Theory to certain destruction, than by insisting upon the diluvial origin of these things, and of their being introduced into the Caves by the waters of the Deluge. As well might he ascribe the "manganese" found in "Lord Barrington's gravel pits in Sedgfield, in the county of Durham, to diluvial origin. (71.) As well might 
he ascribe the lead and tin ore found in the fissures of the rocks, the iron which often pervades the whole mass of the stone, or even the "iron and brass" of which we read before the Deluge!! But I should probably be thought to have imbibed this diluvial mania were $I$ to think it necessary to enlarge upon the proof that things so perfectly and obviously postdiluvul, are not to be ascribed to the operations of the Deluge.

II. The situation of their contents.

The contents of these Caves are so arranged and so circumstanced with respect to each other, as to prove irresistibly that neither their contents nor the Caves were in existence at the Deluge.

I. The loose and moveable character of these contents. Dr. Buckland speaks of the Cave at Wirlisworth as being a large cavern, and communicating with the surface by an almost perpendicular funnel, big enough to admit a rhinoceros whole. This Cave, he says, was "filled entirely to the roof with a confused mass of argillaceous earth and fragments of stone." In the midst of this mass lay the skeleton of a rhinoceros, with numerous other bones. The whole mass was "loose," and "subsided," as the workmen attempted to dig their way through it.

1. These contents could not possibly be so deposited and so left by the Deluge. This Cave, 50 or 60 feet in depth, when the diluvial waters were at their height, would have to sustain the weight of a column of mud supplied by these waters, 28,000 feet in depth, and loaded, as we have seen they must have been with detritus. This slimy mud, probably 
twice as heavy as the water which hurried it into these Caves, would necessarily subside, and fill every cavern and every crevice accessible to water, while the "stones" and "bones" would have made their way hastily to the bottom. This is the infallible test of all our Theory, that stones universally sink to the bottom of the water, wherever they are at liberty to do so. But these, had they been drifted into these Caves by the water, would have been at liberty to sink in it.

2. But this mass of detritus, "gravel and sand," and "fragments of stone," would certainly, as we find they always do, have gone together, by the uniting character of the water, into a solid mass. For what are the "breccias" to which Dr. Buckland so often alludes, but such materials as these united by a "stony cement ?"

II. The peculiar location of these contents in the Cave of Hutton, in the Mendip hills.

1. The description of this Cave is given by Dr. Buckland from Mr. Cattcott's M.S. notes. But our author makes it subservient to his Theory of the Caves and of the Deluge. There are found in this Cave, bones, horns, and ochre; of these, the Doctor says, "It appears most probable from the description " given of these bones, that they were not dragged in " by beasts of prey, but either drifted in by the dilu"vial waters, or derived from animals that had fallen " in before the introduction of the ochreous loam. "The loam itself, and pebbles, are clearly of diluvial " origin." (60.)

2. Now, what I have got to say on this subject is, that the location of these contents, as described in 
Dr. Buckland's pages, infallibly proves that these bones and this ochre were not, as is here supposed, of diluvial origin. The description begins with the vegetable mould on the surface of the ground, and proceeds downwards into the cavern. It is as follows.

"Thus, in opening the pits, the workmen, after " removing 18 inches of vegetable mould, and 4 feet of " rubble ochre, came to a fissure in the limestone rock, " about 18 inches broad, and 4 feet long. This was " filled with good ochre. It continued to the depth " of 8 yards, and then opened into a cavern about 20 "feet square, and 4 high. The floor of this Cave " consisted of good ochre, strewed on the surface of " which were multitudes of white bones, which were "also found dispersed through the interior of the " ochreous mass. In one of the side walls was an " opening about 3 feet square, which conducted " through a passage 18 yards in length, to a second "cavern 10 yards in length, and 5 in breadth: both " the passage and the cavern being filled with " ochre and bones." "Another shaft was sunk from " the surface perpendicularly into (a branch of these Caves, about 20 yards from that last described,) " which passage, to the depth of 30 yards, was filled with " rubble, large stones, ochre, and bones." $(57,58$.

(1.) These ochre, \&c., were not of diluvial origin, it is perfectly demonstrable, for then there would not have been clean good ochre in one of the chambers of these apartments, and nothing but rubble, stones, ochre, and bones, in another. On this we need not enlarge.

(2.) Another infallible evidence is this. A chimney 
$1 \frac{1}{2}$ feet by 4 feet, led, by a " descent almost perpendicular," "the depth of $S$ yards," into a "cavern 20 square, and 4 high." The phenomena exhibited here are remarkable. The chimney was "FILLED with good ochre;" but the Cave below this chimney had ochre only on the floor." This is positively incredible upon the diluvial Theory. The size of this chimney, leading into the Cave below, was 18 inches wide, and 4 feet long; that is, about the area of six modern chimney flues, which are usually 9 inches by 14. It is utterly impossible that this chimney should have been "filled" with ochre taken in by the diluvial waters, without the "Cave" below it being filled also. For, certainly, its own gravity would have made it subside into the Cave, before it could, by possibility; fill the chimney above it. The magnitude of the chimney forbids any supposition of obstruction to the descending waters with their ochreous and loamy contents.

(3.) Again. The "bones" are said to have been "strewed on the surface" of the "orlire" which lay upon the "floor" of this Cave. It is periectly out of character, then, that these bones should have been " either drifted in by the diluvial waters, or derived from animals which had fallen in before the introduction of the ochreous loam," as Dr. Buckland's Theory leads him to imagine. For had they been drifted in by the diluvial waters, and still more had they been previously deposited in the Cave, they would beyond all question have been covered with the loam and not have been "strewed upon the surface" of it. Indeed Dr: Buckland himself so particularly dwells upon the evidence derived to his Cave Theory, 
from the circumstance that the "bones" in the Cave of Kirkdale, \&c., \&c., are only found beneath the "diluvial mud," and not above it, that I feel myself utterly unable to reconcile these statements, or to account for the adoption of positions so contradictory to one another. It shews either the bewildering power of Theory, or the extraordinary want of attention to the points under consideration.

III. The Cave at Wirksworth is another instance of the extraordinary absurdity of which we are treating. It is situated in the face of a very high cliff. Yet the diluvial waters had power to raise into it an "enormous deposit" of "ochreous mud." These powerful waters could only raise "pebbles" into the "mouth" of this Cave, but did not drift them into the Cave itself. And though the "ochreous mud" be an "enormous deposit," it is extremely variable in its quality. It " in many parts is sufficiently pure to have been extracted for sale."-Could this then be diluvial ? Impossible!! (65.)

Some of these caverns are filled up with very different kinds of materials, and in very different ways ; shewing doubtless the various modes in which they have obtained their contents. In some "the vaultings and cellarage" are choaked up, while the " upper chambers" are comparatively empty. In other caverns, it is exactly the reverse; the "fissures" both vertical and lateral are filled with mud, \&c., while the "caverns" are only filled "partially." (110, 111.) All this is consistent with natural and usual occurrences, but for an universal Deluge, carrying with it such "enormous deposits" in its waters, and which 
gain ready access to every one of these Caves, and that to their full extent, to leave such partial effects behind-One Cave filled, and the chimney leading into it, empty; while the next chimney is filled, and the Cave below it, nearly empty - are operations utterly inconsistent with every analogy, and which Dr. Buckland has not explained, nor is likely to explain consistently with reason, with history, and with experience.

IV: Biels Cave.

1. This Cave presents us with a feature in Geology which will prepare us to expect any thing, however contrary to nature, (supposing the Theory require that it should be so), as the result of Geological investigations. Its floor is extremely uneven. There is a vault and then an interruption, like a wall, thick at bottom and narrow at top, dividing the first from a second vault; and the same between that and a following one; so that the Cave presents a series of deep hollows separated from each other by lofty narrow ridges. The roof of the Cave, its height or its form, does not appear to be described, nor is it, perhaps, material. These elevations or intervening walls, Dr. Buckland denominates "pinnacles." They are obliged to be passed by a ladder.

2. It is in this Cave, concerning which our author tells us he was enabled to "identify" "the same bed of diluvial mud." This mud was found "alternating " also as it does at Plymouth with thin beds of blue clay " and coarse sand, mixed abundantly with small frag" ments of greywacke slate and clay slate; and some" times, it seems, with "pebbles." Now, the extraordinary part of this description is the following. 
"It is remarkable that this diluvium is accumulated " on the top of the pinnacles, in nearly as great quan" tity as in the intermediate basins; and here again "we have another analogy to the Caves of Plymouth; "viz. that wherever there was a ledge, or shelf, or " basin, however minute, whereupon there was space " enough for the smallest deposit to take place, from " a mass of water loaded with mud and sand, there " these materials have found a lodgment, and have " ever since remained undisturbed, under a gradually " accumulating crust of stalagmite." (123.)

3. This description of Biels Höhle is fatal to the diluvial Theory of these Caves. Dr. Buckland says, "It is remarkable that this diluvium is accumu"lated on the top of the pinnacles,-nearly-as in the "basins!! I feel surprise that this "remarkable" circumstance did not startle Dr. Buckland, and make him reconsider his Theory, or retrace his steps.. Notwithstanding, however, it was remarkable, it bears " analogy to the Caves of Plymouth," a proof, surely, that neither of them is diluvial. There is no analogy in nature which can be brought in support of so " remarkable" a phenomenon.

(1.) It is directly contrary to every known operation of nature. "A mass of water, loaded with mud and sand," universally deposits the contents which it possesses, horizontally. Every fact derived from "chemical and mechanical science," bears testimony against Dr. Buckland's hypothesis. The gravity of this mud would have infallibly caused its own subsidence, till the "basins" were filled as high as the "pinnacles ;" then, an even surface would be found at top. 
(2.) This principle of muddy lodgments would subvert the foundation of the Theory both of $\mathrm{M}$. Cuvier and Dr. Buckland. Their Geological Theory is no 'Theory, but upon the supposition that all deposits in water are "necessarily horizontal." But the hypothesis of this Cave, and of those at Plymouth, would introduce an entirely new principle into the philosophy of Geologists ; and would render it probable that all, or most of our " inclined," or greatly irregular and uneven strata were so deposited. Then the Theory - the whole system of "horizontal" formations and subsequent revolutions - is at an end!!

(3.) If Dr. Buckland should say, the diluvial waters must be exempt from the usual mode of judging from the cases of water generally, and that we must ascribe to such a singular phenomenon results which are " remarkable." To this I would say, there are two destructive consequences entailed upon such a licence. First, It would justify those who interpret the Scriptures literally, and thence ascribe all the fossil strata to "diluvial operation." Secondly, It would establish a principle, in diluvial operations, which would be ruinous to Dr. Buckland's Theory of the Caves in another direction. It would prove that the diluvial waters deposited their mud under an exemption from the laws of lateral pressure and horizontal subsidency.

New LAw.

1. The consequence of this new law would be, that the mud or deposit in every Cave, exhibiting diluvial introductions, ought to be in proportion to the depth of the water, without regard to the form of the floor or pinnacles upon which it was deposited. 
I repeat that this would be the case. For the water could not have carried the mud to the top of these "pinnacles" without holding it firmly in suspension till it became quiescent. Then the water would deposit, in time, all the mud it held in possession; and this without that mud being subject to lateral pressure or horizontal depression. The result must then be, that as deeper waters would suspend proportionably more mud, the depth of every deposit would be in proportion to the depth of the water. No exemption from this conclusion can be pleaded on account of the diluvial water being sooner removed from Biels Cave than others. For, the fact is, Biels Höhle is so formed that the water must either be absorbed by the rock, or filtered through it, there being no other way for it to get out of such a well. So that the "mud" upon the "pinnacles" would be kept soft, and therefore moveable by the waters a great length of time; for years probably, or rather centuries!!

2. This law would enable us to find, in the same Cave, mud many times deeper in one place than in other, although the floor were level, supposing the top were otherwise. Where, then, we find in the same Cave a lofty roof in one part, and a low roof in another, we shall, by this law, obtain a proportionable quantity of mud; for, by the very character of this new law, the mud does not subside into a horizontal position.

KIRKDALE Cave, then, for instance, would be many times as deep in mud in one part as in another, because it is many times as high. Where also the floor was even, and the roof very full of elevated domes 
and "pinnacles," so would the top of the mud be in the Caves under these domes and pinnacles; because this new law supposes the mud to rest permanently in the spot where it was let fall by the diluvial water. But here we see the ruin of this new law, or of the diluvial Theory. For no Cave is ever described as being of this form in the top of its mud; and Kirkdale, especially, is particularly stated to be nearly level on the top of the mud upon the floor. So that one must be erroneous. Either Biels Höhle and Plymouth Caves do not support this laze and are therefore not diluvial, as the hypothesis supposes, or else Kirkdale Cave and many others are not diluvial, because they do not exhibit a conformity with this diluvial law, established by Biels Höhle and Plymouth.

To say here that the diluvial waters were arbitrary and subject to no regular law, is, in other words, saying that we choose to ascribe this mud to "diluvial operation," because it pleases our fancy, and therefore we do not wish to ascribe it to reasonable and natural causes, because, in many cases we should be unable to assign them.

\section{Gailenreuth.}

1. That the arrangement of the materials in this Cave are not of diluvial operation, is, I think, as demonstrable as that the collection in the British Museum is not. I shall not insist upon the extraordinary discrepancy between the depth of "diluvial mud" in this Cave and that of Zahnlock, which is but 5 or 6 miles distant. This Cave, though in some parts, 20 feet high, contains, in this description, only 3 or 4 feet depth of mud; while that of Zahnlock has 
the same quantity in a Cave but 6 feet high ; beside this latter Cave is 600 feet above the valley while the former is not more than 400. I have before shewn respecting the pebbles in this Cave that they could not possibly be of diluvial introduction, as they are very far removed horizontally, from the mouth of the Cave, and had to go over high obstructions into the farthest wells which they chiefly occupy. But now we must notice the relative location of the bones, mud, and pebbles.

2. The description of these materials respects the third Cave, the way to which leads through two others much larger ones. Its size is not mentioned, but it appears, in the plate, to be quite as large as a common parlour; and it is 25 feet in depth. Dr. Buckland thus describes it;

It is composed of "a breccia of bones, pebbles, " and loam, cemented by stalagmite," "and accu" mulated in a heap of at least 25 feet in depth."This distribution of the component materials of this " breccia is irregular; in some parts the earthy matter " is wholly wanting, and we have simply a congeriès " of agglutinated bones; in others, the pebbles abound ; " in a third place, one half of the whole mass is loam, " and the remainder teeth and bones: at the top and " the bottom of the well, pebbles and bones occur " mixed together in the same proportions as in the " middle regions of it." "I could no where find any " thing like the black animal earth described by pre" ceding observers."

"All these phenomena are in perfect harmony with " those of the other Caves in Germany and England." 
"The diluvial waters rushing, as they could not fail " to do, into these caverns, would introduce the peb"bles and mud, and would also drift down to the "lowest recesses the bones that lay perhaps more "equally distributed than they do at present." $(136,7)$

That this mass of mud, pebbles, bones, and teeth, were thus placed by the Deluge, is incredible, and without a miracle, impossible. For

(1.) These materials, the Theory supposes, were carried into this well by the rushing waters of the Deluge. The waters would have to pass through two previous chambers and passages 50 or 100 feet from the mouth, and over a barrier several feet high. The mud, \&c. in the first Cave, would therefore be at least equal to that in this well. But in the first it is only 3 or 4 feet deep, though the Cave be in some places 20 feet high. It is certain, then, that whatever weighty materials, as " mud, stones, and bones," this rushing water forced into this deep well, would have liberty to move, by the force of gravity, and that they would therefore, certainly subside, and fall to the bottom of the well.

(2.) But this is by no means the case. The bones, pebbles, and mud, are not only loose and moveable, but actually separated from one another; and this not according to the laws of gravity, or affinity; or according to any existing laws, but positively against them all. In some parts, the "eartlyy matter is wholly wanting !" ".. This is certainly impossible unless by subsidence; and then it would have been lodged at the bottom of the well, filling up every hole and cranny found among the bones and pebbles...." In 
others the pebbles abound." What ! separated from the diluvial mud and bones with which they were hurried into the well ? Impossible! unless by graviiation. But they have not sunk in the mass, for they are in the "same proportion" at the "top" as at the "bottom" of the well._" In some parts, there are nothing but agglutinated bones." Impossible! unless the mud and pebbles had subsided from among them. But that they have not, for the "pebbles" are as numerous at the top as at the bottom!

I would therefore observe, First, that from the universal laws of gravitation, it is physically impossible these mud, bones, and pebbles, could be thus separated and assorted by being carried with the diluvial waters rushing into this well.

And secondly, That the perfect consistency of all these phenomena with the usual appearances of modern occurrences, in pits and Caves, is strong evidence that they are of later epochs than that of the general Deluge.

VI. The animal Cave,-the Cave of Kühlock.

This Cave as Dr. Buckland observes " is more remarkable than all the rest," from the circumstance that " the animal remains have escaped disturbance by Diluvial action, \&c." This Cave is situated within 30 feet of the bottom of a gorge which is between 150 and 200 feet in depth. The entrance is 30 feet broad, and 20 high ; but the cave itself is 40 or more, and about the area of a large church, and 100 long. The floor of the entrance rises for about 30 feet, and then suddenly falls again into the body of the Cave. It is covered with black animal earth to the 
depth of 6 feet, containing about 5000 cubic feet in the whole; and is supposed by our Geologists to have been a death-bed for 2500 bears, of whose decayed bones this black earth consists. "The Cave is so dry " that the black earth lies in the state of loose powder, " and rises in dust under the feet." "I could find no " rolled pebbles." The upper portion of this earth seems to be mixed up with a quantity of calcareous " loam," which Dr. Buckland states, must be referred " to the diluvial waters" for its introduction. $(138,140$.

There are two points here of peculiar importance which the author takes some pains to reconcile with his statement of the powerful and violent action of the diluvial waters ; viz. 1. "The absence of pebbles;" and 2. "The enormous mass of animal dust."

1. The absence of pebbles."

Dr. Buckland supposes that the diluvial waters tore away the rocks above this Cave to the depth of nearly 200 feet, and made the gorge in which the Cave is situated, about 30 feet above the river, which runs in the bottom of the gorge. But he still supposes that the rising floor of the entrance would prevent "pebbies" from going into the Cave, and the animal dust from coming out.

This, however, can never be admitted. For we have seen that, according to Dr. Buckland's Theory, several Caves vastly less accessible to pebbles than this is, have abundance of pebbles, even in their most distant recesses.-Besides. The Caves of Zahnlock, scarcely two miles from this, and 600 feet higher than this Cave is, above the same valley, contains "numerous pebbles." It is not possible that the waters 
which raised the pebbles 600 feet up the hill on the other side the valley, should be incapable of raising, or rolling pebbles, 30 feet up an inclined entrance, on this.--Again. This Cave is in Germany, and it was in Switzerland, just by, where our author supposes these waters to have moved blocks of granite from Mount Blanc to Jura, 50 or 60 miles, one of which weighs many hundred tons weight. - This inclined entrance, therefore, is certainly no valid reason why this Cave should not contain diluvial pebhles as well as others.

2. The presence of an "enormous mass of animal dust."

(1.) Dr. Buckland represents this mass to be 6 feet deep, and only the "upper portion of this earth seems to be mixed up with a quantity of calcareous loam," or "diluvial sediment."

It is plain that this cannot be "diluvial sediment," for many reasons. The surface of this rock before it was denuded by the diluvial waters, was 400 feet lower than the Cave at Zahnlock, which skirts the same valley; and which is half full of "diluvial mud." This Cave, then, ought to have had 20 or 30 feet depth of mud in it, while it does not seem to possess 30 inches!-But, before denudation, this Cave was about 200 feet under ground. Then it would have receivel, had it been diluvial, the sediment of $200 \mathrm{feet}$ depth of water; for the whole would have subsided to the lower vaults of course, the last of which was this Cave. If then we take Zahnlock as our example, which is 400 feet higher than this Cave, "and forms one of the most elevated points of this district," (1.30) we shall find that this Cave and the passage leading to it from the surface, would have been choaked up with diluvial mud to the height of 100 feet!!! 
(2.) The "bones" now (greatly) crumbled into "light dust," could not have decayed thus before the Deluge, being in a "dry" Cave, and 200 feet deep in a solid rock. Nor could they have become so after the Deluge, because, as Dr. Buckland constantly remarks respecting the preservative character of the "diluvial mud," the vast covering it must have received, would have preserved them.

(3.) But the very supposition that 2500 bears retired into this hole, 200 feet beneath the surface, in order to die here in succession, is unnatural, and void of all example. I admit that many animals " retire and hide themselves on the approach of death." But I never heard of an instance of animals retiring to die in a Cave where scores, hundreds, and even thousands, of their own species, were dying, or dead, or in all possible states of putrefaction and decay!!! I believe many of us have known the carcasses of less than half a dozen vermin to banish, for a length of time, the whole race of them from the premises.

(4.) Again. Dr. Buckland supposes that the diluvial waters would denude this valley, and tear up this solid limestone rock 200 feet, and yet leave the " light earth" in this Cave, unmolested. With respect to narrow denudations by the Universal Deluge, we have seen, that it is quite out of the question. But admitting Dr. Buckland's hypothesis thus far, what are we to say respecting the effect of such powerful waters in this Cave? Our author contends that these valleys were cut down by the Deluge, and that such events as " the bursting of a dyke in Holland, or of the barrier of an Alpine Lake," are, when compared to the diluvial action, "trifling causes." Now when the 
Alpine Lake burst which occasioned the Deluge of Dranse, as it was called, the water rushed down at nearly 20 miles in an hour.

If then the diluvial waters could be supposed to move at the same rate, and be confined to this channel, possibly they might cut it out to the depth of 200 feet. But then, when rushing by this Cave, their denuding power would be as great on the sides of the channel as upon the bottom. Then when it was tearing up the bottom, it would have torn away the side jambs of this Cave, and the "light eartll" would have floated away like corks on the water.

Besides. The diluvial waters, moving as they "retired" from off the earth, in this violent and rapid manner, would have utterly passed off from this elevated ground, and it would have been left dry, in little more than a quarter of an hour. Instead of this, however, the diluvial waters were 275 days in relurnıng!! - If we say that the waters rushed down and returned, we insure the denudation of the side rocks in return, and endanger the emptying and filling. of this Cave many times; by which operation it is impossible this "light earth" could have remained " $u$ nmolested!!!"'-1 forbear to say more.

Upon the whole; I am not aware of many things which sensible men could embrace, fraught with more gross and palpable absurdities than the Theory which supposes that 2500 bears died in succession in this Cave before the Deluge, and that this NARROW gorge was CUT ouT by an UNIVERSA I flood from the solid rocks, while the "light earth" lay UNMOLESTED all the time in the Cave on the margin of its current!!! 


\section{CHAPTER V.}

\section{DR. BUCKLAND'S THEORY OF THE CAVES.}

EVIDENCE AGAINST IT.

WE observed, when commencing the examination of Dr. Buckland's Cave Theory, that when we had removed the evidence on which he rests his hypothesis, we might make the Scriptural data bear upon the subject. But as every part of these extraordinary diluvial fancies is capable of a direct overthrow. upon its own principles, I thought it right, upon those principles, to remove the professed grounds of evidence upon which our author rests his system. And what I shall now advance is indeed of a somewhat similar character; viz. partly derived from Scriptural data; partly from the obvious consequences of the Theory itself.

The efFect OF Diluvial OPERATION ON these Caves.

It is a certain consequence of the Scriptural representation of the out-breaking of the waters of the Deluge, for the issues of which "all the fountains of the great deep were broken up," that the rocks in which these Caves are situated, would, (had they been there at the Deluge,) have been "broken up" and rent to pieces. 
Their nature, and situation, in connexion with what Dr. Buckland supposes to have been the effect of diluvial action in their immediate neighbourhood, and even in these rocks themselves, make the application of Scriptural principles peculiarly appropriate and conclusive.

I. As it respects the out-breaking waters.

There are three particulars, connected with these rocks, peculiarly worthy of notice:-1. The waters which issue from these rocks.-2. The porous and hollow state of the rocks themselves. -3 . The destruction which Dr. Buckland supposes the diluvial waters to have effected among them.

1. The fountains issuing from these rocks.

Dr. Buckland states that with respect to the Cave rocks of Germany, there are many of them, (as in Franconia for instance), situated at or near the greatest sources of water in Europe. "The position of this " district (he writes) is at one of the great water heads " in central Europe, from which the streams descend " on one side southwards, to the Naab and Danube, " to the Black Sea, and on the other, by the Mayne "and Rhine, to the German Ocean." (124.)

Dr. Buckland also thus informs us with respect to the situation of the Cave rock at Kirkdale in Yorkshire; "This limestone is intersected by a succession " of deep and parallel valleys (here called dales) through " which the following rivers from the moorlands pass " down southwards to the Vale of Pickering, viz. the "Rye, the Rical, the Hodge Beek, the Dove, the "Seven Beek, and the Costa."

2. The porous or cavernous nature of these rocks. 
Of the aforesaid German Cave-rocks, Dr. Buckland says ; "The limestone of the immediate vicinity " of Muggendorf has been, from its cavernous nature, "locally designated by the name of Höhlenkalk (Hole Limestone.') (124-5.) And of the rocks in Kirkdale, he writes thus. "The abundance of such caverns " in the limestone of the vicinity of Kirkdale is evi" dent from the fact of the engulfment of several of " the rivers above enumerated in the course of their "passage across it from the eastern moorlands to the "Vale of Pickering."

3. Respecting the diluvial action which Dr. Buckland considers to have taken place in these rocks; we have before noticed its occurrence, and considered its impracticability. All we have here to remark is the fact of those operations, agreeably to Dr. Buckland's Theory. Denudations, he supposes to be common in the neighbourhood of the Caves:- The tearing up, even of "transition" rocks in their district and forming them into pebbles:- several of these Caves are themselves, supposed to have been literally cut through by the action of the diluvial waters upon the rocks which contain them.

Here we learn that the German Caves are particularly porous, and their rocks are at the fountain head of European rivers. In Yorkshire, we are informed that there are six rivers sent out from a district of about 30 miles in the moorlands, where the Kirkdale Cave is situated. Concerning all which I would observe that, had these rocks been circumstanced at the Deluge as they now are circumstanced, and as Dr. Buckland's Theory requires them to have been, the 
diluvial waters would unquestionably have burst through all the fissures, caverns, and fractured places in these rocks, and made dreadful desolation, probably utter destruction to the rocks where the Caves are situated. The rocks would have been nearly blown up by their violent issuing : and no reasonable man could possibly expect to find any Cave to be quietly left as the Deluge found it.

If these districts are so peculiarly abundant in issuing waters, and if the rocks are sọ remarkably hollow and full of caverns, as even to "engulph" and swallow up rivers which traverse their uplands, it would be next to insanity to believe that when "all the fountains of the great deep were broken up," these "fountains" should have remained undisturbed, and these Caves received the diluvial depositions with as little disturbance as in a Chemist's laboratory: yea, and that the retiring waters which, according to Dr. Buckland, tore up the rocks in the midst of those Caves, full 200 feet deep, should nevertheless relinquish their possession of these worlds under ground, without committing any devastations in their retreat!!

If these Caves and Fissures are what they were at the Deluge, the fountains and rivers must have been so too. (At least we have no reason to suppose them otherwise.) Then it is utterly incredible that the outbreaking and denuding waters could have made such havock "as miles broad and many hundred feet in depth," among solid rocks, and yet have left these hollow and peculiarly exposed Caves and strata without molestation!-I I esteem it utterly incredible that these abundantly watered districts should have had 
" all the fountains of the great deep broken up" in their neighbourhood, and all around them, and have suffered an irruption of earthy materials which would be likely to cover the whole country many 100 feet deep, and yet have sustained no change in their forms, and no deposition on their surface; and, indeed, nothing whereby the Deluge could have been known to have happened, but by a little quiet deposition of mud within the Caves and a few rolled pebbles without them!!!

II. With respect to the retiring waters.

As it is manifest that so destructive a catastrophe as the issuing waters of the Deluge would cause, must have rent and torn these porous and fountain rocks to atoms; so it seems equally evident that the retiring waters would have left behind them effects equally manifest. From the Bible we learn that the waters of the Deluge returned to the caverns in the earth, from whence they issued for its destruction. These rocks, then, and all their under ground channels, and every Cave, cavern, and fissure about them; ought to have exhibited remuants of the wreck which the Deluge had made. Every thing of a vegetable and animal character; every thing afforded by sea and land; would have found an asylum in these caverus.

It cannot be admitted, I should think even by Dr. Buckland, that the diluvial waters should have brought into these Caves diluvial loam, diluvial pebbles, and bones, and yet have introduced nothing peculiarly characteristic of the Deluge, even though its spoils were so numerous. This defect ought, with our author, to be received as infallible. SHELLs, above 
all things, would be found in these Caves, had they been there at the Deluge. For diluvial shells are found in almost every place. The gravel, and loam, and rocks, abound with them. Every one knows that a gravel pit can hardly be any where opened without shells making their appearance in it.

Besides, many of these Caves are near the sea; some of them are now within the reach of waves caused by high dashing "storms :" They all, according to Dr. Buckland, exhibit diluvial remains. Yet strange to tell; that which of all others would have been most likely to be present, and which every neighbourhood exhibits without the Caves, is no where found within them. I do not remember that Dr. Buckland, in a single instance, has noticed diluvial SH E LLS as evidence of diluvial operations in these Caves, although I think he has once noticed them as occurring. But it can never be admitted that Caves situated so near the sea, and whose whole neighbourhood is supposed to abound with materials drifted through the sea, should yet contain no sea shells nor any thing peculiarly marine!

Our author speaks of recent shells, both of sea and land, as found in some of the fissures and ledges belonging to the Caves on the coasts. But scarcely a vestige of ancient or diluvial shells is ever discovered by him!-This is so contrary to all reason and to all analogy, that it may be fairly considered as near to a demonstration. This evidence is negative doubtless. But it is not like the negative character which Geology resorts to in its own favour. That is occult, guess work, gratuitous. But this is visible and of 
nearly universal occurrence; that is, the presence of shells, wherever the diluvial operations are manifest. If we only reflect on Dr. Buckland's Theory; viz. that " the diluvial loam and pebbles" were introduced by a rush of the waters of the Deluge, and have ever since lain, in some of these Caves, to the present time unmolested, we cannot refrain from the assurance, that vegetables, fishes, shells, \&c. would have been certainly introduced in great abundance by the same diluvial waters.

I admit that these arguments apply only on the supposition of Dr. Buckland's Theory so far as it respects these Caves. For, on Scriptural grounds, the Caves, had they been there at the breaking out of the Deluge, could only have been furnished with such portions of the wreck as the earliest operations of the Deluge would have produced, agreeably to what we before observed respecting the introduction of mud and pebbles of diluvial origin ; unless, indeed, we could suppose that the rushes of the diluvial waters would have brought materials over the mouth of the Caves, which would have slid into them by the force of their own gravity. But it is reasoning which is good and applicable against his Theory. And it is applicable to every place among these rocks into which the waters of the Deluge would have returned. For then the diluvial wreck would be lodged in every one of their recesses. And these effects ought to be expected in some proportion to the watery character of the neighbourhood, and the porosity and cavernous nature of the rocks,

But as there is nothing whatever peculiarly diluvial, 
or which carries its own evidence with it that it is so, in any one of these Caves, or in any of the cavernous portions of the earth connected with them, we are obliged to reject the Diluvial-Cave Theory altogether as having No EvIDENCE in its favour, and every possible evidence A GA INST IT.

\section{INFERENCE.}

One important inference is to be derived from the subject as it now stands before us. We perceive that the $\mathrm{C}_{\Lambda}$ V Es whose contents are esteemed diluvial, have nothing peculiarly diluvial in them; but the rocks have. The rocky substance which contains the Caves is furnished with shells which we should have expected to be in the Caves, and not in the rocks which inclose the Caves. But as they are found imbedded in the rocks, and not enveloped in the diluvial mud in the Caves, the infercnce is, that the rocks are THEMSELVES of diluvial origin, and not the CONTENTS of the Caves.

SUPPOSED ORIGiN OF THE MUd AND PEBbles in the Caves.

It is plain that the mud found in the Caves can, on no pretensions, be esteemed of diluvial introduction, if it can fairly be accounted for otherwise. If, indeed, we could not account for its introduction, we should not be authorised, without evidence, to ascribe it to the Deluge; much less in the face of positive proof of its error. But, it is clear, that the mud may be accounted for, with perfect ease, upon natural principles, without resorting to any hidden, 'distant, or inconsistent causes of its introduction. There are many ways in which dirt, dust, earth, and mud, might have entered these 
Caves; yea, must have entered them, to some extent. We may observe, to prevent mistake, that the pcbbles could not get into the distant and retired vaults and chambers by precisely the same means as the mud, whether that were considered to be the Deluge, or otherwise.

1. Rains and wind might carry or wash earth and dust into the Caves, many of which have, and alwavs had, mouths sufficiently exposed for that purpose. It seems impossible that Caves, in some situations, should have large entrances, were they even lateral entrances, without being subject to clouds of dust. And it is perfectly incredible that heavy rains should not have washed down through the fissures and vertical mouths of the Caves considerable quantities of earth from without. And as these Caves became enlarged, and fissures and cracks began to open to the surface, no one can say how dirt, loam, or pebbles, or bones, might be hurried down from above.

This, as one mode of admission, exactly corresponds with what Dr. Buckland observes about the loam within the Caves being in "agreement in chemical composition" with the loam roithout, in the adjacent neighbourhood of the Caves.

2. "Dust fallen from the decomposition of the roof," and mud arising from the wet dripping through it. Dr. Buckland writes as follows respecting portions of the roofs in the Caves.

"Caves in limestone are usually more or less con" nected with fissures of the rock in which they exist, " and the solid matter which once filled them, appears, 
" in many cases, to have been carried off through the " fissures by a long continued and gradual percolation " of water removing the softer or decayed portions of " the rock, either in a state of solution or mechanical "suspension, so that no traces remain either in the "Caverns or fissures." (Note, p. 5.)

What Dr. Buckland says here about water dripping through the roof and "removing" these decayed portions out of the Cave, so that " no traces" of them remain, is incredible in any case, and in most cases, impossible. For the Caves, in almost every instance, descend considerably from the mouths inwards; so that percolating water could not wash one particle out of the Cave's mouth. And to suppose it to have been "removed" out of the Cave by being washed through the floor, is quite out of question. For had water been capable of washing the decayed parts of the roof through the fractured parts of the rock, the diluvial waters would have done the same to the mud which it is supposed to have carried into the Caves ; especially as those waters, when at the height, would have possessed the advantage of a pressure of miles depth of flood above them.

Besides, such Caves, as Zahnlock, Kühlock, andKirkdale, which offer the least obstruction of almost any Caves to the emission of mud from within, have in reality the greatest body of mud in them; thus leaving it exceedingly probable that the reverse of Dr. Buckland's supposition is the truth, and that mud has actually been washed into the Caves instead of out of them.-But it is not surprising that our author should suppose that water has actually washed into the Caves 
and out of them again, considerable portions of the decayed roof, while he denies that any waters save those of the Deluge could possibly have access to the Caves? If water could do the one without the Deluge, it surely could effect the other.-The case is clear. The decayed portions of the roof have certainly furnished a part of the mud which he finds in the Cave. For when it once fell from the top it had no possible means of getting away through the floor.

To be sure it would be instant death to Dr. Buckland's Theory to admit this. He therefore risks the boldest and most unaccountable suppositions. I am aware that he tells us the "mud" within the Caves does not agree in "chemical composition" with the roof. But there are many answers to this objection. 1. The very transition from a healthy to a "decayed" state, would cause some change in the "chemical composition" of the roof. The decayed parts are supposed to be soluble in water, which the remaining parts are not, except in a very slight degree. 2. There is actually found upon the floor, by Dr. Buckland's own admission, no small portion of the same materials with the roof. He tells us with respect to Kirkdale Cave that the "loam" was " mixed with much " (note, much) calcareous matter which seems to have " been derived in part from the dripping of the roof, "and in part from comminuted bones." (10.)

Thus we learn from our author's own description of the composition of this diluvial mud, how easily mud may, and actually does get into the Caves independent of the Deluge.

Again. Had this mud been introduced at once 
into this Kirkdale Cave, as Dr. Buckland contends at large that it was, the decomposition from the roof and from the comminuted bones, would have been benerth the "diluvial mud," or above it. It could not possibly have been "mixed" with it, as we find it was. If the contents of these fissures were washed into the Caves by "gradual and long continued percolation of water," it is impossible that the deposit could go away as it fell: for the very character of a slow dissolution is utterly repugnant to such an idea. It could not go through the floor; for even the intimate solution of the carbonate of lime lodges upon the floor in the character of stalagmite, and does not descend lhrough it.-Nor could there be, by the very supposition, water enough to flood the Cave and so float out this mud, for that would be utterly ruinous to the Theory, which consists in the very supposition that no waters but the diluvial waters could possibly flood the Caves!

3. "Animal carth." Dirt carried in by the animals when they dragged in their prey-decayed portions falling from the roof-loam washed through the fissures and porous parts of the roof into the Caves-dust blown in with the winds, seem quite enough to account for the mud in most of the Caves. This mixed up with comminuted bones, decayed flesh, animal frecs, \&c., would make a compound precisely of the character of that which is now found in several of the Caves. Indeed, Dr. Buckland himself admits that most writers before himself considered this deposit as "animal earth." He calls that " diluvial loam" and "brown loam" which others who had described it before him call "animal earth" and "black earth," 
This seems perfectly to accord with the description so often given, viz. that there is a deal of loose brown earth in the Caves. The dust-the drippings from the roof, - the "calcareous matter,"-and the animal earth, when dry, would form exactly the "loose brown earth" so commonly spoken of as found in the Caves. But " diluvial waters," which, according to Dr. Buckland's hypothesis, must have furnished these Caves with an aggregate of clay, gravel, sand, and pebbles would have left a mass as solid as a heap of clay or a bed of gravel.

Thus Dr. Buckland, from his own pages, furnishes a most satisfactory solution to the difficulty arising from mud and pebbles in the Caves. Pebbles would, not unfrequently be rolled in through the funnels or fissures, and when they once got into the Caves, animals, or boys, (since their desertion by animals,) might easily cast them further into them. Indeed, it strikes me that the numerous splintered bones which now lie under a mass of large round pebbles in the Cave called Bauman's Höhle, at a great distance from the mouth, were very likely broken by boys throwing the pebbles upon them in wantonness or play.

Every part of Dr. Buckland's description of the contents of these Caves is consistent and natural, on the supposition that these mud, pebbles, \&c., were, in many of these cases, introduced in ordinary ways, and by ordinary means. I suppose no pit, well, or Cave, was ever left open long together in situations where men, animals, or elements had access, without partaking of the contents of their neighbourhood.

(For 
Dr. Buckland expressly asserts that the loam within the Caves corresponds with the loam without.) Much less could we suppose that those Caves should escape the materials from without, which were frequently inhabited by living creatures whose very mode of living on prey, would have a constant tendency to introduce filth into them, but to carry nothing out.

"Rock Basins."

Connected with Dr. Buckland's denudations and his Caves, is the singular circumstance of rock basins. His Theory which respects not only the action of diluvial waters, but of modern waters causes him to adopt the following hypothesis relative to the excavating of rock basins. He also quotes from Major Inrie a description of similar basins, made in a similar way, upon the summit of the rock of Gibraltar. Dr. Buckland describes the front of the Cave of Paviland, which has three or four holes like basins in its entrance in this way;

He states the mouth of the Cave " to be from 30 " to 40 feet above high water mark, so that the waves " of the highest storms occasionally dash into it, and " have produced three or four deep rock basins in the "very threshold, by the rolling on their axis of large "stones, which lie at the bottom of these basins." (83.)

How extraordinary must be the nature of prejudice! Surely the force of Theory was never more manifest. How otherwise is it to be accounted for that men of understanding and science could be led into an opinion so extravagant ? The dashing of water has no tendency to cause stones to roll on their axis. This effect requires a compound impulse which, probably, nothing can produce but the power which projected and sustains 
the planets. At least we are not acquainted with any operations in nature which have such an influence. I admit that $c$ ddies and whirlpools and whirlwinds have a motion somewhat allied to the one supposed. But these have their respective local causes; and actually require hollows or basins, ready formed, as the causes, and not as the effects of their operations. But, in the instance which Dr. Buckland mentions, it would require "three or four" whirling eddies, independent of each other, though all arising from the same cause, and all within the circuit of a few feet!

As it is impossible for rushing waters to communicate the motion required, so it is impossible for such water to continue it. If the waves were a continued current, the cause of their whirling motion must be sought for elsewhere. If they were recurrent every returning wave would demolish its own performance. Nor would it be possible to retain for a moment, whirling stones in one identical spot or centre, in the midst of a flood, dashing, turbulent, and restless !This idle supposition requires, moreover, that the stones themselves, should not wear out, as they wear away the rock; or else it requires that fresh stones should be introduced in succession, into their place. And then, the sand produced by the grinding away of the rock and stones would need to be carried away, while the grinding stones continued their operations.

Major Inrie, I suppose, considers that the basin on the rock of Gibraltar was produced by diluvial operations, but Dr. Buckland views the holes in the Cave of Paviland as formed by the modern sea. It is fair then to expect that the present sea is now 
enlarging these holes, or making fresh ones. And we may hereafter have an opportunity of catching the waves and pebbles at their operations, so that some future observer will be able to describe the mode in which the dashing waters and dancing pebbles produce this singular phenomenon.

The Major, Dr. Buckland observes, examined on the summit of Gibraltar, a "rock basin" "five feet deep and three feet diameter," "the edge of its mouth he observes was rounded off as if by art"-_." its sides and its bottom retaining a considerable degree of polish." (1.57.) Doubtless this edge and these sides were rounded by art, as truly as the fonts in our churches. The basin (he adds) exhibits a "surface smoothed over (as if it had been polished,) in a way which the natural rock never presents." (131.) True; and therefore we are assured that these basins are no more the work or operation of dashing waters, (which though they would doubtless "polish," they could not produce) than is the "royal pillar" or "large insular block of stone" in a "side chamber" of the bears' den, which these animals are supposed to have "polished" by chasing each other up and down it for their pleasure. (132.)

It would not have been necessary to notice this whimsical notion of "rock basins" being ground in the stone by revolving pebbles, had it not been for the sake of shewing to what extravagancy our theoretical conductors would lead us, could we only be induced to adopt without evidence and without scruple, their wild and visionary reveries. The veriest enthusiast that ever told a tale of wonder, could never embrace 
and propagate a notion more strictly confronted by all the operations of nature and common sense, than is this hypothesis that revolving pebbles have scooped out and polished these "rock basins."-..Authors who can convert Druidical fouls into Diluvial vases, may easily be supposed to convert post-diluvial Caves, into ante-diluvial formations.

Such then is the conclusion of the discussion respecting this diluvial Theory of the Caves. There is not a rational argument in its favour, but every evidence which could be wished for against it. Like our author's Theory of denudations, it contradicts every known principle of action, and introduces fancies, miracles, and impossibilities in its place.-The following conclusions, then, may be esteemed as clearly demonstrated.

1. That Dr. Buckland's Theory of denudations, is erroneous.

- The superficial loam, clay, sand, and pebbles, were not formed by the mechanical action of the Deluge, out of primitive and secondary rocks, and transported from those parent rocks, by the diluvial waters, to their present situations.

- The valleys and narrow channels in the rocky and other strata were not excavated by the violent and rapid motion of the retiring waters of the Deluge.

2. That the Caves, excavations, and fissures, now abounding in the rocky strata, did not receive their mud, bones, and pebbles, by the action of the diluvial waters.

- The rocks themselves in which the Caves are situated, had no existence, as fossil rocks, before the Deluge. 
--The contents of the Caves, generally, may be accounted for from the post-diluvial operation of natural causes.

- And the deposits of ochre, manganese, \&c. found in some of these fissures, must, probably, be referred to the class of the Almighty's works seen in metalsearths-salt-alkalis-coal-bitumen, \&c. \&c. which are found in veins and particular spots of the earth; and for which no man has hitherto been able, in the least rational degree, to account.

3. Of pebbles, gravel, \&c, I know but little and therefore shall say little. But it is not to be controverted,

(1.) That loam, clay, and sand, existed from the Creation.

(2.) That pebbles of various kinds are formations, per se, and are even now being formed. 'Mr. Gisborne mentions in the neighbourhood of Scarborough, that he discovered pebbles forming round a kernel of clay in all stages of their progress.

(3.) There are many beds of pebbles, in the earth, independent of common gravel beds, and very different from them. There are large banks of these upon various parts of the sea shore; under the cliffs, and perhaps under the town of Brighton; and some formed into rocks of puddingstone, as in Hertfordshire. No one seems able to give any rational account of these. Dr. Buckland's hypothesis respecting chessil bank being drifted from the valleys into the sea, is, like most of his opinions about pebbles and transportations of rocky fragments, wild and unsatisfactory.

How many of these pebble-beds are antediluvial, or 
post diluvial I can form no judgment. It might seem probable that such masses as chessil bank, and the beds about Brighton, \&c. were lodged, prior to the Deluge, upon the sea shore, and thrown into their present situation by that catastrophe.-And possibly gravel beds, were local ejectments, from the rocks, partly perhaps, formed by the Deluge, and partly, very probably, concreted since that period, or before it.-These, however, are only stated as conjectures. But it may not be improper to repeat that they seem to be perfectly in character with the Scriptural suggestions respecting the Deluge.

\section{Of Shells in GRAVEl, and Clay, \&c.}

It may be expected (though much ought not to be expected) that I should take some notice of the very common circumstance of shells among gravel \&c. Some of these, as the Belemnites(or thunder-stones) are considered by Geologists to be an "extinct genus" of sea shell-fish. Whether they be indeed extinct we have I believe, seen enough long ago, to doubt whether any body knows. But if they be an "extinct genus" of shells they ought, by the imperative claims of modern Geology, to be found in the lorwest, hardest, and, as Geology esteems them, most ancient of secondary rocks, and not in clay and gravel, near the very surface of the ground. But we all know that in the most superficial soils, they are not uncommon. In some situations, they are frequently turned up by the plough.

The explanation given of this fact by Geologists, is not only unsatisfactory, but evidently, untrue. Their Theory supposes these and other extinct animals to 
have been "washed" out of ancient rocks by "diluvial waters," and scattered about the earth as we now find them. But from our discussion respecting denudations, \&c. we are prepared at once to see the fallacy of such a pretence.

1. There is no matrix or original rock to which they, or the materials in which they are imbedded, can be traced.

2. I suspect that the nature of the stone into which these shells are now turned, does not justify the assertion of their being derived from very hard and (supposed) ancient rocks. But this I must leave for the decision of men of science.

3. Their form and state, certainly forbid any such supposition. It is perfectly clear that if these shells were once imbedded in solid rocks, such as limestone or marble, as we know many are; they would be a component part of that limestone or marble. They would be as truly a part of the stone as any other part is. Hence, then, it is certain, that if diluvial waters had torn the rocks to pieces in which these shells were imbedded, as Geologists contend, they would have come to us as fragments of those rocks, and not as we have them, in their unimbedded character.

If they had been rolled and drifted ever so much, they would still have been portions of rock, though formed into pebbles, as Dr. Buckland supposes (I believe) all pebbles to have been. On the supposition that these shells were portions of rock, we ought never to find them alone, or separated from the rock. Or, if we did, it should be considered as a rare exception. As well might we expect to separate the shells from 
our marble chimney pieces. It is true, they are sometimes found adhering to other stones. And I see no reason why they should not be sometimes enveloped in them; if, when they become petrified, the accretion should form around them. But this is a perfectly different thing from the petrifactions in marbles.

Besides. The sharp edges of shells in gravel are usually blunted and broken off, as shells rolled about among themselves, or other hard materials, might be supposed to be. But if they were washed off from rocks, it would be perfectly accidental what part of the shell became worn, or whether any part of it. But this hypothesis is so perfectly merged in the general Theory of Modern Geology, which we have many times over seen to be absolutely void of foundation, that I need spend no more time in its refutation. I would only observe, in conclusion, that we may well be content to be ignorant respecting the formation of most, or all " petrifactions." They seem to be greatly concealed from us. We, however, have the satisfaction to be assured from the preceding discussion, that we know just as much about them as our Geologists. 


\section{CHAPTER VI.}

\section{DR. BUCKLAND'S THEORY,}

THE HISTORY OF EXTINCT ANIMALS.

IT only now remains for us, so far as the Theories of Geologists are concerned, to examine the subject of "extinct animals" in the Caves, \&c. We are now, however, prepared by the discovery of such frequent instances of error among them, to hold, at a low rate, their opinions on this subject; because, however learned or well informed they may be, their erroneous Theory must always mislead them: But the numerous discoveries of fossil bones which are now continually taking place will, probably, ere long, produce an entire revolution in the systems of Geology, and prove the importance, as well as propriety of the Scriptural aphorism, "Let God be true, and every man a liar."

The reader well knows that the subject of " extinct animals" is the foundation of the modern Geological Theory; and that numerous revolutions, effected at distant intervals, in the strata of the earth, are professedly proved by the exclusive testimony of extinct animals. For the presence of different animal fossils in the strata could prove nothing but upon the assump- 
tion that those fossils are successize : but the sole evidence of succession is-" "extinct animals." But we have betore largely proved that this modern Theory has

1. No evidence fur more than ONE REVOLUTION.

2. That that revolution was the Deluge.

Few persons will now, I confidently trust, after thoroughly weighing the subjects discussed in the preceding Treatise, place any reliance on the mere assertions and assumptions of modern Geologists ; or place any dependance upon their pretences to facts, phenomena, and demonstrations; as few things ever called by those names have been more grossly abused, or the reader's confidence more lamentably imposed upon. We have seen the fallacy of their Theory, and the correctness of the Bible narrative. It only remains for us now to see if any thing can be made of the animals which Dr. Buckland esteems extinct, and in which he places so much confidence.

We shall, in this chapter, give a brief account of these animals; and, in the next, notice the probability or improbability of their extinction.

\section{THE HISTORY OF THESE ANIMALS.}

1. Dr. Buckland professes to have ascertained the following animals in the Cave of Kirkdale.

Hyæna, tiger, bear, wolf, fox, weasel, elephant, rhinoceros, hippopotamus, horse, ox, deer, rabbit, or hare, water rat, mouse, birds. Four of these quadrupeds - the hyæna, elephant, rhinoceros, and hippopotamus, are said to be EXTINCT; the other NINE, not extinct. This, indeed, is stated upon the authority of M. Cuvier. (41.)

2. The bones found in this Cave are stated to 
belong to the "same species with those that occur in " the alluvial gravel of England, and of great part of " the Northern hemisphere," In Siberia, the "regions " of extreme cold, on the utmost verge of the now " habitable world, the bones of elephants are found " occasionally crowded in heaps along the shores of the " icy sea from Archangel to Behring's Straits, forming. " whole islands composed of bones and mud, at the? " mouth of the Lena, and encased in icebergs, from " which they are melted out by the solar heat of their " short summer, along the coast of Tungusia, in suf" ficient numbers to form an important article of "commerce."

"Lieutenant Kotzebue (of the Russian Navy) dis" covered to the north of Behring's Straits, a moun" tain of ice 100 feet high, out of which a great num" ber of bones and teeth of mammoths make their " appearance when it is melted." (Rel. Dil. 46.)

This account of Dr. Buckland's respecting the bones in the Cave of Kirkdale, \&c., is referred to by Professor Jameson, in nis Notes upon M. Cuvier's Theory, and approved. He further states, that " it " is certain all these animals lived and died in the " district where their remains are now found in the " period immediately preceding the Deluge." (368-9.)

Dr. Buckland, however, goes further, and states that the animal remains were introduced INTO THIS Cave before the Deluge. Here, at least, we are at issue. The evidences upon which the Professor grounds his opinion is found summarily in the following passage.

"The general dispersion of bones of the same 
" animals through the diluvial gravel of high latitudes " over great part of the Northern hemisphere, shews " that the period in which they inhabited these regions " was that immediately preceding the formation of this "gravel, and that they perished by the same waters " which produced it. M. Cuvier has, moreover, " ascertained, that the fossil elephant, hippopotamus, " rhinoceros, and hyæna, belong to species now un" known; and as there is no evidence that they have, " at any time, subsequent to the formation of the " diluvium, existed in these regions, we may con" clude that the period at which the bones of these " extinct species were introduced into the Cave at "Kirkdale, was antediluvian. Had these species ever " established themselves in the northern portions of " the world since the Deluge, it is probable their " remains would have been found, like those of the " ox, horse, deer, hog, \&c. preserved in the postdilu" vian accumulation of gravel, sand, silt, mud, and peat, " which are referable to causes still in operation. (41.) Dr. Buckland writes thus in the next page; "It, "was, indeed, probable, before the discovery of this "Cave, from the abundance in which the remains of " similar species occur in superficial gravel beds, which "cannot be referred to any other than diluvial origin, " that such animals were the antediluvian inhabitants " not only of this country, but generally of all those " northern latitudes in which their remains are found; " (but the proof was imperfect, as it was possible they " might have been dritted or floated hither by the " waters from the warmer regions of the earth ;) but " the facts developed in this charnel-house of the ante- 
" diluvial forests of Yorkshire, demonstrate that there " was a long succession of years in which the elephant, " rhinoceros, and hippopotamus, had been the prey of " hyænas, which, like themselves, inhabited England " in the period immediately preceding the formation " of the diluvial gravel." (42.)

Dr. Buckland further informs us, that his " object " is to establish the fact, that the animals lived and " died in the regions where their remains are now " found, and were not drifted thither by the diluvial "waters from other latitudes." (44.)

From the above extracts we learn, that there are many points involved in Dr. Buckland's views of the Caves and their connexions. Some of these may probably be correct, though the 'Theory, as such, may be quite erroneous. The main point at which the Doctor labours, is, that this Cave was tenanted by the hyanas before the Deluge. Some things he adduces as evidence of this case as a fact ; others are connected with the truth of his position; some are essential to to the case; others may be only circumstantial. If we examine the subject with care, it is possible we may discover what is probable, and what is incorrect. The case is evidently complex, though I believe it capable of more simplification than is at present attained. We will try to analyze this very important case. I say important: For if, as Dr. Buckland has laboured to prove, and Professor Jameson asserts,

"It is certain all these animals LIVED and died in " the district where their remains are now found, in the PERIOD immediately PRECEDING the DELUGE;" The Theory of Dr. Buckland and M. Cuvier is 
established, and all we have endeavoured to prove from Scriptural data and physical principles must fall to the qround. The whole case seems to be something like the following.

I. The Kirkdale Cave was inhabited by WILD BEASTS.

1. The positive evidence for this is, it is scattered over with bones; which bones must have been dragged into it by wild beasts for food.

2. The case is strengthened negatively, by the consideration that the animals to which many of the bones belonged, are much too large, either to go into the Cave voluntarily to die there, or to be drifted into it whole by the diluvial waters; and the circumstances of the bones are such as will not admit of the supposition that they were drifted in separately, or piecemeal, by the waters of the Deluge.

This part of the case, thus simplified, does not appear unreasonable or improbable ; yet it is certainly within the range of possibility, (although we may not be able to guess the reason for it,) that these bones might have been taken into this Cave by man. However, I would not contend against the opinion, that the Kirkdale Cave was tenanted by wild beasts.

II. But was this Cave inhabited before THE DELUGE?

This is the point in which all the importance and all the difficulty lies. Our Geologists, we see, consider it "certain" that it was occupied before the Deluge. We, on the other hand, feel perfectly confident that it was not. The Evidence is all. Dr. Buckland's proof of the antediluvian occupation of this Cave is found 
In positive cridence-the contents of the Cave; viz. mud, pebbles, stalagmite, and bones of extinct animals.

In negative evidence,-the NON-OCCUPATI ON of this district by the extinct animals since the Deluge.

The proof of this latter position is, that "there is no evidence" of their "post-diluvian" possession, and that had they possessed it, we should probably have found them among "postdiluvial accumulations."

The Circumstarces aND CONTENTS OF THE Cave.

Dr. Buckland considers this Cave to have been closed ever since the Deluge. But this, with every other point, independent of the "extinct animals" we have already settled. We have, at large, endeavoured to prove that it is PHYSICALLY INPOSSIBLE the mud and pebbles could be formed and introduced into the Caves by the diluvial waters. In addition to which we shewed that the Caves and their contents were so circumstanced as to demonstrate that neither the one nor the other was IN EXISTENCE at the Deluge. Of these things, therefore, we need say no more.

- With respect to the extinct animals, whether extinct ;

- Whether they ever occupied the northern climes;

- When they occupied them;

- Or how their bones came there; these are con. siderations to which we must shortly attend. "But we must first try to finish the subject of the Caves and the assumed occupation of the district by animals now called extinct. Suppose the bones of these animals 
are (for the present) admitted to be extinct,-suppose also we allow, as we have already allowed, that the Kirkdale Cave was occupied by wild beasts which dragged these bones into the Cave,-can all this be consistent with what we previously proved respecting the Caves being post-DiLuvia L ?

To this I shall answer in the affirmative. It is perfectly clear that the bones in the Kirkdale Cave may belong to extinct animals; and they may have been dragged into it by beasts of prey, though the Cane and the rock be both of diluvial operation. There are Two ways in which this may be true. And I am not prepared to say positivcly which of them is the correct one, but I prefer the LA TTER.

- The extinct animals might occupy these districts after the Flood.

- They miglut be destroyed by the Flood and their bones dragged into the Cave after the Flood.

The latter supposition does not confine the extinct animals to the occUPATION at all of these northern districts.-They might be drifted by the diluvial waters from "other latitudes." Though I do not deny that the animals we are now considering, might occupy the districts in the neighbourhood of these Caves, I still think it extremely improbable that they should have been food for hyænas then dwelling in the Caves.

1. How could hyænas kill these elephants, \&c., which they are never known to kill? Or how could they dismember them before putrefaction; or often find them in a putrified state? 
2. How very rarely could such animals be found dead within reach of their dens?

3. And for a number of these animals to unite in dragging their prey from a distance, piecemeal, seems not a very natural supposition.

4. And to suppose that the fieces of these hyærnas should have remained a year under water in the Cave during the Deluge, and possibly for centuries after, without being dissolved or affected by it, is a circumstance which cennot be credited without proof.

With respect to the two positions before mentioned, they have each their difficulties. The latter, which supposes the animals to have been destroyed by the Deluge and their remains to have been introduced into the Cave afterwards, has only to encounter the objection arising from the distance of time, between the Deluge and the subsequent establishment of wild animals in this island; a difficulty of no very formidable magnitude.

The former hypothesis, viz. that the animals occupied this district after the Deluge is attended with difficulties of another nature.

Dr. Buckland says there "is no evidence" of their having inhabited this island after the Deluge. True. But we have." no evidence" that they occupied it before that catastrophe : for the testimony of Kirldale Cave, which seems the only testimony, to their antediluvian residence, we have shewn to be wholly void of reality.-With respect to the probability of finding, their remains in post-diluvian gravel, \&c., had they dwelt here since that event, it may be admit- 
ted as "probable ;" and so far it pleads against this position.

A more weighty objection, however, might seem to arise from the consideration that these animals must (on the above hypothesis) have become extinct sINCE the Deluge; a notion which it is somewhat hard to admit. Geologists, however, cannot make this objection, because it is in evidence against themselves, that extinct animals, such as the Irish elk, have been found in peat bogs which they esteem post-diluvian.

Thus we see, (allowing Dr. Buckland both his positions-that the bones in this Cave are the remains of extinct animals, and that they were introduced into the Cave by wild beasts - neither of which is certain), how easy it is to explain their admission into the Cave upon principles which are entirely opposed to his Theory respecting its antediluvian occupation. It is quite obvious that such animals MIGHT, (though I think it not probable) have lived in this district subsequent to the Deluge; or they might have lived there prior to that event, or been drifted thither from other parts of the earth, and introduced into the Cave after the land became re-inhabited by wild animals.

There is one point more relative to Dr. Buckland's arguments for the antediluvian character of this Cave, which nevertheless has been indirectly answered: it is the inference which he draws from the fact of the following analogy; i. e., that

"Similar SPECIES OCCUR IN SUPERFICIAL GRAVEL BEDS."

This fact, however, is more favourable to the sup- 
position that the animals, whose remains are found in the Cave, were drowned by the diluvial waters, and their bones introduced into the Cave, after that event, than to Dr. Buckland's hypothesis-that the said animals died a natural death, before the Deluge, in the neighbourhood of this Cave, and were dragged into it during its antediluvian occupation. If it be admitted that the "gravel beds-cannot be referred to any other than a diluvial origin," this can only make it "probable that such animals were the antediluvian inhabitants--of this country" in proportion to the fact-that diluvial products are usually found in the places which they previously occupied. But Dr. Buckland, is himself very far indeed removed from such an opinion, as he considers antediluvian rocks to have been transported by the Deluge many hundreds of miles from their prior situation.

D. Buckland, however, we see, suspends the proof and certainty, that those animals occupied the northern districts before the Flood, upon "the facts developed in the charnel house of the antediluvian forests of Yorkshire." But we have, I hope, proved that whether or not thoseanimals occupied “this country" before the Deluge, they never occupied this Cave before that event. As therefore, Dr. Buckland's argument for antediluvian occupation of the country, rests upon the evidence that they occupied the Cave; and as that evidence is shewn to be utterly fallacious, both his positions must fall together. He has neither proved their occupation of the Cave nor of the country, before the occurrence of that catastrophe.

Our author has not, I believe, at all explained a 
very important fact which he himself relates; namely, the

OCCURRENCE OF MODERN ANIMALS IN THE Caves.

There are, as we have seen, according to the statements of our Geologists themselves, NINE quadrupeds out of the THIRTEEN found in this Cave, which are modern and existing animals. This is a most important matter in the science of Geology, and ought to have been accounted for by Dr. Buckland, consistently with the Theory which he professes to embrace. This is an anomaly which we must examine.

It is perfectly clear that this $\mathbf{F A C T}$ is inconsistent with our author's received THEORY, and with that of M. Cuvier, upon which it is grafted. If modern animals were in the Cave with the ancient, and all were introduced, as Dr. Buckland supposes, before the Deluge, it will prove that these modern animals and extinct animals are, notwithstanding the Geological Theory, of the same era. It will also destroy Dr. Buckland's argument against these extinct animals having occupied this country subsequently to the Deluge: or, it will afford an argument which will prove that they did actually occupy it after that event. The Doctor, in a quotation above, says,

" Had these species ever established themselves in " the northern portions of the world since the Deluge, " it is probable their remains would have been found, " like those of the horse, ox, deer, \&c., preserved in " the post-diluvial accumulations of gravel," \&c. 
What, now, does this argument prove? If the finding of animal-remains in the same place will prove any thing respecting the eras in which their species existed, the union of the horse, ox, and deer, in the same Cave with the elephant, rhinoceros, and hippopotamus, will prove them all to be of the same era; and, consequently, either all antediluvian or all postdiluvian. But we have proved that this Cave is, itself, post-diluvian. Then, according to the above argument, they will all be post-diluvian. Thus, then, Dr. Buckland would afford an argument in favour of the postdiluvian occupation of this country by the elephant, rhinoceros, hippopotamus, and hyæna, which our Geologists assure us are now become extinct. But, if so, extinct animals prove nothing but the folly of the system which is built upon them.

The foregoing argument would also prove that men and animals, called extinct, are of the same age; and thus the whole system, as before argued, would fall ; or else it will afford some inferences very inconvenient to Dr. Buckland's “ Reliquiæ Deluvianæ," and all his pretensions founded upon it.

\section{INFERENCES.}

We have lately seen that this LAST resource of Geology ; viz. the testimony of Dr. Buckland's Caves (for they all take their character and interpretation from the Cave at Kirkdale,) has entirely failed. In consequence of which it will follow

I. That the general Theory is erroneous.

This has indeed been more than sufficiently proved in the first volume, \&c., but every point of error bears upon the same principles. The Limestone 
rocks in England and Germany, where Dr. Buckland's Cave scenes are laid, are precisely of that sort of formation, and belonging to that class of rocks, from which M. Cuvier and Geologists generally dèrive their most material evidence for "NUMEROUS REVOLUtions." If, then, we have specifically proved that the LIMESTONe rocks in which the Caves are situated, are themselves of DILUVIAL production, it will equally apply against the general Theory, and against all the material evidence upon which it rests. Had Dr. Buckland succeeded in establishing his a NTEdiluvian Theory of the Caves, it would have been the firmest bulwark which the " Theory of the Earth" has ever possessed. But as it has fallen, M. Cuvier's system," resting essentially upon the same foundation, must fall with it. It is further satisfactory to reflect that, as these limestone rocks have been disposed of conformably to the Scriptural account of the Creation and Deluge, all other strata containing ancient organic remains become referable to the same system, and conformable to the same principles.

But it will follow, moreover, that neither Dr. Buckland nor M. Cuvier, \&c., has given ANY specific, peculiar, and certain EVIDENCE of

\section{The Noahic Deluge.}

The last evidence to which we have long been looking forward, is Dr. Buckland's Denudation and Cave Theories. We have now, however, proved, and I hope, most satisfactorily, that тuEse $\mathrm{CAvgs}_{\mathrm{Av}}$, and their contents, are, every one of them, of POST-DILUvIAN occurrence: and that the Theory of denudations is equally void of foundation. The point of 
“EXTINCT A NIMALS," moreover, whose remains are found in these Caves, and in the northern districts generally, we have also shewn, does not afford any aid to Dr. Buckland's Theory of diluvial operations ; nor any evidence respecting different epochs or revolutions.

$I$ readily admit, indeed, that Dr. Buckland has produced abundance of evidence respecting sоmE catastrophe, and he might and ought to have adduced a great abundance more; but that he has proved, or can prove, while he maintains a system involving numerous such catastrophes, that the "phenomena" which he has exhibited are "referable to the LAST INUNDATION of the Earth ;" we may positively deny. It is as certain as evidence can make it, that Dr. Buckland's scheme can never hang together. It is inconsistent with itself, like that of M. Cuvier, in every direction. But, especially, in addition to all we before proved respecting the error of his denudations and his antediluvian Caves, it will further appear that he must be utterly unable to retain his Theory-of numerous revolutions--and yet prove, specifically, the Noalic Deluge. If we examine this matter we shall find that both these authors fail in this point.

I. They afford no specific P $\mathrm{H}$ Y I C A L evidence.

We have all along seen that M. Cuvier denies "human bones" to be associated with the fossil elephant and rhinoceros, \&c., which elephant and rhinoceros, \&c., they all admit, belonged to the "last revolution" or Deluge. Dr. Buckland also, as we before noticed, firmly contends that "humun bones" have never been found in the diluvial deposits." (169.) 
The writer of the article "Fossil Remains" in the Edinburgh Encyclopædia, asserts repeatedly that mens' bones have never been found in the alluvial soil. The absence of human bones from the fossil strata is a common article in the creed of modern Geologists. This, however, instead of pleading in favour of Geology, will plead strongly against it. For, if it be as Dr. Buckland asserts,

A "fact that human bones" have not been found in the deposits which our Geologists call "diluvial,"

This fact will go far to prove, against Dr. Buckland, that such deposits are not "diluvial." For if those deposits were diluvial, mens' bones ought to be found there. Had Dr. Buckland proved the fact that human bones are found among the deposits which he esteems "diluvial," and that they not found among those which he esteems antediluvial, it would have gone farther in proof of his and M. Cuvier's Theory, than any thing which they have advanced. They would, so far, have had the only authentic history of the Deluge in their favour. But under existing circumstances, it is entirely against them. For upon the principle of "numerous revolutions" Dr. Buckland has no right to assert that deposits (from which man and other modern beings peculiarly diluvial, are absent,) are of diluvial operation, and not rather of the operation of one of those prior revolutions by water, of which he holds so many.

Indecd, it is utterly impossible that the Scriptural truth of the Deluge and modern Geology, can exist together. For the sole argument upon which this Geology is built, is the ABSENCE of ONE sort of 
relics, and the PRESENCE of ANOTHER. This is the sole evidence on which it is concluded that the "shelly strata" existed thousands of ages before man. The argument then cannot be resisted. For if the absence of human bones in the shelly strata be proof that no human beings were living on our globe during the formation of those strata, the absence of human bones at the Deluge will prove that there were no human beings at the Deluge.

It is manifest therefore, that Dr. Buckland, adopting as he does M. Cuvier's Theory of "nninerous catastrophes," has clearly shut himself out from all just pretensions to prove, upon indisputable ground, the Scriptural Deluge. The whole of the "EXTI NCT SPECIES" must, if the Geological system have either truth, or consistency in it, be referred to Deluges ANTERIOR to that of the Bible. And it is quite certain that all such "ALLUVIAL" deposits as their Theory allows human bones to be associated with, are clearly POST-DILUVIAL.-With respect, even to the deposits of "loam and gravel" on which Dr. Buckland relies as evidence of the Scriptural Deluge, it is certain he does this in direct opposition to the opinion of many Geologists, as we have before shewn, and to his own Theory. For the essence of that Theory is, that the strata are proved by their peculiar fossil remains. Then the "loam and gravel" in which the "extinct species" are found must necessarily be placed as early as the animals which distinguish them. But the extinct species, denote agreeably to the Geological Theory, revulutions prior to the Deluge; therefore the "loam and gravel" in which they are found, must also be prior to the Deluge. 
In correspondence with the above conclusion, we find, as we have shewed before, that M. Cuvier, Mr. Webster, Messrs. Conybeare and Phillips, all consider the strata where the elephants and mastodon, \&c. are imbedded to be an alluvium "far more ancient" than the Scriptural Deluge.-Indeed, I think this matter lies within a very small compass.

- The Geological Theory which Dr. Buckland adopts not only embraces, but positively consists in, numerous revolutions and catastrophes of which (could it have any place) Noah's Flood would be the LAST.

- That these several Deluges or revolutions, are proved by their respective animal remains.

-That the "extinct" animal remains, prove ancient Floods. This is the life of the Theory.

-It is also declared expressly, that the remains of large quadrupeds are the cHIEF evidences of these revolutions.-In fact, if their evidence be taken away, the whole Theory is literally destroyed.

IT WILL CERTAINLY FOLLOW THEN, that

Noah's Flood, which was the last Deluge, if it have any place in the Geological series, must embrace that deposit (and agreeably to the Bible data,) only that deposit in which EXISTING animals and MAN are found.

-The Deluge next before Noah's Flood must embrace the "EXTINCT SPECIES."

-And the second Deluge before Noah's Flood must comprise the "EXTINCT GENERA."

Let it be particularly observed that if these three classes of ANIMALS and their respective STRATA be confounded, the whole CRITERIA (as we largely 
shewed in the second Book of the first volume) of the modern Geological Theory, are positively subverted and destroyed. The system is entirely built upon the assumption that both the strata, and the animals designating the strata, are perfectly distinct and unmixed.

Dr. Burkland, therefore, must now choose his place.

1. If he take, as he has hitherto done, the GEo LoGICAL side of the question, he must give up all proof of the Scriptural Deluge.

- His diluvial gravel is not (in his sense,) DILU V I A L.

- His drifted granite blocks and denudations are all proved erroneous ; - Not DILUVIAL.

- His elephant is an extinct species; and, therefore, (according to the Theory, ought to be, one revolution before our DeLuge.

- The mastodon he mentions is an extinct genus; and, therefore, two revolutions prior to the DELUGE.

- His Cave considerations are obviously post. diluvian.

There is nothing in all these which so much as touch upon any proof of the Scriptural Deluge.

2. If Dr. Buckland take the side of the DELUGE, then,

- If the elephant and mastodon, \&c., prove Noah's Flood, and the superficial soil in which their remains are imbedded, to be diluvial; forasmuch as these are extinct species and genus, their being diluvial, will instantly strike the Geological Theory dead.

- If they were drowned by a former Flood, that cannot prove the Noahic Deluge. Therefore, 
- It cannot be proved at all by this system.

11. They afford no Morat evidence of the Scriptural Delige.

Dr. Buckland does indeed speak of the Scriptural Deluge as leaving " evidences deeply sculptured upon every stratum ;" and of its being wholly of a punitive character. But may we not ask where he derives this information? It is not from Geology. For he expressly states that only animals, not man, are found in the "diluvial deposits." He has drawn from Europe, Asia, Africa, and America, proofs of 4 Deluge. (220223.) But among all these there is not one " HUM $A \mathrm{~N}$ BONE." - If, then, as we have before noticed, their Theory were the true Theory, those deposits from which men and modern animals are excluded, cannot possibly be D I LUv I a L deposits.

Diluvial deposits, (if the Bible has any meaning, and the animal remains in the strata are to designate and prove the eras of those strata,) must be distinguished by the presence of the HUMANRACE. But the deposits which Dr. Buckland's Theory makes to be diluvial, have no human bones in them. Where, then, we may further ask, are the " evidences deeply sculptured on every stratum," that the Noahic Deluge only tended to destroy, and that it was wholly " PU N ITIVE?" Are granite blocks and the bones of AnIмA LS evidence of "punilive" operations-of operations solely punitive ?”

With regard to the "evidences deeply "sculptured on every stratum," it need only here be added, we have proved that those evidences are wholly gratuitous and assumed. And, further, that with regard to the 
SPecific Deluge to which Dr. Buckland endeavours to apply those evidences, they have not, on his Theory, any, even the least legitimate application.

Besides, if it be true, as Dr. Buckland contends, that the "superficial loam and gravel" were undoubtedly of diluvial origin, instead of viewing the Deluge only as "punitive," or as tending "only to destroy," we ought to view it as the greatest of blessings; for, it it is perfectly clear, that the whole surface of our globe would have been utterly barren and uninhabitable without them.-All this time, therefore, we have discovered No MORAL evidence of the operations of the Scriptural Deluge. The only rational inhabitant of the globe being, by the united consent of all Geologists generally, and of Dr. Buckland in particular, studiously exchided from those deposits which the Geological Theory makes Di Luvi a L.

Dr. Buckland has confessedly exhibited no evidence of a punitive character but shattered rocks and animal remains. But if these be adequate evidence of moral obliquity, or of divine judgments, Mr. Gisborne, whom Dr. Buckland views as advocating an erroneous system, has argued rightly by considering breaches in in the earth and animal remains as evidence of a punitive catastrophe.

It is a very remarkable fact that neither Mr. Gisborne nor Dr. Buckland, in all their attempts to demonstrate the Scriptural character of the Deluge; and to prove that Punitive Justice has deeply affected every quarter of our globe; has produced one relic of the "HUMAN RACE" as evidence of that catastrophe which ma N's guilt alone brought upon the Earth !!! 
It is then inevitable, as a consequence of the preceding statements, that

1. Either Dr. Buckland has, by making extinct animals, \&c., Diluvial, destroyed his own GeologICAL Theory;

2. Or he has produced no proof, nay, and destroyed the possibility of producing proof (consistently with his Theory,) of the Noa hic Deluge.

So little reason had the Quarterly Review, in its notice of Dr. Buckland's "Reliquiæ Diluvianæ," to extol his demonstrations of the Scriptural Deluge, to the disparagement of the labours of " divines." That Review declares as follows :

"Certainly we may pronounce the author [Dr. "Buckland] to be the first who has placed beyond " the reach of controversy or cavil, and to have put " the finishing hand to an argument so long laboured " at by divines, that the Earth, after having been " inhabited for ages, was, at the period recorded in the " Sacred History, covered even to the highest sum" mits, by a sudden, simultaneous, universal, transient "flood of waters." (Q R. 1823, p. 158.)

That the Earth affords most abundant evidence in favour of the Mosaic narrative respecting One Universal Deluge, is certainly true; but it is also as certainly true, that our Geologists, by advocating " numerous catastrophes," infallibly deprive themselves of all unexceptionable and specific evidence in proof of that individual catastrophe.-The Bible, therefore, gains nothing, and looses every thing by their profered assistance. 
Respecting what is gone before, I would observe, that I am not insensible to the labours of M. Cuvier, and to the pains he has taken, from a reference to HISTORICAL documents, to prove a recent Deluge about the period which the Bible ascribes to Noah's Flood. But this evidence, however valuable, belongs to IISTORY, recorded or traditionary, and not to Geology. But I think no true believer of the Mosaie narrative will thank him for continually merging the writings of "Moses the man of God," among those of heathen authors, and appearing to consider them as all alike, fallible.

"Berosus (he says) has even described it, (the "Flood) with circumstances so similar to those of "Genesis, that it is alnost impossible what he says of " it should not have been taken from the same sour"ces." (234.) "Same sources!" From what sources, pray, did Moses derive his history of the Deluge?-Again.

"Along with the Armenians, we include the "Arabians, Persians, and Abyssinians of the present "day. Their ancient books no longer exist; they " have no history but that which they have recently " composed, and, which they have modelled after the "Bible; so that their account of the Deluge is bor"rowed from Genesis, and adds nothing to the au"thority of that book." (236.) "Adds to the authority!" What can ADD to the AUTHORITY of that which is infallibly true?

The same thing M. Cuvier had said before respecting the Abyssinians borrowing from the Bible. 
"Hence all that their books contain respecting the "Deluge is borrowed from Genesis, and does not " contribute any support to its authority."-" In order " to discover some truly historical traces of the last " universal Deluge, we must go beyond the vast " deserts of Tartary." (162.)

Of this I shall only at present, observe; I judge it impossible that such oblique and, as it were, undesigned and incidental remarks from an author like M. Cuvier, should not have a malignant influence upon the word of God. 
THERE are several further particulars relative to the animal remains found in the Caves and in the strata, which claim our attention. We have, I trust, fully satisfied the reader that the evidence adduced by Dr. Buckland in support of his antediluvian Cave Theorywhether that evidence be derived from what he calls diluvial mud, diluvial pebbles, or stalagmite; and lastly, from the presence of bones in the Cave which Dr. Buckland contends, on the authority of M. Cuvier, belong to animals which are now extinct. The Cave Theory, therefore, of Dr. Buckland, we consider to be perfectly disposed of, and put aside. It is possible, however, that some further illustration of the contents of the Caves may arise from our present inquiries.We stated, in the last chapter, that there were several points which would require further consideration, such as - Whether animals be really extinct - Whether they occupied the northern latitudes - When they occupied them-Or how their remains came thither?

It will not be expected that I should be able to give satisfactory solutions to any of these difficult and 
unrevealed subjects. But a relative satisfaction may, perhaps, be obtained. Relative, I mean, as it respects the Theories of Geologists, and the veracity of the Biblc.-I shall, first say a few words upon the fundamental point of modern Geology, and inquire

\section{RESPECTING EXTINCT ANIMALS,}

Whether it be probable that they are really extinct.

Dr. Buckland refers to M. Cuvier's opinion respecting this essential and all important point, as if he had an assured and undoubted subject before him. He says ;

"M. Cuvier has ascertained, that the fossil elephant, "rhinoceros, hippopotamus, and hyæna, belong to "species now unknown." (Rel. Dil. 41.)

"Unk nown ;" is, in M. Cuvier's language, synonymous with, "extinct."- Has "AScerTaINED :" How? and by what data? The author's own experience respecting what has been, cannot prove much; and surely his appeal to an ancient Egyptian mummy is not any satisfactory evidence. But we shall not go into this subject now; nor say over again what we have already said, in the chapter on extinct animals, in the first volume. However, as upon this very subject alone, modern Geology has suspended all its pretensions, we must say a few things respecting it. The subject of extinct animals cannot be made available to the purposes of Geologists, on many accounts.

1. Unless modern and existing animals were found among the ancient, so as to obtain their ancestry among fossil animals, New Creatrons would be necessary for their production. This, of itself, as we have shewed, is destructive to the system of M. Cuvier, 
and of all who look only to "chemical and mechanical causes" to account for changes in Geology. Because new Creations bring us to a supernatural cause, to which, such of our Geologists, never can appeal.

M. Cuvier asserts that he has discovered 40 genera and 70 species which are entirely unknown to naturalists; and they are therefore assumed to be extinct. But he certainly has no data for such a conclusion. He might perhaps, and with little less truth, assert that there are hundreds; for nearly all the fossil animals are esteemed unknown. But as new Creations are the inevitable result of such an assumption, I suppose M. Cuvier will not risk such consequences of his opinion. But there is a class of writers who advocate

New Creations.

All persons professing Christianity must hold new Creations, so long as they adhere to successive formations and numerous revolutions. I shall refer to one for all. The last Quarterly Review for September, 1826, adopts without reserve, the notion of successive Creations.

"Their organic contents (it says) indicate successive " changes in animal and vegetable life:" (p. 536): and adds ; "It is clear therefore to demonstration, that " all, at whatever distance of time created, are parts " of one connected plan. They have proceeded from " the same author, and bear indelibly impressed upon " them the marks of having been designed by one " mind." (538.)

As this however is roundly asserting what is strictly SUPERNATURAL, we certainly cannot admit it with 
out proof. But what evidence, in a case like the present, can be fairly allowed to prove such a fact? Nothing short of our own personal knowledge, or indubitable testimony, can be admitted. But both these utterly fail us. We never saw such an event, as is here assumed. Nor is there any authentic history which attests it. Without puzzling our minds with difficult inquiries about the nature of that evidence which would legitimately prove successive Creations, we may perhaps satisfy ourselves in our discussions with Geologists by a few reflections.

If (as in the above quoted Review) we assert successive Creations, forming "one connected plan," and "designed by one mind ;" we clearly assert, in other words, that God has gone out of his usual way to produce these new Creations : we assert that the Almighty has by his own hand changed the course of nature, and removed the animals previously existing in order to create new ones in their place: and that these destructions and new Creations are all a part of one and the same design.

It is enough to inquire, under such circumstances, whether it be more PrOBABLE that the Almighty should so suddenly change the course of his proceedings, as to destroy all the existing animals and create fresh ones; or whether, in the course of some thousand years, he should effect such variations in animal nature, as those under contemplation? Which is the GREATER DEVIATION from the NATURAL COURSE of things? - We are certainly bound by philosophy and common sense, to adhere to the least difficulty, which is that, of course, which varies latst from what 
we see and know. Indeed this argument (from the course of nature) and this alone, forms the ground of the assumption-that fossil animals were not the ancestors of the existing races; namely, because animals never deviate so much from their usual form and size : that is, in other words, they never deviate so much from the ordinary course of nature. Upon what principle, then, we ask, do we assert successive Creations, which altogether differ from the course of nature?

When it is said that animals have never varied so much, as fossil animals do vary from existing ones, such Christian authors as Dr. Buckland and the afore mentioned Reviewer, must assume that the Almighty has always so continued and kept them from deviating. For what Dr. Buckland has said of matter cannot be less true respecting animals ; namely, "That laws impressed on matter"-can only denote the continued exertions of the will of the-first Mover." The first giver then of these unchanging laws to animals, has by his own will "continued" those laws in their undeviating character. This must certainly be the meaning of Christian Geologists when they say that animals have not varied so much from their original form and character. And M. Cuvier holds the same notion, though he ascribes their permanency of character to "general causes."

The Christian Geologist, therefore, when he speaks of the permanent nature of animal forms, says, in meaning at least, the Author of their nature has been pleased to continue that nature, and has never changed it. But now these same authors, in advocating new Creations, conTRADICT their former philosophy, and 
assert that God has changed their character, yea, and not changed it graducilly, and as we might naturally suppose, by the influence of food, time, and climate: But instantly and totally; and that immediately by his own hand; For new Creations can proceed from no other cause. In order therefore to avoid a comparatively small and gradual change, our authors will adopt the doctrine of changes a 1000 fold greater, and less likely to take place.

ALL ANALOGY is instantly violated, if we resort to new creations, There is no instance of any such thing in nature. We have no knowledge, we have no record of any such event. And I am perfectly at a loss to see upon what ground of reason or argument Christian professors can adopt so extraordinary a notion. It is directly contrary to every thing we know of God and of his dealings. Some animals may, no doubt, be extinct. But, I think, all we see, and what we read in the Scriptures, would lead us to form a conclusion directly the reverse of Geologists. It was likely that

The Deluge should Form an Epoch.

Now, if there has been an Universal Deluge, by which all the previous animals were destroyed, save a single pair of each kind for future propagation, it was a thing to be expected that such an event should exhibit very great changes in animal nature. And 1 am not aware that such animals as the elephant, the rhinoceros, the hippopotamus, and the hyæna, \&c. have varied more, supposing them all to have been derived originally from one pair, than we ought to have expected.

We learn from the Bible that animals were living upon the earth 16 or 17 centuries before the Deluge. 
And since that catastrophe it is between 4 and 5000 years. Let it now be fairly considered whether the change in elephants be too great for a course of so many years? The fossil animals which our authors chiefly contemplate are supposed to have occupied the northern regions before the Deluge. These might certainly have roamed, greatly unmolested, towards the north, for 1000 years. But the elephants which now occupy the south only, might be derived from a pair which never departed far from their Asiatic original.situation. What do we find, then, more than we ought to look for? How great a change may have occurred since?

Changes, since the Deluge, as we shewed in the first volume, have taken place, to a great extent, both in animals and man. So great, indeed, are the changes in the human race, that, as we there noticed, they lead M. Cuvier to consider both the Tartars and Negroes to be of a different " race" of beings from Europeans. M. Cuvier, as we also noticed, mentions very great changes in animal nature-as some swine having acquired a solid, instead of a cloven hoof, and some families which have six fingers on each hand. Why, then, should this author say that the opossum (alluded to before as discovered by Dr. Buckland) " is of an extinct genus," because it has " 10 teeth in a series in the lower jaw ?" (Quarterly Rev. as above, 529.) Or what authority have we to say that the plesiosaurus is an extinct animal, because it has 30 vertebræ in its neck, while even the swan, which has more than any other modern animal, has but 23 ? Or the iguanadon and mogalosaurus, though they might have been big as a crocodile 60 feet long? 
How do we know that no such animals are now living upon earth? Or how can we tell that no modern animals were derived from them ? If we say, with the last Quarterly before-mentioned, that

"The fossil species appear to be all, with a few exceptions, extinct ;" (522.)

We must also say that modern animals, with very few exceptions, appear to be all NEW CREATIONS. But this position no Christian can ultimately support. For the whole conceit proceeds upon the assumption of distant epochs and numerous revolutions. All of which, I hope, we have fully proved, are perfectly visionary and impracticable.

Suppose, as I trust we have also satisfactorily proved, that the Bible means literally what it says, when it speaks of the Creation and the Deluge; who would then speak of nearly all the fossil species being extinct? Did our Deluge extinguish them ? Then whence came the existing animals? And what became of all the races of animals preserved in the Ark ? Have there been more Deluges than one since the Creation, upon the ground of Scripture? And were not animals which were preserved, of the same species with those destroyed ?-To deny these Biblical truths, and still to assert new Creations, and that because the difference between animals buried 4 or 5000 years ago differ, both in their form and size, from living ones, is not only unphilosophical, but unbelieving.

We are therefore at length come once more to a final and infallible crisis with our Geologists; and though we pretend not to identify the species, or even the genera of animals, before and since the Deluge, and 
do not wish to be over nice as to a species of animal, whether or not extinct, our conclusion is directly the reverse of that of modern Geologists-we would maintain, UPON THEIR OWN SHEWING, that

“ The FOSSIL SPECIES APPEAR TO BE ALL, WITH VERY FEW EXCEPTIONS," STILL EXISTING.

The process to this conclusion is short and infallible. There are two descriptions of Geologists concerned.

1. Such as M. Cuvier.

But with this author we finished the matter of extinct animals long ago. He instantly fled from the face of NEw CREations. He told us that MODERN animals are not new creations, but came from some " other part of the globe." THus he retained, indeed, his hypothesis respecting "extinct animals;" but he destroyed his THEORY by giving up their SUCCESsion. It was admitting that the " existing animals" and "the extinct animals" were collateral, and of the same age: not older and younger; not ancient and modern. - We need not, therefore, spend time, in proving that M. Cuvier could not maintain his own hypothesis of extinct animals, even upon his own principles; because, for the purposes of his Theory, the hypothesis is perfectly useless;-If he has no sucCESSION, he has No THEORY !

\section{Christian Geologists.}

With these, also, the course is short. I shall take those (as specimens of argument) upon which Dr. Buckland especially rests his evidence of the Deluge, such as the extinct elephant, rhinoceros, hippopotamus, and hyæna. 
1. These animals, although asserted to be extinct, are found in the loam, in the gravel, and in the various different strata, generally near the surface of the earth, in all parts of Europe: they have been discovered as far south as the plains of Mexico, and as far north as Siberia. They are inclosed in the earth, and frozen up in icebergs.

2. These, therefore, are asserted by Dr. Buckland, \&c., to have been deposited in those situations $\mathrm{BY}$ the Deluge. And this they certainly were, or Dr. Buckland has no proof of the Deluge.

3. Our conclusion then is, if these animals were destroyed by the Deluge, their species are not EXTINCT.

(1.) This is evident from the BIBLE, which so expressly declares that two and two of EVERY SORT were taken into the Ark to "keep seed alive upon the face of all the earth."

It is quite clear from the above, that the animals preserved in the Ark were the posterity of the antediluvian animals, and the progenitors of the postdiluvian.

(2.) It is clear also from Geology, unless it will advocate the two following positions ; namely,

First, That though the Bible says " of every living " thing of all flesh, two of every sort shalt thou bring " into the Ark, to keep them alive ;" yet, with "very few exceptions," they were ALL DESTROYED.

Second, That "with very few exceptions," all our EXISTING ANIMALS were newly created AFTER The Deluge!!!

I see no way of evading these destructive conse- 
quences, without (like M. Cuvier) effecting the ruin of Geology itself. For, if Geologists choose to say that our existing races of animals are derived, as the Scriptures have stated, from the animals preserved in the Ark, and that they were not newly created after the Deluge: I would answer that this is quite ruinous to their Geology in various ways.

- It makes, as M. Cuvier's evasion does, the " existing species" of the SAME AGE with the "extinct species," and therefore destroys the very design for which the extinct species are resorted to-viz. to prove a SUCCESSION of eras.

- It runs into another ruinous consequence; namely that of mingling the remains of "existing animals" with those of "extinct animals"; for, except the few which were preserved, they were all drowned by the same Deluge, and must therefore be mixed together somewhere.

- It is however, the very essence of Geology, as we all well know, that existing animals are мот INTERMIXED, or found in Formations of the same epochs with the extinct ones.

Thus, then, we arrive by the force of demonstration to our previous conclusion: viz.

That the Fossil species, With Very few EXCEPTIONS, ARE UNDOUBTEDLY STILL IN EXISTENCE.

\section{INFERENCES.}

1. The natural conclusion from the foregoing discussion is that, such animals as the elephant, rhinoceros, hippopotamus, \&c. are only v A R I ETIEs derived from antediluvian animals of the same species. 
2. There may indeed be animals living of different species from the known ones, which may have been derived from the fossil animals. But naturalists do not appear to possess any CERTAIN DATA by which to pronounce the fossil animals to be of a different species from known and now existing animals.

3. THE MARKs respecting the genera and species have been established by man. He cannot therefore say what are the boundaries of nalure any further than his observation goes ; which in the present case, must needs be imperfect. For M. C'uvier's inference from the Egyptian mummies, is not only unsatisfactory but ridiculous. It affords, at best, only that loose kind of generalization which might be applied to the support of any Theory.

4. It appears certain that many of the animals called extinct, were animals derived from the same original progenitors with existing animals; and that the $\mathrm{DE}_{\mathrm{E}-}$ LUGE has formed the GRAND EPOCH which has produced the variations.

5. Probably many of the fossil animals might have travelled northwards, while, since the Flood the same species may have continued in the south.

6. Do not the variations of colour, size, and form in the HUMAN SPECIES, all of which, though apparently very permanent, have certainly been produced since the Deluge, almost wholly justify all the changes we discover between the aforesaid fossil animals and existing animals?

7. No naturalist has ever yet explained how it is that all the animals in New Holland should be totally different (as M. Cuvier admits they are) from all 
known animals in Asia and Europe; and yet it is certain that all their tribes migrated from Asia since the Deluge.-.Queries: Have these animals REALLY become ехтілст in Asia where alone they originated, and, for an unknown period, lived, since the Flood? or have time and place caused so great a CHANGE in their sharacter that their ANCESTORS cannot be identified, though still living in Asia, by being compared with their degenerated offspring? (See vol. I. pp. 219-229.)

8. Lastly. From the above reference, the reader will see that M. Cuvier considers the Negroes as well the Tarlars to be "a race of men differing entirely from us." But he has not explained to what cause this difference is owing. Query ;

(1.) Would a colony of Tartars or Negroes in Europe, become in time like Europeans? or Europeans in Africa, like Negroes?

If the affirmative be admitted, Geology has no foundation for asserting them to be of different races, nor for saying how far animals may not change.

If it be denied, we know from the Bible that, as a fact, it has been realized.

(2.) How long have Negroes been what they now are? Or is there no history or data from which a judgment can be formed?

On what ground, then, can Geologists define the limits of time and change respecting animals ?

I have no fears that infidelity should turn short about and assert here, that the Bible speaks falsely respecting Negroes, as it does also respecting the Creation. That time is past. 


\section{TROPICAL, ANIMALS IN NORTHERN LATITUDES.}

It will not be necessary nor perhaps desirable that I should discuss this subject at great length. I do not find sufficient data for any positive conclusion. Dr. Buckland admits that before the phenomena of the Kirkdale Cave were developed, the evidence that tropical animals lived in these latitudes, was imperfect. But we have shewn that Dr. Buckland's Theory respecting Kirkdale Cave is erroneous ; and that animals might very probably occupy that Cave after the Deluge, and drag into it the remains of animals destroyed by that event, whether such remains were deposited upon the spot or drifted thither from other latitudes. All that I have considered it important to oppose in Dr. Buckland's Theory of the Caves, is their antediluvian. occupation by wild animals. And he does not himself advocate the opinion that his extinct animals dwelt in Britain afier the Deluge.

1. Without being very sanguine in the opinion, I admit that it is probable the elephant, rhinoceros, hippopotamus, \&c. did, BEFORE THE DELUGE, live much FURTHER NORTH than they now do.

I think it is evident, however, that the remains of many of these animals are now found much further northward than they could possibly live. I think that Dr. Buckland is perfectly right in believing it impossible for such large animals to subsist on the frozen shores of Siberia during their long winters. But they might occupy latitudes pretty far north in the temperate zone. Although, I confess, it is far from being clear 
that such animals did occupy such high latitudes before the Flood. But

1. The woolly-haired elephant and rhinoceros found whole in the icebergs renders it probable. And, without searching for reasons,

2. The great diversity in the size and form between the post-diluvial animals of corresponding species in the south, and fossil animals, bears the same testimony.

II. Every thing, however, which we know, seems to bear strongly against the probability that these animals, as Dr. Buckland very well argues, ever established themselves in these districts SINCE THE DELUGE.

1. There does not appear to be any such division or epoch among the fossil remains of the north, as there probable would be between antediluvian and postdiluvian remains. While,

2. It is quite certain that such immense numbers of these remains as are now found in the northern regions, and even in ice mountains, could never have been deposited where they are found by any event inferior to the Deluge, or subsequently to it.

I am aware that some writers in Scotland have lately maintained (without, as it appears to me, even a shadow of evidence, ) that the bones found in Siberia might be occasioned by ordinary or extraordinary land-floods, or some such thing. But, surely, landfloods could never form mountains of ice a hundred feet in height, and lock fast in the mass of ice such prodigious numbers of bones and tusks of elephants as are there found. Besides; The bones are very commonly mixed with "marine weeds" and other 
productions of the Sea. I know that some have even boldness enough to call this fact in question, in direct opposition to the testimony of Mr. Pallas who expressly states that he himself actually witnessed it with his own eyes.

3. If elephants, \&c. have not occupied the north since the Deluge, it is probable also that the fossil hycena has not. I do not think that Dr. Buckland has established the fact that the animal bones which are accimulated in the Kirkdale Cave were taken there by the hycenas. Other wild beasts, such as wolves, might do that as well as hyænas; for their characters and habits are very analogous.

III. In connexion with the above positions, $\mathbf{T}_{\mathbf{H}} \mathbf{E}$ DELUGE as an EPOCH Or GRAND DIVISION among fossil animals, is very important.

We have before spoken of the Deluge as likely to make a large CHASM in nature. If to this we may add the probable fact that the chief of the fossil animals, before the Deluge, occupied the north, but that since the Deluge their corresponding species have only occupied the south, we shall perceive an harmonious scheme arise before us. The antediluvian animals though on no account necessarily extinct, may be supposed to have been both much larger and widely different in the form and, perhaps, in some cases, in the number of their bones. It is true, this cannot be ascertained as a fact until more be known of the antediluvian fossils of southern climates. And indeed Geologists are not only premature, but arrogant and presumptuous to think of establishing a "Theory of the earth" with next to no knowledge of so great a 
part of it. But the change here supposed, is not irnprobable from what we know of situations which (possibly like the present) have been greatly secluded from the society of man.

This sentence of the Bible, "there were Gis nts in those days," so emphatically declared respecting the antêdiluvian inhabitants of the globe, may possibly apply to animals as well as man. And it seems to imply that men of gigantic stature were then not uncommon. We read even as late as the time of King David, of giants with six toes and six fingers in the place of five, whose stature was nearly twice the height of a modern middle-sized man, and whose weight would probably be many times as great. If the human race (as Geologists seem very confident) did not interfere with the wild and natural habits of these antediluvian animals in the northern climates, it is easy to believe that their FORM and SIZE might in the course of 1600 years become extremely varied from their Asiatic originals.

That we do not more frequently: meet with those gigantic bones of the human race mingled with those of fossil animals, may be accounted for, either as Geologists account for it; namely, that men probably inhabited the Asiatic regions only; or by another circumstance which we have long ago particularly noticed; viz. the extreme unwillingness of Geologists to acknowledge human bones, even, when they have been discovered.

1. The reader must be careful to notice that in all we have here said, both about tropical animals before the Deluge occupying the north, and in the application to 
animals of the Scriptural language respecting men, is only suggested as a probable circumstance from the analogy of cases. On subjects where data are so imperfect, it were arrogant, not to say impious, to assume airs of importance and confident dictation. The whole of these suggestions may one day prove to be nothing more than mere speculations. However, as the whole seems natural, and, from present data, not improbable, I have thought I mighı be allowed to throw out the foregoing hints on points on which Geologists speak with the fullest confidence.

\section{CONSEQUENCES OF TROPICAL ANIMALS INHABITING THE NORTH.}

I should not have noticed this point, but for the consideration that Geologists make the matter of this Northern occupation a fact which they view as demonstrated. The fact, however (if we must admit it as fact,) that animals which now only occupy the tropical regions of the earth, did once occupy climates very far north, involves consequences very unfriendly to the first principles of modern Geology. For these fossil animals, the elephant, the hippopotamus, the rhinoceros, and hyæna, are allowed by Geologists to be of the same genus with the animals of the same names now living in the south, though not of the same species.-This, as we have before noticed, would either involve the strange and unscriptural notion that all the northern species of the same animals were destroyed, while the southern species were preserved at the Deluge; or, it would involve us in the belief that all their species were destroyed, and a totally new 
race subsequently created. These, however, are points which few Christians, under due consideration, would presume to advocate.

But, if it be true, that animals once lived in the north, which can only now live in the southern regions, it must of necessity follow, that the climates have changed their nature, or the animals their's.

With me this change is no difficulty; for, I believe, that every animal on the globe could gradually be brought to live in any climate, as we know to have been the case respecting the human race; and, indeed, with not a few of the animal tribes which now live in all climates.-But Geologists have adopted, for the sake of their Theory, such rigorous and unbending notions respecting the perpetuity of animal capabilities and propensities, as will make the above consideration bear hard upon their Theory. We shall therefore take a little notice of this subject.

I. The CHANGE OF CLIMATES.

On this subject I cannot largely enter. Dr. Buckland has given a summary of the arguments used on buth sides of this question. (4.5.) M. Cuvier, on the one hand, contends, that the elephant and rhinoceros preserved in the ice, both of which seem to have been covered with hair or wool, peculiar to the north, belonged to a species of animals which could "endure " the rigours of a northern winter." To which it is again answered, "that the abundant occurrence of " fossil crocodiles and tortoises, and of vegetables and "shells (i.e. the nautilus,) nearly allied in structure " and character to those which are now peculiar to " hot climates, in the secondary strata, as well as in " the diluvium of high north latitudes, render it more 
" probable that the climate was warm in which these "plants and animals lived and died, than that a " change of constitution and habits should have taken "place in so many animal and vegetable genera, the " existing members of which are rarely found, except " in the warmer regions of the present earth."

To the above, Dr. Buckland adds the "still greater " objection arising from the difficulty of maintaining "such animals as those we are considering amid the " rigours of a polar winter." To all which we may add the utter impossibility of the animals living upon the spot where their bones are now found, and to the number in which they are found, even to the "forming "whole islands composed of bones and mud at the " mouth of the Lena, and encased in icebergs." (46.)

Here, we see, that Geologists, as Dr. Buckland and M. Cuvier, who embrace the same general system of Geological revolutions and formations, divide upon the subject (not whether these animals did indeed occupy the north, for they are both firm in the assurance that they did, but) whether the CLIMATE has changed its character, or the VEGETABLES and ANIMALS, theirs. For a change in one must have taken " place, if it be TRUE that these vegetables and animals once lived and thrived in the north, which can now only subsist in the south. I did not intend to give any opinion upon this difficult subject. But I cannot help expressing, in conformity with what I before observed, that these authors are very probably both wrong to a very considerable degree.

The "vegetables" in the northern climates appear to me to form a much greater difficulty than 
the animals; because we have no analogy which bears any testimony that such gigantic vegetable productions, as occur in some parts of the northern regions among the fossil strata, could ever be produced but in a warm climate. And to think of removing the difficulty by saying, "the vegetables have changed their nature,' appears quite absurd. For we might as well say at once, that they growed by miracle. But such animals could never live, it must be admitted, in regions bound up for many months together, under ice and snow.

In admitting, then, as I have before somewhat hesitatingly admitted, that tropical animals did, before the Deluge, occupy the north, I could by no means allow that they lived so far north, as our authors contend that they lived. They might, however, I think, live in England, and in the north of Germany, and where there is abundance of vegetation, even under the present climate. But with respect to their depasturing in the frozen regions of Siberia, that appears to be quite out of the question. What therefore seems pretty clear between these contending opinions and hypotheses, is

1. The "woolly"-haired animals seem not consistent with Dr. Buckland's opinion respecting a lot climate in those regions.

2. The impossibility of their wintering in Siberia is strongly against the animals inhabiting so northerly' a climate.

3. They might, however, probably obtain all their character for hair and wool, in the north of Germany and the south of Russia; and be, by the diluvial 
waters, drifted into their present situations, among the icebergs of the northern regions, and be there preserved under the mountains of ice, from the Deluge unto the present time.

This supposition makes No С н A $\mathrm{NES}$ at all necessary either in the climate or animals, greater than reason and analogy warrant.-The ANIMALS might be brought gradually from somewhere near $\boldsymbol{E} d e n$, where they were first created, into the north, BEFORE the Deluge; and AFTER IT, the same animals might gradually migrate from Ararat into the south, and there continue where we now find them.-The mounTAINS OF ICE in which so many bones are imbedded, might easily be admitted as probable, under the consideration that the Deluge (commencing as we before observed in the autumn) had to endure a northern winter. And from the circumstance of the sudden discharge of such bodies of water both from the earth and the atmosphere, it would only be analogous with what we often witness, should we suppose a degree of cold somewhat corresponding with that discharge, to have been generated by that catastrophe.

Dr. Buckland considers it "premature," and therefore declines the discussion of the CAUSE, which might occasion a change of climate in the north. But we cannot let this subject pass so. It seems extraordinary that the instant our Geologists find a difficulty, instead of meeting it fairly and giving such an answer to it as (at least) is consistent with their own Theory; they pass by and leave it behind. Dr. Buckland has laboured to "establish two important facts ; 
" 1 st. That there has been a recent and general " inundation of the globe."

" 2nd. That the animals whose remains are found " interred in the wreck of that inundation were natives " of high north latitudes, and not drifted to their pre" sent place from equatorial regions by the waters that " caused their destruction."

He further adds, that it "is nearly certain that if " a change of climate has taken place, it took place " suddenly." And further that it was probably " pro" duced by the same cause which brought on the " inundation. What this cause was, whether a change " in the inclination of the earth's axis, or the near ap" proach of a comet, or any other cause or combination " of causes purely astronomical, is a question, the dis" cussion of which is foreign to the object of the " present memoir." (47-8.)

The Quarterly Review (for October, 1823, p. 474), considers the change of climate required to have been probably effected by "a change in the position of the "poles of the earth, or of the inclination of its axis to " the plane of its orbit." And adds; "Indeed no "other cause seems adequate to the production of " those great catastrophes which have broken up the " surface of the earth, produced revolutions in the " basin of the sea, and converted its ancient bed into " nountains, hills, and plains."

Whether the Newtonian philosophy and the nature of gravitation, connected with the centripetal and centrifugal force would allow us to suppose a change to be effected in the "inclination of the earth's axis" without that change also producing a corresponding 
change in the length of the axis, and thereby a total derangement of the surface of our globe, I need not here inquire. Because the foregoing extracts suppose that, by the change in the inclination of the axis, a " dreadful catastrophe" would take place. It is plain the Reviewer considers this change in the Axis or in the position of the Poles ;

1. To have produced a change in the climate.

2. A revolution in the earth and sea, and such a revolution as hath racked the earth to pieces.

As this hypothesis is alluded to by himself, (and apparently adopted by the Reviewer), in order to account for the change of climate which Dr. Buckland's Theory makes necessary; I would observe that this hypothesis will not answer the design, but rather destroy it.

For either this change in the earth and its accompanying catastrophe took place at our Deluge or they did not.

First ; If they did not, the design is not answered, the change of climate at our Deluge is not accounted for. For certainly the bones of elephants, \&c. were deposited by the Deluge, and the animals must, by this Theory, have lived and died where they are found.

Secondly, If these changes did take place at the Deluge, the Theory itself which makes the change necessary, will be destroyed. For,

(1.) The modern " Theory of the Earth," promulgated by M. Cuvier, and adopted by Dr. Buckland, every where supposes (and, indeed, would be utterly ruined, were it otherwise) that the Earth, at the 
Noahic Deluge did not undergo any material change at all; and that the sea and land did, on no account, then change places.

(2.) But especially Dr. Buckland's Theory of the Caves, and of the superficial gravel and loam, entirely depends upon there having been next to no change effected in any substantial parts of our globe. Yea, he every where supposes that the caves and the coasts, the water, and the land, are, even to a few feet, what they were before the Flood. It is clear, however, that the REvoLUTION in the earth which the Reviewer supposes to have occurred by a change in the inclination of the earth's axis, would have entirely dislocated and deranged the whole surfuce of the earth. I say, surface; for, even in the most ancient and disruptive catastrophes, the "Theory of: the Earth" will not allow that any but a superficial breaking up of the globe ever occurred; and that the "primitive rocks" were never destroyed by them. The Scriptural account, too, of the Deluge, is clearly opposed to any violent derangement of the substantial parts of the earth.

A catastrophe, therefore, like the one contemplated, must needs have disturbed and entirely removed, a large portion of the secondary strata from one part of the Earth to another. For, without this, the globe could not have suffered great disruption by the Deluge.

This hypothesis respecting a change: in the earth's axis, and a revolution consequent upon it, as it would destroy Dr. Buckland's Theory of the caves, and of the superficial loam and gravel, so it would not account for the woolly coats of the animals which 
were frozen up in the ice. For, as Dr. Buckland and M. Cuvier observe, the change must have taken place suddenly, and their carcases must have been frozen suddenly, or, in the hot climate which is contended for, they would soon have putrified. But where, in this hot climate, did these animals obtain their woolly coats, which are peculiar to cold climates?

I should not have thought it necessary to say so much upon this point, but for the consideration that Dr. Buckland's hypothesis respecting the animals occupying the northern climates before the Flood, is so deeply affected by this other admission respecting the cause of that change of climate. which he supposes to have been necessary.

II. The change in the nature of the A N I MA LS.

As a change of climate cannot be supported consistently with either philosophy or Dr. Buckland's Theory of the Caves, we must of necessity admit a change in the nature of the animals. But to what will this admission lead? Dr. Buckland says "Cuvier "adds the further fact, that there are genera of " existing animals, e. $g$. the fox tribe, which have "species adapted to the extremes both of polar and " tropical climates.".

But may we not ask why these foxes should be considered as different species of this tribe? Do they differ more from each other than the different varIETIEs of the "human species" differ from each other? Let M. Cuvier answer. "Thus (he writes,) although " the wolf and the fox inhabit all the climates " from the frigid to the torrid zone, we hardly find 
" any other differences among them through the whole " of that vast space, than a little more or a little less " beauty in their furs. I have compared the skulls of "foxes from the most northern regions, and from "Egypt, with those of France, and found no dif" ferences, but what might naturally be expected in " different individuals." (117.)

Assuredly, then, these are not different species of foxes by M. Cuvier's own shewing. He says

" $A$ specics comprehends all the individuals which " descend from each other, or from a common paren"tage, and those which resemblc them as much as they " do each other."

From the above extracts from Dr. Buckland's and M. Cuvier's writings, it would almost appear that, among our Geologists, the marks which divide the species of the same genus appear and disappear as the occasion requires. One thing, however, is evident from M. Cuvier's definition above given, it appears that from the "frigid to the torrid zone," there is but ONE SPECIES of fox and of wolf in existence. Because, he expressly says that the "differences among them" are those of "individuals," and not of the species. And, from the Bible, we learn, that there is only one species of the human race in all the climates of the globe.

Hence, then, we perceive that it is not the CLIM A TE which designates the species, because the same species live in all climates. Then, it will not follow that elephants in the north are proved, from that circumstance, to be of a different species from those in the south. Before M. Cuvier, therefore, can be allowed 
to have adduced, even a probability, that the fossil elephants are a different species from existing ones, he must either prove that our existing species lived in the south, when his fossil ones lived in the north, or that they have been newly created since the Deluge.

But we have before proved that the modern Geological Theory is defective in both these respects. It professes, as far as it professes any thing, that all its researches into the fossil strata do not exhibit one specimen of the existing species of elephants, \&c. in the antediluvian world of animals: and M. Cuvier says he does not advocate new creations. The inference, then, is plain; M. Cuvier has no adequate data for concluding the fossil elephants, \&c., of the north to be different species from the existing species of the south. For, surely, if all were allowed that M. Cuvier argues respecting Egyptian mummies of the most ancient date, proving their subjects to have had not the "smallest difference" from animals of the same "species which we now see," it has no parallelism to prove any thing between antediluvian animals and existing animals, or between animals in the frigid and those in the torrid zone. The whole, then, about even a difference of species, is gratuitous. The genus is admitted to be the same. Therefore, a CHANGE has somewhere taken place.

If then the same genus may possess different species which can accommodate their nature and habits to such various climates - or if even the same species may vary so much as to be able to occupy all climates, on what adequate ground will M. Cuvier deny that animals which vary so greatly in their propensities and 
mode of living, may not also by change of time, place, and food, become also as variable in their form and size?

The consequence of all this is the destruction of the modern Theory of Geology. It is built upon distinctions which are not proved, and upon the supposition of permanences which are found to be changeable. If Geology have any meaning, animals before the Deluge were found only in the north, which are now found only in the south. Analogy would therefore lead us to conclude that the animals are the same species; but being divided from each other by the distance of 4 or 5000 years, and by all the variations produced by a southern, instead of a northern climate, and being probably more under the eye and controul of man, has produced the differences which we witness,-differences probably not greater than ought to be expected under circumstances like those we contemplate.

Thus, all things are straight. The Bible, and reason, and philosophy, unite. While, on the ground of Geologists, every thing is inconsistent and unaccountable. For, if we reject the possibility that the same species of animals can live in different climates, we must resort to that grand absurdity - that all the different species of animals on the globe were created after the Deluge, in the respective situations where we find them!!! 


\section{CHAPTER VIII.}

\section{MISCELLANEOUS SUBJECTS.}

DR. BUCKLAND.

IT will probably be inquired, with some anxiety, what then has Dr. Buckland proved? he has professed to come forward armed with new evidence, and furnished with documents which, till of late, have been entirely concealed from the view of mankind; have these discoveries thrown no light upon the dark and mysterious science of Geology, and upon the state of things in the antediluvial world? To this I would answer, that Dr. Buckland's Cave Theory proves nothing whatever respecting the DeLUGE; because the Caves are certainly post-diluvian.-His denudations, moreover, we have seen, prove nothing, upon his principles, because those principles are found to be erroneous.

If, however, we lay aside, as useless, or rather much worse than useless, the Theories of Geologists as wholly unsupported and untrue, we shall see that Dr. Buckland has done much in proof of the Scrip. tural Deluge. We shall recapitulate a few particulars. The caves, fissures, breccias, \&c.; of which he has said 
a good deal, all come to nothing, by reason of one general failure--they are all post-diluvian. But

I. With respect to ancient animals in the strata.

(1.) The facts which Dr. Buckland, in connexion with other Geologists, has laid before the world, are very important. In the case of animals, such as the elephant, rhinoceros, hippopotamus, and hyæna, though we have no certain reason to say, with Geologists, that they are EXTINCT species, we gain a very strong argument from their peculiarity, in favour of a grand epoch-an extensive, and as far as it respects such animals,-universal change. The whole of the northern hemisphere is furnished with fossil remains which do not now exist there; and whether these remains were imbedded where they formerly lived, or were drifted from some other part of the globe, there is nothing but the Scriptural Deluge which affords any explanation of such phenomena.

Had all the animals lived now in the situations where these bones are found, it might have been a question whether such deposits were not the effect of natural causes. But now they bespeak the necessity of some such event as the Deluge, both to destroy those animals, if they dwelt in the north, and introduce them into a south climate, and to drift them thither, if they never dwelt north before the Deluge.

(2.) The situation of the animals in the north, especially in the ice banks about the rivers, and in mountains of ice such as ordinary floods never produce; and the circumstance of marine productions, in union with these animals in situations where the sea never does, under ordinary circumstances, come, is demonstrative 
proof of a catastrophe such as the Scriptures reveal. The elevated position in which many of the bones of which Dr. Buckland has given us the history, appears again to shew that an universal Deluge must have floated them thither.

(3.) The situation of the valleys and secondary hills, \&c., which our author has described, seem evidently to point out a diluvial action, such as common floods never exhibit. Various other points, to which 1 need not allude, are capable of being made subservient to the same event.

II. But the Theory of modern Geologists embrangles, confounds, divides, and thereby destroys the evidence which naturally belongs to the case.

1. Then extinct animals, in the first place, make it impossible for Dr. Buckland or any one else, holding his system, to bring them as evidence of our Deluge, when their Theory makes them peculiar to preceding catastrophes. ${ }^{\text {h }}$ But view these animals independent of Theory, and their evidence in favour of one universal Deluge is irresistible.

2. But the shells, and the rocky strata which envelope millions of sea animals, and sea as well as land productions, are a body of evidence in favour of a Deluge, which no ingenuity can ever resist. But

n Let it not be said that I here misiepresent Dr. Buckland's Theory, for that he always considers the extinct species to have been destroyed by the Deluge, and not as I have supposed by former revolutions. This, I admit, but he does it for the purpose of obtaining their" evidence in favour of Noah's Flood, of which he has scarcely a particle of proof, without these extinct species. But let it be remembered that (as we have often shewn) he applies the extinct species to the Deluge, in direct violation of the general "Theory of the earth" of which we are above speaking. 
here again, Dr. Buckland's Theory makes him rob the Bible of the evidence which is its just and natural due. He gives the testimony of these-which is infinitely the strongest testimony which the strata afford of the Bible Deluge-to other and prior revolutions: while those revolutions are so uumerous and so undefined, that nothing but confusion and uncertainty arise out of them.

3. Dr. Buckland's evidence, therefore, even when stripped of his Theory which is the bane of his evidence, is still IMPERFECT, as it only goes over a part of the phenomena, which ought to have been produced. If he had exercised his Geological talents in shewing that the "fossil strata" generally are of "Diluvial origin," he would have deserved well of every friend to biblical and philosophical truth.

4. His attempt moreover, is not only imperfect but as far as the caves go, it is unjust and erroneous. By bringing forward as evidence of the Deluge what is manifestly post-diluvian; namely, his animaltenanted caves; he gives an air of antiquity to recent occurrences, and throws a false gloss over the whole discussion.

It is, moreover, injurious. Because, while it professes to prove the operations in the cave to be "diluvial," it necessarily leaves it manifest that the caves themselves must be ante-diluvian; which, on the Scriptural data they cannot possibly be. Thus while credit, from a spurious source, is professedly given to one portion of Holy Writ, discredit is thrown upon another. This is almost like taking a man, in friendship, by one hand, while we are cutting off the other. 
5. Dr. Buckland, then, to speak in their own language, is GENERICALLY right but SPECIFICALLY wrong. He is right (though not upon his own system) in making "ancient animals" evidence of THE DeLUGE; but he is wrong in producing the bones in the caves as evidence of that event, and in producing ONLY THIS KIND of "fossil remains," when he ought to have adduced every lind of fossils, save those of modern occurrence, as evidence of Noah's Flood, instead of placing the fossils, in what he calls the "regular strata," to the account of "MORE A NCIENT REVOLUTIONS."

III. I am far from wishing it to be understood that Dr. Buckland is not sincerely and earnestly desirous of proving the Mosaic Deluge. But I do not feel easy at the manner in which he has attempted to do it. He considers that the "truth of the Mosaic records is-materially involved" in the proof of the reality "of an universal Deluge." I think so too. But surely it will effect more materially the truth of the Mosaic records if we leave it to be inferred that those records have published the grossest errors, in the very point respecting which of all others they profess to be best informed. The following words, "In six days the Lord made heaven and earth, the sea and all that in them is ;" are a part of the ten commandments, they are several times repeated-and come to us with a stamp of truth peculiar to those commandmentsthey were "written with the finger of God:" "and "the writing was the writing of God graven upon the "tables." - I hold it impossible that modern Geology, under any profession or apology, can do justice to 
Revelation after leaving upon the above sentences, \&c. the imputation of error, mistake, or falsehood.-But I must not further anticipate a future subject.

\section{CHRONOMETERS.}

The chronology of Geologists, though a point of very great importance to their Theory, is not only imperfect, but like almost every other part of their system, without data. It is however quite obvious that nothing whatever of a scientific character can be fairly established, unless some ideas, as to time can be satisfactorily fixed upon. But it does not appear that any data upon which to build any fixed periods, are obtained, or can be obtained by Geologists. - We shall only glance, at a few particulars connected with this interminable subject.-We shall notice two periodstheir views of time before the Deluge and after it.

Antediluvian Chronometers.

There are Two chronometers-the strata and the fossils - by which Geologists profess to establish their Theory of formations which they esteem ancient; i.e. not only antediluvian, but probably "thousands of ages," before the Deluge. I need not pursue a subject of this description extensively, and shall therefore content myself with adducing one or two instances.

1. The strata.

M. Cuvier, as we have often seen, states that a vast time must have elapsed, during the formation of the rocky strata.

But respecting either the manner or time of the formations, Geologists have no data for the establishing 
any opinion. They never witnessed the formation of such strata; and on their own ground, they never can witness it; because their perpetual statement is, that the formation of such strata has "long ago ceased." It is moreover impossible that they should even give any probable guess; for there is, according to their Theory, not only no such operations now taking place; but there are none of the same "causes" to be any where discovered: so that no operation in nature is, at the present period, to be found which has any, even the most distant analogy or agreement with them.-But this we have already noticed. And the whole depends upon the next topic.

2. The fossils.

The fossil remains in the strata may be reasonably supposed to afiord some data respecting the formation of the strata in which they are imbedded. But there is a great deal of fallacy generated here by erroneous Theories. Unless we knew something about the mode of their formation, we have no data, respecting the time which they took up in being formed. Now there are obviously two ways in which we may imagine those fossil strata to have been deposited.

1. The slow and gradual agglutination of the shells of fishes which died in the course of nature, and which formed by degrees even mountains of shell-limestone rocks and marble rocks, at the bottom of the sea.

2. The ejection of the bottom of the sea, by the out-breaking of the diluvial waters from beneath it, when there might be large collections of shells in the bed of the sea from which collections the Deluge, by its deposits of slimy debris, \&c. might form the existing strata. 
Of these two statements Geologists take the former; We on the other hand, have largely endeavoured to prove that the true, correct, and only way in which they may rationally and Scripturally be accounted for', is the latter.

An argument is used to advocate the former sentiment, by a writer in the Quarterly Review, for September 1826. He writes thus;

"Their organic contents indicate successive changes " in animal and vegetable life, and the study of the " whole phenomena attending them has uniformly im" pressed the minds of naturalists that periods of great " duration elapsed during their accumulation."(p. 536) The same views are strongly maintained in the Edinburgh Encyclopædia. (Article, Fossil remains, p.735.) "Impressed the minds of naturalists." Upon what principles, and calculating upon what data? The impression on the mind of a naturalist, is nothing better than the impression on the mind of an enthusiast, unless he can give some rational account of the cause of the impression;- - unless he can give reasonable grounds and reasonable arguments for his impression. It is useless saying, it "has uniformly impressed" their minds. Multitudes do nothing if truth be not on their side. But, as a fact, it is not correct. For it is only a modern impression, and not "uniformly" so even now. We have before observed M. Cuvier himself acknowledges, that " during a long time, two events or epochs only, the Creation and the Deluge, were admitted." And before the infidelity of the Continent introduced the modern Theory, I believe, the opinion was as uniformly for two epochs 
only, as it is now for many. And when infidelity loses its influence and the enthusiasm of modern Geologists has had time to cool, that rational and Scriptural sentiment, the belief of "two epochs only,"the "Creation and the Deluge,"-will become general a second time.

In the works above alluded to, the arguments for "slow" and "tedious production," and for "periods of great duration," it is evident that the very point which is the subject of dispute and difficulty is taken for granted; that is, the mode of the formation of the STRATA; for with respect to the Fossils it is impossible for any man to say that the SIXTEEN CENTURIES which elapsed between the Creation and the Delnge would not be a sufficient time for their accumulation.-With respect to the notion of "successive strata" and "changes (among animals) in their species and genera" which "indicate the slow succession in which these rocks were formed," we have largely shewn that the Theory involved in that language is neither true nor practicable. - "Changes in the species and genera" involve, as we have also shewn, new Creations. But Creation is a miracle. And we have as much right to say a miracle created these fossils IN THESTR A TA as we now find them, as to say a miracle created them in the sea, and then afterwards placed them in these mountains.

It is perfectly certain, if we assume data which are not supplied us by Revelation or by the operations of nature, we resort to miraculous causes. But having done this, we cannot reason upon the nature, the manner, or the time of those causes, or their operations. 
'The reason is, we have no DATA RESPECTING MIRACLES. And if we were to argue from analogy, which is all we have from which to argue, that a subsequent miracle will be of such a certain character because the miracle was so which went before it, we destroy the character of iniracles, and merge them in the course of nature.

The truth is we have no DATA by which to calculate, with any probability of correctness, the time either for animals increasing, or for the process of rocks in their formation; 1600 years might surely, for aught we know to the contrary, be time enough for animal remains to collect in the sea. And as animals were not allowed to be eaten by the antediluvians, we have no authority to assert that shell fish were then greatly disturbed by man. Their vast numbers, therefore, might easily be allowed. We are informed that a gentleman in India placed a few snails in a vessel, and it soon became filled with them.

Post-miluvian CHRONOMETERS.

These are more numerous. There appear to be two sources of calculating time respecting post-diluvian occurrences ; - the one may be called moral, the other natural. The former consists in the marks of civilization and the progress of the arts and sciences among mankind; the latter, in various natural events which are taking place in the operations of nature. These consist in the deposit of rivers - the progress of sand in forming downs by the sea coasts - the disintigration of hills - the growth of coral islands-the formation of peat bogs, \&c.

I. The natural chronometers. 
Respecting the changes which are every where taking place on the face of the Globe, though nothing of a very visible difference is perceived, I shall not say much. 1. Because the data which they afford for the calculation of the time which elapses are very imperfect. And 2. Because, however accurate they might be, they do not apply as any data for calculating ancient formations. If none of the causes which disintegrate mountains or form downs, were the causes concerned in those ancient changes, we can derive no analogy from which to judge of one by the other. The whole importance therefore of modern calculations arises from another source.-I do not find the least reasonable foundation upon which, in consistence with their own Theory, M. Cuvier can make the following deduction (which Dr. Buckland applauds) either as it respects the specific Deluge of the Bible, or the period of its occurrence. He says,

"I am of opinion with M.De Luc and M. Dolomieu, " that if there is any circumstance thoroughly estab" lished in Geology, it is, that the crust of our globe, " has been subject to a great and sudden convulsion, " the epoch of which cannot be dated much further " back than 5 or 6000 years ago." (174.)

Dr. Buckland views this declaration as the result of a rational deduction of this celebrated author, from his knowledge and contemplation of the phenomena of nature alone. On the other hand, I believe we ought to view the matter in a very different light: the opinion both of M. Cuvier and of Dr. Buckland respecting this "sudden convulsion" which they suppose happened 5 or 6000 years ago, is, that it was merely 
a superficial inundation, or a sudden rushing of water out of the sea, over the earth:-an inundation causing the most external of all the fossils, (save those which are comparatively modern,) to the exclusion of all the ancient genera, and even the extinct species.

Concerning such a sudden convulsion, (as we have particularly shewn, when considering the specific evidence which M. Cuvier and Dr. Buckland, have adduced in proof of the Scriptural Deluge,) Geologists have produced no testimony from natural phenomena. Nor can they, because there is none which does not utterly destroy their own Theory. I consider the passage of M. Cuvier above quoted, not as being dictated by the force of Geological appearances arising out of his modern Theory, but rather as an admission of a fact so firmly established by the united testimony of all historians, sacred and civil, that it cannot, with any propriety be denied.

Voltaire, I admit, had boldness enough to deny the fact of the Deluge, because it so strongly corroborated the truth of the sacred narrative. And I conceive we allow too much to modern unbelievers if we suppose that they would so readily admit the fact of the Scriptural Deluge, if they had not contrived to evade the natural infercnce by a system which merges it in numerous revolutions.

M. Cuvier conceives "that the human race has " only resumed a progressive state of improvement " since that epoch, by forming established societies, " raising monuments, collecting natural facts, and con" structing systems of science and learning." (Ib.)

With respect to this "progressive" state of improve- 
ment which the individuals who escaped that catastrophe have "resumed," I can only say, that so far as the progress of arts and sciences is made a criterion of the age of the human race, or of the time which has elapsed since the Deluge, it is an.ambiguous, and, as used by our modern philosophers, a false criterion. The chronological system of Geologists involves troo errors of vast importance, which a due attention to the history and narrative of Moses, ought to have corrected.

1. It supposes that the human race commenced its career in a state of barbarism, and has ever since, been gradually improving.

2. It does not recognize moral causes as having any concern in the physical changes of the globe.

1. With respect to the original barbarism of the human race it is bad in divinity and false in fact. And it is in close alliance with that sentiment of atheism which supposes that the animals have arisen by time and acquirements, from animalcules and monads, to quadrupeds and men. It is impossible to believe the Mosaic narrative of the human race without learning from it that man was originally made in the "image of God." And that that "image," whatever else it might embrace, included especially the intellectual and moral character and likeness of the Divine Author of his nature.-The same narrative assures us, that it is erroneous in fact.

Adam not only paid due respect and obedience to his Maker when, at first all the works of Creation were pronounced "very good ;" but he discovered a high degree of intellectual endowment and wise insight 
into the natural character of his fellow creatures. He gave an appropriate name to his Wife, and names to all Cattle significant of their nature and propensities. When, therefore, Man first came out of his Creator's hands, he exceeded in knowledge and wisdom all our naturalists and philosophers as much as they exceed a child at school. It is true indeed that his intellect very soon deteriorated with the loss of his moral character, by his departure from the Most High; but even then, he was far enough from becoming instantly savage or barbarous.

Of the Antediluvian inhabitants of the globe we know comparatively little; but the same divine historian informs us in Genesis, that both music and the arts were cultivated. From Noah and his Wife sprang the human race after the Flood; at least so far as respects the male line of our antediluvian progenitors. And they could not lose in the Ark the knowledge which they previously possessed. Their erections and works of art were, of course, destroyed; but as this family themselves constructed that astonishing building, the Ark, they could not be ignorant of architecture. - How absurd, then, to represent the incipient race of men as building their rustic huts with a few sticks across, and a little grass, moss, or sods upon their top for a covering ! - In the nineteenth century we surely do ourselves great dishonour by thus becoming retrograde in our perceptions of moral evidence and of the divine record, by the adoption of a sentiment so barbarous and unnatural. The world, deteriorated by its fall from moral rectitude, and after the "Tower of Babel" was attempted and frustrated, the art of build- 
ing and the enjoyments of civil society soon became little known to a large portion of the human race.

2. Physical changes from moral causes.

This is nearly allied to the former, and to many important matters in this discussion, especially the Deluge. Geology never recognises moral evil as the cause of natural catastrophes. And yet if there be one principle more true than another, and more deeply fixed in the thoughts of every well regulated mind, it is the principle which assures us that the "Judge of all the earth will do right." Not only the instruction of the Bible, but every thing we see and feel, convinces our unprejudiced minds, that natural evil never precedes moral evil; and that sin is the author of pain, as well as of death.

The bearing of these truths upon many of the marks by which modern Geologists and philosophers judge of the age of man, and of the time which has elapsed since the last catastrophe, is obvious. Moral causes have produced the changes. The Bible unfolds the mystery:

"A fruitful land (he turneth) into barrenness for the wickedness of those that dwell therein."

And how does the offended Observer of the conduct of man execute his divine displeasure? By drying up their rivers, or by covering the fruitful soil with sand from the sea shore. It is no objection to this principle, that arbitrary rulers, and loss of independence and industry, may be often concerned as the immediate negative cause of these evils. For these are themselves a part of the punishment of a guilty people. 
But such events as are looked to for the purpose of chronometers, are apparently inflicted by the more visible hand of God. Many ancient, rich, and once flourishing towns and villages are now buried, to the height of their highest turrets, under a mass of sand, drifted by the winds from the sea shore into the interior of Egypt, \&c. It is more than probable, that had such men as Joseph lived in Egypt from before the time of Moses to the present day, the "sands of the desert" would have been a fruitful field. And no one can say that certain vegetables, or a forest, planted early in the way of its progress, might not have warded off great part of the mischief.-The flight of sand is as certainly under the Divine direction, as the flight of locusts, and may be truly employed with the same wise and just intentions of chastising an apostate nation.

Are there not, however, in the page of HISTORY, counter indications to " the progressive state of improvement" assumed by our Geologists ?

It is certain that mankind, since the fall, do not naturally exhibit a "progressive state of improvement" in civilization, in the arts, and in useful knowledge. And of this our Geologists must be aware. Yea, they well know, that many nations, once the glory of the world, have degenerated into gross ignorance and a partial barbarism. From Egypt to Persia, monuments of departed greatness are every where visible.-Where is the ancient Pharos of the Nile? Where is Tyre? Where is Tadmor? Where is Babylon and Persepolis? Anıl, above all, where are the magnificent Temple of Solomon, and even the city in which it was built? Those who look only to 
" natural causes," may choose to merge the mystery here in the change of governments, the tyranny and oppression under which the people groan, and the consequent loss of liberty, energy, and industry. True. But what occasioned these changes, these oppressions, this loss of intellectual and mental energy?

The cause was moral. The Bible reveals the secret. The downfall of these places, and their consequent slavery or dispersion, were almost as clearly foretold by the Prophets, as they were subsequently recorded in history? "Egypt shall be a desolation:" "Babylon shall sink, and shall not rise from the evil that I will bring upon her :" and the MORAL CAUSE is as clearly declared; "they have shed innocent blood in their land." (Joel iii. Jer. li.)

- Can any man resist the evidence from Scripture respecting the transfer of the Four Great Monarchies, the Babylonian, the Persian, the Grecian, and the Roman? and that the cause was moral? Is that Divine declaration "Jerusalem shall be trodden down of the Gentiles?" and is the predicted dispersion of the Jews to go for nothing with us ? Why are these standing living monuments overlooked or disregarded? How are we to account for this? Where is the cause? Does this arise from a "progressive state of improvement in the human mind?"

This subject may be delicate: it may, in some of its ramifications, be difficult. But the broad truth is, and that truth confirmed by undeniable and extensive facts, that MORAL CAUSES have actually changed the whole face of society in Europe, and in a great portion of Asia, within the epochs to which authentic 
history reaches. Why is ancient Palestine, which was once the "glory of all lands," become a proverb for degradation? And why is England, which was once a mere appendage to Rome, now mistress of so large a portion of the globe?-The answer is plain, and the evidence irresistible,_Moral causes have done this. The blessing of the Most High departed from his ancient people, because they rejected his Word, and crucified his Son; and the blessing of the Almighty has rested upon England, because she adhered to God and to his Truth in its purity, while great part of the professing Christian world still dishonoured him and his Word, by their antichristian tyranny, by their religious barbarisms, and their halfheathenish idolatries.-Let Britain, however, "not be high-minded, but fear!'”

May we not ask here whether these tangible-these historical facts, do not indicate their appropriate-their moral causes? And indicate them too, far more legibly and conclusively than, do numerous natural phenomena, upon which our Geologists rely, as indexes of certain epochs of time. It need not be doubted that numerous natural phenomena-as the increase of turf bogs - the deposit of many rivers - the washing down of cliffs, \&c. \&c. vary not a little with the state of the inhabitants, the cultivation of the soil, and the national or local improvements which may have been made. And, certainly, the industry, the wealth, and the improvements of society very much depend, proximately or remotely, on the moral character of those societies. Two things are obvious.

1. That the calculations, both from natural and civil phenomena, respecting the epochs of the world, 
the age of man, on the "progressive improvement" of the human race, are often very ambiguous, and must ultimately prove fallacious, if the moral causes of many and various changes are not taken into the account.

2. That Geologists have run into all the errors which we contemplate, from their rejecting the aid of the Bible, in the construction of their Theory.

\section{NEGLECT OF REVELATION.}

1. With respect to many of the Continental Geologists who have aimed at the undermining of Revealed truth, by their anti-christian speculations, the matter is plain; the Scripture here applies, "Because they received not the love of the truth-God hath sent them strong delusion, that they should believe a lie." The extraordinary anomalies and absurdities, therefore, into which they have fallen, may be easily accounted for. They aimed their shafts at Divine truth, and they are turned against themselves. More gross departures from the wise exercise of a rational and accountable mind are not easily to be found, than are demonstrably unfolded in the Theories of Geologists. - The cause is moral. "Professing themselves to be wise, they became fools."-Thus that word which they despise and oppose, both predicts their character, and overthrows their machinations.

Probably such authors may feel indignant that a person, displaying no acquaintance with their science, should have the presumption to call their speculations in question; and the more so, because he professedly 
derives the essential parts of his argument from the Word of God. If such persons, however, would only do justice to their character, as men of science, and candidly attend to the counsel of that Word which they despise, they would then learn that the Almighty has ways and means of bringing their devices to nought, of which they have little apprehension. They would perceive it recorded that God maketh "foolish the wisdom of this world." And that, on some special occasions, "God hath chosen the foolish things of " the world to confound the wise; and weak things of " the world to confound the things that are mighty; "And base things of the world, and things which are " despised, hath God chosen, yea, and things which " are not, to bring to nought things that are; That "no Alesh should glory in his presence. (1 Cor. i. 20, 27.)

2. But with respect to Geologists who profess Christianity, the case is somewhat different, and not so easy to be accounted for. Nor can it, I think, be accounted for, without reflecting discredit upon themselves. Though they have no intention to injure the Word of God, they do not pay respect to their acknowledgement of its worth and character. If they believe the Bible to be indeed a Revelation from Heaven, that Revelation must be true, and useful to every purpose to which it applies. But it expressly professes to give us information upon the subjects both of the Creation and the Deluge. Notwithstanding this, all the USE to which I can find our modern Geologists, applying the Scripture is, to make men. tion of it, and then devise some: way "(by certair 
hypotheses, perhaps) of getting rid of it as soon as possible. It is perfectly clear, in every part of their discussions, that they approach the Bible with reluctance, and leave it the first opportunity.

\section{BIBLE ADVOCATES.}

It will very probably be said in excuse of Geologists and reproof of me, that those who have professed to adhere to the Scriptures, and to derive their instruction, respecting these matters from the Sacred pages, have only exposed the Bible and made themselves ridiculous; and therefore modern Geologists and Divines both, have thought it better and wiser to leave the Scriptural narrative pretty much out of the question. Such authors, it may be said, yea, has been said, as Granville Penn, Esq. and Mr. Catcott have too nearly approached to the danger expressed in the preceding sentence; and have neither afforded assistance to Geology nor defence to the Sacred Records.

In answer to the above objection, I would make a remark or two. And I must admit with respect to that learned and very respectable author, Granville Penn, Esq. that, though I have a very high opinion, generally, both of his philosophical discussions with physical Geologists, and of his answer to Mr. Faber's extension of the Sabbath Day; I cannot consider his Theory as either Scriptural or practicable.-Respecting Mr. Catcott, I shall transcribe a passage from the Quarterly Review, for Sept. 1823, where, in reviewing and extolling Dr. Buckland's “ Reliquiæ Diluvianæ," the writer makes the following remarks respecting Mr. Catcott. 
"Wedded to his hypothesis, that all these pheno" mena are the effects of this one single catastrophe, " he is driven to adopt the absurd conclusion, that " the whole crust of the globe was then dissolved into " a soft pulp, which gradually hardened again and in"closed those remains in the several strata as they hap" pened to be dispersed through the waters of the De" luge; not offering a syllable to explain how the same "process, which, according to him reduced the solid " rocks and even metalic instruments to a fluid, yet " spared not only bones and teeth, but all the myriads " of animal exuviæ preserved as we find them, even " in their finest and most delicate forms."

"The natural consequence of these abortive at" tempts of the friends of religion was to encourage " desertion into the ranks of the enemy. Disgusted " by such preposterous reasoning and convinced of its "falsehood, men rushed, as is too common, into the " opposite error. It soon became the fashion to doubt " the truth of the Mosaic history of the Deluge, and "Linnæus even ventured to declare that he saw no " evidence of such an event in the present state of the " earth. Philosophers of the French School had long " treated it as a fable." (140.)

1. Let it be remarked that this same Reviewer, only five pages further on, censures M. Cuvier for betraying a "morbid eagerness to separate his reasonings " from Scripture, and to seek no support or confirm"ation from that quarter." But why did not this learned critic point out the true use of Scripture in Geology; and shew us the salutary medium between "preposterous reasoning" from Scripture, and none 
at all? If the friends of the Bible do not know its proper value, how should those who do not profess to believe in its pretensions ? I suspect that such procedure in the advocates of Geology and of the Bible, is little less "preposterous" than the "reasoning" of which they complain.

2. I would here observe, that neither of the authors above censured has taken the Scriptural representation as the ground work of his Theory.

-The Bible does not allow us, with Granville Penn, Esq., to suppose that the sea and land generally " Changed Places" at the Deluge.

- Nor does the Scriptural narrative inform us like Mr. Catcott, that the strata were "DissoLvED" at the Deluge; it states that they were rent, or "BROKEN UP."

3. The form and location of the strata, both in their external and internal structure, utterly forbid the notion of an universal solution of the crust of the earth at the Deluge. For, in that case, we must have expected an universally flat and smooth surface and uniform texture in the strata, unless we suppose the laws of gravitation to have been suspended; and, indeed, every law, both chemical and mechanical, with which we are acquainted.

4. The Scriptural statement, to which, I hope, it will be allowed, we have very faithfully adhered in the preceding treatise, is, as I trust, we have fully and satisfactorily seen, liable to no reasonable objection.

5. I presume, moreover, it is equally plain and satisfactory, that No OTHER scheme but what is built upon the suggestions of the Brble, can possibly explain 
How the secondary strata came into their present situation, or even consist with the EXISTING STATE of the strata.

6. With difficulties not explained in the sacred Scriptures, we have before said we do not ineddle. It is enough to justify both the Scriptures and the present writer, if the substantial portions of diluvial operations" are found to be there pointed out, and are no where else explained by man.

-And with respect to metals, or "metalic instruments," whence they came, or how they came into the strata, Geologists have no right to expect me to explain ; for, upon their own principles, they, themselves, know as little of their origin as the labourers who dig them up.

7. Geolugy, on the other hand, as we have many times seen, has difficulties perfectly destructive, not only of Scriptural verities, but of its own existence, in ways and cases almost innumerable. In allusion, however, to the Quarterly Reviewer's charges against Mr. Catcott's reasoning as " absurd," " preposterous," and false, I cannot forbear saying, that advocates of Geology should, before they censure others, exhibit a scheme of their own which is not liable to such reprehension. I do not advocate Mr. Catcott's notion of the "dissolved" strata, nor believe it to be either Scriptural or adequate; but I will say this, that it is not one quarter so "absurd" and "preposterous" as the system of modern Geology which the same learned Reviewer espouses. For

(1.) Whatever EFFEct was produced upon the " crust of the globe" at the Deluge, (had that been 
even to the dissolving of its strata,) it took place at the outbreaking of the diluvial waters, and was confined to their emission. There is no need, therefore, to suppose that the bones and shells must necessarily have been dissolved in the muddy debris in which they were subsequently imbedded.

(2.) Geology, however, in every one of its numerous formations, must suppose either that the strata previously deposited were literally " dissolved," so as to afford matter for every subsequent formation, or else that new matter (as well as new animals) was created on every catastrophe, or revolution, by the immediate hand of the Most High!!! - It is with astonishment and regret that we view, at every step, such extraordinary consequences following from modern Geology, without a "syllable to explain how" its numerous catastrophes happened, or from whence came the new "chemical changes" of the fluid for every new formation. 


\section{CHAPTER IX.}

BAD EFFECTS OF MODERN GEOLOGY ON THE BIBLE.

ALTHOUGH we have, at the commencement of this discussion, noticed much evil as connected with and actually arising out of modern Geology, in application to revealed truth, we cannot refrain from inserting a few additional remarks upon this subject. The first impression made on the mind of a considerate person reflecting upon the subject would almost certainly be this; namely, that if the $\mathrm{Di}$ vine Being should reveal to his rational and responsible creatures any thing respecting Creation, that Revelation would respect Creation as such, and not THIS or THAт Creation; but the true original beginning of the creatures ; for time, place, and parts, make no difference with the Most High. Any specification, therefore, of a transmutation in our globe, called Creation, which leaves it to be inferred that indefinite numbers of such events had gone BEFORE, would apparently be far worse than no information at all. Because it would rather intimate than deny an indefinite or INTERMINABLE SUCCESSION of revolutions.-This, however, can never be admitted as a genuine interpretation of the Mosaic narrative respecting the Creation. 
For, as an " eternal series" of formations and revolutions has been long credited in the philosophical and Gentile world, it was of infinite importance that correct notions respecting the Creation should be recorded in the Word of God. Idolatry, demonology, and the worship of the heavenly bodies, were common in the time of Moses. Surely, then, an exact narrative of the time and MANNER of Creation was a desideratum. The information, therefore, that " in six days the Lord made heaven and earth," was inconceivably desirable and momentous. Upon the truth of this information, St. Paul tells us, "by faith we understand that the worlds were framed by the Word of God." And in consequence of this the apostles went abroad among the heathen, declaring, "it is the Lord that made the heavens." "We preach unto you that ye should turn " from these vanities to the Living God, which made " heaven and earth, and the sea, and all that are " therein." Indeed, the great object of man's worship and His right to claim respect and adoration from his creatures arise so entirely out of this truth, we may be quite sure that great correctness would be attended to in the record of Creation. For this fact is made in the Bible the grand criterion of claim between the true God and idols. Obscurity, therefore, much less error, can never be contemplated in the narrative of an event so decisive and important.

M. Cuvier.

The reviewer of Dr. Buckland's " Reliquiæ Diluvianæ, as we long ago intimated, admits, indeed, that M. Cuvier makes no valuable use of the Mosaic narrative, but conceives that this celebrated Theorist had 
no bad design against revealed truth. ${ }^{1}$ We made it a particular point in discussing the subject of Geology, not to involve the chain of that discussion in any supposed designs of the authors whose opinions were particularly controverted. And now I do not find it necessary to impute to M. Cuvier motives of an hostile nature against the Bible. But when we consider that many continental Geologists have shewed a strong sceptical and even infidel bias, we might wonder the less if M. Cuvier had done the same.

Thus much, however, may be said with truth, that if M. Cuvier had studiously set himself to do mischief to the Volume of Inspiration, he could not have adopted a more effectual method. His present conduct, whether designed or not, has certainly a more injurious tendency than open hostility to the Scriptures would have had. Did not Hume and Gibbon attempt to bring discredit upon religion by inference and insinuation, more than by open and avowed hostility. And would not those celebrated historians have rejoiced at the pretended discoveries of modern Geology, and seized the opportunity of making allusions and comparisons detrimental to Revelation? Nor is it to be supposed that Geologists themselves would have been long silent upon the subject. Had their new science taken sufficiently deep root in our Christian land to warrant a hope of success, they would,

i " Even Cuvier, whose writings never indicate hostility or disrespect "towards Revelation, and who seems to have been actuated by a sincere " love of truth, yet betrays a morbid eagerness to separate his reasonings from "Scripture, and to seek no support or confirmation from that quarter." (Sep. 1823, p. 145.) 
doubtless, have had both skill and boldness enough to let us know, that as we had received Geology as true, we must confess our Bible to be false. But is it likely that Dr. Buckland, \&c., would have received their Geology, had it come to them with the bold stamp of infidelity on its front?

It may be asked, why should M. Cuvier have made so many allusions to the "book of Genesis," or why introduce it at all? He certainly does not belicve the account which Moses has recorded of the Creation; nor does he esteem it to be even near the truth. Nay, he considers (as we have seen) that his history of the human race was given in correspondence with the traditions of Egypt. Indeed, he believes the Hindoos, respecting the earth's formation, to be much nearer the truth than Moses. M. Cuvier seems togive him some credit as to the event and chronology of the Deluge, but he clearly disbelieves his account of the $A r k$ and of the whole human race as springing from the family of Noah after the Deluge.

How remarkably is that saying of the Bible-which declares that the "weakness of God is stronger than man, and the foolishness of God is wiser than man"fulfilled in modern unbelievers. Their systems and their views confront and thwart one another. Some time ago historians (as we before intimated,) endeavoured to prove the Bible to be in error, from the vast antiquity of the histories among such nations as Egvpt and India. But this assumption of antiquity by the " human race" being in direct hostility to M. Cuvier's Theory, has been met by him with a rigorous scrutiny and refutation. We ought to thank the All-wise God 
for this, and not our author. He had obviously no intention of establishing the correctness of the Bible, but the truth and antiquity of phenomena which are the foundation of his own Geological Theory.

Mystical interpretation of the Bible.

If Geologists could establish the truth of the Theory they assume, whereby they attempt to prove the immense anti,juity of our globe, and its numerous revolutions ANTERIOR to the HUMAN RACE, they would, even upon the least unfavourable construction which can be put upon the case, introduce a most unaccountable and dangerous mysticism into the interpretation of the Scriptures. We need not here repeat our former arguments upon this subject. But it is perfectly clear that the Mosaic narrative professes to be, and really is, or it is nothing, a plain H Iston $\mathrm{Y}$ of the CReation. Of such an event, it is perfectly certain, that neither Geology nor philosophy gives us the least information.

But if modern Geology be correct the Bible history is not a history of Creation, properly so called; but only a history of the last revolution but one, in (perhaps) an endless series of revolutions. As a history of creation, therefore, that narrative must be in the highest degree figurative. If, however, an historic narative is found to be so highly wrought up and coloured as to have deceived the religious world, for nearly 6000 years, into a belief that the said narrative was historically correct, what may we not apprehend from such a discovery? If we cannot depend upon the literal and only certain construction of language respecting an event with which every rational creature 
is concerned, and language moreover, expressly declared (in its essential parts) to be written by the " finger of God ;" upon what can we depend ?

If the HISTORY of Moses be a FIGURE, what are we to say of his Doctrines? What dependence can we place on the record respecting the temptation - the fall,- -and even the redemption of man, as intimated by the woman's seed? Will not these doctrines stand in danger of being proved fgurative also ? And will not Soc I I I a s gain an unanswerable argument in favour of their errors? and will they not have some pretence for turning the "mysteries of our holy religion" into Eastern mataphors, into historical figures, or poetical fictions !! It is certainly incumbent on our English Geologists, if they have any.regard for Divine truth, to shew why a "CHRISTIAN PHILOSOPHER" (as a late writer chooses to call himself) should not believe and treat the fall and redemption of man as fables; and this, too, very greatly on the alledged ground, that Grevilogy has proved the history of Creation to be fabulous!! -Such, beyond a doubt, is the genuine bearing of modern Geology, upon the Scriptures of Truth.

If the history of Creation be proved figurative, as Geology in fact would prove it to be, the $\mathrm{S}_{\text {Авватн }}$ will be figurative likewise; for it entirely depends upon the narrative of Creation. No history, however, can be plainer than those of Creation and of the institution of the Sabbath day. If these are figurative, all may be so. And our Saviour's remarkable words, "If ye had believed Moses ye would have believed me; for he zorote of me;" can never be proved to have a plain 
and intelligible meaning. But no one, surely, will deny that christianity ITSELF is, in no small degree, suspended upon the certainty that Moses zorote of Christ, and that there is an intelligible correspondence between the prophetic description given by Moses, and the fulfilment of it in our Lord and Saviour Jesus Christ.

\section{The Hindoos.}

This people, who are now becoming more interesting from our connexion with them, have contrived to extend the history of their origin to more than "two millious of years." Although M. Cuvier rejects this extravagant fiction, he tells us; "Yet the Hindoos " are not entirely ignorant of the revolutions which " have affected the globe, as their theolugy has in some " measure consecrated certain destructions which its "surface has already undergone, and is still doomed “to experience." (160.)

It may not be amiss to observe here, that M. Cuvier, in the above quotation, gives the Hindoos credit for possessing a "Theology" which not only recognizes and consecrates past "revolutions" in the earth, of which the Bible knows nothing, but which actually predicts or forelells revolutions which it " is still doomed to experience." Where the Hindoos obtained this information, M. Cuvier does not say. But we can think of but two sources from which such information could even be supposed to have been derived; namely, Geology and Revelation. Our author, I believe, never makes an acknowledgment respecting any predictions contained in the Bible. And we suspect that, in the decided preference which in the 
above particulars, he has given to the Theology of the Hindoos, he has brought himself into an awkward dilemma.

Either the Hindoos possessed, as far back as "three thousand two hundred years, which nearly corresponds with the epoch of Moses ;" their Geologists equal, at least, to M. Cuvier in skill and knowledge of the strata; or they possessed communications which were supernatural. Without stopping to argue these points, it may be important to observe, (as the sacred books of the Hindoos, which lead M. Cuvier to make the above statements, "go back" as far, according to his opinion, as about the time of Moses,) that either Moses possessed information equally good with the Hindoos, or he did not. If he did, we see the injustice of M. Cuvier in giving his confidence to their writings in preference to those of Moses. If he did not, M. Cuvier ought to have satisfied us how the Hindoos came to be so much better informed than the man to whom the "Lord spake face to face," "as a man speaketh unto his friend."

The translator of M. Cuvier's Theory has given us the following information in a note. (160.) "We " may fix the time of Buddah, or the ninth great " incarnation of Vishnu, in the year 1014 before the " birth of Christ. The Cashmirians, who boast of " his descent in their kingdom, assert that he appeared " on earth about two centuries after Crishna, the "Indian Apollo.-As the three first avatars, or de"scents of Vishnu, relate no less clearly to an univer" sal Deluge, in which eight persons only were saved, "than the fourth and fifth do to the punishment of 
" impiety, and the humiliation of the proud ; we may, " for the present, assume, that the second, or silver " age of the Hindus was subsequent to the dispersion " from Babel." (Works of Sir Wm. Jones, I. 29. 4to, Lon. 1799.)

From the above extracts, in connexion with the decisions of modern Geology, we may observe, if revolutions have taken place in the earth with which the Hindoos were acquainted, and the sacred writers were not, it will follow, that the Bible must so far have been written under information greatly inferior to that of the Fables of the East; because it comprises within "SIX D A X s" the operations which Hindoos and Geologists well know to have taken up "thousands of ages." Or, if we suppose that the Scriptures knew nothing of those prior formations and revolutions, the ignorance and error of its writers are the more remarkable. For they profess to speak of the original Creation ; and, therefore, of all they know, and of all they suppose can be known. To profess, moreover, an acquaintance with the works of God, and with the time and mode of their formation, of which (according to the conclusions from Geology) they, in fact, know nothing, implies an arrogance and presumption which admit of no palliation or excuse. Even Saint Paul must have been guilty of worse than solemn trifling, if Geology says true, when he declares that by "faith we understand that the worlds were framed ;" when, in truth, it appears that we understand nothing about it.

If Geologists be right, even the claim to respect and adoration which the Almighty makes for himself 
in opposition to that of $i d o l s$, on the recorded fact that he made the earth and the heavens, will be taken from him. For thus the Hindoos can confront Moses in the description of this important matter, and will be likely, therefore, to confirm themselves in their heathenish superstitions. If the Bible be thus interpreted, the notion of M. Cuvier-that Moses recorded an Egyptian tradition and not Divine truth, respecting the origin of the world and of the human race-may perhaps become a received opinion among Divines, and be looked upon as the most rational way of accounting for the extraordinary errors which he has committed.

And if so, the records of Creation, throughout the Bible, must be henceforth viewed as less veritable and less authentic than the parallel records of Hindostan. And, in the very first article of faith recorded in the Bible, by which all the rabble of heathenism is stabbed to the heart, we must with shame confess that the heathen had wiser and better informed instructors, than those have, who "through faith understand that the worlds were framed by the word of God."

What a bulwark for disbelief of the Bible will the Hindoos derive from this modern Geology? when they come to be informed what a discovery, fatal to the credit of Moses, has of late been made by some French philosophers. And will not these same Hindoos further say, we shall now be able to correct the Christians in some other points of infinite importance between us. We (they may very appropriately argue) have our histories of Creation and of Redemption as well as they: and as we have found 
them wrong and ourselves right in the matter of Creation, we may not fear but we shall be able to do the same with respect to redemption; the Christians believe there was but one period, or six days in the work of Creation; Geology has now proved us to be right in believing there were many: the Christians likewise believe there has been only one incarnation of the Deity; but as to this also we feel sure that some Newton or Cuvier in Theology will by and by prove that here they are also mistaken, and will cause them to believe with us that there have certainly been many Incarnations!!!

BAD EFFECTS, ESPECIALLY ON YOUNG MINDS.

I. As it respects young students.

I believe it impossible for any person who duly appreciates the word of God, to retain the same respect for it after embracing this system of modern Geology as before. But on young minds the effects may be far more serious. They are only commencing the study of Theology, and the historic evidences of the Bible. And this Theory must form (especially in our Universities) one among many objections to its truth. And it will be an objection the more formidable from its occurring at least to many, before the Bible is upon rational conviction, admitted by them to be true; perhaps before it be admitted even by divines themselves.-One of two evils must needs be produced on these youthful minds.

1. A silent suspicion that Moses may have been wholly mistaken. And if, as according to M. Cuvier's intimations, he received aid from former writings and from traditional information common among the 
Egyptians, he will only be looked upon (as M. Cuvier looks upon him) like other historians, who wrote partly what they learnt from others, either Patriarchs or Egyptians, and partly what they themselves supposed likely to have taken place.

2. Or, if they can believe any thing respecting the Inspiration of Moses as a general principle, they must certainly get into some way of excepting from that claim his History of Creation; and, perhaps, of the Deluge. For it is utterly impossible upon every explanation yet invented (and, I presume, invention has done its utmost,) to give credit to that narrative AS THE WORD OF God, if we adopt the principles of modern Geology.

But this is not all. For the same vein of thought and writing runs through both the Old and New Testament. David, Solomon, the Prophets, as well as John, Peter, and Paul ; yea, even our Saviour himself, are involved in the SAME CHARGE. If, therefore, we except the History of Creation from the claim to inspiration, in order to retain Moses as a veritable author in other matters, we must except all the other writers in the Bible from the claim to inspiration, when they, like Moses, treat upon the subject of Creation.-The consequence then must inevitably be, that every zoriter of the Scriptures must sink in credit with mankind, in degrees proportioned to the distance that he is found to be from the truth. And the mischief cannot be estimated, if we admit a Theory which would prove the Scriptures erroneous; and that where even the Hindoo heathens are better informed than the writers of Divine Truth ! ! 
That Scriptural writers should be silent, or even ignorant upon subjects of science which they do not profess to teach, is no objection to the validity of their testimony respecting matters which they are expressly commissioned to reveal. But, in cases of historic fact, some of which they have even delivered to us as the very words of Jehovah himself, it is utterly impossible that they can have written mystically, or rather erroneously, without shaking, in every department, the foundation of their credibility.

I am aware that some Christian authors have intimated that such divine writers as Moses and Saint Paul might, upon subjects of philosophy, write, not only ignorantly, but erroneously, without invalidating the truth of their testimony in matters of religion. This supposes the sacred writers to have, sometimes written under Divine superintendence, and at others as being under no such guidance. But, surely, this can never be admitted, unless in matters respecting which they were previously well informed, without utterly destroying all just pretensions to their divine inspiration. In such case, we should never have any satisfaction as to what part of the Bible helonged only to man, and what to the Most High; or, in short, what is truth and what may be error.

II. As it effects even catechists and children.

Our divines, whether in answer to Infidels, or in their didactic discourses, have been accustomed to say, that if the sublime doctrines of Christianity are, some of them, professedly mysterious, her precepts, which are summarily included in the TEN CommandMENTs, are so plain, that he may; run who reads 
them; and so simple and easy to be understood, that even a child may comprehend them. So strongly, indeed, has our National Church felt the truth of this sentiment, that she has actually made the Ten Commandments a part of her catechism and of her devotional instruction; and has written them upon the walls or altar piece of every church in her communion.

Hence, then, not the infidel or the learned, but every child may complain that he has actually been misinstructed from his birth. Our minister, he may say, and say justly, speaks much of our keeping "holy the Sabbath day;" and states to us the great sin of breaking the Sabbath. But it now turns out that we have no Sabbath. For, certainly, Christ and his A postles established no new commandment respecting the Sabbath day; and the old institution of that day is now proved to have been founded in etror or in fable. Whatever obligation, therefore, the Jews were under to keep their Sabbath in commemoration of their deliverance from Egypt, it is perfectly clear we are under no obligation at all.

Might not, then, even a Sunday school-boy inquire, ' how could this invention of the six days Creation arise? Was it a forgery of priests and kings to keep their people in awe and subjection?' But, every child may now say, surely it is more than time that priestcraft were detected and abolished, and we are much obliged to our French neighbours, whose philosophical investigations have enabled us to discover the cheat. They have demonstrated that the reason assigned for establishing the Sabbath is a forgery. But the reason for the Sabbath is not only the foundation of the 
command, but is of the very essence of the command itself. If, therefore, the foundation of the command and its essence be gone, all is gone.

It may be also further added, the fourth command is of the same authority with the other nine. If that, therefore, fall, the others cannot stand. For God claims our obedience to his commands on the very ground that he created us and all the world. But, if Geology be true, we cannot know from Scripture, that God "created the heavens and the earth" at all. For, if the record of the time and the manner of Creation be erroneous, the record of Creation itself may be so too. Nay, Geologists have discovered that Creation, as the subject is treated in the Bible, only means a new moddelling of the earth which previously existed. And if respecting the time and manner of Creation, which are as much a part of the creative narrative as Creation itself, we are misinformed, we shall be unable to find in the Bible any account to be depended on respecting an original Creation; or, rather, we are left in doubt whether there ever was any such thing.

REFLECTION.

If what we have endeavoured to prove in the preceding Treatise be substantially true; viz. if we have shewn that Geology, in its modern character, is nothing better than a fallacy imposed upon the world from assumed data, from arbitrary principles, and false reasoning: If, moreover, consequences such as we have been stating, would necessarily follow the adoption of the system of modern Geology, it becomes a grave question whether our British Geologists have shewn the wisdom and the caution which so weighty a subject demanded. 
They have translated M. Cuvier's " Theory of the Earth." They have made it the code of Geological investigation, and given it the most unqualified sanction of their authority, without, as it should seem, any thing like a due inquiry into its merits and defects ; they even give lectures upon its verity at the University of Oxford; and they appear, in a measure at least, to be aware of its danger. Dr. Buckland owns that there is danger from modern Geology to persons "who have not examined the detail" "of the irre" fragable moral evidence on which the general autho" rity of the sacred writings is established ;" but he seems to think that that authority " cannot be invali" dated by occasional differences touching minute " details of historical events, or by objections on "grounds so hypothetical and uncertain as those " afforded by the yet imperfect science of Geology." (Lect. 22, 23.)

How so respectable an author as Dr. Buckland could propagate a "Theory of the Earth" as true, which was confessedly built upon an "IMPERFECT SCIENCE," and was fraught with consequences so dangerous, and which was only established upon " hypothetical and uncertain" grounds, I am unable to explain. I take it for granted he will not undertake to defend the "science of Geology" as built on certain "grounds," while he maintains that the "oljections" arising out of it against the Bible are raised on grounds which are "hypothetical and uncertain."-And how he could bring himself to designate as "occasional differences touching minute details of historical events," those effects of Geology which involve the whole 
Bible history of Creation in figure, fable, or falsehood, we must leave it to himself to explain.

I think it must be admitted that all the young students who may hear either at first or at second hand, that Dr. Buckland is decidedly of opinion that the "literal and popular interpretation" of the "Mosaic narrative" cannot be supported, are not so firmly rooted in their belief of the Sacred Records, as not to be shaken by the obvious tendency of his opinion. They will neces. sarily perceive that these records are not literally true; if, therefore, they cannot make out a sense in which they can be true (for it is certain Dr. Buckland has not made out a true sense for them,) they must suspect them to be false. And no man living can, on Geological principles, say, that they are not false.

But are our English Geologists prepared to meet all the consequences which are likely to ensue from such an introduction, and adoption, and propagation of this infidel system? Nothing short of the positive and well-tried demonstration of two points ought to have emboldened them to act as they have acted, in so all important a matter.

1. A demonstration of the truth of the Theory.

2. A demonstration of its consistency with the Divine Records.

If these two points had been as demonstrably true as they are infallibly erroneous, we might have thanked our Geologists for their zeal, and ought to have profited by their speculations. As it is, I consider this introduction of the French Geology into our seats of learning for young divines, as the grandest piece of policy which the Enemy of Truth has made use of in 
modern times. Men already well - established in the evidences of Biblical truth may fancy they believe the Bible and believe M. Cuvier. But it is a fancy, or rather a delusion. They may give credit to Geology as a system, and to the Bible in some of its statements, and may try to reconcile them both. But to believe them both, upon rational conviction, is impossible; because they are not both either true or consistent ; and cannot therefore be believed, unless they can believe contradictions to be true.

Mr. Sumner, and Dr. Buckland, and Mr. Faber, all change the plain and obvious meaning of the Bible narrative before they even pretend to believe it. What then may we not expect from the next generation? Allowing Geology its claims, we may defy the whole body of Geological divines to defend the Scriptures against the re-action which we must expect will ensue from French infidelity, on account of our reception of their modern Geology.

I shall only make one reflection on what has been hitherto advanced.-As Geologists, even by their own acknowledgments, have nothing, or next to nothing, but " matter for curiosity," as the great excitement to the pursuit of their science--as their Theory makes no developement of phenomena worthy of God or useful to man-(for Geologists themselves scarcely ever make discoveries, they only speculate on their causation) - nothing which leads us to adore the Most High or stand in admiration of his works while they urge us as they did the psalmist, to exclaim, "In wisdom hast thou made them all :" It becomes a question for them to solve, how they shall answer it to him in 
the great day of account-that they have risked the credit of his word in the pursuit of a curious speculation -and whether for so doing they can confidently expect him to say "well done good and faithful servant, enter ye into the joy of your Lord"?

I have not forgotten that Dr. Buckland professedly wrote his "Reliquiæ Diluvianæ" for the purpose of proving the Mosaic Deluge. But we have seen how he has failed. Some others, adopting the same system of Geology, inform us that the ends to be attained by this science are several-as advancing the sciences of mining, of procuring water, and of agriculture : (I should be glad to learn, that these professions are realized,) - " But, perhaps, above all in vindicating the truths of divine revelation." (Oxford Quarterly Magazine No. II. p. 75.)-How extraordinary is the delusion under which those men labour, who believe that modern Geology vindicates Revelation!!

\section{CONCLUSION.}

I. I hope it will, upon strict investigation be found, that the Geological system we have been examining, is not only without foundation, but positively, and to a very high degree, erroneous.-Exclusive and peculiar fossils are wholly without evidence,-numerous successions and revolutions are unsupported and impracticable,-while the new creations they would involve, are miraculous and destructive to the Theory, and even to the Scriptures; for existing animals, on the modern Theory, must, (as we have shewn) have been created since the Deluge; so that both the fossil and physical character of Geology, are erroneous and impossible. 
II. On the other hand, I trust, we have seen that both the plysical and fossil state of the globe, are correctly correspondent with the suggestions and history of the Bible.

1. The History of CREATION is strictly a narrative of plain fact. The "LITERA L and popular interpretation" of that history, which Dr. Buckland acknowledges, would be subverted by modern Geology, is the only correct and true interpretation.

2. The Scriptural account of the Deluge, will alone account for the phenomena of the fossil strata.

(1.) The waters from out of the earth, account for their abundance.

(2.) The rending and casting up of the strata, account for the exterior form of the secondary formations, and for the fossil state of the globe generally.

(3.) The shells of 16 centuries, elevated by the breaking-up of the bottom of the sea, partly, perhaps, in a consolidated state, partly in a slimy mud, and partially in a loose state, account for all the shells in the rocky strata, and (in connexion with those deposited during the Deluge,) for shells scattered through the globe.

3. The DELUGE affords an EPOCH among ANIMALS, by which the inexplicable phenomena found by Geologists, are easily explained; as far at least, as they are in our present state of ignorance intelligible to us.

4. The dispersion of animal remains and their ancient and modern character are accounted for. While the peculiar character of animals in different 
countries which has been occasioned since the Deluge, is in perfect correspondence with the striking chasm discoverable in animal fossils, made by the Deluge.

Thus then I hope we have proved every part of our subject which we professed or engaged to prove; and that both the prospectus, and the title of this Treatise are perfectly justified. We adopted the title, "Scri PTURAL GEOLOGy" not from the vain notion that the Bible taught us the DETAIL, but the PRINCIPLE of Geological phenomena. And I trust it is no arrogance to say, after what we have been discussing, that the state of the strata cannot possibly be accounted for on any other principle.

- The Bible therefore stands perfectly UNA FFECTED.

-And Geology falls to the ground.

These two points, I believe, were all we engaged to to prove. But if we have shewn that "the Theory of the earth," as exhibited and defended by modern Geologists, is perfectly erroneous, and that the Scriptural statements both respecting the Creation and Deluge not only remain unaffected by this Geology, but actually account for the state of the strata and their phenomena; it will follow that,

The actual phenomena of the strata prove the history of the Bible to be true.

If the modern Theory of Geology had been corresrespondent with the phenomena of nature, as opposed to the literal interpretation of the Scriptures, it is perfectly clear that the Bible must have suffered greatly, from the discovery. But as Geology is proved to be erroneous and the Bible correspondent with the actual 
state of natural phenomena, the circumstance proves the reverse, and shews the truth of the Scriptural narrative.

I repeat it. The actual agreement of the secondary strata, and indeed of the primary also, with the Scriptural statements respecting these matters, proves the INFALLIBILITY of those who recorded those statements.

Now, though we expect from the Bible, no detail of circumstances respecting what are the state and situation of the fossil strata, we have seen enough respecting the cause and operations of the Deluge to prove the real ground and principle upon which we account for the actually existing state of those strata. We see that the Bible k now s how those strata became what they are, though Geologists do not know. Then, I repeat it,一тнат KNOWLEDGE which the Bible exhibits respecting this matter, is DIvINE.

Geologists have themselves, given us a description of the existing state of the stratified phenomena. And the leading characters who have lately given us this description, have not done it with a view to prove the truth and corroborate the testimony of the Bible; For they obviously do not believe it. Yet this description corresponds, in all its material points, with what the Scriptural record, requires it should be.

I do not now allude to Dr. Buckland's attempt to associate a false Theory with a true Bible. That association we have seen is unnatural and mischievous. The Bible shatters such Theories and such alliances like a potter's vessel. As well might iron and clay, Christ and Belial, unite, as an infidel Geology unite 
with the word of truth. We have seen, beyond reasonable controversy, that Dr. Buckland has not exhibited and cannot exhibit, without overthrowing his own Theory, one particle of appropriate evidence of the Scriptural Deluge. So utterly repugnant is the Bible, to an agreement with modern Geology.

It is obvious that Moses, had he not written his narrative by divine inspiration, could not have formed, could not have Invented an account of the Deluge which should so exactly account for what has taken place in the secondary strata. For, it does not appear that Moses was a Geologist, or that he intended to give information respecting any thing but the FACT of the Deluge, - How the Deluge arose,-and in what MANNER the animals were preserved. But in doing this, he tells us what is absolutely inconsistent with modern Geology; and what gives us a clew to the whole mystery of the strata. ${ }^{k}$

If then, Moses, who was not a Geologist, has given us an account of the Deluge, which will enable us to understand the nature of that catastrople, and the formation of the strata, and which is incomparably siser, and better than is given of the Flood, or of the formation of the strata, by the united wisdom of Geo-

${ }^{k}$ I hope no one will undertake, from our claiming for the Bible a knowledge and description of the formation of the substantial portions of the secondary strata, to force the Scriptures into any such fanciful interpretations as Mr. Hutchinson and his followers have done. That evil might, indeed, follow from Geology, but it is an interpretation as unwarranted by what we have advanced, as are those arising from Geology itself. The fair and natural inference from the present discussion is, that all the Scripture, except such as are manifestly figurative, should be literally understood, and as such, interpreted. 
$\log$ is $1 s$, with all their advantages of modern science, and experience in the mysteries of their art:-The thing speaks for itself.-Moses obtained this superior wisdom FROM A BOVE.

Further. As Moses RECORDED the narrative of Creation and the Deluge, not as a man versed in the sciences which might hereafter give occasion to objections against his record; so the present DEVELOPEMENT of that narrative, in its application to the subjects discussed in the foregoing pages, is not the work of a man skilled in the science of Geology. He has little information but what Geologists themselves have furnished; and no Theory but what the Bible has afforded. He is no ingenious or fanciful speculator, like one who first invents a specious system, and then brings forward a mass of learned and cunningly framed devices to support the fabrications of his own imagination.

The author commenced this discussion under the full conviction that the Mosaic narrative was LITERALLY CORRECT. And, in pursuing his object, he is sure that he has not wrought himself up into the enthusiastic flights of a heated imagination. He has uniformly persevered under the influence of rational conviction; and, he hopes, not.without very general and substantial consistency. Except the kind correction of a few of his friends, which he here acknowledges with gratitude, he has sought no instruction (in Theory or argument,) but that of his Bible; and no aid but that of its Author. He has lived nearly forty years under the full and firm belief that the Scriptures are strictly and literally, true. And 
he rises from this discussion under stronger assurance of their veracity and importance.

The Bible, in all its struggles under the opposition of infidels, the doubts of sceptics, and the hesitations of false friends, has always come off triumphant, and it always will; because truth can never, by any sophistry, or by any talents, be turned into falsehood. But it has not always occurred, as in the present instance, that the very subject which gave rise to the objections against the Bible, has afforded positive testimony in its favour. We have not, however, to thank Geologists for making their modern science subservient and subsidiary to Divine Truth, but we have to adore the Majesty of the Most High for compelling, even its adversaries, to do honour to his Sacred Records.

I particularly desire to except Dr. Buckland from all hostile designs against revealed religion. But I can never excuse him for joining in such an unhallowed cause, or for advocating so false and mischievous a system. Through his example, we may assure ourselves, that many of our Divines, who are not, and I hope never will be, scientific Geologists, have, (very indefensibly, I allow), given their confidence to the Geological speculations and anti-biblical Theories of M. Cuvier. And in consequence of this they are driven to palliate or excuse the want of science, the ignorance, and even the error of the Sacred penmen ; instead of boldly standing forth in their defence, and spurning the Theory which has led them into error.

I allow, as I before allowed, that Sacred writers may be silent about science or even ignorant of it, 
without impeaching their infallibility as recorders of divine revelation. But whatever they do declare, and on whatever subject (as we before observed from Bishop Horsley) is certainly true. They were under divine and supernatural guidance, and therefore personal ignorance in the zoriter is no defect; and error is impossible.

Once more. I further trust that, not only the Truтu of the Scripture narrative will be confimed by the discussion of this subject; but that the INTERPRETATron of Scripture will be more duly attended to. The History of Creation and of the Deluge, spreads itself over a very considerable portion of the Bible; and many crude, and even erroneous interpretations of it are to be met with. It is not too much to hope, that if the glosses of " science falsely so called," shall appear to have been satisfactorily answered, that, interpretations, more consonant to Scriptural truth and philosophical accuracy, will be more cautiously adhered to.

The author is apprehensive that his reader may complain of want of order in his arrangement and of perspecuity and force in his argument, especially in the latter part of this volume; and he is aware that, under different circumstances, various improvements might have been effected. But these defects, he hopes the candid reader will excuse. For the writer commenced this (to him at least) very arduous subject, under great bodily debility, which has been considerably increased during its progress, and perhaps by the attention necessary in pursuing it.-He has many times been obliged to desist for want of power both in body 
and mind, to proceed; and he had no expectation that delav would open before him a brighter prospect. '

With respect to Geologists, the author has not much hope that he has written to their satisfaction. And if they cannot overthrow his arguments, they may possibly quarrel with the manner in which he has treated them or their Theory. To this he can only reply that he has certainly not shewu intentional disrespect to any one. Not being personally acquainted with even one of our Geologists, he certainly owes them no personal disesteem. On the other hand, he is most willing to give "honour to whom honour is due." And he hopes that this will be accepted as a satisfactory assurance, that no feelings of animosity or of personal hostility, have ever, during the whole discussion, infested his mind. Nay, so far otherwise, he may safely declare that, probably, not a page has been written but under a sense of the Almighty's presence and of his own accountableness to him, for "every word" he writes. He is nevertheles quite satisfied of the impossibility of blaming an author, or of refuting his doctrines in a way satisfactory to that author himself or to his adherents.

The writer is conscious that he inherits, and very

1 This consideration, may perhaps, plead the author's justification in not having taken more general notice of writers on the subject of Geology, and of their Theories; and especially of some who have made attempts to reconcile modern Geology with the Bible. After all, however, it is possible that labour and time would have been spent to little purpose: for Dr. Buckland appears to have adopted the only two ways by which Geologists make an attempt at reconciliation. Nor is the writer aware, though he has occasionally met with several partial schemes, that any thing whatever, like truth and consistency has yet been published on that side the question. Mr. Conybeare's hypothesis appears to be in fact, one of those which Dr. Buckland has adopted. 
deeply possesses, the imperfections of human nature. And these no doubt, notwithstanding his ardent prayers, and his anxious care, will be found mixed up with his labours.- This Treatise, however, such as it is, he commits to the AUTHOR of that Book the cause of which he has espoused, and in the assured truth and perfection of which, he ever hopes to live and die; and to the courteous reader whose good he earnestly seeks, and who, he hopes, will not impute the defects and imperfections of the writer, to the want of truth in his subject. TruTH he values above all things. But the truths of the Bible alone, have the keys of "eternal life." He will, therefore, esteem it his greatest honour and happiness, if, before he go to be judged by that word, he shall have done any thing which may tend to illustrate its truth, to unfold its correctness, or to shew its importance.

GEOLOGY is the lasl subject to which the adversaries of Revelation have resorted, and from which, as a science of an ambiguous and not very tangible character, they perhaps hoped to derive some objections to its truth of no very easy solution. And no doubt when the subject should have become sufficiently general and adequately rooted, they would (could they not have been resisted, have turned our Geology against our Bible, and made us pay dearly for our unwise confidence and easy credulity.

Whether, however, Geologists have any deep-laid or concealed design against Revelation, or not, the mischievous tendency of this modern Theory is too evident to pass unnoticed. The author (and probably 
almost every person at all conversant with the subject,) has repeatedly heard the remark-' But how are these "numerous revolutions, which Geologists assert to " have taken place in the earth "thousands of ages" " before man was created, to be reconciled with the " history of the Bible, which assures us, that "in six. " days the Lord made heaven and earth, the sea, and " all that in them is?"-The truth is, as we have many times seen, such revolutions never can be reconciled with the Bible; and, what is more, they are as incapable of being reconciled with the first principles of reason, and with the laws of physical operations.

I ardently hope, however, that we shall profit by past experience;-Shall value more our Bible and its plain and obvious instruction;--shall follow the infallible guidance of this invaluable and long-tried friend, and " meddle not with them that are given to change."

THE END. 
. 



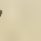


